\title{
A COMPARISON OF MEDICAL ETHICS AND MANAGERIAL ETHICS IN THE HEALTH SECTOR
}

by

Jane Elspeth Bryson

\author{
A thesis \\ submitted to the Victoria University of Wellington \\ in fulfilment of the \\ requirements for the degree of \\ Doctor of Philosophy \\ in Psychology
}

Victoria University of Wellington

1997 


\begin{abstract}
This multidisciplinary doctorate research draws on the disciplines of psychology and philosophy in its consideration and comparison of medical ethics and managerial ethics in the health sector. There is very little research which has compared the ethics of doctors and managers even though they work alongside each other in health organisations. Hence this thesis not only adds to the body of knowledge but also contributes a new perspective to applied ethics via the multidisciplinary approach.
\end{abstract}

The empirical research was conducted in three phases. First, a pilot study which interviewed via the repertory grid method six doctors and managers from a Crown Health Enterprise (i.e. a public sector health provider organisation which manages a number of hospitals). Second, a series of repertory grid interviews conducted with nineteen doctors and managers from seven Crown Health Enterprises throughout New Zealand. In the third phase, the ethical constructs and role perceptions identified in the first and second phases were incorporated into a questionnaire which was distributed to 799 doctors and managers in three Crown Health Enterprises.

The questionnaire posed a range of questions on role perceptions, ethical dilemmas faced, influences on ethically challenging decisions, ethical issues, and required respondents to rate an ethical manager, ethical doctor, unethical manager and unethical doctor on a range of constructs and rate which construct contributed the most to being an ethical manager and to being an ethical doctor. The main aim was to identify similarities and differences between doctors and managers.

The questionnaire analysis revealed a complex three way interaction between doctor/manager raters and the ethical/unethical doctor/manager being rated. This interaction was best represented by seven of the bipolar constructs. Additionally it was found that a highly ethical doctor was seen as honest, focused on patients' best interests, and principled - has standards which are lived up to privately and publicly. The highly ethical manager was seen as honest, flexible and open to others' ideas, recognises and uses the skills of others for their good and the good of the health service, committed to and works hard for the public health service, and takes a long term/strategic view of issues and the wider implications of decisions. 
Overall it was concluded that the results showed that medical ethics and managerial ethics can be discussed within a general moral framework which allows for different priorities in each role. And that the fundamental difference in priorities between doctors and managers, lay in their basic role orientation - doctors focused on the patient, and managers focused on the organisation. 


\section{ACKNOWLEDGMENTS}

This research would not have been possible without the cooperation of numerous busy, hard working doctors and managers. Neither would it have seen fruition without the support and encouragement of friends, family, colleagues and members of the academic community, in particular my supervisors Professor Sik Hung Ng and Chris Parkin.

Significant progress on the research was made during the tenure of a one year Postgraduate Scholarship of the Health Research Council of New Zealand, and with research funding from the Victoria University of Wellington Internal Grants Committee. 


\section{CONTENTS}

$\begin{array}{lll}\text { ABSTRACT } & \text { ii }\end{array}$

ACKNOWLEDGMENTS iv

CONTENTS V v

LIST OF TABLES ix

LIST OF FIGURES $\quad x$

CHAPTER 1: INTRODUCTION 1

Approach to the Research 2

SECTION ONE: MEDICINE AND MANAGEMENT 4

CHAPTER 2: MEDICINE, MANAGEMENT AND HEALTH MANAGEMENT:

A HISTORICAL PERSPECTIVE ON THE WESTERN TRADITIONS 5

Introduction $\quad 5$

$\begin{array}{lr}\text { The Western Tradition of Medicine } & 6\end{array}$

Western Medicine Comes to New Zealand $\quad 11$

$\begin{array}{ll}\text { Management } & 14\end{array}$

$\begin{array}{ll}\text { Health Management } & 21\end{array}$

Health and Hospital Management in New Zealand 25

Themes of Connection and Contrast: Medicine and Management 29

Summary Chronology of the Development of Western Medicine and

Management

CHAPTER 3: DOCTORS AND MANAGERS TODAY- THE NATURE OF THEIR WORK $\quad 38$

Introduction 38

$\begin{array}{ll}\text { Pressure and Change } & 39\end{array}$

Backgrounds, Expectations and Accountabilities $\quad 40$

Content of Work 41

Underlying Assumptions $\quad 43$

The Moral Nature of Being a Manager or a Doctor 44

Summary 45

SECTION TWO: APPLIED ETHICS 46 


\section{CHAPTER 4: APPLIED ETHICS - PHILOSOPHICAL FOUNDATIONS AND} MAIN STREAMS OF THOUGHT

Main Schools of Thought in Ethical Reasoning and Theory 48

Applied Ethics $\quad 49$

Medical/Biomedical Ethics $\quad 51$ Alternative emphases $\quad 56$

Observations of, and gaps in, the medical ethics literature $\quad 57$

Business/Managerial Ethics $\quad 58$

Observations of, and gaps in, the business ethics literature 63

$\begin{array}{ll}\text { Professional Ethics and Role Based Ethics } & 64\end{array}$

Medical Ethics and Managerial Ethics: Similarities and Differences $\quad 66$

CHAPTER 5: MEDICAL ETHICS, MANAGERIAL ETHICS: EMPIRICAL KNOWLEDGE AND METHOD

$\begin{array}{ll}\text { Introduction } & 70\end{array}$

$\begin{array}{ll}\text { Empirical Research on Medical Ethics } & 70\end{array}$

$\begin{array}{ll}\text { Empirical Research on Managerial Ethics } & 72\end{array}$

Health Management Ethics $\quad 77$

Other Available Information on Medical and Managerial Ethics in New Zealand 79

The NZMA Code of Ethics $\quad 79$

The NZIM Code of Ethics $\quad 80$

The ethical standards for Crown Health Enterprises (1993) 81

The (New Zealand) Health \& Disability Services Consumers’ Code of Rights (1996) 82

The American College of Healthcare Executives Code of Ethics 82

Complaints against doctors and managers for breaches of ethics 83

$\begin{array}{ll}\text { Summary } & 84\end{array}$

$\begin{array}{ll}\text { Method in Applied Ethics } & \mathbf{8 5}\end{array}$

The Contribution of Psychology to Method in Applied Ethics 87

Criteria for Choice of Research Method and Repertory Grid Technique $\quad 89$ The repertory grid interview $\quad 91$

Selection of Combination of Methods for the Research 93

$\begin{array}{ll}\text { Summary } & 93\end{array}$

SECTION THREE: EMPIRICAL RESEARCH 95

CHAPTER 6: THE PILOT STUDY AND INTERVIEW STUDY 96

$\begin{array}{ll}\text { The Pilot Study } & 96\end{array}$

Empirical Research Questions 96

$\begin{array}{ll}\text { Research Participants } & 96\end{array}$

Interview Procedure $\quad 96$

$\begin{array}{ll}\text { Introduction to interview } & 97\end{array}$

$\begin{array}{ll}\text { First repertory grid } & 97\end{array}$

Second repertory grid $\quad 98$

$\begin{array}{lr}\text { Evaluation questions } & 99\end{array}$

Results $\quad 99$

$\begin{array}{lr}\text { Responses to introductory questions } & 99\end{array}$

$\begin{array}{ll}\text { Responses to the first repertory grid } & 100\end{array}$

Responses to the second repertory grid 103 
The Interview Study $\quad 106$

$\begin{array}{ll}\text { Empirical Research Questions } & 106\end{array}$

Participants 106

Selection of participants 107

$\begin{array}{lc}\text { Interview Procedure } & 108\end{array}$

$\begin{array}{lr}\text { Variations from pilot study procedure } & 108\end{array}$

$\begin{array}{ll}\text { Introduction to interview } & 108\end{array}$

$\begin{array}{ll}\text { First repertory grid } & 108\end{array}$

$\begin{array}{lr}\text { Second repertory grid } & 109\end{array}$

$\begin{array}{ll}\text { Influences on decision making } & 110\end{array}$

$\begin{array}{ll}\text { Results } & 110\end{array}$

Responses to introductory questions $\quad 111$

Constructs from the first repertory grid interview: ethical and unethical colleagues 112

Constructs for consideration in next phase of research $\quad 115$

Second repertory grid constructs: ethical dilemmas $\quad 115$

$\begin{array}{ll}\text { Influences on decision making } & 118\end{array}$

Other comments on, and observations of, the repertory grid interviews 119

$\begin{array}{ll}\text { Discussion } & 120\end{array}$

Role perception $\quad 120$

$\begin{array}{ll}\text { Constructs underpinning ethicalness } & 121\end{array}$

Ethical dilemmas and influences on decision making 122

CHAPTER 7: THE MAIN STUDY 124

Questionnaire Design 124

Pre-testing of Questionnaire 124

Selection of Survey Participants $\quad 125$

Questionnaire Administration $\quad 125$

$\begin{array}{lr}\text { Participants } & 126\end{array}$

Results 127

Section A: The role of managers and doctors in Crown Health Enterprises 127

Section B: Ethical and Unethical Doctors and Managers 135

Section C: Ethical Dilemmas $\quad 144$

Section D: Background Information 158

$\begin{array}{lr}\text { Summary } & 159\end{array}$

SECTION FOUR: CRITICAL ASSESSMENT \& CONCLUSIONS

CHAPTER 8: MEDICAL ETHICS AND MANAGERIAL ETHICS: IS THERE

COMMON GROUND?

The Role of Managers and Doctors in CHEs 164

Ethical Doctors and Ethical Managers - Similarities and Differences 166

Ethical Dilemmas 168

Influences on Decision Making 169

Support Required for Ethical Reflection and Future Ethical Issues for Doctors and

Managers

$\begin{array}{ll}\text { Doctors, Managers and the Separatist Thesis } & 174\end{array}$

$\begin{array}{ll}\text { Summary } & 176\end{array}$ 
CHAPTER 9: CONCLUSION $\quad 178$

$\begin{array}{lr}\text { Medicine and Management in Health Organisations } & 178\end{array}$

$\begin{array}{ll}\text { Doctors, Managers and Ethics } & 180\end{array}$

Contribution of the Research to Applied Ethics and to Psychology 182

$\begin{array}{lc}\text { Future Directions for Research } & 184\end{array}$

$\begin{array}{ll}\text { Postscript } & 185\end{array}$

REFERENCES

APPENDICES 


\section{LIST OF TABLES}

Table 6.1: Constructs elicited from doctors to describe ethical doctors and ethical managers

Table 6.2: Constructs elicited from managers to describe ethical doctors and ethical managers

Table 6.3: Overall mean ratings of elements against each participant's constructs (Pilot Study)

Table 6.4: Bipolar constructs supplied for rating in first repertory grid 109

Table 6.5: Bipolar constructs supplied for rating in the second repertory grid

Table 6.6: Frequency with which constructs are cited amongst the 5 most important guides of ethical behaviour

Table 6.7: Overall mean scores of elements (ethical and unethical doctors and managers) rated against supplied constructs

Table 6.8: Bipolar constructs where the emergent pole represents unethical elements 115

Table 6.9: Frequency with which constructs are cited amongst the 5 most important constructs that contribute to a situation being a serious ethical dilemma............. 116

Table 6.10: Ethical dilemma classification labels.

Table 6.11: Frequency of types of ethical dilemma cited by doctors and managers in the interview

Table 6.12: Averaged rankings of influences on ethical dilemma decisions.....

Table 6.13: Averaged rankings of influences on everyday decisions

Table 7.1: Doctors' and managers' views of what the role of a manager in a CHE is, and what it should be

Table 7.2: Difference (\% should be - \% is) in doctors' and managers' views of the role of the manager in the $\mathrm{CHE}$.

Table 7.3: Doctors' and managers' views of what the role of a doctor in a CHE is, and what the role should be

Table 7.4: Difference (\% should be - \% is) in doctors' and managers' views of the role of the doctor in the $\mathrm{CHE}$

Table 7.5: Three-way interaction effect reported from a three-way mixed univariate ANOVA 
Table 7.6: Percentage of doctors and managers who chose each construct for defining a highly ethical doctor.

Table 7.7: Percentage of doctors and managers who chose each construct for defining a highly ethical manager

Table 7.8: Test of significance of difference in choice of constructs for highly ethical doctor and highly ethical manager, by doctors and managers

Table 7.9: The considerations which most often apply to the ethical dilemmas faced by doctors and managers

Table 7.10: Frequency with which doctors take into account certain factors when faced with ethically challenging situations

Table 7.11: Frequency with which managers take into account certain factors when faced with ethically challenging situations

Table 7.12: T tests showing differences in the frequency with which doctors and managers take into account certain factors when faced with ethically challenging situations

Table 7.13: Analysis of variance of three most helpful factors when addressing ethical issues

Table 7.14: Percentage of times each factor was chosen by doctors and managers in the "top three" most helpful when addressing ethical issues....

\section{LIST OF FIGURES}

Figure 4.1: Hierarchy of Relationships, Beauchamp \& Childress (1989) p.6... 50

Figure 4.2: Levels of Justification, Bayles (1989) p.19. .50

Figure 7.1: Mean ratings of ethical doctor, unethical doctor, ethical manager, unethical manager by doctor and manager raters 136

Figure 7.2: Mean rankings of considerations important to resolving ethical dilemmas by doctors and managers.

Figure 7.3: Level of support from colleagues, manager and CHE overall, for reflection on the ethics of difficult decisions .... 


\section{CHAPTER 1 \\ INTRODUCTION}

What are the fundamental similarities and differences between medical ethics and managerial ethics in the health sector? This is the question which will occupy our minds throughout this thesis. There are several reasons for being interested in this question and responses to it, ranging from the theoretical (i.e., it represents a large gap in the applied ethics literature) to the practical (i.e., it would be helpful for health organisations to understand and thus manage these similarities and differences). Four themes best represent the author's interest in the question:

1. Firstly, most countries are facing, and will continue to face, ethically challenging decisions on the development and use of medical technologies, and on resource allocation in public health systems. Doctors and managers are two very powerful role groups working alongside each other in health organisations all over the world. Frequently managers and doctors find themselves in conflict on the appropriate response to ethical challenges in their health organisations. Hence there is a need to understand their ethical views so that both groups can work with different perspectives more effectively.

2. Unfortunately, to date, the response in many health systems to this difference in ethical orientations has been a defensive one. In a report commissioned by the New Zealand Prime Minister's Department in 1992 consultants advised the deregulation of medicine. They commented on the power of doctors in the new health system and noted that they could undermine the development of innovative and competitive methods of health care by anticompetitive behaviour: "The ethical requirements (of the New Zealand Medical Association) can provide a vehicle for anticompetitive behaviour, particularly if membership of the association is valued by medical practitioners...it will be important to ensure that anticompetitive practices within the health sector are subject to the Commerce Act” (The Dominion, 2/10/92). At the highest level of power in the state these statements are testimony to a growing paradigm shift towards the view that a business/commercial model should govern all relationships and transactions in our society. Such statements are also testimony to the insidious way in which one set of principles (i.e., business/management) are used to judge another set of principles (i.e., 
medical) and thus conflate the two. They leave us wondering - what are medical ethics and managerial ethics, are they the same? Or are there fundamental differences?

3. Ethics, however, (i.e., the study of moral decisions, right and wrong behaviour) has traditionally been a territory inhabited by philosophers speculating on how one should lead a 'good' life. As Frederickson (1993) observed:

ethics is a world of abstractions, philosophy, and values while administration is a world of specificity, application, and practice. Research is one way to bring ethics to practice and practice to ethics. It is by research that knowledge of ethical issues, attitudes toward ethics, and ethics behaviour is developed. (p.43)

Frederickson believes that a carefully built and verifiable knowledge base in ethics will complement philosophical and normative perspectives. This is also the assumption of this research.

4. Thus it is the intention of this research to bring new perspectives to applied ethics from a multidisciplinary base. In an earlier article, (Bryson, 1993) the writer suggested that psychological research can contribute to the understanding of the context of ethical dilemmas and decision making, and the impact of organisation structure and functioning on the ethics of decisions taken. In this way psychology can provide a broader base than the traditional casuistry of philosophy, in order to explore and inform ethical theory.

\section{Approach to the Research}

Thus this thesis is a multidisciplinary work, drawing on several bodies of literature in order to better understand the ethical world of doctors and managers in health organisations. The thesis is organised in four sections which reflect an overall approach to thinking about ethics. This approach has been most notably articulated by philosopher Alisdair MacIntyre (1981) in his book “After Virtue”. MacIntyre stressed the need to ground our ethical principles in the socio-cultural context and highlighted our tendency to forget our western historical roots and hence the ideologies which have so rapidly become tacit assumptions in our thinking and discussions, for example, those such as equality, individual liberty, free choice, and those of state responsibility for well being of citizens, the free market economy. In a similar vein Bayles (1989) noted that "professional ethics can be properly analysed only against a set of social values and a conception of the general role of professions in society" (p.5). Thus the thesis is 
grounded in historical and current ideological context prior to exploration of the ethical terrain.

The first section of this thesis examines the nature of medicine and management, initially through a historical review of the western traditions of both practices, and afterwards by a contemporary insight to the role and work of doctors and managers. The second section addresses the area of applied ethics, its philosophical foundations, and its base of research method and empirical knowledge in medical ethics and managerial ethics. The third section reports on the three phases of empirical research employed in this thesis. The fourth, and final, section assesses the findings of the research against the socio-cultural and ethical backdrop of the previous sections, and draws some conclusions on the common ground of medical ethics and managerial ethics today.

It should be noted from the outset that some key definitional parameters are used for the purposes of this research. "Medical" is taken to refer to the work of doctors, and thus "medical ethics" to the moral choices that are made by doctors in their work. Similarly, "managerial" is taken to refer to the work of managers, and in the empirical research of this thesis, to managers in publicly funded health organisations; "managerial ethics" is taken to refer to the moral choices that are made by managers in their work. In the most part, unless stated otherwise, the health system referred to in this thesis is the state funded health system, and Crown Health Enterprises (CHEs) are the main health providers within this system in New Zealand. Each CHE is constituted of one or more public hospitals, community health and allied health services, and corporate activities. 


\section{SECTION ONE: MEDICINE AND MANAGEMENT}

This section consists of two chapters which are aimed at renewing and adding to our familiarity with medicine and management. The first chapter, Chapter 2, provides a historical perspective on the western traditions of medicine and management. It traces the development of medicine to the strong professional grouping it is today. It also traces the practice of management through time and the advent of modern organisations in which managers play a pivotal role. Management in hospitals and in health organisations is also examined. A summary of themes and a chronology comparing the development of medicine, management, and health management highlights the importance of the influence of the socio-political and economic environment - a theme which will underpin much of this thesis. Chapter 3 examines the nature of the work of doctors and managers today. It considers the various backgrounds, expectations, and accountabilities of, and pressures on, doctors and managers. The content of their work, and the moral nature of their roles are also discussed in an effort to provide a fuller picture. 
CHAPTER 2

MEDICINE, MANAGEMENT AND HEALTH MANAGEMENT: A HISTORICAL PERSPECTIVE ON THE WESTERN TRADITIONS

\section{Introduction}

The intention of this chapter is not to document an exhaustive history but to reflect on the past in order to inform an examination of current medical and managerial practices. As the New Zealand hospital and health sector has drawn much from the British and American traditions of medicine and management, the author has referred in the main to those cultures in tracing the historical roots and development of these disciplines.

Overall, this history shows how strongly the practice and profession of both medicine and management appears to have shaped and been shaped by the changing political, economic and social cultures in which they have existed. Indeed, today one could contend that the pressures on the health manager and the doctor are a product of massive political, economic, technological and cultural change. As will be illustrated in this chapter, the stresses felt now are not entirely new but they have never been felt in this way before.

The literature on aspects of the history of medicine relies on a number of markers in tracing developments. These markers are: codification/documentation of ethics, regulation of membership of the profession (including entry to it, and discipline within it), uniform processes of education (academic) and training (hospital based), establishment of professional associations, a growing body of literature and changing institutional/organisational arrangements in the venue for the practice of medicine and its target audience, and recently the incredible advances achieved in medical knowledge. This is a history of the development of a craft to a protected and respected profession.

The literature on the history of management is also punctuated by various markers. The most significant of those are the Industrial Revolution and the advent of large organisations with planned structures and salaried managers. Practically speaking this is a history of systems of control. Theoretically speaking this is a very recent history of a 
search for a single coherent model of management. The prevalent management model, as we will see, is shaped by the dominant political and economic forces in society.

The history of health management is not contained in a stand alone body of literature. It can be drawn from the literature on hospitals and health services - their management and funding. It is a history of changing masters and role - from poor house to the clinical home of the medical model. The latter still dominates our approach to health care. This is the fertile ground where in recent times the current business management model and fluctuating government policy have met the medical model. This is also a history of changing state political attitudes to responsibility for the health care of its citizens.

A summary chronology of the development of western medicine and management is presented towards the end of this chapter to illuminate an examination of the themes which connect and contrast these traditions.

\section{The Western Tradition of Medicine}

In the history of many cultures medicine as an occupation was at first closely allied with religion - the shaman, the priest, the tohunga - all took on a mixed role of healer, spiritual guide and storyteller in their respective societies. The earliest written history which is cited as referring to medical matters dates back to 1750BC and the Babylonian Kingdom of Hammurabi (Chapman, 1984). However, in many ways one could regard Hammurabi as the earliest known protagonist of health management as a concern of the state. This leader documented both payment and punishment for healers. The amount the healer was paid decreased according to the decreasing social status of the patient, and if the patient was a slave then the master paid the reduced fee for the slave. Similarly if the services were unsuccessful or resulted in the death of the patient there were various penalties ranging from loss of a hand to replacing the slave or paying a fine. As far as we know there were no documented medical ethics at this time - however given the legal imperatives just outlined one would expect that there was a very strong incentive to "do no harm" to one's patient.

It is a jump forward to around 500BC to the next well documented era. The golden age of Greek thinking and activity saw the development of classical philosophy and ethics. 
Prior to and during that time the Greeks had a strong tradition of craft clans where fathers passed specialist skills down to their sons (or adopted family members). The Asklepiadai were the clan of physicians and healers which maintained a monopoly on healing services. There were asklepian centres throughout the ancient world which were places dedicated to healing and worship of Asklepius. Hippocrates is said to be a descendant of Asklepius on the island of Kos - although there is actually very little known about Hippocrates, he had a reputation as a great physician and observer. The collection of Greek writings on medical topics known to us as the Hippocratic Corpus is of uncertain date and authorship, although it is generally accepted that most were written between 430 and 350BC (Chapman, 1984). The Oath, attributed to Hippocrates, contains a number of prohibitions characteristic of Pythagorean dogma which makes its date and authorship somewhat uncertain. However the Oath is credited as being the base of medical ethics, and the body of Hippocratic material gives insights into actual Greek medical practice. There was no licensing or regulating of medical practitioners. However, their medical education was by apprenticeship (similar to the Asklepian family tradition) and practitioners tried to identify themselves with the apprenticeships or schools with good reputations. Usually only the rich could afford the services of the best trained medical practitioners although some cities did support public physicians further evidence of some state or at least municipal involvement in health management. Most of the poor and slaves tended to rely on folk remedies and uneducated practitioners. Not unexpectedly, in this system the status of the physician was more dependent on that of his patient than on his position as a medical healer.

The Roman Empire, which was well advanced in terms of public health initiatives (e.g., their sewerage and water systems), benefited from their conquest of the Greek Empire and its experience of secular medicine gleaned from enslaved Greek physicians. At this time medicine became more of a theoretical rather than practical pursuit for the educated Roman. Several outstanding physicians documented the medicine of the time, for example Galen (who was Greek speaking) wrote about one hundred treatises. Scribonius Largus, a Roman physician, appears to have been the first to designate medicine as a profession with an ethical commitment to the patient rather than just a craft. He believed that a physician should place his obligations to his patient's interests above his loyalty to the medical guild: “ a true physician must treat all and sundry - rich and poor, friend and enemy - alike; he must do no harm; he must be learned in his profession” (Chapman, 1984, p.41). 
However, the fall of the Roman Empire and the onset of the Middle Ages led to increasing ruralisation of communities in western Europe and more reliance on folk remedies. In the latter part of the Middle Ages (i.e., 12th and 13th Century) universities were founded in France, Great Britain and Italy, teaching predominantly theology. Documentation in Great Britain from the 12th century shows that half of the known physicians appear to have been monks and clerics - probably because higher education was largely restricted to the theological. There is also evidence from legal documentation of the courts in Great Britain at that time that there was a distinct healing profession which was held liable for misadventure due to lack of diligence in the treatment of patients. Throughout the later Middle Ages various guilds of healers emerged.

At this time the universities also recognised medicine as a postgraduate course students first studied liberal arts and then specialised in medicine, law or theology. The main purpose of the advanced medical degree was not so much to practise it but to teach it hence the title "doctor" from the Latin "docere” to teach. However in France, as was to happen in Great Britain, the physicians began to differentiate themselves from the untrained barber surgeons. Various French monarchs held that physicians should restrict themselves to treating the upper classes, while barber surgeons could deal with the masses. Similarly in early 16th century Britain the London physicians through petition to King Henry VIII (by Thomas Linacre, an eminent Padua university educated physician) managed to elevate themselves to a College such that they were regarded as higher educated gentlemen while the surgeons and apothecaries were dubbed unlettered craftsmen and quacks. In fact people were prohibited from practising medicine in England without the licence of the College. Thus the regulation of medical practice began in a more formal way. Over time the College also developed penal and ethical statutes, but most of these were concerned with maintaining the College rather than focusing on the welfare of patients. Hence we see the gradual emergence of a trained and regulated profession, the services of many of whom were monopolised by the upper classes.

This focus on the profession rather than the patient continued, and there was a developing ground swell for reform. It can be reasonably argued that this was part of a general ground swell from the working classes who via the industrial revolution found 
themselves urbanised en masse to work in factories in often appalling conditions. These changes in social structure and experience brought with them severe public health problems and general civil unrest. The French Revolution in the late 18th century saw the overthrow of the monarchy, and amongst other changes in its aftermath the introduction of national training for doctors (1795) and a national licensing system (1803). In France and Scotland (England and America followed suit later in the 19th century) hospitals in conjunction with the universities became the major training ground for a new generation of doctors.

There is no doubt that the Industrial Revolution had multiple ramifications - it changed the face of society irrevocably - for the whole way people lived and organised themselves both individually and collectively. Extended families were split up and thus unable to care for each other in illness or bad times. The rapid urbanisation meant that there were much larger distinct "populations" with public health problems emerging as sanitation and housing systems (such that they were) failed to cope with the numbers of people. French philosopher Michel Foucault has referred to the "medicine of social spaces” at this time i.e., a rising political concern with health, such that the government of a territory (e.g., municipal or state) takes on responsibility for the health and well being of its constituents. Indeed in Great Britain the State intervened and passed the Public Health Act in 1848. Medical attention, which had previously been reserved for the wealthy only, became a priority also for the poor (particularly when their illnesses threatened the well being of the wealthier).

As a result, throughout the 18th century a large number of city hospitals were founded or developed from their origins of centuries before, as places for the indigent, into places for the care of the sick and centres of study and teaching of medicine. The hospitals, as well as caring for the urbanised individuals alienated from their extended families, provided doctors with an unprecedented amount of humanity for observation of diseases and trial of medical treatments. Throughout this time medical knowledge increased markedly as doctors had more and more sick bodies to observe (and the dead to dissect). Medicine advanced from simple classificatory systems to the more sophisticated anatomo-clinical system. This, combined with Lister's revolutionary use of antiseptic processes in surgery in the 1860s, and a greater cognisance of the importance of hygiene, transformed hospitals into the institutions we are familiar with 
today. These developments were such that by the late 19th century the hospital had truly become the workroom of the doctor.

There is no doubt that rapid commercialisation in eighteenth century Britain destabilised traditional professional hierarchies. As a result the rather individualistic “gentlemanly codes of honour proved insufficient for the doctors” (Baker, 1993, p.9). The publication of “Medical Ethics” by English physician Thomas Percival in 1803 attempted to direct proper behaviour of doctor towards doctor hence the book dealt primarily with issues of professional etiquette but also addressed the doctor-patient relationship. Percival recommended that doctors should strive "to unite tenderness with steadiness, and condescension with authority, as to inspire the minds of their patients with gratitude, respect and confidence” (Corfield, 1995, p.204). An earlier form was published in 1792 when it was drafted as a set of rules to settle a dispute that was disrupting the Manchester Infirmary. Indeed Corfield goes on to state that "this period did not invent professional ethics. But it did see the start of an important new specialist literature which extended both the theory and the practical applications of the subject" (p.204). This was the beginning of a new era of explicit codes of ethics in the professions. Baker (1993) suggests that by becoming accountable to their peers doctors asserted a collective autonomy against their new patrons, the hospital trustees, "the codified collective autonomy was to become the moral basis of nineteenth century medical professionalism” (p.9).

In England, in addition to general hospitals, a new type of hospital began to spring up, these were special hospitals. They were set up generally by a lone practitioner to deal with a specific ailment such as, skin diseases, venereal diseases. They enjoyed patronage by a range of paying customers and in fact drew some custom away from general hospitals. Granshaw (1989) suggests that "special hospitals were established for one purpose only - the self interest of their founder” (p.208). Certainly if the doctor had a loyal upper class following he could make a good living from his hospital. This was very unpopular with the British Medical Association who saw the special hospitals drawing doctors away from contributing at general hospitals where new doctors were trained and which accommodated poorer patients. The Association saw the rise of special hospitals as "contrary to the best interests both of the profession and of the public” (p.211). 
Both the practice of medicine and the profession of medicine have gone through significant change in the last 200 years developing and systematising their role. Firstly, as already noted, medicine became a profession - an organised self regulating group rather than scattered individuals or "quacks", controlling who entered the profession and educating those wishing to enter the profession. The British Medical Association came into existence (under a different name) in 1832 and operated as a quasi trade union for its members. In 1858 the Medical Act was passed in Britain which delegated regulation to the doctors themselves and saw the formation of the General Medical Council of Great Britain (only those on its register were entitled to style themselves as doctors). The modern representation of the Hippocratic corpus became encapsulated in the Declaration of Geneva (1948) of the World Medical Association. This is frequently used as the Physician's Oath at the time of being admitted as a member of the medical profession and forms the basis of most codes of medical ethics.

Secondly, doctors increasingly stressed scientific knowhow aimed not at sectional gain but at the general good. This sharing of knowledge amongst practitioners and the development of the hospital fuelled the scientific revolution in medicine of the nineteenth century including the development of anaesthetics, antiseptics and immunology, refined surgical techniques and classification of diseases (nosology). And in this century the massive advances in disease control, surgical methods, genetic manipulation, organ transplant. Corfield reports that the sharing of knowledge formalised in Britain as early as 1774 when some local groups of doctors began to meet regularly to promote their professional interests.

\section{Western Medicine Comes to New Zealand}

Throughout the 19th (and 20th) century British doctors emigrated to the colonies to set up medical practice and start a new life. Interestingly New Zealand did not lag far behind the British in establishing the boundaries of the profession - in 1867 and 1869 the Medical Practitioners Act was passed in the New Zealand Parliament introducing compulsory medical registration for the whole country through the forerunner of the New Zealand Medical Council. The Council however had no disciplinary powers.

The first New Zealand medical degree was conferred in 1887 at the Otago Medical School, and the New Zealand Medical Association was established as a branch of the 
British Association and published its own journal. The early twentieth century witnessed the passing of the Tohunga Suppression Act and the Quackery Prevention Act. Thus, arguably, in forty short years the foundations for the medicalisation of a new society was complete.

Michael Belgrave, in his 1985 doctoral thesis on the professionalisation of medicine in New Zealand from 1867 to 1941, traces the transformation of medical practitioners "from a group of scattered, divided, and socially mixed medical entrepreneurs, into the politically powerful, educationally homogeneous and economically successful profession of the 1930s” (p.i). He suggests that a role typified by independent, educated Victorian gentlemen of medicine transformed successfully into an occupational role defined by scientific training and technical skill. This transformation mirrored that occurring in other countries and was fuelled by the rapid advances in medical science, the newly established boundaries of the profession, and the medical needs of populations laid low by epidemic and war.

The wounded from the First World War (1914 - 1918) provided the opportunity for massive improvement in surgical technique. Hence it is not really surprising that in 1927 the Australasian College of Surgeons was established with 42 New Zealand fellows. As Belgrave (1985) notes, after 1918 medicine saw "the emergence of full time specialties...providing services to hospitals and developed under the protection of hospital salaries” (p.165). Indeed in the 19th and early 20th century Friendly Societies in the colony paid doctors to treat those who could not afford treatment, and many doctors also held state appointments to maximise their incomes. From 1924 the Medical Council was able to hold its own hearings and to fine doctors for breaches of medical ethics. Belgrave reports that "this was a less drastic means of professional discipline (than the Supreme Court) but one that ultimately proved more effective, at least when the moral authority of the Council was recognised” (p.82). The literature observes various changes in medicine and the medical profession. Medicine in the twentieth century has experienced unprecedented growth of its knowledge, technology, and overall capability. The medical profession has changed from a domination by patronage systems in which practitioners worked for and according to the direction of the upper class in 18th century (England) through to the emergence of collegial control with the establishment of professional associations and registration, and the growth of hospitals with salaried career structures and communities of colleagues. An important range of 
health care services has emerged including nursing, ambulance services, and rehabilitation services of various kinds. These have had the effect of producing a spectrum of allied health professionals (as opposed to doctor plus assistants) which in turn generates a certain kind of management need.

It is thus interesting to note that the Medical Practitioners Act 1995 and the Health \& Disability Commissioner Act 1994 change some of these professional arrangements in quite fundamental ways. Some seventy years after the Medical Council was granted permission to discipline members of the profession this has been revoked and a Medical Practitioners Disciplinary Tribunal separate from the Council has been established. Even more astonishing is that the Tribunal is chaired by a lawyer, with three medical members and one lay member. The Medical Council retains responsibility for medical registration and introduces new recertification and competence programmes in a range of moves seemingly focused on greater control of entry to, and continuing practice in, the profession. The Office of the Health \& Disability Commissioner in 1996 issued a Code of Health \& Disability Services Consumer Rights outlining consumer rights and provider duties. Consumers are able to lodge complaints with the Commissioner's Office about any health provider e.g., doctor, nurse, other health professional, manager, Crown Health Enterprise, other health provider organisation. These complaints will be investigated and actioned by the Office or referred to the relevant Disciplinary Tribunal.

Government has thus legislated for individual rights that must be met by health providers, and has attempted to make all health providers more accountable to their public. This is a stark contrast to the arrangement of medicine and health care in the last three hundred years, however maybe it is not that far removed from the rules King Hammurabi had in place for healers nearly four thousand years ago. 


\section{Management}

The activity of management, like the activity of medicine, has been with us for centuries - from organising tribes and fighting forces, through to commerce in Greek and Roman civilisations and beyond to the agrarian and mercantile pursuits of the middle ages and pre-industrial times (i.e., up to the mid 18th century). Similar to the history of healing and medicine one could trace through the ages the skill and practice of managing. To plan, organise and control other people and resources was central to the success of numerous states and empires. Frequently these systems relied on the hierarchical structures of the societies in which they existed - the "station" in life to which people were born and remained. State control of the economy was closely guarded by such early civilisations as the Egyptians, Greeks and Romans. Economic power lay in the hands of those who had political power. Most planning and organisation at this time depended to a large extent on the seasons and natural events, and on the social order the stringent hierarchy of a feudal system, or church authority or dictates of monarchy. Ruling, fighting, farming, trading, praying or serving - life was not a complex series of choices !

However eventually change came to all levels of society. Importantly the authority of the Catholic church was challenged by the rise of Protestant beliefs during the Reformation of the 16th century and traditional values were questioned. Economic, social and political attitudes were changing. Philosophers and thinkers like Locke, Hume, Adam Smith, Bentham (to name but a very few) provided the ideals of democracy and individual rights which were to radically influence western civilisation. The American Civil War and the French Revolution both saw ordinary citizens fighting for a fairer society, for independence and the right to rule themselves - people were no longer tied to a particular fate in life and new forms of government were needed to reflect that. For the first time economic power and political power started to be separated, as Wren (1987) comments "the overthrow of mercantilism and the emergence of the laissez-faire economic philosophy severed the state from its role in economic planning. The market, through the consumer, was deemed the best method of allocating scarce resources toward human ends” (p.411). The new economic order of capitalism based on the concepts of private property and individual liberties was to profoundly

affect standards of living and levels of personal freedom. These changes in belief and 
organisation combined with another revolution borne by minds applied to things mechanical - the Industrial Revolution.

We have touched briefly on its effects on medicine through urbanisation, radical changes in social and state structures and consequent issues of public health - however it also changed the face of work and workers. The Industrial Revolution spawned our modern organisations and with them managers who were no longer necessarily the owner of the business but were salaried "professional" managers. The American Academy of Management considers “May 26, 1896, to be the beginning of management as a formal discipline. It was on this date that Henry Towne called for both management research and education at a meeting of the American Society of Mechanical Engineers.” (Dunham \& Pierce, 1989, p.133). Other sources also confirm the age of the discipline, for instance Duncan (1989) notes "management as a recognised field of study is a century old, yet it is far from mature as either a theoretical or empirical science”(p.69). Indeed it is only in the last 100 years that the plethora of organisations, as we know them, and their attendant management tasks, have emerged. Associated with this has been the development of management theory and organisation theory, management as an academic discipline, the "professionalisation of management" through such education, and formation of business schools and management associations. The University of Pennsylvania opened the first undergraduate school of business in 1881, and the American Management Association was founded in 1923. The New Zealand Institute of Management (NZIM) was founded in 1944. Then, of course, books and journals on management started to appear and a body of knowledge began to accumulate. Wren (1987) summarises this phenomenon:

the 19th century brought some recognition of a managerial function, but it was not until the 20th century that we began to isolate, identify, and study management as a separate function applicable to all types of organisations. It was here that we saw the problems of managing becoming so acute that they required a separate body of study (p.421).

The history of management is also linked to our developing understanding of organisations. Many disciplines have added to this understanding, but of particular note are sociology and psychology (social, and industrial/organisational). Sociologist Max Weber is widely regarded as the father of classical organisational theory. His theory of bureaucracy profoundly influenced organisational form and theory. Weber saw 
organisations as systems of control, and bureaucracy as a type of formal organisation in which impersonality and rationality are developed to the highest degree. Thus, in Weber's model, bureaucracy rests on rational-legal authority which defines the rules of the game and relegates individual personality to a secondary theoretical role (Tannebaum, 1966). Weber believed that the bureaucratic organisation was technically superior to other forms of organisation because it combined "specialist skills subordinated to the goals of the organisation, and the exclusion of private, personal emotions and interests which might detract from the attainment of those goals”(Haralambos, van Krieken, Smith \& Holborn, 1996). Thus the manager is clearly characterised solely as the agent of the organisation and its goals. Organisations exist to deliver a product/service or make money, or both. Hence, at base, management exists to ensure efficient and effective resource allocation - ensuring things are done, goods and services completed on time, at a certain cost and quality level. Throughout the twentieth century a long line of management and organisation theorists and consultants have attempted to shed light on the secrets of successfully managing an organisation, and have struggled to arrive at a coherent theory of management to rival Weber's bureaucratic model.

In the classical school of organisational theory, psychologist Henri Fayol noted the importance of managerial ability to organisational performance and was amongst the first to codify managerial activities in order to understand them. Amongst the early practical theorists much credence was given to the principles of Scientific Management founded by F.W. Taylor who stated that "the principal object of management should be to secure the maximum prosperity for the employer, coupled with the maximum prosperity for each employee”(Wren, 1987, p.125). Taylor has captured in one sentence the dilemma for many rival theories of management - i) the tension for the manager of serving the employer/owners, while ensuring the well being of the employee; ii) the tension between a belief in 'economic man' versus ‘social man' - that some theories are based on the assumption that man aspires to greatest monetary gain, and others that man has other social needs which can be stronger than the economic need.

Reinhard Bendix (1956) classic industrial text, "Work and Authority in Industry: Ideologies of Management in the course of Industrialisation”, traces the changes in managerial ideology and practice. He notes that 
during the 1920s and 1930s the managerial conception of 'the worker' and 'the manager' underwent significant changes. The worker came to be viewed as an embodiment of aptitudes and feelings, which had to be assessed so that his job assignment would be advantageous to him and profitable to the enterprise...the imagery of superior virtues (of managers) changed from the praise of qualities ideally suited to the competitive struggle to a praise of qualities ideally suited to the management of men and to the advancement of careers in a bureaucratic environment (p.308).

Bendix cites Elton Mayo and his researchers as important forces in the changing conception of management. As a result of his famous Hawthorne experiments Mayo concluded that the "managerial task may be defined as the endeavour to provide an organisational environment in which employees can fulfil their 'eager human desire for cooperative activity'; the major objective of management is to foster cooperative teamwork among its employees” (p.317). In this view the emphasis of managerial concern shifted from economic self-interest to attitudes and feelings of workers and cooperative activity. However Bendix asserts that Mayo's ideas found “only limited acceptance in managerial practice, but that its contribution to managerial ideology has been pervasive” (p.319). He goes further to say “many American managers have adopted the language of the human relations approach, whether or not they have adopted its practices or its ideas” (p.326).

A brief review of the area reveals a range of approaches to management theory, probably best summarised by Harold Koontz (1961, 1980), who noted 11 main schools of management thought from the human relations approach through to sociotechnical systems approach, and operational theory. However despite these numerous attempts management is not a well understood area, partly, according to Koontz, because many of those who teach management have never been practicing managers themselves thus are not familiar with the reality of day to day management activity:“ it seems to some like having professors in medical schools teaching surgery without ever having operated on a patient” (p.176, Koontz, 1980). Indeed, Duncan (1989) points out that "well into the decade of the 1960s what we know about administrative behaviour and what managers actually do was based more on commonsense impressions and mythology than on empirical facts” (p.90). 
A review of recent management journals will reveal more empirical research being conducted than was obviously the case in the 1960s. Management, organisational behaviour and industrial/organisational psychology texts typically address issues of motivation (worker and manager), personnel selection, leadership and decision making, job satisfaction, job design, training, group dynamics, group conflict and team development, organisational culture, organisational structure and change (Cooper, 1991; Dunnette \& Hough, 1990; Kolb, Rubin \& McIntyre, 1984; Leavitt \& Pondy, 1964; Schein, 1980). However the management discipline seems no closer to a general theory of management and is highly susceptible to the latest trend. Management by objectives (MBO), for example, was the buzzword technique of the early 1980s. Peters and Waterman's "In Search of Excellence” was regarded as the management text of the late 1980s until all the organisations researched and praised in it began to fail (further analysis showed that a concentration on only financial performance indicators had been a shortsighted way to measure success). The learning organisation (made popular by, among others, Peter Senge’s book “The Fifth Discipline” which is based on the action research school of thought) has now come to prominence as the way our organisations should operate. These examples of changing management thought do not always represent a logical building of thought/ideas one upon the other but rather they are more often a response to changing social or economic values and thus often disconnected from previous ideas. It is this which makes it, I believe, difficult for the management discipline to arrive at a coherent general theory. Additionally it is arguable that one is limited in what one can say generically as much depends on what is being managed. Indeed, Schein (1980) notes in his text on organisational psychology that organisations are complex social systems, thus "almost all questions one may raise about the determinants of individual human behaviour within organisations have to be viewed from the perspective of the entire social system” (p.6). One could also argue that management has to be dynamic in its form and practice. Although its raison d'etre remains essentially the same throughout time (i.e., efficient and effective use of resources), management has to be responsive to the changing cultural mores and values and political imperatives in order to succeed.

To be a manager in the 1990s is quite different from being a manager in the 1890s or 1950s, or even the 1980s. One of the most marked differences in New Zealand lies in the far greater prominence accorded the rights of individuals - as employees ( e.g., Health \& Safety in Employment Act, Privacy Act, Employment Contracts Act, Human 
Rights Act etc.), and as consumers (e.g., Fair Trading Act, Consumer Guarantees Act, Human Rights Act, Privacy Act, Health \& Disability Commissioners Act etc.). Wren in his book 'The Evolution of Management Thought' (1987) concludes that “management is one of the most dynamic of all disciplines, as technology, institutions, and people change, our ideas of management evolve in order to cope with our oldest problem - the allocation and utilisation of scarce resources to meet the manifold desires of human society" (p.427) and that "the discipline of management is a product of the economic, social, and political forces of the past and present” (p.5). Indeed one could argue that the growth of capitalism and democracy as the practical reality of philosophical arguments for private property and individual liberties, have in a post-industrial society, yielded a growing tension between individual rights and insufficient resources to meet the needs of every individual. It is this tension which thwarts the public sector. As Ng (1980) notes “compared to the power wielded in pre-industrial society, power in complex industrial society has become more impersonal, more anonymous, and is embedded more in organisational positions than in individuals"(p.8). Hence organisations are increasingly removing power from the individual while existing in a society which supposedly values individual liberty. The manager, as agent of the organisation and a member of society, walks a confusing line between the two.

Organisations exist to deliver a product or service in order to make a profit for owners/shareholders. However, the general consensus in the literature is that no general theory of management has emerged, although there does seem to be a common theme in terms of what is regarded as the manager's role in an organisation. This is encapsulated in Henry Mintzberg's 1973 “The Nature of Managerial Work” and in other recent work on managerial competencies (e.g. Boyatzis, 1982; Rippin, 1995; Yukl, Wall \& Lepsinger, 1990). Mintzberg formulates the management role in terms of what managers actually do - this includes: interpersonal roles, informational roles, decision roles and negotiating roles. Cox and Cooper (1988) review Mintzberg's work along with that of others and conclude that problem solving, decision making and skills with people are key for good managers. Rippin (1995) in her research into the competencies of effective managers across a range of New Zealand industries found six factors: interpersonal skills, conscientious and organised, strategic behaviour, problem solving, drive and enthusiasm, and honest feedback. 
Reference to any one of the multitude of management texts in existence will also find general agreement on the main functions of management as controlling, planning, organising and directing or leading (e.g., Dunham \& Pierce, 1989; Wren, 1987). Trice (1993) observes in his research that two overarching ideologies - professionalism and unionism - stem from the 18th century as ways to maintain control over work. In the current New Zealand labour market one could argue that the focus on individual contracts rather than collective agreements with worker groups has led to the ideology of unionism being supplanted by the ideology of corporatism and managerialism. Trice (1993) notes the administrative subculture in organisations assumes that management knows best how to organise the work and the workers.

It is probably not surprising then that there is still an underlying cynicism about what managers do and their values - that it is there to exploit, to use its power over workers, that it is somehow "dirty" whereas the professions are "clean”. This is partly a residue of belief from the industrial revolution in the United Kingdom in which the growth of the union movement was necessary in order to protect many workers who were subjected to appalling pay and conditions. It is also partly a function of the fact that it is so difficult to pin down a general theory or explanation of management activities.

Both doctors and managers would claim in some form to be ancient and honourable (probably more particularly medicine). However both would be stretching the truth somewhat - medical activities have not always been as highly valued and were seen essentially as a craft (hairdressers could well lay claim to the honourable past in the guild of barber surgeons). Likewise managerial and business activities were seen as a trading activity. Ironically it was the industrial revolution which was the catalyst for the greatest changes in the practice and professionalisation of both medicine and management.

An industrial society required a different set of assumptions about the nature of people; that they could have the freedom to choose their own government, that they could be self directing, that they could pursue property and wealth as natural rights, and that they could devise means for the redress of grievances and injustices. It was in this context that individual liberty became a value. (Wren, 1987, p.422)

It is these industrial and post-industrial societies which have created health and management systems as we know them today - emphasising individual rights and 
autonomy. In effect medicine and the state have been intertwined ever since the Industrial Revolution and it was thus only a matter of time before management (on behalf of the State) became an integral part of the picture of health delivery.

\section{Health Management}

The role of management in health organisations can be traced by reviewing the history of hospitals in western countries which yields a number of insights into the practice of management and medicine in hospitals. As alluded to in the history of medicine and healing, one could regard the Babylonian King Hammurabi as an early exponent of state regulation on health matters by his documenting payment and punishment for healers. Indeed even the Cult of Asklepius in the Greek world relied on the management of temples and healing places by the priests who had trained in the healing art. However, throughout medieval times hospitals were very different places in both purpose and practice to the modern hospital. Their purpose was primarily as a resting place for weary travellers, the indigent and sick for people who had nowhere else to go. They were normally managed and funded by the church, and there was very little, if any, medical attention associated with them. They were seen as places of "pauperism and death” (Granshaw \& Porter, 1989, p.1). It is important to remember that the role and power of the church was central to the organisation of society at that time and for many centuries after - people were born to a particular station in life and to a particular fate the church reinforced this fate and eased the transition from this world to the next.

However, the beginning of new growth in medical knowledge and university education meant that from the fifteenth century onwards physicians were increasingly associated with hospitals. They provided care for patients and experimented with different treatments. Over the next few hundred years, as medical knowledge grew and the “profession” started to emerge controlling who could practise as a physician, more hospitals were established as centres of study and teaching, and some for personal profit. Medicine and hospitals began to share a common history.

Several key themes characterise the changing purpose and practice of hospitals throughout history. Firstly, hospitals are creations of particular societies. Rosen (1963) sums this up observing 
the hospital has to be seen ... as an organ of society, sharing its characteristics, changing as the society of which it is a part is transformed, and carrying into the future evidence of its past .... a historical sociology of the hospital in this sense requires a delineation of political and economic conditions, social structure, value systems, cultural organisation, and social change in relation to the health conditions and needs of populations at various historical periods. (p.2)

Thus we are able to see that the hospital's function has changed from a religious charity rest house for the indigent in a feudal society, to physician owned specialist hospitals for the wealthy paying patient in the new free market economy of the 19th century. The publicly funded or endowed general hospitals of that time then evolved to our current technologically sophisticated publicly funded hospital system available to all and the private hospital system for the wealthy or those able to afford health insurance.

A second theme is the reliance of hospitals throughout the ages on a funding source, be that through philanthropic endowment/donation, city/region funding, state funding, or charging of patients. Once again that funding source has been a reflection of the political and economic structures of the time.

Thirdly, the advancement of medical knowledge and technology also intertwines with the changes in societal structures and population needs through time. This is clearly illustrated in French philosopher Michel Foucault’s (1963) “The Birth of the Clinic”. Foucault discusses "medicine of species" and the emergence of clinical medicine in the late 18th century which replaced the traditional classificatory medicine. This led to the introduction of a new training regime for doctors centred on the clinic/hospital, and the reorganisation of medical practice and of hospitals. The face of medicine and of hospitals changed radically. Where once the hospital was a public service meant for the destitute and financed by either government or charitable foundations, generally religious, in the late 18th and 19th century the medicalisation of hospitals saw them become privileged sites of learning and therapy. Foucault maintains that clinical medicine needed bodies to study in order to develop medical knowledge - people were no longer a set of unique external symptoms, they were patterns of disease processes. Hospitals as the venue for studying these processes and providing medical treatment thus became more disciplined. Hygiene standards were introduced and patients were segregated according to the type of their illness. A whole new hospital architecture emerged as they became integral to the medical model. It is significant that this 
reorganisation of hospitals and the medical profession occurred immediately after the French Revolution which, in disposing with the monarchy, found a new political concern with the health and well being of the population as an essential objective of political power. This Foucault refers to as part of the phenomenon of the "medicine of social spaces”, that is, medicine which works through the government of a territory and its population not through individual contract between doctor and patient (Cousins \& Hussain, 1984).

In Europe and Britain the concern of the state with the health of its populations was further fuelled by the multiple effects of the Industrial Revolution, particularly its effects on public health. So, as governments of the people and for the people were formed and accepted responsibility for the health of citizens, doctors had greater access to a wide range of complaints en masse which enhanced the development of medical knowledge and technique. Throughout the late 1800s, as demands became greater on hospitals and medical knowledge more refined, the institutional structures became more formalised with administrator superintendents, matrons and medical staff. Epidemics in urban centres and various wars with their associated heavy casualties also created demand to process many cases in a short period of time which heightened the need for administration and organisation within the hospital.

The first generations of hospital superintendents had not been selected for their presumed technical competencies; indeed, they were meant to learn their craft on the job. Presiding over essentially domestic arrangements, the early nineteenth century superintendent's chief qualifications had been his probity and his willingness to spend his life within the confining walls of the hospital....the role was that of caretaker; superintendent's were not expected to initiate or innovate. (Vogel, 1989, p.245)

By the end of the 19th century hospital superintendents in America had begun to draw on each other's experience and met regularly through such new forums as the American Hospital Association where they discussed issues such as the early 20th century shift to practices of 'scientific management'. Vogel comments "like self consciously scientific managers and technical experts in other fields, superintendents sought to forge a professional identity”(p.249). However,

doctors proved the most enduring challenge to hospital administrators ... it was to the age-old content of medical practice - the almost priestly role of explaining 
disease and reassuring the sick - that doctors owed their advantaged position in the culture generally and in the hospital particularly. Superintendents would find it difficult to interpose administrative edicts between doctor and patient. (p.251) In addition, medical schools restricted access to the medical profession to the wealthy or well connected, thus exacerbating the social superiority that most hospital physicians enjoyed over their administrator counterparts.

Thus began, in modern western hospitals, an ongoing power struggle between doctors, administrators, and hospital trustees or boards. Sociologists Perrow (1963) and Starr (1982), amongst others, have discussed the shifting of power in American hospitals. They identify trustee domination 1885-1929, followed by medical domination 19291942, and then administrative challenge 1942-1952, followed by multiple leadership 1952-1958. Perrow explains the power shifts according to the prominence of particular task areas at certain times. He cites five task areas as likely to be:

both difficult and critical for organisations at different times: 1. Securing inputs in the form of capital or operating subventions. 2. Securing acceptance in the form of basic legitimation of activity. 3. Providing production skills where these are nonroutine and highly specialised. 4. Coordinating the activities of organisational members. 5. Coordinating relations with other organisations, clients, or consumers (Perrow, 1963, p113).

Hence Freidson (1963) suggests that "the most appropriate model for the analysis of the hospital (and other organisations that, like the hospital, typically bring together a variety of professions) should not stress organisational structure so much as the continuous negotiation and renegotiation of order among the participants”(p.xii). The sociology and psychology of power literature aids our understanding of systems of control and authority bases which can explain the relative power of doctors and managers, but it is not the task of this thesis to extensively review the power literature. Rather it should be noted that the shifting sands of organisational and social power form an important part of the context in which doctors and managers carry out their duties. Clearly the power structures will influence which set of ethics will be given priority at any given time. This study, however, is concerned with describing two different ethical systems operating within the New Zealand hospital system and identifying similarities and differences in the ethical perspectives of the two groups on which the research is focused: doctors and managers. 
The history of hospital and health services in New Zealand is such a constant negotiation of order over time among doctor, administrator/management, hospital board, and state/government. Hence it is instructive at this point to review the passage of health and hospital management in New Zealand.

\section{Health and Hospital Management in New Zealand}

The late 1840s onwards saw the establishment of small charitable cottage hospitals in various New Zealand towns. There was limited state involvement in health care of this small and scattered population. However the population grew, and as we have discussed medical professionals became more organised and powerful as a group. In 1885 the Government passed the Hospitals and Charitable Institutions Act. This legislation set up hospital boards throughout New Zealand with members appointed by local authorities to oversee the running of local hospitals, and the period from 1880 to 1920 saw the gradual displacement of the charitable hospital by the medical hospital. In this period the number of hospitals increased fourfold and the number of patients treated eightfold. Treatment, if not paid for by the individual, was subsidised by a local authority or Friendly Societies. By the 1930s the hospital had become the recognised workshop of the medical practitioner in New Zealand.

In 1938 after "protracted negotiations with the medical profession" (Laugesen \& Salmond, 1994, p 11) the first Labour Government passed the Social Security Act which heralded a state funded health system in New Zealand allowing universal access to health care according to need. Thus public hospitals in New Zealand and the Department of Health (in charge of public health initiatives and oversight of hospital funding) became the mainstays of the health system which continued to develop in line with changes in medical technology and practice. A small private sector market still existed for the services of medical specialists who most often attended their private paying patients alongside publicly funded patient commitments.

The hospitals themselves developed into hierarchical, centrally controlled, bureaucratic organisations (as was typical of large organisations throughout this time period). Each hospital was led by triumvirate management: the chief administrator controlled all 
administrative requirements (e.g., buildings, laundry, cleaning, catering, gardens, secretarial support, finances) the matron/chief nurse controlled all nursing staff (e.g., their training and registration, deployment in the wards) and the medical superintendent had oversight of the medical staff. No one person formally had overall control of the hospital organisation although the triumvirate reported into the Hospital Board which was made up of local representatives/members of the community which the hospital served.

In 1974 the second Labour Government produced a white paper “A Health Service for New Zealand” which suggested reducing the number of hospital boards into 14 regional health authorities. However "bitter medical opposition” (Laugesen \& Salmond, 1994, p12) saw this proposal shelved. There was dissatisfaction with the hospital system and the inefficiencies that plagued it, for instance, "overexpenditure on buildings, failure to develop either adequate information systems or management which provides a positive impetus to improve productivity” (Neutze, 1993, p17). The Hospital Boards themselves were another source of concern as their membership generally lacked in financial and management skills (Laugesen \& Salmond, 1994) and were often intent on securing benefit for their interest groups only.

Thus in 1983 the National Government passed the Area Health Boards Act which was not finally implemented until 1989 by a Labour Government. This merged the 29 Hospital Boards (providing secondary care) and the 18 Health Development Units (providing public health services and formerly part of the Department of Health) into 14 Area Health Boards, with fewer board members than their predecessors and, in a new departure, each headed by a General Manager.

The 1988 "Unshackling the Hospitals: Report of the Hospital \& Related Services Taskforce” (referred to as the Gibbs report) recommended radical restructuring of the New Zealand hospital system as a way of promoting greater efficiency and equity in the use of government funds. They noted that "one of the central reasons for governments becoming involved in health care is the concern for fairness and the possible outcomes that would otherwise result” (p.5). In reviewing the existing hospital system the taskforce concluded that:

medical staff whose expertise lies in the area of diagnosis and treatment are obliged to manage the waiting lists and become arbiters of who receives hospital treatment 
in many areas of non-acute care .... health professionals, by default, have assumed progressively more power over areas for which they have received no specific training or brief. (p.5)

Thus, not surprisingly, the recommendations of the taskforce involved removing the triumvirate management structure (of doctor, nurse and administrator) which had led to this situation and, they believed, was responsible for gross inefficiency, lack of accountability and the worst aspects of consensus management. In its place they suggested a general manager of each hospital organisation to "provide clear accountability, develop leadership and give a single point of reference for strategic planning, setting objectives, decision making, action and information” (p.40).

In their analysis leading to the recommendations the taskforce report also referred to observations made by the 1983 National Health Service (NHS) Management Inquiry Report in Britain in which it was noted that "clear similarities between NHS management and business management are important” (p.18). The Inquiry Report goes on to argue that although the NHS is not for profit its management could learn from business management practices, more particularly in having "predetermined standards and objectives” and "a keen sense of how well they are looking after their customers” (p.18).

Thus the new management structures and personnel that were ushered in to New Zealand in the implementation of Area Health Boards and the subsequent 1993 health reforms were focused on management, setting and measurement of hospital performance. They also heralded the demise of a career path for nurses and doctors unless they were willing to relinquish clinical responsibilities and become a manager reporting to the General Manager. Some did transit into management.

As well as providing a single point of accountability in the general manager and emphasising managerial skills, the Gibbs report had also recommended radical structural changes in the health system as a whole. These were picked up by the National Government in July 1991 when they announced in the document "Your Health and the Public Health" the dismantling of the existing health system ( including the newly formed Area Health Boards) and the creation of a new system based on managed competition to take final effect in July 1993. The rationale as stated in the transition to new structures by the National Interim Provider Board (NIPB) was that "competition is the only way of ensuring on a continuing basis, constant innovation and best value at 
optimum quality for every health dollar” (p.9). Thus, as Ng, Jenkins, Dixon and Cram (1992) noted "the changes were not solely economic but also ideological, reflecting firstly the complex power relations between occupational groups in the health services, and secondly the political drive to restructure the state sector and deregulate the market”(p.60).

The core of the new health system lay in the structural separation of the funders of health services from the purchasers, and from the providers, of those services. This resulted in: a) a changed role for the Department of Health, which became the Ministry of Health (essentially a policy advisor to the Minister, and overall funder of the health service) with a separate organisation, the Public Health Commission, taking over responsibility for funding and policy advice on public health initiatives; b) the establishment of four Regional Health Authorities (RHAs) as purchasers to enter into contracts with health providers (both public and private - whoever submits the most suitable bid for a contract) for particular services; c) the establishment of 23 Crown Health Enterprises (CHEs), the public providers of health services, reporting to 23 commercial boards of directors.

These changes occurred in an environment of widespread state sector reform (Scott, 1993). The reforms focused on separating policy activities from service delivery, and on removing state business activities from state service regulation. They also aimed to introduce a more "commercial and businesslike" orientation in state sector managers. The guiding philosophy for implementation of these reforms was that if the structures were right efficiencies would naturally follow. The State Owned Enterprises Act 1986, the State Sector Act 1988, the Public Finance Act 1989 and the Employment Contracts Act 1991(ECA) were fundamental pieces of legislation in these structural reforms. The ECA, which covers both public/state and private sector, drastically reshaped the process of entering into and maintaining an employment relationship.

The crucial legislation for the health sector was the Health \& Disability Services Act 1993 which states that Crown Health Enterprises are "to be as successful and efficient as comparable businesses that are not owned by the Crown” (S.25(2)(d)). A perusal of the Annual Reports from the CHEs will show that in line with the Act, they all focus on commercial viability through increasing revenue and achieving operational efficiencies, and as an adjunct they mention clinical, quality and operational targets (1994/95 Annual 
Reports). A number of CHEs also reported that in their first year they had flattened their management structures and "established key management skills by recruiting a senior management team with a mix of health and commercial backgrounds"(Auckland Healthcare: Annual Report 1994/95). Not surprisingly 11 of the 23 CHEs appointed chief executives from the private/commercial sector. Most CHEs appointed some management staff from the commercial sector (often in commercial services positions, or customer satisfaction, finance, or information systems, and some to health service management positions). However, three years after the introduction of the new health sector structures a large number of chief executives have left the system - "13 out of 23 chief executives have quit or not renewed their contracts” (The Dominion, 3/7/96, p.3). All the chief executives appointed from the commercial sector have left, and most have cited underfunding, political interference and conflicting expectations of government, staff and patients, as the factors which make it impossible to manage well.

In an overview of the New Zealand health reforms Salmond, Mooney and Laugesen (1994) acknowledge that the reforms were necessary in order to better focus resources to achieve defined and agreed objectives. They also note that:

the health profession had to be encouraged to share their power with those people whose primary and professional skills were in management. The aim had to be to develop effective partnerships between the health professionals as the clinical providers and purveyors of care with those charged with the management of health service resources and the implementation of the government's social and economic policy objectives. Managers and health professionals had to learn to work together. (p.2)

\section{Themes of Connection and Contrast: Medicine and Management}

Parallels between medicine and management can be seen by viewing their histories concurrently as outlined in this chapter and thrown into sharper relief by a summary chronology. Three themes are particularly worthy of further comment: 
The history of both medicine and management is intimately linked to the culture and society in which they exist. The changing fortunes/status which they have both experienced, from craft or trade to profession or position of power, has been a direct result of the ideology and beliefs of the societal leaders and the sophistication of the societies they inhabited. Capitalism and democracy, secularism and science, have all contributed to the continuing change in western society. We are now reaching a crucial decision point in how we continue to organise our society, we are at the point where our desire for equality of all people (and hence their individual rights) is in chronic tension with an apparent insufficiency of resource to meet the needs of all individuals. This is exacerbated in the health sector by the high costs of many (but not all - some get cheaper) new medical technologies in combination with the public demand for access to all available treatments. This tension is currently at the heart of the health manager's role and the doctors role. It is the core of the tension that can exist between the two roles. Ironically, capitalism and the 'free market' were supposedly the answer to this tension by a process of self regulating supply and demand. Health however is not a 'commodity' that conforms to such economic expectations.

The development in recent times of medicine and management has been interlinked. Doctors have needed hospitals in order for the profession to develop and prosper, managers have needed organisations (like hospitals) in which to practice the art of management. As discussed earlier in this chapter, hospitals provided the forum for sharing of and training in medical knowledge and the "captive" patients for developing that knowledge and the organisational structure to provide regular income and career structures for doctors. Hospitals were also an obvious way for the state to discharge its duties in providing for the health of its citizens. Managers of hospitals were required to ensure that the state or private investment in hospital delivered health service was appropriately administered. Thus doctors had to work with, through, and for, hospital administrators/managers. Those managers had to work with, through, and for, the doctors and the hospital trustees.

Both roles also form power groups and as such utilise systems of control. Managers seek to maintain control over employees and the organisation in terms of what services it delivers, how it delivers, and at what cost it delivers. Doctors seek to maintain control over their profession and its specialisations by regulating who can enter and practise in it. In recent years both managers and doctors in hospitals have experienced changes in 
their levels of power through increasing levels of state intervention in the health service and a worldwide trend toward emphasising the rights of the individual. The increasing legal definitions of individual rights (of both patients/health consumers and employees) through the Human Rights Act, Employment Contracts Act, Code of Health \& Disability Services Consumers' Rights, Health Information Privacy Code, Privacy Act, Health \& Safety in Employment Act and similar regulation, have attempted to reduce the perceived power imbalance between doctor and patient, manager and consumer. Interestingly this legislation in terms of employer and employee has arguably increased the power of the employer over the employee.

2. Both medicine and management embody a group of activities, a group of people and a set of values.

The earliest tradition in medicine saw the healing craft passed from father to son. Even nowadays there are "medical families" who choose to train in medicine generation after generation. Similarly from early times to the present day there have been "family businesses" or a tendency for succeeding generations to choose to enter managerial pursuits. Some would argue that upbringing in the particular milieu of that vocation imbues certain values and ethics which become an integral part of one's personal identity and hence choice of life vocation. Medicine attempts to continue its "milieu" through its relatively homogeneous education processes at medical schools around the world, and its strict control over entry to the profession and ongoing education within it. Additionally there is now a strong tradition of codified medical ethics guiding physician behaviour. Management on the other hand has had no such consistency in the education of managers nor are managerial ethics exemplified in the manner of medical ethics. Managers come from many different backgrounds and the only barrier to their entry is the organisation and whether it considers a person to have the required skill to be a manager. However in the past decade there has been increasing emphasis on business degrees such as the Master of Business Administration or Master of Management and commerce degrees generally, as providing useful education for managers. As yet there is no compulsion for managers to attain these qualifications but some organisations would not consider appointing managers without them. In the health sector, as in other industries, many managers are drawn from the technical staff of nurses, pharmacists, doctors and other health professionals. This change of role can occur without the benefit of management training or skill development, but is based more on a positive assessment of that individual's interpersonal, and organisational ability. For many 
technically trained people, management offers an alternative and sometimes the only upward career path.

One could reasonably assume that the notion of group membership and professional loyalty must be stronger for doctors whose whole professional education and maintenance is tailored to produce such collegial connection. Medical skill is integral to the health industry, hence doctors tend to remain working in the health sector for an extended period of time and often for their entire working life. Managerial skill is integral to the functioning of organisations generally and managers are able to transport their skills to a variety of industries. One could suggest that doctors are loyal to the profession (i.e., the embodiment of their career), and to the patient (i.e., the focus of their skills and role). Managers are loyal to the organisation in which they are employed (i.e., the focus of their skills and role), and to their career future (for some this is solely in the health sector, for others it spans different industries and aims at more senior or more interesting roles). Hence, for the doctor, the organisation has little relevance other than as a venue for the practice of medicine. For the manager, however, the organisation has great relevance as an entity which is to function effectively in order to deliver its services.

3. Both medicine and management are underpinned by a body of knowledge and a public persona/image which is often different to their actual practice

In the last century medicine has seen unprecedented development in its scientific knowledge and capability. Doctors have traditionally separated themselves from alternative therapies/healers, claiming to be more "scientific" than those they ostracise. The medical profession have created their own mystique and false infallibility around the scientific 'medical model'. It, therefore, is not surprising that patients hold high, and somewhat exacting expectations, which often cannot be met.

In contrast the theoretical base of management appears ill-defined and looked upon as an activity susceptible to the latest fad rather than a rigorous science. Thus although managers espouse certain current beliefs about best management practice, these often are not consistent with their actual management practice. Additionally the crux of management is to be responsive to the desires of the "owners" - i.e., their ultimate employer - the Board, or the State, or majority shareholders. 
Paradoxically, both management and doctors can end up feeling scapegoated and caught in a "no win" situation - the managers caught between their employer and their employees (i.e., doctors and other staff); the doctors caught between their employer (i.e., the manager) and their patient.

The following chapters will continue to explore and develop these themes. 


\section{Summary Chronology of the Development of Western Medicine and Management}

\section{Medicine}

Themes: protection and development of a craft to a pursuit of ducated gentlemen to a profession with an ever expanding base of knowledge and capability

460 - 377 BC Hippocrates and the Greek tradition of healing

AD 131-201 Galen and the Roman tradition of medicine 860 - 1037 Rhazes and Avicenna and the Arabian tradition

Middle Ages (through to 1500)

Universities established teaching theology and law, and later medicine

Paris 1110, Bologna 1158, Oxford 1167, Cambridge 1209,

Padua 1222 etc

1518 College of Physicians established in London to provide protection from quacks

1600s William Harvey, who studied in Italy, discovers

circulation of the blood. Various other anatomical discoveries at

this time.

1681 Royal College of Physicians established in Edinburgh

1700s Jenner vaccinates against smallpox

1795 France introduced national training for doctors and licensing system in 1803

1803 Thomas Percival, English doctor, publishes “Medical Ethics" his book on ethics and etiquette in the profession, based on rules of governance he drafted to settle a dispute at Manchester Infirmary in 1792

A concern with health of populations emerges

mid 1800s British educated doctors emigrate to New Zealand and other colonies

1846 American Medical Association established;

1847 American Medical Association publish code of ethics

based on Percival's ideas

\section{Health Management}

Themes: serving the interests of a changing set of masters, the changing nature of hospital management and funding of health/hospital services

1750BC Hammurabi, Babylonian king, documented payment and punishment for healers

Cult of Asklepius - temples and healing places managed by priest/ess

Medieval Hospitals were generally managed and funded by the church, aimed at travellers, the indigent and the sick.

St Thomas’ Hospital, London established 1215

From 15th century onwards physicians increasingly associated with hospitals to provide care for patients

1700s large number of hospitals established e.g., 1719

Westminster, 1721 Guys, for treatment of the sick and as centres of study and teaching of medicine

Many doctors setting up their own specialist hospitals for personal profit

1800s General Hospitals providing medical training

1848 (UK) Public Health Act to control epidemics and health of the labouring poor (particularly in factories)

\section{Management}

Themes: different mechanisms of control from systems of class/caste to unionism, professionalism, corporatism and managerialism

\section{Management of tribes and fighting forces}

Very active commercial sector of society involving management of assets and people

Slavery, feudal systems, patronage systems, other class based systems

Gyseat world exploration and expanding trade and commeree, entrepreneurs/small business men

Family businesses and trades passed from generation to generation.

1500s the Reformation of the Catholic Church

1640 - 1660 English Civil War

1760s acknowledged as the start of the Industrial Revolution 1765 Watt invented the steam engine

1769 Arkwright's water frame

1779 Hargreave’s spinning jenny

Salaried managers were employed to run factories for the

owners

The beginning of mass production mechanisms

Changed the face of England and Europe with the creation of urban areas around mills and factories. Slums developed and public healh problems enseed - for the first of populations and their needs emerges.

1789 the French Revolution - overthrow of system of monarchy for a fairer political system of ruling the people for their well being 
1858 (UK) Medical Act - licensure became responsibility of the state

1860s Lister uses antiseptic processes in surgery

1867 Medical Practitioners Act and 1869 amendment passed in

$\mathrm{NZ}$ - introduces compulsory medical registration in 1868 for the whole country - but no disciplinary powers

1886 NZ Medical Association founded, became branch of British Medical Association

1887 NZ Medical Journal starts publication

NZ Medical Association adopts a Code of Ethics

Otago Medical School confers its first medical degree

1900 Public Health Act which establishes a Minister of Public

Health and a government department of public health with a

Chief Health Officer (a doctor) - state medical and public health

service

1907 Tohunga Suppression Act

1908 Quackery Prevention Act

Influenza epidemic in New Zealand

1918 Wartime advances in surgical techniques

1920s Establishment of separate clinical societies in NZ and Australia eg 1927 Australasian College of Surgeons

1924 NZ Medical Council permitted to hold own disciplinary hearings and fine doctors

1929 Fleming discovers uses of penicillin

1938 Social Security Act - entitled all New Zealanders to free public hospital treatment as of right. Doctors were paid for their work in the public hospitals - previously they had done it as charity and combined with private patients whom they charged. Friendly Societies had also paid doctors to treat their members. post-1945 a schism in the medical profession emerged between hospital specialists and general practitioners
1847 Wellington Hospital opens, 1851 Dunedin and 1862 Christchurch

ate 1800s Hospital structures more formalised, administrators, matrons and medical staff. In New Zealand the gradual

displacement of the charitable hospital by the medical hospita (1880 - 1920). In America Hospital Superintendents were meeting regularly in the newly established American Hospita Association

1885 Hospitals and Charitable Institutions Act which set up Hospital Boards throughout New Zealand - members appointed by local authorities.

20 hospitals in NZ treated 6471 indoor patients.

Limited State involvement in New Zealand health care-

responsibility lay with local authorities, and with Friendly

Societies which paid for health care of the poor

Post-1900 Spectacular growth in NZ Hospital services ( also rapid growth in population)

1921 - 88 public hospitals treated 48489 indoor patients with 3143 staff

1930s the hospital had become the recognised workshop of the medical practitioner in New Zealand

1938 Social Security Act heralded the State taking a much more comprehensive role in the health care of its citizens
Capitalism accompanies the Industrial Revolution, with an emphasis on private property and individual liberties

1861 - 1865 American Civil war

1881 First university courses in management run in America at University of Pennsylvania

26 May 1896 Henry Towne at the American Society of Mechanical Engineers calls for management research and education

Emile Durkheim and Max Weber - theories on bureaucracies

F.W.Taylor - Scientific Management

Elton Mayo - the Human Relations School

1920s and 30s onwards saw the development of different

"schools" of management thought

\section{American Management Association founded}

late 1920s and 30s the world economic depression - widespread job loss and resultant poverty

The First and Second World Wars result in more involvement of women in the workforce assisting the war effort.

1935 Election of First Labour Government in New Zealand and birth of the welfare state.

1944 New Zealand Institute of Management founded 
1947 Nuremberg trial of Nazi physicians and 1949 Nuremberg Code of basic ethical requirements for medical research World Medical Association formed, Declaration Of Geneva the basis for international code of ethics

1952 College of General Practitioners established in New Zealand

1960 Continuous Renal Dialysis is developed in the USA 1960s the double blind crossover drug trials start to be commonly used to support evidence based decisions for use of drugs

\section{4 (revised 1975) Helsinki Declaration re protection of} research participants

1979 Duplication of the human embryo at George Washington University, USA

Association of Salaried Medical Specialists - essentially a trade union aimed at securing better pay and working conditions for medical specialists

Establishment of the Coalition for Public Health - a lobby made up of medical professionals, economists and others interested in maintaining a public health system. 1990s Human Genome Project (USA and Europe) - developin the genetic map of all people, seeking to patent certain aspects of discoveries

Increasing number of complaints against medical practitioners brought to the NZ Medical Council by patients

Mid-1980s onwards - an explosion in the equipment and technology potentially available to assist diagnosis and treatment of illnesses

1990s Development of practice guidelines for clinical management of illnesses in a resource efficient and safe manner
1948 World Health Organisation established by the United Nations - forerunners to this organisation had included the International Sanitary Conferences first held in France

1956 NZ Government assumed full responsibility for funding health (i.e., no contribution from local rates)

1960s Those requiring renal dialysis in the USA far outweigh the number of machines available - a "life and death"

committee is established to decide who should receive dialysis. NZ - system of numerous hospital boards with triumvirate management (administrator, medical superintendent and chief nurse)

1974 Labour Government White Paper "A Health Service for New Zealand" suggested 14 regional health authorities - but medical opposition saw it shelved.

1983 Area Health Boards Act passed by National governmen to establish the 14 boards

Late 80s Ethics Committee structure revised throughout NZ to include lay members - in response to Cartwright Enquiry - their mandate further broadened by 1993 Act

1988 "Unshackling the Hospitals" Gibbs report recommends dismantling the triumvirate (doctor-nurse-administrator) arrangement in hospitals

Six years after the legislation was passed establishment by the Labour Government of 14 Area Health Boards each with a General Manager

Destruction of nursing and medical administrative career paths led to a number of former health professionals choosing to become managers with no clinical role

1991 National Government announced intention to dismantle existing health system and create a new system based on

"managed competition" to take effect in 1993.

1993 Health \& Disability Services Act

abolition of Area Health Board structure and establishment of

23 Crown Health Enterprises (i.e., providers) reporting to 23

commercial Boards of Directors and 4 Regional Health

Authorities (i.e., purchasers), changed role of Ministry of Health (funder), and establishment of Public Health Commission

Large number of Chief Executives and senior managers of CHEs appointed from outside the health sector - Telecom a
Ongoing struggle in academia to find a single theory of management

1961 Koontz publishes article on the "management theory jungle" highlighting at least 6 different approaches to management theory

1960s The Civil Rights Movement, particularly in America, draws attention to inequalities, and emphasises everyone's individual rights.

1970s and 80s consensus in literature tends to see management as a combination of controlling, planning, organising, directing/leading.

Henry Mintzberg - managerial role includes: interpersonal role, informational role, decision role, negotiating role.

Koontz updates his article with 11 identified approaches to management theory (1980)

1980s Popular management theory emphasises structures which are "flat" devolving power to business units, focusing on "the bottom line"/profit etc. Period of constant downsizing often at the expense of middle management positions.

New Zealand Government radically restructures the public New Zea by splitting public busicess spliting policy activities, service delivery and business thus turning some Departments into State Owned Enterprises operating for profit - 1986 State Owned Ent
Act, 1988 State Sector Act, 1989 Public Finance Act. Act, 1988 State Sector Act, 1989 Public Finance Act. individual rather than collective agreements, to allow more flexibility for the employer to reward individually for performance and to employ for specified periods of time.

Emphasis on short term employment contracts for management positions and job mobility, particularly the transportability of general management skills to any industry or organisation

1990s management theory emphasises teamwork and lifelong learning for managers and employees

Government policy emphasises efficiency in the form of privatising of businesses that they believe need not be run by government, and within remaining government departments contracting out/in services that can be cost effectively provided 
Day surgery increases in popularity in order to reduce waiting lists and avoid using hospital bed space and resources.

Increasing reliance on Medical Defence Union, as litigation becomes more common in NZ

1995 Medical Practitioners Act - heralds a number of changes aimed at tighter control over ongoing membership of the profession e.g., introduces competence and recertification programmes, a new system of vocational and general registration

Most radically it separates the Medical Practitioners

Disciplinary Committee from the Medical Council where it has traditionally been based (as a committee of doctors and one lay person), and establishes it as a Tribunal chaired by a lawyer.

Under a complicated new system any complaints against

medical practitioners must go first to the Health \& Disability

Commissioner for investigation and possible referral to the

Disciplinary Tribunal. particularly popular former employer!

Hospital wards shrinking as patients placed back in the community to convalesce/recuperate

CHE Establishment Unit \& Ministry of Health issue guidelines

of ethical standards for CHEs

1994 Health and Disability Commissioner Act - Appointment of Commissioner and staff to advocate for consumers

of Commissioner and staff to advocate for consumers

CHEs report on first year of business - all are focused on
commercial viability through greater efficiency and increase

commercial viability through greater efficiency and increased

out laundry services and hotel services .

1995 Abolition of Public Health Commission and absorption

of function into Ministry of Health

1996 Publication of Code of Health and Disability Services Consumers' Rights detailing consumers rights and health providers duties. Consumers may lodge complaints against doctors, nurses, other health professionals, managers, the $\mathrm{CHE}$ itself etc to be investigated by the Commissioner's Office. June 1996 - three years after the establishment of CHEs of the 12 private sector/commercially experienced CEOs appointed in 1993 only 1 remains in the health sector. Many have departed claiming that political interference and chronic underfunding by the RHA (purchaser) have made their jobs of managing viable organisations impossible. from independent businesses e.g., cleaning, gardening,

building maintenance and security type services.

A number of state owned enterprises are privatised and sold e.g.,. Telecom

A number of in house staff are laid off as services are contracted out.

1994 New Zealand Institute of Management develop a Code of Ethics for managers 
CHAPTER 3

DOCTORS AND MANAGERS TODAY - THE NATURE OF THEIR WORK

\section{Introduction}

Managers engage in planning, organising, controlling people and resources to produce goods or services and make a profit. Doctors in hospitals are the high-tech healers, diagnosing, treating and saving life at any cost. These are the popular images of managers and doctors but behind the generalisations lie the complexities of their work and an interesting array of similarities and differences between the two roles.

A scan through any of the descriptive research on managerial work today will reveal a characterisation of such work as varied, fast paced, uncertain, political and reliant on interpersonal skills and contacts (Duncan, 1989; Dunham \& Pierce, 1989; Mant, 1977; Rippin, 1995; Wake Carroll, 1993). Hales (1986) in his critical review of the research on managerial work notes also that "managerial activities are riven by contradictions, cross pressures and conflicts. Much managerial work involves coping with and reconciling social and technical conflict” (p.104).

Characterising the work of the doctor is not so easy. As Stoeckle (1988) notes “today’s literature on the work and experience of the (medical) practitioner is largely anecdotal” (p.83). However, if one were to summarise its features they would, with a few additions, be surprisingly similar to those listed for management. Hence one might list them as: varied; often fast paced and frequently uncertain; reliant on technical skill and ongoing mastery of the body of medical knowledge, as well as interpersonal skills and contacts; team based but independent with a range of complex institutional interrelationships; and a core professional relationship with the patient.

In this chapter we will explore key themes of connection and contrast between the work of doctors and managers today. These themes are: pressure and change; backgrounds, expectations and accountabilities; content of work; underlying assumptions; and the moral nature of their work. 


\section{Pressure and Change}

Political, social, cultural and technological change have been felt throughout history by both medicine and management. Schon (1983) noted that "the role of the physician will be continually reshaped over the next decades by the reorganisation and rationalisation of medical care; (and) the proliferating roles of enterprise will call for a redefinition of the businessman's role” (p.15). Indeed the 1980s ushered in a range of structural and legal changes in the New Zealand health arena which are still occurring in the 1990s. The massive state sector and health sector structural reform brought far greater emphasis on the manager's role. The ILO in Geneva published a paper in 1989 by Joseph Prokopenko on the management implications of structural adjustment in which it noted the changes having a critical influence on the roles of managers thus:

organisational environment is becoming more market driven, cost-conscious, complex, faster, international and culturally diverse; organisational structure is "flatter", decentralised and fragmented, yet integrated by overall strategy and corporate culture; "horizontal" management is becoming more important than "vertical", hierarchical management; people and talent are recognised as being the most precious resources of the organisation. (p.86)

The increasing emphasis on the importance of managing these factors in order to have efficient and successful organisations has placed greater pressure on managers to deliver the promised goods.

The work of the modern doctor has also undergone great change. Stoeckle (1988) summarises three key changes:

1) as practice is corporatised in a more bureaucratic/industrial mode, the doctor becomes an employee and the doctor/patient relationship responds to corporate interests; 2) as clinical work uses more medical technology it becomes not only more technical and specialised but also more divided and deskilled; 3) as information systems monitor the doctor's work, it becomes more standardised and prescribed (p.77).

The 1980s in New Zealand also saw the Cartwright Inquiry into cervical cancer procedures at National Women's Hospital which ultimately led to the nationwide introduction of informed consent procedures for patients undergoing any operation. This changed medical practice by ensuring that doctors fully explain a medical situation and treatment options to the patient. This has been further reinforced by the introduction 
of patient advocacy services, and most recently the Code of Health \& Disability Services Consumers' Rights (refer Chapter 5). All these changes placed more emphasis on the autonomy of the individual patient and have heralded an era of far greater public/media scrutiny of medical and managerial practices and discussion of ethical issues in health. This scrutiny places pressure on both doctors and managers.

\section{Backgrounds, Expectations and Accountabilities}

Managers come from a vast range of educational and organisational backgrounds, and like most of us develop their management style through a tendency to repeat behaviour that is successful or rewarded or comfortable. Fondas and Stewart (1994) explore the notion that expectations held by others partially define the job of the manager, although a large part of the role is how the incumbent behaves in it. Expectations of managers can be conflicting - depending on the group to which the manager is accountable at any particular time. In a Crown Health Enterprise the manager can be accountable to the Board, the staff, the patients and their families, the RHA or Ministry of Health, the general public, the politicians of central or local government, etc. Hence those expectations may range from being able to take the hard decisions regarding cost containment to ensure, above all, a profitable organisation; through to providing care and treatment at any cost for all people regardless of age and health status.

Doctors, on the other hand, emerge from a relatively consistent educational background - all completing a medical degree and internship - being introduced to the theory and practice of medicine in exactly the same way. This training and education is further reinforced by the hospital organisations or practices in which they work, and the professional groups to which they belong. However, similarly to the manager's predicament, there are a range of expectations of the doctor's role depending to whom they are accountable. Margaret Stacey (1992) in a commentary on the accountability of doctors notes that:

there are so many ways in which a doctor may be held to account for his or her actions: for clinical actions to individual patients and, in medical audit, to colleagues; by law in terms of obligations to patient or employer; to the profession for her/his behaviour; to employers for the money spent and the priorities adopted in treatments; to the state in relation to contracts. (p.109) 
The expectations of these different groups range from the infallible expert with a cure for almost anything; through to the rationer of resources to those most medically worthy. As Cole (1995) explains in his Medical Council guide for doctors entering practice in New Zealand, the Crimes Act 1961 imposes a legal duty of care on doctors “to have and to use reasonable knowledge and skill”. Doctors can, under New Zealand law, be tried for manslaughter. Thus the doctor's behaviour is subject to "multiple jeopardy” through possible criminal proceedings, civil proceedings, disciplinary proceedings, proceedings under the Health \& Disability Services Consumers' Code of Rights, and managerial/employer scrutiny. Such "multiple jeopardy” does not exist for managers. This all has the effect of reinforcing doctor's accountability to and for the individual patient, and thus exacerbates the potential for tension with the managerial role.

Both managers and doctors are employees caught in the tension between a humanitarian organisation and a resource constrained enterprise. The various stakeholders, from patients to parliament, all have rights and legitimate claims but not all of them can be met all the time.

\section{Content of Work}

The last twenty years have seen a massive expansion of medical knowledge. As a result practice parameters and practice guidelines have emerged to simplify the decision process for doctors. They provide a shortcut to assimilating the vast array of diagnosis and treatment information. Practice guidelines go as far as recommending the best ways of managing certain clinical situations. Thus the doctor's work is primarily gleaning information from individual patients in various ways, arriving at a diagnosis, and at a preferred treatment plan with which the patient is in agreement, and conducting the treatment often of a technically complex nature (e.g., some surgical procedures, some drug therapies etc). The doctor's tools of information gathering include talking with the patient and sometimes with their family, performing physical tests on the patient and taking samples from the patient for further analysis, and monitoring progress and response to certain courses of treatment.

Goldman (1980) notes that the medical battle in the past was waged primarily against diseases, with the congruent goals of i) prolonging life, ii) reducing suffering, iii) preventing/curing illness and iv) promoting patients’ overall well being. Now, Goldman 
claims, the context of chronic illness (and new technology) brings these goals into conflict with each other. This highlights two key factors in the nature of medical work, firstly the element of proximity to action and results, that is, the doctor is very close to the target of his/her actions and the results are frequently immediate (and sometimes long term) affecting both the patient, the doctor and others. Secondly, there is a large element of uncertainty in medical practice. Beresford (1991) reported interviews he completed with Canadian physicians in a variety of clinical settings and identified three sources of uncertainty affecting the allocation of medical resources. These were: “technical uncertainty (which) arises from inadequate scientific data; personal uncertainty (which) arises from not knowing patients' wishes; conceptual uncertainty (which) arises from the problem of applying abstract criteria to concrete situations” (p.6). He concluded that uncertainty is an unavoidable part of the context-specific decisions doctors are required to make - decisions that require the exercise of judgement.

The last twenty years have also seen a massive change in managerial practice although not necessarily much advance in managerial knowledge. Managerial practice has changed in part due to the vast improvement in communications and information technology and in part to the increased career mobility of managers. The former means that managers have more information available more quickly than ever before and the means to disseminate it rapidly; the latter means that managers are not always committed to one particular organisation for more than five years. Both these factors lead to greater change and variety in organisational practices. They also lead to a shorter term focus. Shortell and Kaluzny (1988) summarise a small number of studies which have been completed on the work of the health service manager. The work of the health service manager was reported as internal management, organisational development, external relations and environmental surveillance. The large majority of work was internal management, that is, personnel management, financial management, logistical management, organisation design, service delivery and legal work. One could say that the manager diagnoses and treats the organisation which involves dealing with large numbers of staff in order to gather information. Information comes in the form of face to face, electronic and paper discussions of issues, which are generated informally and formally, for example, from serendipitous meetings to monthly management reports. All this information feeds into the manager's decision making about the organisation. 
Simon (1960) calls decision making the "heart of executive activity". As such, manager's work, like the doctor's, is characterised by uncertainty. Duncan (1989) observes that managers do not operate under conditions of perfect knowledge, so uncertainty is the normal state of affairs. He reports that in solving organisational problems the manager conducts a sequential search for randomly generated alternative solutions and achieves satisfactory rather than maximum outcomes. "Intuition and judgement have more to do with management than objective data, hard facts and precise science” (Duncan, 1989, p.102). In terms of proximity of action and results, the manager is generally removed from the effect of his/her decisions and their impact on a broad range of other people. The time period between action and result is often delayed. Some would argue that this allows managers to be more objective while others would suggest that it makes them uninvolved and potentially unaware of impacts.

Hence both managers and doctors deal with uncertainty as an integral part of the job. They also both deal with people, but for managers dealing with people is instrumental to organisation performance, whereas for doctors the patient is the means and the end of medical practice.

\section{Underlying Assumptions}

Our modern hospitals and health organisations are the forum in which two strong ideologies meet - the business/management model and the medical/disease model. As outlined in the previous chapter both ideologies have a long history and pervasive sets of underlying assumptions. In the medical model a pathological approach underpins practice i.e., all people are regarded as diseases waiting to happen. Hence the doctor's focus is the individual and their disease. The doctor's paramount concern is the well being of the patient. In the business model a market and efficiency orientation underpins practice ie. all organisations can be run as businesses, and a business will be successful if it is an efficient player in the market. Hence the manager's focus is the organisation and its efficiency - looking for opportunities and new ways of organising or doing things to improve the financial bottom line. One could argue that the organisation is the manager's "patient” on which contextual information is regularly collected, a diagnosis made, and as a result judgement exercised and decisions/choices made on resources worth investing or actions to be taken. The manager's paramount concern is organisational survival. So it is possible that managers and doctors may see similar data 
but interpret it differently because their level of focus is different i.e., the organisation vs patients. The healing relationship exists to reassure, comfort and cure - a responsibility shared amongst the doctor and the health team. The managing relationship exists to shape and develop employees, to facilitate production/service provision - a responsibility shared by the manager, management team and corporate support staff.

Not surprisingly one of the areas that demarcates and yet joins together management and medicine is language. Both have a distinct language but both also have in common the language of the 'health' sector. Goss (1963) suggests that the power balance in hospitals rests with the role with greatest task difficulty - which for many years was the doctor. However it is interesting to speculate on the increased difficulty of the manager's role due to the administrative arrangements of the current health reforms (i.e., jargon, contracting, funding splits, limited resources and increasing demand, etc.). One could argue that this is counterbalanced by increasing difficulty of medical decisions due to such factors as increasing technology, increasing costs, ethical considerations. Thus maybe we are at an unusual period in history where doctors and managers are in a state of dynamic tension due to the difficulty of both of their tasks.

\section{The Moral Nature of Being a Manager or a Doctor}

Medicine has never been truly autonomous, although it would have us believe otherwise. It has exchanged reliance on patronage for reliance on hospitals and their structure as a source of advanced technology as well as patients. Medicine has never practised unfettered by financial concerns. As Pellegrino and Thomasma (1988) report, "the twin themes of self-interest and altruism have been inextricably joined in the history of medicine”(p.123). But aside from, or maybe in spite of, these institutional arrangements medicine has maintained a "moral" dimension due to the doctor:patient relationship and the trust on which that is based. The doctor, we are told, has an overwhelming duty of care to any and every patient. The ethics of the medical profession guide the behaviour of its members and underpin the essence of the medical role. 
Management is entirely reliant on an organisational form for its existence. Managers are agents of the organisation, and the "moral" dimension of management which guides behaviour is often enshrined in laws pertaining to workplaces and organisational activities. But there is much in management that is not spelt out in law and hence relies on business/managerial ethics. We readily acknowledge the moral component of medical work - certainly we let doctors do things to us we wouldn't normally let friends and family, let alone strangers, do to us (e.g., examine our bodies inside and out, remove body parts, drug us, etc.). In this way we can see a direct connection between ourselves, the impact of the doctor's actions and the trust that exists in the doctor:patient relationship. However we are not as ready to acknowledge the moral component of managerial work, viewing "business as business”. And yet, we know that a large portion of manager's time is spent in dealing with other people, and making decisions that affect others. But their dealings are not always as immediate or directly impactful as that of the doctor.

Hence the basis of medical practice and managerial practice, particularly in health organisations, involves decisions about the rights and welfare of persons, about courses of right and wrong behaviour for individuals and for the organisation. These are issues of moral choice; these are ethical issues. To understand the medical and the managerial roles it is therefore necessary to understand their moral/ethical component.

\section{Summary}

Doctors and managers work in frequently uncertain and often unforgiving environments. Their roles and technical expertise are different. Their backgrounds, the expectations others hold of them and their accountabilities are different. But both are under pressure from increased external scrutiny of their work, and both are caught in the tension between a humanitarian organisation and a resource constrained enterprise.

Essential to their differences is the doctor's focus on the individual patient and the manager's focus on the organisation. They both make decisions affecting the rights and welfare of other people but they approach those decisions from different standpoints. To understand the medical and the managerial roles it is therefore necessary to understand their moral/ethical component. This is the focus of the next section of the thesis. 


\section{SECTION TWO: APPLIED ETHICS}

To aid our understanding of medical ethics and managerial ethics, this section is organised in two chapters. The first, Chapter 4, reviews the literature, predominantly philosophical, on applied ethics. It starts with a brief description of the main schools of thought in ethical reasoning and theory, that is, the philosophical foundations, prior to an examination of applied ethics generally and medical and managerial ethics in particular. The connected area of professional and role based ethics is also introduced, and some suggestions are made on the similarities and differences of medical and managerial ethics. Chapter 5 reviews the empirical research that has been completed in the area of medical ethics and managerial ethics, highlighting the themes and gaps that exist in the body of research knowledge. The final part of the chapter examines the research methods employed in applied ethics and makes some suggestions for an alternative approach to be utilised in this study. 


\section{CHAPTER 4}

\section{APPLIED ETHICS - PHILOSOPHICAL FOUNDATIONS AND MAIN STREAMS OF THOUGHT}

\section{Introduction}

Applied ethics has its roots in the mainstream traditions of western philosophy. Since the first of the Greek philosophers various schools of thought have outlined principles for living and even codes of practice, and most have wrestled with defining the notion of a good life, or a good society. This chapter will summarise the main schools of thought in ethical reasoning before reviewing the now popular field of applied ethics, and in particular medical ethics and managerial ethics.

Generally discussion in ethics occurs at any one, or all, of three levels:

i) meta-ethics is the analysis and understanding of what moral terms, principles and justifications mean, abstracting from their specific content. It is about understanding how we think and argue about ethics. It does not involve making any substantive commitment or choice between ethical positions;

ii) general normative ethics involves developing ethical theories which are designed to guide behaviour via various ethical principles. It is the study of what ought to be done in various situations. Some philosophers also believe that there is a counterpart to general normative ethics which is particular normative ethics. This lies at the heart of applied ethics, and looks at what ought to be done in specific cases. Both general and particular normative ethics involve making substantive choices between ethical positions;

iii) descriptive ethics, as its name implies, is the study of what is actually done. That is it describes the ethical reality of day to day dilemmas and decisions.

Meta-ethics and descriptive ethics are often described as non-normative ethics.

In this chapter the discussion occurs mainly at the level of normative ethics as we examine the ethical theories that influence the field of applied ethics. There will, however, naturally be an occasional overlap into non-normative ethics in this chapter and indeed in the rest of the thesis as we explore the ethical issues of the moment. 


\section{Main Schools of Thought in Ethical Reasoning and Theory}

There are two main schools of thought popular in modern moral philosophy deontology and teleology. Deontological theories take a duty and rights-based approach to moral action, focusing on the duty, what one ought to do, independent of any consequences. The best known proponent of deontology was the 18th century philosopher Immanuel Kant, who believed that once a moral rule is established it is exceptionless, for example, morality forbids us to lie in any circumstances even when a lie may save a life. Hence for Kant actions were intrinsically right or wrong and one had a duty to pursue the right action. Kant also believed that people were deserving of respect as ends in themselves rather than merely as means to other people's ends. In essence Kant was an egalitarian seeing people as equally deserving of respect, a view often reflected by deontologists. Indeed this notion is embodied today in the idea of universal rights which set limits on how people may treat each other. Other deontologists hold more moderate views of moral rules, e.g., some allow that we have a number of duties which may conflict with each other in some situations and our moral task is to discern which duty has priority. Ross's theory of prima facie duties is an example of this viewpoint.

The core of teleological theories is the denial that any action is intrinsically right or wrong. Consequentialist theories are the most popular of teleological theories, i.e., the moral value of an action is a function of its consequences (real or probable). At one extreme such theories acknowledge the presence of self-interest in our actions as is found in the ethical egoism associated with the work of Thomas Hobbes in the 17th century. In ethical egoism a person acts only to promote for him/herself the greatest balance of good over bad results. Other consequentialists however have the common interest at their core rather than self-interest. Most well known in the consequentialist mode of reasoning is utilitarianism as argued by John Stuart Mill and Jeremy Bentham. For the utilitarian the ethical action is that which maximises the welfare or happiness of the greatest number of people affected by it. Mill's argument placed some constraints on action by pointing out that rules such as those against killing, promise-breaking and lying are beneficial and thus justifiable on appeal to the "greatest happiness" principle. In this way Mill was a rule utilitarian - developing rules or guidelines for action because on average such rules produce the most good and the least evil in broadly similar situations. Jeremy Bentham on the other hand was an act utilitarian, judging 
each action independently without reference to preestablished rules or guidelines. In this formulation each person affected by an act is counted equally and each act is considered in isolation. Other philosophers, like Locke, Rousseau, and in the 20th century John Rawls, have taken a contractarian approach. In this approach a social contract is suggested in which people, acting from self-interest, agree on rules likely to be most generally satisfactory even when they may involve some personal sacrifice. Rawls (1971) believes that rational and self-interested people in his theory will reject utilitarianism and opt for the concepts of right and justice. Rawls, in this way, styles himself as a deontologist. In another permutation of teleological thought natural law theorists suggest that ethics must be based on concern for the human good. Natural law assumes a natural order in relationships and that rational people will do, or not do, certain things based on reasoning and a divine plan. In the 13th century St Thomas Aquinas synthesised this thinking with Christian dogma, which in essence bases natural law on doing good and avoiding evil.

Other theories exist but these are the most popular representatives of deontology and teleology. Key in all these formulations is the positioning of self-interest versus the common interest, and generalisable rules/guidelines versus unitary act-based choices. As we will see in applied ethics, the reality of moral discussion often rests on a mixed base of deontological and teleological reasoning - sometimes appealing to overriding moral duties, and sometimes appealing to the competing consequences of actions in order to arrive at the morally appropriate choice/decision.

\section{Applied Ethics}

According to Joan Callahan (1988) the task in applied ethics "is to resolve specific moral issues and morally problematic concrete cases which arise in different areas of life” (p.7). She maintains that "applied ethics borrows insights from meta-ethics and theoretical normative ethics; but the concentration in applied ethics is on finding acceptable resolutions of moral problems of present and practical urgency” (p.8). Almond (1995) believes that one more than borrows insights from ethical theory, that "without a theoretical underpinning, arguments in applied ethics would be merely arbitrary” (p.6). Many applied philosophers subscribe to this view. 
Beauchamp \& Childress (1989) have produced a graphic presentation of the relationship between ethical theories and actions implementing decisions (Figure 4.1)

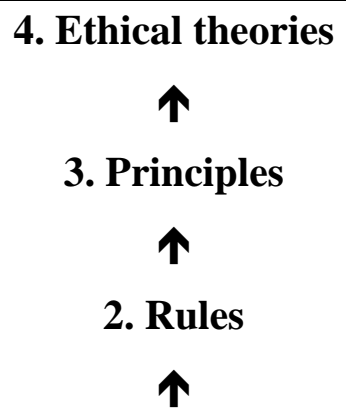

1. Particular judgements \& actions

Figure 4.1: Hierarchy of Relationships, Beauchamp \& Childress (1989) p.6

Similarly Bayles (1989) describes different levels of justification for acts (Figure 4.2).

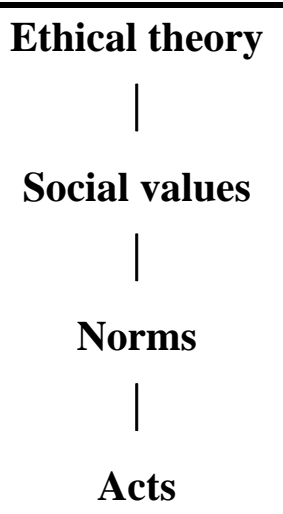

Figure 4.2: Levels of Justification, Bayles (1989) p.19

Applied ethics thus involves the consideration and analysis of particular problematic choices to act. These are informed by an appeal to existing rules or norms or, in their absence, by broader principles or social values and ultimately by ethical theory.

Professional ethics is one large area overlapping with applied ethics which includes discussion of a range of professions and the duties, obligations and problems of professionals such as lawyers, engineers, doctors. The area of biomedical ethics is itself huge. Administrative ethics in the public sector, and business ethics are also growing areas of discussion. 
Some philosophers, however, regard applied ethics as a misnomer - they claim that ethics and ethical theory is, by its very nature applied (Jamieson, 1988; Sylvan, 1993). They cite Kant, Bentham and Mill who all explored fundamental ethical principles and their application to particular cases (e.g., capital punishment, suicide, truth-telling, etc.) in the exposition of their theories. This, however, is not an entirely fair use of the work of these philosophers. It is a reinterpretation of their past positions, which were formulated without awareness of the modern distinction between pure and applied ethics, for which they are now being used. In a more convincing argument MacIntyre (1984) asserts that this misnomer is a harmful mistake. He suggests that the term applied ethics and the abstraction out into separate areas of application such as medicine, law and business rather than enhancing moral/ethical thought serves to obfuscate it within the problems of that profession. He gives the example of doctors and nurses discussing truth-telling to a patient - "their questions concern what the rules are and whether they need to be extended or reformulated, questions perhaps occasioned for them by peculiarly medical issues and questions peculiarly urgent for physicians and nurses, but not at all peculiarly medical questions" (p.512). He sees this as "nothing other than reopening that general discussion of truth-telling in which Aristotle, Maimonides, Aquinas, Kant and Mill are among their predecessors” (p.512). MacIntyre asserts that the rubric of applied ethics protects professional power and authority from scrutiny and disguises the general moral importance of what is occurring.

MacIntyre's concerns are valid ones. It is all too easy for different professions to think that their experiences/dilemmas are unique and that they should be exempted from the moral obligations that apply to others. This will be a point of discussion later in this chapter when we consider the "separatist thesis" which suggests that some groups have different moral obligations from those that apply generally. However, one assumes that MacIntyre's argument is more an acceptance that various moral domains may generate distinctive issues but that this is because of the non-normative features of the domain rather than any uniqueness of relevant principles.

\section{Medical/Biomedical Ethics}


Toulmin (1973) observed that medicine had saved the life of ethics. Certainly modern medicine has supplied a never-ending source of practical ethical dilemmas as the boundaries of life and death are constantly extended and financial considerations cloud straightforward decisions. Grodin (1995) engages in a useful discussion of the demarcations between bioethics and medical ethics which reveals changing definitions throughout time. However, bioethics is seen primarily as "a broad term which incorporates an applied ethical inquiry into all situations where biology affects human affairs. These affairs may be medical, such as genetics and health care practice, or nonmedical, such as animal rights and ecology” (p.7). Grodin goes on to portray medical ethics as "a narrower term referring to applied ethics in the medical realm" (p.7) and medical professional ethics as focusing on the conduct of physicians or other health care professionals in a professional setting. However Roth (1995) describes medical ethics as "the discipline that analyses the way in which moral decisions are made in the field of medicine...(and) seeks appropriate patient care, humane biomedical research, equitable distribution of medical resources, and a just health care delivery system” (p.538). This is a definition very much of our times. In earlier periods of history medical ethics would have applied solely to appropriate patient care. Medical ethics has been continually influenced by changing cultures and states, and more recently also by advancing medical technology and capability. This has brought a changing emphasis in ethical principles often mirroring prevailing social values. Thus ethical principles have moved from paternalism (i.e., doctor makes decisions for the patient) to autonomy (i.e., the patient has a right to make their own decisions), from non-maleficence (i.e., do no harm) to beneficence (i.e., actively doing good).

The Hippocratic Oath for instance emphasised the competence of the doctor. It stressed not treating that which is beyond medicine or in an area in which one is not trained, do no harm (non-maleficence) and if possible reduce suffering and severity of illness, and the doctor was to be a virtuous person. Percival and later Sir William Osler (in the late 18th and 19th century) emphasised a beneficence based understanding of medical ethics, that is, acting for the benefit of the patient. Nowadays as well as beneficence and non-maleficence, we have a very strong call for patient autonomy or self-determination, which parallels the 20th century rise of individual rights, to the point that our governments legislate and regulate to ensure such rights, for example the Health \& Disability Commissioner Act and Human Rights Act, referred to in Chapter 2. 
As observed earlier the unprecedented range of ethical dilemmas in 20th century medicine has also meant a huge amount of philosophical activity, some of which this chapter will review.

There are a number of alternative formulations of medical ethics in the literature, most focusing on one or two overriding principles, but of particular prominence in recent decades have been theories promoting autonomy. Veatch (1981) maintains that modern liberal political philosophy based on Locke and Rousseau's interpretation of social contract, and Kantian ethical commitment to respect of persons (as ends in themselves) results in a political philosophy/social ethic that has within it an incipient medical ethic - that of autonomy in which self-determination rules. Veatch himself promotes a contractual or covenantal model of relationship between doctor and patient which he believes allows greater moral equality between the two parties. In this conception "the basic norms of freedom, dignity, truth-telling, promise-keeping, and justice are essential to the contractual relationship" (p.91, 1988) and the patient's right to be a selfdetermining/autonomous individual is respected, with the doctor as the agent of the patient. Modern philosophers such as Childress, Dworkin and others have also emphasised autonomy of the patient as the basis of ethical medical practice. Hence this century has seen a massive swing by philosophers (and legislators) towards patient autonomy as the pivotal consideration of which to take account. This is in stark contrast to the Hippocratic tradition which has underpinned medical ethics for centuries and which is notable by the complete absence of patient autonomy as a consideration.

Other philosophers have chosen to emphasise beneficence which is a principle with great intuitive appeal for medical ethics. Pellegrino and Thomasma (1988) are the best known modern exponents of beneficence in which they reject the emphasis on rights and duty-based ethical systems in favour of virtue based theory grounded in the physician-patient relationship. They propose a fiduciary model focused on the character and virtue of the doctor who always acts in the best interests of the patient. They call this 'beneficence-in-trust'. This is a consultative healing process between doctor and patient both recognising their own values bases, the fact of illness, individual and social needs, personal and institutional aims, acting in one another's best interests in the relationship - the patient carrying out the negotiated plan for his/her health. Pellegrino and Thomasma acknowledge that the patient autonomy model grew out of changes in society (i.e., the rise of individual rights) - one could also justifiably submit that those 
same changes have shaped the new nature of beneficence-in-trust as a more collaborative model of beneficence.

However, one of the most influential and pervasive sets of ethical principles for medicine has come from the work of Beauchamp and Childress (1979) and it has become known colloquially as the "Georgetown mantra" (so-named for Georgetown University from where the work emanated). The ethical principles which form the mantra are a combination of those we have already explored: respect for autonomy, non-maleficence, beneficence, and justice. In this model ethical decision making in medicine applies these four principles in its considerations.

Autonomy is described by Raanan Gillon (1994) as deciding for ourselves on the basis of deliberation. Thus respect for autonomy is a moral obligation/duty as long as it is compatible with equal respect for the autonomy of all potentially affected in a situation. In the medical context this means consulting with, fully informing, involving in decisions, and obtaining informed consent from, patients for medical intervention and treatment procedures. Hence maintaining medical confidentiality and promise-keeping (e.g., being on time for appointments) and other such rules are also seen as part of respect for autonomy. Thus respect for autonomy requires good communication and interpersonal skills. Implicit in Gillon's position is, one assumes, a duty of respect for persons from which respect for autonomy flows.

Beneficence and non-maleficence are often considered together, because, particularly in medical care, in the process of benefiting others we can also risk harming them. Medicine is aimed at benefiting the individual patient with minimal harm, this is the traditional duty of care. Thus there is a need for ongoing education and development of medical skill, to be able to make assessments of risk and probability.

Justice is often treated synonymously with fairness and Gillon (1994) summarises it as "the moral obligation to act on the basis of fair adjudication between competing claims”(p.xxv). He divides this into: distributive justice (i.e., fair distribution of scarce resources), rights-based justice (i.e., respect for peoples rights), and legal justice (i.e., respect for morally acceptable laws). Gillon goes on to suggest that "for those decisions about justice that are organisational, professional or societal my role in determining them should only be that of a member of the relevant organisation, profession, or 
society.”(p.xxvii) This would appear to suggest a role-based justice which influences criteria for fair adjudication.

While many have found the four principles useful in their deliberations over ethical dilemmas, there are many areas of disagreement and confusion. Criticisms of the principles fall into several camps:

- Questioning of whether these are principles, or prima facie duties which thus will conflict at times and require resolution or balancing. Critics note that the principles do conflict and it is unclear how this conflict should be resolved, and to what higher order ethical theory one can appeal for further reasoning. Hence Clouser and Gert (1994) assert that they are not action-guiding principles but "a category of concerns, a listing of issues that should be considered in dealing with the problem in question" (p.251). Zaner (1988) accuses many in medical ethics of simply picking a principle, like beneficence, and applying it without regard for other possibilities.

- The use of the four principles in the literature is confused due to the varying definitions-in-use for the principles. For instance Jensen and Mooney (1990) discuss the variety of definitions of autonomy across a spectrum from deontological autonomy, through relativistic and social autonomy to paternalism. They conclude with a range of questions which illustrate that different forms of autonomy are changing over time in health care and they leave us uncertain of who has the right to decide in health care settings. Beneficence also has been the subject of redefinition, most prominently by Pellegrino and Thomasma (1988) as has been discussed in this chapter. The concept of justice is also subject to wide debate. Thus the principles are characterised by the singular lack of common definition.

- An uncertainty over the scope of the principles, that is, to whom do they apply? Does the doctor owe a duty of beneficence to everyone who could be benefited, and how much benefit is owed ? Are we all equal in regard to the principles?

In response to many of these criticisms Beauchamp (1994) counters that "it is insupportably optimistic to think we will ever attain a fully specified system of norms for health care ethics” (p.12). He states that "principles are starting, foundational points in health care ethics, not solely sufficient or final appeals” (p.3), and that they are prima facie. That is, they are binding until there is good reason to do otherwise, for instance if they conflict with another of the principles, in which case a balancing is required 
relative to the particular demands of the situation. Beauchamp goes on to suggest that what is required for the specification of principles is reflective equilibrium, a method formulated by John Rawls (1971). In this method we start with our considered judgements, paradigms of what is morally proper or improper, and then we search for principles which are broadly consistent, matching and developing them in order to make them coherent. In this way Beauchamp contends that "general ethical principles and particular judgements can be brought into equilibrium” (p.11).

\section{Alternative emphases}

It will be recalled that Pellegrino and Thomasma (1988) referred to their beneficencein-trust model as virtues/character-based, whereas most of the other formulations have been predominantly rules/duty-based. In recent years virtues-based arguments have had a resurgence, having once been popular in ancient times as the Greeks pondered the characteristics required to live a good life, they were popularised again by MacIntyre’s “After Virtue” (1981) which speculates on the type of city state in which virtues will flourish. Thus virtues-based approaches speculate on the type of character required to lead an ethical or good life, and they often speculate on the type of environment which would produce or nurture such a virtuous person. William May (1994) observed that "bureaucracies have made society increasingly hostage to the virtue of the professionals who work for them”(p.76). However, although there has been discussion of characteristics required of the virtuous doctor (e.g., beneficence-in-trust) there has not been much discussion of the type of medical environment which would optimise the virtuous doctor or patient.

Another approach which has increased in development and popularity over recent years is that of the feminist emphasis on relationship networks and care ethics. This approach was initially inspired by the work of Carol Gilligan (1982, 1987, 1988), who identified a moral perspective focused on care (i.e., not to turn away from someone in need) which was voiced predominantly by women. This perspective contrasted with the justice orientation (i.e., not to act unfairly towards others) voiced predominantly by men. Gilligan notes that "the shift in moral perspective is manifest by a change in the moral question from 'what is just?' to 'how to respond?’”. (1987, p.23) Thus the justice orientation is one that is focused on rules and hierarchy, but the care orientation is focused on making human connection and relationships. Susan Wolf (1996) in a recent publication addressing feminism and bioethics notes: 
it is no accident that bioethics has largely ignored gender and feminism .... the answer is to be found in the deep structure of bioethics - in its early embrace of a liberal individualism largely inattentive to social context; in its emphasis on deduction from ethical principles rather than induction from concrete cases; in its tendency to view ethical problems either dyadically as problems between individuals, or nationally as problems for the entire society, but rarely at an intermediate level attentive to the moral significance of groups; and in the failure of bioethics to be sufficiently self-critical by examining whom the field serves and how (p.5).

\section{Observations of, and gaps in, the medical ethics literature}

There are a number of problems in the literature which warrant further comment before leaving the area of medical ethics.

- The area which is potentially of greatest concern to medical ethics is that of definition. There is a tendency in recent times to fudge the differences between medical/biomedical ethics, bioethics and health care ethics. Medical ethics has traditionally applied to the medical task, appropriate types of treatment and the doctor:patient relationship; bioethics covers a wide range of medical, nonmedical, scientific and environmental ethical issues; and health care ethics encompasses the ethical issues associated with running a health care system. This blurring of definition has led to the inappropriate conflation of principles from medical/biomedical ethics to the much broader area of health care ethics as can be seen in the Roth (1995) definition of medical ethics at the outset of this discussion.

- There are a variety of different possible levels of ethical exploration - ethics of the system, ethics of the organisation, ethics of the role, ethics of the individual. However, there is a strong individualistic strand in medical/biomedical ethics writing which leaves it poorly equipped to deal with organisational and systemic issues. The physician-patient relationship is paramount in the literature with very little exploration, if any, of the doctor-manager or doctor-organisation roles and relationships and what governs them. Because of this focus on individual conduct there is a general reluctance in the medical ethics literature to explore broader social responsibilities of the profession as a whole, and a tendency to attribute all the duties, responsibilities and skill requirements to the doctor, and very few to the patient and to others. In contrast health care ethics is prepared to look at community 
and social structure issues, but where these issues are particularly strong they tend to become labelled as political rather than ethical. This in turn reinforces the individualistic emphasis in biomedical ethics, as ethics becomes associated only with the individual or personal. Feminist ethics, and the revival of Aristotelian ethics, have shown, and will continue to show, this division between ethical and political to be less salient.

- It is important not to confuse all medical, legal and managerial judgements with moral judgements (Buchanan \& Brock, 1989; Campbell, 1984)

- Much of the literature overlooks the fact that medical ethics is partly about relationships of unequal power and how we manage them fairly/ethically. That balance of power has changed throughout history and thus the dominant ethical principles have also changed. As we saw in Chapter Two, up until the 18th century the doctor was often reliant on a system of patronage by patients, medical knowledge was limited and challenged by other sources of healing. Through medical ignorance a lot of harm did befall patients but essentially ethical practitioners tried to act in the patient's interests. In the 20th century the range of medical knowledge and capability is huge, challenges from alternative sources of healing are minimal as society has become medicalised. Many doctors are employed in the public health system and are reliant on the funding of that system for the services they can deliver. Patients expect to be more involved in, and informed of, their medical treatments thus ethical discussions focus more around patient autonomy/respect for persons in determining the patient's best interests.

\section{Business/Managerial Ethics}

In 1975 Daniel Callahan of the Hastings Center announced that he had found no literature on morality and health care management (Levey, 1992). We are still not exactly overrun with such literature even though a lot has been written about medical ethics and about business ethics. Thus a good starting point in considering the ethics of health care management is to explore the literature on business ethics generally, and within that any literature on managerial ethics particularly in health.

Roth (1995) describes business ethics as "the study of moral behaviour in business and organisational circumstances; the application of ethical concepts to business 
relationships...it examines business goals and values, such as profit and power, in the light of traditional ethical principles and concepts”(p.112). Thus no discussion of business ethics is complete without considering the wider system within which business operates. Western business exists within a capitalist, democratic framework. Capitalism, the control of money and business by capitalists, relies on individual freedom to make and control money and it relies on all individuals not being equal so that some may make money from the labour of others. Democracy, a form of government in which the people have power freely to elect representatives to carry on the government, relies on equality as a fundamental good, and individual freedom within certain legally imposed limits (the limits are generally to protect others' freedom). Hence there is an inherent tension between capitalism and democracy in the differing status and freedom they accord individuals. Similar to the experience of medicine, in recent decades business has been forced to respond to changing social values which have altered the balance of this tension, for example, employment practices have been radically affected by the civil rights and women's rights movements. Thus in all issues managers face the question of how far beyond minimum legal standards they are expected to go by prevailing social expectations.

Generally ethicists have used three ethical concepts to analyse and judge the morality of business behaviour - utility (i.e., results, consequences of business decisions - managers do cost:benefit calculations), rights (i.e., managers identify stakeholders, their rights and duties and those of the company), and justice (fairness to all affected parties). Thus there is a mixed deontological and teleological thrust in most business ethics writing, that is, one has certain duties as a business person, and one wishes to maximise the consequences of business activity for the good of the business.

However, many of the texts on business ethics fail to be explicit about their underlying assumptions. For example, their implicit conception of justice/fairness tends to focus on stakeholders and “who does this hurt?” (Dunham and Pierce, 1989; Tuleja, 1985). Or on can I get away with this legally and personally. Kenneth Blanchard (1988) in his very popular “The Power of Ethical Management” cites three key ethical checks - is it legal? is it balanced? how will it make you feel about yourself? DeGeorge (1982) describes American business values as freedom, profit, fairness (including honesty and truthfulness), equal opportunity and pragmatism or efficiency. However, the question begged by this type of formulation is one of scope; to whom do these business values 
apply - to the owners of businesses, to the employees, to the customers, to the general public?

Where writers on business ethics have been more explicit about underlying assumptions an interesting mixture of ethical principles, rules and social values emerges. Elaine Sternberg (1994) and Elizabeth Vallance (1995) cite justice and ordinary decency as the key principles in business ethics. Both their formulations of ordinary decency encapsulate honest and responsible behaviour at all levels of business thus engendering trust-based relationships; and also refraining from coercion and physical violence “typically within the confines of the law”(Sternberg, 1994, p.82). Similarly justice is seen as fair dealing to those contributing to the overall goal of achieving long term owner value - those who contribute more/work harder should be rewarded more than their counterparts. Hence one can see that utility and rights are subsumed even in these definitions without benefit of clear articulation.

In a scathing critique of the business ethics literature Richard Lippke (1995) contends that a defensible approach to business ethics must explicitly address questions about social justice. Hence, rather than focusing on individual character and conduct as most other business ethics writers do, he argues for an egalitarian social justice and a society and business community structured to reinforce these ideals. Lippke concludes that "since the egalitarian understanding of ethical behaviour is so at odds with the prevailing norms and expectations regarding managerial conduct in advanced capitalist societies ... (that) the prospects for ethical behaviour by corporate managers in such societies are dim"(p.188). He also comments that "the conflict between business and ethics is one born of the egalitarian interpretation of the latter in conjunction with the intractable structural features of the former” (p.188).

V Barry (1979) cited in the Journal of Business Ethics (1992, p.173-178) identifies six moral duties in business - fidelity, justice, non-injury, gratitude, beneficence and selfimprovement. American philosopher Robert Solomon, and other writers, emphasise the importance of trust in the business relationship. Solomon (1996) goes on to explore the notion of virtue ethics and the organisation as a community in which virtues may flourish. However very little of the literature on business ethics specifically addresses management ethics, the implication being that the manager is either the agent of the business and acts in its interests; or acts out of self-interest. 
Feldman (1996) laments the lack of literature addressing the question of management ethics and goes on to critique the work that has been done as reducing morality to politics and providing "an intellectual rationale for the contemporary dark ages of moral behaviour with its worship of the cult of the individual”(p.283). Dunham and Pierce (1989), in their text "Management", maintain that ethical judgements are based on personal values that have been learned over a number of years. Thus they contend that managerial ethics are not fundamentally different from other ethics. They note that management decisions affect the health, safety, morale and behaviour of all organisation members, and that for managers ethical issues surface in numerous interactions with an organisation's external and internal stakeholders. They suggest that sometimes managers behave unethically simply because they do not take the time to think about the implications of their actions - because they are usually overworked and highly stressed. And yet, as discussed in Chapter 3, medical work is also highly uncertain and stressful, but it is generally cognisant of the dramatic impact of decisions. Hence Dunham \& Pierce, like others in business ethics, tend to have taken a rather simplistic view of the ethics of the individual without considering the ethics of the management role. However if we turn to the public sector we find more focused consideration of the ethics attached to the administrative/management role. Writers on administrative ethics in the public sector are typified by Dunsire (1994) who cites four principles: honesty (i.e., promise keeping in government), fairness (i.e., to all citizens not just one sectional interest), stewardship (i.e., acting on behalf of the nation and the common good) and competence (i.e., providing effective, responsive services).

Looking more specifically at health management we find a small range of literature all of which either overtly or covertly implies that the ethics of health management are different or more vital than those of business management generally. McNerney (1985) considers health care administrators "are obligated, professionally and by institutional imperative, to become involved in and provide leadership in ethical issues” (p.331). He cites changing social values, advances in medical technology, and increasing economic and financial pressures as factors which make dilemmas in health care an administrative decision not just a clinical decision. Griffith (1993) asserts that health care managers share not only in those features of business ethics that require honesty and integrity but also in the internal morality of health care itself. McNerney believes that the institutions that survive are those "that come to grips with the existential questions of obligation and justice”(p.333). Maxwell (1994) asserts that management undoubtedly needs to be 
underpinned by a code of principled behaviour. He believes that the health management activities of 1) managing clinical activity, 2) allocating resources, 3) managing the politics of health, and 4) rendering public account, all involve a variety of ethical challenges. Thus health managers have a range of duties associated with supporting health care workers in creating the conditions in which good clinical work will prosper and broader public duties of truth-telling. Maxwell sees the principles of efficiency and justice, and respect for democratic processes, as well as personal integrity, as the foundation stones of an ethical public sector health manager.

Kurt Darr (1991) in his book “Ethics in Health Services Management” observes that: there is little tradition in business of an independent duty or obligation beyond that established by law - the emphasis in business has been and is on profitability and caveat emptor. The business ethics literature discusses concepts such as honesty, integrity, benevolence, the duties employees have toward each other and toward the organisation, and the duties organisations have toward employees. Here there is some similarity with health services. Lacking, however, is the concept of respect for persons, with its emphasis on autonomy, fidelity, and confidentiality. Nor is beneficence a focus of business ethics. The principle of justice is found only at the periphery of business ethics. These differences between business and health services....distinguish the two fields of endeavour, whose foci and purposes are simply different. (p.93)

He then goes on to discuss the fiduciary responsibilities of health service managers to act, not for personal gain, but in the best interests of the organisation and its patients. Essentially Darr sees the health manager as the moral agent of the organisation with a duty to minimise the risk of conflict of interest or eliminate it once it is present.

Andrew Wall (1989) 'Ethics and the Health Services Manager', and 'Values and the NHS' (reported in Bulletin of Medical Ethics, August 1993) states: "there are several sets of ethical principles that underpin the value base of the NHS (National Health Service in the United Kingdom). These are : utilitarianism,...individual rights... the ethics of care...duty based ethics.”(p.3) He goes on to critique these and assert that managers are the custodians of the process of decision making as they are ideally placed to make disinterested choices about use of resources because they are removed from individual patient contact. He considers it appropriate for managers in the public sector to implement the wishes of the government of the day, but if they consider such actions 
deleterious to the patients or community they should speak up. Managers are custodians of public resources and thus must have openness in their decisions to ensure accountability. They should involve the community in debate about efficient use of resources, and managers should follow certain principles, namely: “demonstrate justice, recognise the value of the individual, recognise value for the community, and demonstrate a sense of duty.”(p.4). In a similar vein, Reiser (1994) offers the following values to guide health care organisations: humaneness, reciprocal benefit, trust, fairness, dignity, gratitude, service, and stewardship.

In contrast to Darr and Wall, Mariner (1995), in a discussion of the ethics of managed care organisations (privately owned health organisations) in the United States, notes that the ethical principles governing business are designed to promote fair competition. These include honesty, truthfulness, and keeping promises. Business organisations have fiduciary obligations to their shareholders not their customers. Doctors, on the other hand, have a fiduciary obligation to their patients as there is an assumed significant inequality in knowledge and skill between physician and patient. Equally one could add that some believe that health managers should and/or do have a fiduciary responsibility to the organisation's customers - the patients -but that is a view which is not held by those taking a purely commercial view of the health business.

\section{Observations of, and gaps in, the business ethics literature}

- Much of the business ethics literature relies on case studies which tend to underline the philosophy of 'if we can get away with this action we will do it', or 'if it costs less to be bad than to be good then we will be bad and make amends later'. These in effect are decisions based on legal and economic considerations, not on ethical considerations but the literature is often unclear about the decision criteria in use.

- There is a tendency to discuss business ethics without ever considering or discussing the inherent ethical imperatives of western economic models in which our businesses exist. Thus writers justify ethics as good business or making business sense - and then outline some rather altruistic form of good business which probably is not good business within a capitalist/free market model which stresses profit maximisation. 
- There is a tendency to focus on individual ethical conduct, rather than the actions or policies of an organisation (some of that is emerging now but mainly in terms of encouraging ethical behaviour of individuals within the organisation). There is also a large body of literature, not addressed in this thesis, on the corporation as a moral person, which attempts to reduce the organisation to the status of an individual.

- There are three main approaches employed in the literature for exploring business ethics. Many use case studies, some give check lists of questions to ask in a decision making process in order for it to be ethical, and others outline ethical principles or values that should somehow underpin the practice of business.

- There are some areas of overlap in the principles which are variously propounded to underpin business ethics such as, justice, honesty, trustworthiness, non injury.

- There is concurrence in the different views on health management that justice, respect for persons, and beneficence, are (amongst others) the underpinning ethical principles.

- There has been no exploration of intersecting points of ethical tension between the institutions of health organisation/medicine/management/other professional groups (all become employees rather than distinctive groups).

\section{Professional Ethics and Role Based Ethics}

There is also a small but growing literature on the areas of professional ethics and role based ethics, both of which impact on medical and managerial ethics. Much of the literature centres on the definitional debate surrounding the term 'profession'. However the consensus seems to be that a profession is distinguished by involving extensive intellectual training and provision of services which are "important to the organised functioning of society” (Callahan, 1988, p.26). The traditional professions such as law and medicine also have state licensing of their professionals, an active professional body, and they enjoy a high level of autonomy in their work, social status and rewards. 
Interesting discussions have emerged in the literature, growing from professional ethics, which query whether some roles are inherently more ethical than others. These discussions are typified by three main exponents - Goldman (1980), Gewirth (1986) and Bayles (1989). Goldman completes a thorough analysis of medical ethics in terms of the role of the physician vis-a-vis the patient, which even takes into account the influence of the hospital surroundings and procedures on the patient's role. He concludes that his analysis shows that strong role differentiation for doctors is not justified and "they must learn to act within the same moral framework as the rest of us” (p.229). In a similar argument Gewirth discusses what he terms the 'separatist thesis' of professional roles which suggests that "professionals, by virtue of their expertise and their consequent roles, have rights and duties that are unique to themselves and that may hence be not only different from, but even contrary to, the rights and duties that are found in other segments of morality” (p.282). Thus, it is argued, the professional can infringe certain moral rights of their clients. He sees institutions (e.g., professions, families, governments, teams) defining roles which have certain rights and duties, and he discusses the medical professional role and others. Gewirth concludes however that the separatist thesis is mistaken as he believes that institutional rules must conform to the general principle of morality which applies to all human actions and institutions. Both Goldman and Gewirth look at the doctor as a professional and as a member of a profession, and conclude that there is enough room for them to act within the same moral framework as all others. Interestingly neither examine the doctor's role as an employee of an organisation. Is there justification in the role differentiation argument for the doctor acting differently from other employees? Or within the examination of institutional rights should one consider the overlap or conflict between doctor as member of the profession and doctor as member of the organisation? However, Bayles (1989) acknowledges professionals can be self employed or employees and that different duties and challenges attach to those classifications. He suggests that both universal norms (e.g., duties of promise-keeping, not murdering etc.) and professional role-related norms apply to professionals in their activities and are included in professional ethics. Bayles maintains that "the central issue in the professional-client relationship is the allocation of responsibility and authority in decision making - who makes what decisions” (p.70). He outlines five models of relationships between professionals and clients, each with different obligations: agency, contract, friendship, paternalism, and fiduciary (which he considers the best ethical ideal model). The fiduciary model's implication that professionals must be worthy of client trust provides 
a criterion for determining professionals' obligations to clients. Thus he sees seven virtues and responsibilities of professionals - trustworthiness/honesty, candour, competence, diligence, loyalty, fairness, and discretion. He believes that clients have certain obligations also, but that these are "merely the specification of a universal norm to the professional-client context...the fiduciary model indicates that special obligations apply to the advantaged party - the professional.”(p.100) Bayles suggests that the social values/principles relevant to professional ethics are freedom and self-determination, protection from injury, equality of opportunity, privacy, and minimal well-being.

McDowell (1991) also expounds a virtue-based approach to the dilemma of the professional wanting to earn money. He discusses the external marks of professionalism and internal commitment to a professional character (which encompasses competence, fidelity and honesty). He maintains that a professional is expected to act differently to a business person in dealing with clients. They are there to serve the client not just to make money - thus a relationship of trust exists not an arms-length market transaction. This is consistent with the fiduciary relationship suggested by Darr, Mariner and others in the context of the health management role.

\section{Medical Ethics and Managerial Ethics: Similarities and Differences}

Throughout history ethics and moral rhetoric have been an academic pursuit. At best they provided principles, rules and judgements that in later years formed canon law and the basis of contract law and our legal system. At worst they failed to impact on the day to day decisions and actions of people. To a large extent we still seem to "make the rules as we go along” and rationalise some order or consistency into them later on. Such is the dynamic nature of life. Medical ethics and managerial ethics are no exception to this pattern of development. They have in common the tension between trying to set up guidelines (guides to action) in advance as against responding to each situation as it occurs, relying on one's position in it to legitimise action and rationalising such actions as part of the natural order after the event. The principles most popularly cited in business/ managerial ethics appear to be character-based such as, honesty, trustworthiness, fidelity and justice (which is never consistently defined in the literature). For health managers in particular, respect for persons and beneficence are seen as important additional principles. Those most popularly cited in medical ethics are beneficence, non-maleficence, autonomy/respect for persons and justice. However, as 
discussed earlier in this chapter, the definitions of these principles is not always consistent. It is also clear from the literature that a professional relationship, such as that between doctor and patient, is regarded as a trust-based fiduciary relationship.

The discussion of principles in both managerial and medical ethics is characterised by a lack of definitional consistency, and a focus on individual conduct without the benefit of considering the broader economic, political and socio-cultural context in which medicine and management occur. Pellegrino and Thomasma (1988) consider three contextual changes as crucial to the modern principles of medical ethics, those changes are:

i) shift in locus of decision making from physician to the patient (i.e., philosophical shift of primacy of beneficence to primacy of autonomy in physician-patient relationships), ii) unprecedented expansion of medical technological capability, thus expanding range and complexity of clinical and policy decisions in health care, iii) the entry of economic considerations as primary forces in individual and policy decisions regarding health and medical care thereby creating a conflict between the canon of economics and the canon of traditional medical ethics.(p.11)

One could also observe that ironically the principle of autonomy and self-determination that has come to underpin modern medical ethics also underpins modern western economic and political trends.

Roth (1995) categorises ethical issues as macrocosmic (i.e., large scale, societal and often public policy) and microcosmic (i.e., small scale, often individual). In the health system and its organisations there is always tension between consideration of issues at both these levels. One could argue that day to day medical ethics focuses through necessity at the microcosmic with occasional forays into the macro. Additionally day to day management focuses at both levels, but that for hospital management the macrocosmic represents the organisation and the local population it serves, not society as a whole. The pressure on both doctors and managers is the tension between these two levels and the day to day government focus which vacillates between macrocosmic (the good of my country) and microcosmic (the good of my constituent).

The literature, however, maintains that key points of difference between medical ethics and business/managerial ethics lie in their core principles. It is argued that business ethics is not the same as professional ethics. Under the free enterprise system it is 
ethically permissible for business persons to make pursuit of their own advantage their primary goal (as long as it is lawful), whereas professionals have additional ethical obligations that limit pursuit of self-interest (Bayles, 1989; Roth, 1995). Similarly, if we regard doctors as the agents of the profession and medical ethics, and managers as the agents of the organisation and business ethics, we find a small number of writers starting to argue for their incompatibility. For instance, in an article about Managed Care Organisations in the United States, Mariner(1995) notes that:

MCOs were created to achieve economic objectives that may be fundamentally incompatible with traditional principles of medical ethics .... even if it is possible to agree that certain ethical principles ought to apply to managed care, the market may make it impossible to live fully by those principles. Finally it is important not to mistake ethical managed care for an ethical national healthcare system. Good MCOs may be able to provide efficient, high quality care; but in the long run, they are not likely to be able to do so and simultaneously cut costs and promote equitable access to care...we have a choice: either abandon the goal of universal access to healthcare, or regulate the health care system by eliminating those marketplace standards that conflict with equitable access to care. (p.236-7)

Mariner goes on to discuss the possibility of developing new ethical standards for MCOs (different to those of ordinary commercial enterprise) that first, recognise the organisation's medical responsibilities as well as their business functions; and second, reflect ethical principles that apply to all human endeavours, such as fairness, honesty, and truthfulness, respect for persons, and justice. This view has also been expressed by others. Kurt Darr (1991), for example, believes health service managers have additional ethical responsibilities (including respect for persons and beneficence).

In a recent conference paper delivered by David Seedhouse on business values and health care values (AIC Medico Legal Conference, April 1994) he maintained that there is no overlap between business values and health care values. His main argument is that the former are driven by "the most obvious and dominant belief in the overriding importance of financial profit”, and the latter have "at their heart a belief in the fundamental importance of helping other people achieve as much of their potential as possible”.

Hence such writers believe that there is an apparent paradox in the coexistence of the business ethic and the medical ethic in health organisations. The business ethic stresses 
competition and organisational self-interest at the expense of others (e.g., competitors) as a good thing; whereas the medical ethic (and professional literature) stresses that practitioner self-interest at the expense of others (e.g., the patient) is a bad thing. This raises several interesting questions including: Do we know which ethical principles doctors and health managers have in common and which are different ? Taking the arguments from professional and role ethics, in particular the separatist thesis, - do doctors and managers have the same ethical duties as each other and as everybody else or do they have additional/different ethical duties to each other and others? In the next chapter we will review the existing empirical knowledge in these areas. 
CHAPTER 5

MEDICAL ETHICS, MANAGERIAL ETHICS: EMPIRICAL KNOWLEDGE AND METHOD

\section{Introduction}

Theory attempts to explain phenomena and make them predictable. However, beyond, and sometimes behind, theory building lies empirical knowledge - what we think we know from what we think we have observed. Medical and managerial ethics are remarkable for the paucity of comparative literature generally, and complete absence of comparative empirical research in particular. Taken separately, medical ethics is distinctive in the large volume of theory building and the limited amount of empirical research of doctors themselves, with the focus more commonly resting on specific dilemma cases. Managerial ethics is distinctive in its tendency to be absorbed as part of business ethics generally. Within that literature health management ethics receives very little attention. Medical ethics has no shortage of normative ethical analysis - looking at what should be done in various situations - however, it is not well endowed with descriptive ethics of what is actually done or believed on a day to day basis by medical practitioners. Business and managerial ethics have the opposite problem - there is a large literature of descriptive ethics and less in depth normative ethical analysis.

It is the intention of this chapter to report on the empirical research in medical and managerial ethics, and to then provide further discussion of research methods employed in applied ethics.

\section{Empirical Research on Medical Ethics}

Much of the large literature of normative ethical analysis described in the previous chapter relies on the examination of case studies from medical practice, however research involving doctors themselves (i.e., rather than the cases they are involved in as one of many players) is not so plentiful. The small amount of research that has focused on doctors and their views on ethical issues is typified by the following two studies: 
Miyaji (1993) conducted semi-structured interviews with 32 American doctors probing their practice of truth-telling in the care of dying patients. He found three basic types of practice which were supported by five normative principles: respect for the truth, patients' rights, doctors' duty to inform, preservation of hope, and individual contract between patient and doctor.

Rawwas, Strutton and Pelton (1994) conducted a mail survey of 251 American mental health care practitioners examining their views on ethical conflicts and practices in their work environments. Issues of confidentiality and honesty seemed to be in conflict with government imposed regulations and laws. However most respondents felt that ethical standards were higher than ten years ago primarily due to increased education and professionalism. A small number felt standards were lower due to greed and increased competition.

The author is aware that there is other, as yet unpublished, research in progress at universities in New Zealand and Australia, particularly in General Practice and Community Medicine departments which probes for instance, general practitioner and consumer perceptions of ethical issues.

One of the most interesting pieces of research, in the context of the comparative task of this thesis, is the 1993 work of Overman and Foss. They compared the ethical perceptions of several thousand physicians and citizens in Colorado in an attempt to empirically test the "separatist thesis": that professionals by virtue of their expert knowledge and role have different ethical obligations and positions to those not in their profession. The two groups were surveyed by postal questionnaire. The questions used 5 point Likert scales measuring opinion on various situations. Responses were categorised on seven ethical dimensions which were: professional autonomy, beneficence, access, equity, resource allocation, organ transplant, handicapped newborn, plus an eighth overall dimension of ethical commitment. They found enough evidence to support separate professional ethics for five of the seven dimensions (not access, nor handicapped newborn). However, these differences were more in degree than in kind. They observed that these differences were much more in the direction of individual ethics (autonomy, beneficence) and much less in the direction of social ethics such as access, equity and resource allocation. They were also surprised to find no difference in ethical commitment between physicians and citizens. 
Scanning within New Zealand there is, as overseas, much commentary on medical ethics but very limited published empirical research. What research there is, tends to focus on particular issues such as attitudes to sexual transgression in the doctor:patient relationship (Coverdale, Thomson, \& White, 1995; Thomson \& White, 1995), health professional attitudes to justice and the government's benefits and payments system (Longstaff, 1993).

Henk ten Have and Gernt Kimsma (1990) emphasise the need for more empirical research to construct a more sophisticated view of moral experience in medicine. Certainly there is not a well developed picture emerging from the small amount of research thus far, although we can draw some common threads together:

- Doctors appear to work to a particular ethic which is different to that of non health workers, and which is focused around the best interests of the patient and certain duties/obligations attached to that (e.g., truth-telling, confidentiality, maintaining competence levels, etc.);

- There are a variety of forces in society which influence ethical behaviour of professionals, including their professional grouping, education in ethics, levels of competition and greed, etc.;

- There is a rapidly changing medical capability and hence range of dilemmas to be faced.

However we know very little empirically about what doctors regard as ethical and unethical, what influences them in ethically challenging decisions, what they themselves regard as the common ethical dimensions of their work, and how these factors compare with their health management counterparts.

\section{Empirical Research on Managerial Ethics}

In the last decade business ethics has become a hot topic in the western world.

There is a large amount of published overseas research in the area, much of it is contained in the Journal of Business Ethics, and the Journal of Business and Professional Ethics (Randall \& Gibson, 1990). Perusal of articles in these journals 
shows that business ethics and managerial ethics are treated synonymously. Gael McDonald (1992) reports most business and managerial ethics studies are done by way of questionnaire. Many focus on particular occupations and the ethical dilemmas or practices within them (e.g., most commonly marketing, accounting, computing). Some focus on the organisation, some on Chief Executives and some focus on managers more generally. Those that focus on managers cover a broad range of perspectives from in depth studies of personal values and moral reasoning, to probing of managers ethical behaviour in organisations, to surveys of manager attitudes to business ethics.

Derry, reported in Frederick (1987), examined moral reasoning in work related conflicts by testing Carol Gilligan's thesis of the two modes of moral orientation: justice versus care. Derry maintains "the mutual responsibilities and expectations embedded in corporate roles are an important consideration as the individual weighs his or her own values and attempts to distinguish between right and wrong courses of action” (p.27). Thirteen of 40 people interviewed (i.e., 32.5\%) said they experienced no work related moral conflict. Derry concluded that "certainty about roles and obligations seemed to underlie many of the considerations people voiced in resolving their moral dilemmas” (p.38), and that the work environment demanded a rights/justice/rules orientation rather than a care orientation.

Dunnette (1991) reports that in the period 1976-1990 the Annual Review of Psychology featured 75 of its 290 chapters on subjects relevant to industrial/organisational psychology. Of those, one chapter related to moral judgement. Most, he reports, covered organisational behaviour, personnel selection, career development, attitudes and motivation. In another review of industrial/organisational psychology, Freeman (1990) reports on recent scholarship on ethics in the workplace. For ease of analysis he categorises business ethics along four levels: a) societal (relationship among basic institutions of society), b) stakeholder (relationship between organisation and key groups with a stake in the organisation), c) employee policy (internal stakeholders, corporate culture, employee rights), and d) interpersonal. However, although the levels form a useful taxonomy, the scholarship reviewed does little to shed any light on ethics at any of these levels.

James Weber (1993) explored the relationship between personal values and moral reasoning using the value inventory developed by Rokeach and the moral reasoning 
characteristics of Kohlberg's stage theory of moral development. Fritzsche (1995) also explored personal values as potential keys to ethical decision making (although his sample were marketing managers). Both studies, not surprisingly, yield an interesting connection between personal values and ethical decision making. However, they both acknowledge the most important limitation of their research is that they assess hypothetical situations or intended behaviour rather than being able to observe actual managerial action. Thus the generalisability of their results is uncertain.

In an earlier piece of research Fritzsche \& Becker (1984) via a mailed survey linked management behaviour to ethical theory by classifying responses of managers to a series of vignettes according to the ethical theory represented by the response. They found a strong bias towards following a utilitarian orientation, which they felt could be explained by the strong role economics plays in managerial decision making. Additionally they looked at whether utilitarian responses were rule or act philosophies. They found that individuals following a rule or a rights philosophy tended to place greater weight on ethical values relative to economic values, and individuals adhering to an act philosophy took the reverse position. They use these findings to suggest further research which questions practitioners' reliance on utilitarian philosophy and whether managers should be encouraged to embrace justice or rights theories. Once again the researchers note that the data represent the action the respondent stated he/she would take, which may differ from the action that would actually be taken.

Other researchers have also, in different ways, examined the economic motive in business ethics. Fiore et al. (1992, cited in Cooper, 1994, p.21) examined the relationship between professional ethics and organisational goals. Their survey of 330 managers found that "stress on economic goals tends to decrease support for professional ethics, whereas an increased interest in various non-economic goals increases the level of support for professional ethics”. The implication of this finding is that greater emphasis on economic motivations such as might occur with privatisation of government agencies will likely decrease adherence to professional ethics.

This is the theme, in part, of Robert Jackall's classic sociological study "Moral Mazes" (1988) in which he interviewed managers at every level of two large industrial firms and a large public relations agency. He concluded that in the confusing and conflictual world of management, and of 'pleasing some of the people some of the time', that "one 
unintended consequence of their personal striving, (is) a society where morality becomes indistinguishable from the quest for one's own survival and advantage” (p.204). This impression also dominates recent New Zealand and Australian based research. Management magazine, the popular trade publication of the New Zealand Institute of Management, has published a number of features on business ethics. In its November 1988 issue it ran a feature article on "The decay of business ethics” which noted that "ethical issues now tend to be resolved in terms of self-interest or, in business, in terms of profit” (p.27). It cites a recent English survey in which $80 \%$ of those polled did not consider business people to be generally honest. The magazine writer asserts that "ethical deviation is more likely to occur indirectly where actions are separated in time and distance from results” (p.30). The conclusion emphasises the need for top managers to model ethical behaviour and to encourage and reward others' ethical behaviour.

In December 1992, Management magazine featured another article on ethics. The magazine conducted a fax poll of readers which revealed that most respondents believe that senior management has an important role to play in setting the corporate ethical environment, and that this should focus on leading by example and encouraging rather than enforcing compliance. Eighty-two percent of respondents considered that the need to make a profit is the main reason managers behave unethically, and $66 \%$ considered failure to think things through also led to unethical behaviour.

Brennan et al. (1992) conducted a mail survey of 250 New Zealand businesses to examine managers' attitudes to business ethics. The survey document contained a number of multi-choice questions and four vignettes with specified options for their response. The results showed that many agreed with a statement that ethical standards in business had fallen over the last decade. Paradoxically although most considered themselves ethical and agreed with the statement that "good ethics is good business", many also reported that they would act in an unethical manner in certain situations. Most thought a company code of ethical practice would be useful (even though only $38 \%$ of the companies surveyed currently had one) - they believed that a code would be useful for its ability to set standards. However, M Cash Mathews (1988), in his U.S. based research, showed that codes did not influence ethical behaviour. In a similar vein Stewart and Sprinthall (1993) in research on US public administrators found no relation between ethical behaviours and codes. They found that if the administrator was familiar 
with the content of an ethical problem and there had been considerable discussion and analysis of the issues, then there was a greater likelihood of deeper moral reasoning on the problem. "In unfamiliar situations where little has been discussed or processed, individuals are highly likely to employ less democratic and more self-serving reasons"(p.217). Laboratory experiments with graduate students by Hegarty and Sims (1978) found that unethical behaviour was higher under conditions of increased competition, and when the behaviour was rewarded.

Popular American magazine The Economist (August 19, 1995) in a brief article on business ethics (p.57-8) notes that a recent U.S. survey found that employers (half of whom had ethical codes) often discouraged managers from “over-investing” in ethical behaviour, and that successful managers were granted considerable ethical leeway. They also noted that in America and Europe restructuring had reduced the number of middle managers which tended to cut corporate lines of communication making it harder to impart ethical standards to employees.

Kazi Alam (1991) surveyed by mail the chief accountant/company secretary of the top 200 New Zealand organisations. The survey examined whether moral considerations were taken into account in selecting accounting policies for different purposes, and whether more emphasis should be given to ethical dimensions of financial reporting in the business and accounting curricula. Many respondents believed that the ethical values of their organisations had declined during the last five years due to the economic climate, selfish approach of key managers and ruthless competition. Commitment of top management and clear statements of ethical standards were considered the most important factors in ensuring an ethical corporate environment.

The researcher interviewed Colin Hicks of the New Zealand State Services Commission, author of the public sector ethical guidelines released in 1995. Hicks had interviewed numerous public sector managers and Chief Executives and summarises their views of the key principles of public sector administrative ethics as: honesty, fairness, neutrality and being professional. He emphasises that the purpose of such ethical principles in administration is to promote and enhance confidence in the government institution. 
Soutar, McNeil and Molster (1996) studied the impact of work environment factors on ethical decision making of managers via 105 survey questionnaires returned by Western Australian publicly listed companies. They found that $40 \%$ of the managers who responded reported no instances of ethical conflict at work, although 58\% had faced conflict over the past five years. The practices most commonly cited as causing ethical dilemmas included concealment of information, lack of concern for long term effects of actions, and being unfair to individuals. The major influences on behaviour were reported as behaviour of superiors and peers, the ethical practices of one's industry, formal company policy, society's moral climate and personal financial need. The researchers concluded that "institutionalisation efforts have little chance of succeeding unless the written words are accompanied by ethical actions and behaviour on the part of top management. Consistency must be demonstrated between actions and the stated organisational ethics posture if ethical behaviour is to be truly accepted as a norm within an organisation”(p.96).

\section{Health Management Ethics}

A small empirical research literature base exists addressing the ethics of health managers as a group apart from managers generally.

McNeill, Walters and Webster (1994) identified the most common ethical issues of concern in Australian hospitals using data collected by means of a questionnaire mailed to hospital managers. End of life concerns, patient autonomy issues, questions of resource distribution, and communication difficulties commonly raised ethical concerns in Australian hospitals (both public and private sector). Responses varied according to the size of the hospital of the responding manager - larger hospitals reporting more concern with not for resuscitation orders, treatment of HIV/AIDS patients and interprofessional conflict.

Lemieux-Charles, Meslin and Wortley (1993) from the University of Toronto Hospital Management Research Unit reported on a provincial study they completed on ethical issues faced by clinician-managers in resource allocation decisions. They surveyed physicians, nurses, social workers, physiotherapists, pharmacists, psychologists and other health professionals in Ontario hospitals who had assumed a managerial role in 
addition to their clinical responsibilities. They designed a survey questionnaire on the basis of a literature review and focus group exercise on ethical issues in resource allocation. They found several themes emerging: 1) there is limited use of available ethics resources by clinician managers; 2) collaborative resolution of ethical issues poses a challenge; and 3) organisational strategies are important. In reporting specific results they found that the top three factors influencing clinician managers when addressing ethical issues in resource allocation were: personal values/beliefs, law/legal standards, and general clinical experience. Within that finding doctors were more likely to be influenced by personal beliefs and clinical experience; while nurses and other health professionals were more influenced by legal standards, discussions in interdisciplinary teams and hospital policies.

Chown (1990) surveyed 200 institutionally based health administrators to determine their sensitivity to the ethical components of their work and to identify the ethical problems which they actually faced in practice. Administrators perceived a major ethical dimension in their work in activities such as developing mission statements (79\%), decision making (75\%) and quality assurance (75\%). In addition to their personal values, respondents reported using consultations with colleagues (72\%), ethical principles (57\%), organisational policies (37\%), consultations with an ethics committee (22\%) and the CCHSE code of ethics (20\%) to help them resolve ethical problems. They reported that allocating resources and intergroup conflicts were the most common ethical problems faced during the past two years.

Although there is a range of published empirical research on business and managerial ethics it still remains an area that is not well understood. Much of the research focuses at the level of individual managers and their developmental stages of moral reasoning, thus for broad comparative purposes about the ethical nature of work roles the research is not particularly useful. However, some of it, particularly the small amount on health management, provides useful information on ethical issues at work and factors which influence their resolution. Common themes emerging in the business research include:

- Agreement on a decline in ethical values in organisations over the past decade

- Self-interest or business profit/economic goals leads to unethical behaviour

- Failing to think things through to the long term, not discussing or processing issues, leads to unethical/more self serving behaviour 
- Managers need to lead by example, to model ethical behaviour

- Mixed evidence exists on the utility of ethical codes and statements of ethical standards, but there is agreement that managerial behaviour should be consistent with any stated organisational ethical standards.

Themes emerging regarding health managers and ethics include:

- Ethical issues around resource allocation, and interprofessional conflict

- The influence on ethical decision making of personal values, organisational policies, and consultations with colleagues or teams

Thus we know some of the influences on ethical and unethical behaviour, hence also the implied standards of what is ethical in business. However, the ethical construct has tended to be predefined by the researcher not the manager, and health managers as a subgroup have received limited attention. There has been very little, if any, research comparing the ethics of different role groups within an organisation. In particular we do not know how health managers and the doctors they work alongside view the ethical frame of their respective activities or the influences that act upon them in ethically challenging situations.

\section{Other Available Information on Medical and Managerial Ethics in New Zealand}

The other information readily available on medical and managerial ethics are the codes of ethics which ostensibly guide the actions of doctors and managers in health organisations. Veatch (1981) observed that "codes of ethics are summaries of behavioral norms for particular groups, such as members of a profession” (p.89). For this reason the codes applying to doctors and managers have been reviewed and comparisons drawn between them.

\section{The NZMA Code of Ethics}

The New Zealand Medical Association (NZMA) accepts the responsibility of delineating the standard of ethical behaviour expected of New Zealand medical practitioners. They note that the profession has a duty to safeguard the health of the people and minimise the ravages of disease. In particular the code preamble emphasises six principles of ethical behaviour: 
applicable to all physicians including those who may not be engaged directly in clinical practice: 1 . consider the health and well-being of your patient to be your first priority; 2. strive to improve your knowledge and skill so that the best possible advice and treatment can be afforded to your patient; 3. honour your profession and its traditions; 4. recognise both your own limitations and the special skills of others in the prevention and treatment of disease; 5. protect the patient's secrets even after his or her death; 6. let integrity and professional ability be your chief advertisement. The code goes on to outline three areas of responsibility (with considerable detail on each area) these are: 1 . responsibilities to the patient; 2. responsibilities to the profession, and 3. responsibilities to society. (Refer to Appendix A for full code)

It is apparent that the code focuses on the well-being of the patient and in that context on the practice of medicine, the maintenance of competence, and professional conduct. It should be noted that rules 47, 48 and 49 (Provision of Service in a Competitive Environment) are recent additions to the code in response to the government legislation establishing Crown Health Enterprises. These three rules send a very clear message of the high priority placed by doctors on patient interest and public interest regardless of the financial cost. For example, “49. Standards of care should not be compromised in order to meet financial or commercial targets whether these are set by a doctor personally or by an organisation". The code of ethics is enforced by the ethics committee of the NZMA and by the Medical Council, both of whom have received complaints about practitioners from patients and occasionally from colleagues.

\section{The NZIM Code of Ethics}

This code, developed in 1994, is aimed at all managers who are members of the New Zealand Institute of Management (NZIM). Hence at the outset one should note that the Code may not apply to all managers in the health sector (unless they are NZIM members), however it is of interest as a representation of management ethics. NZIM considers that "the management profession is an integral part of the successful operation of modern public and private organisations and the ability of these organisations to contribute to societal well being”(refer to Appendix B for full code).

The code lists four broad areas of responsibility (and details duties in those areas): 1 . responsibilities to those who use our managerial skills (employers), 2. responsibilities 
to the community, 3. responsibilities to those who are the object of our managerial skills (public, customers, fellow employees), 4. responsibilities to the profession.

Interestingly most of the duties outlined in this code are required by law anyway, for example, disclosing conflicting financial interests, avoiding discriminatory practices, fair and equitable treatment of employees. The code is not enforceable by NZIM in any meaningful way. It may, however, be reflected in managerial performance agreements, and, as noted, much of it is enforceable by existing law. In contrast to the NZMA code is the order in which the broad areas of responsibility are listed. Doctors place responsibilities to the patient first while for managers responsibility to customer, public and employees is third and in first place they have responsibilities to employer/organisation; doctors place responsibilities to the profession second where it is fourth for managers; and doctors place responsibilities to society third and managers place it second. That both groups choose to order their responsibilities in this way further emphasises the medical focus on the patient and the profession, and the managerial focus on the organisation and society.

\section{The ethical standards for Crown Health Enterprises (1993)}

These guidelines were developed by the Ministry of Health and the Crown Health Enterprise Establishment Unit to assist the newly formed CHEs to meet their statutory obligations under the Health and Disability Services Act 1993. The guidelines identified general ethical principles which CHEs were expected to apply to all their activities. They included: respect for dignity, rights and cultural needs of clients or patients, and the responsibility to provide care and equity of access to health and disability services for all patients or clients. CHEs were expected to develop specific policies and procedures for: privacy, informed consent, duty to provide care, ethical review procedures, procedures in the event of death, obligations of board and management. The obligations of Board and management included:

a) maintenance of an appropriate quality of services and care within the CHE, b) fostering of a culture of ethical behaviour by all persons working or studying within the CHE, c) provision of appropriate mechanisms for staff and management to report concerns about the quality or ethical appropriateness of services or care, and of mechanisms to investigate or take action on any such concerns (p.4).

The guidelines also make various suggestions about the mechanisms organisations can use to implement its recommendations including; access to an accredited ethics committee, setting up consumer complaints service and patient advocacy service, 
having statements of rights and responsibilities, and guidelines for staff on procedures in ethically difficult situations (e.g., emergency care, death, treatment dilemmas, application of health information privacy code).

These guidelines seem to have been very much focused on the patient as health consumer foreshadowing the 1996 Health \& Disability Services Code of Consumer Rights. It is interesting to note that they also focus on the organisational and management mechanisms that can be employed to meet ethical obligations to consumers and were to be monitored on an annual basis as part of a review of CHE performance.

\section{The (New Zealand) Health \& Disability Services Consumers’ Code of Rights (1996)}

The Code which came into effect on 1 July 1996 outlines that

1. Consumers have rights and providers have duties-(1) every consumer has the rights in this Code. (2) every provider is subject to the duties in this Code. (3) every provider must take action to-(a) inform consumers of their rights; and-(b) enable consumers to exercise their rights.

The Code specifies the rights under the following headings: 1. right to be treated with respect; 2. right to freedom from discrimination, coercion, harassment, and exploitation; 3. right to dignity and independence; 4. right to services of an appropriate standard; 5. right to effective communication; 6. right to be fully informed; 7. right to make an informed choice and give informed consent; 8. right to support; 9. rights in respect of teaching or research; 10. right to complain.

It is clear that the 1993 ethical standards for CHEs were the forerunner to this Code. However it is also interesting to compare the ten heading principles in the code with the NZMA Code of Ethics (Appendix B). All of these principles are areas which are addressed by the NZMA Code of Ethics as matters of ethical concern to doctors. Hence the effect of the Code of Rights is to extend that ethical concern to managers and all staff of health provider organisations, and to make it a matter of enforceable obligation via the Health \& Disability Commissioner’s Office.

\section{The American College of Healthcare Executives Code of Ethics}

As a point of contrast to the NZIM code and CHE guidelines it is interesting to briefly examine this American health management code. The College was first established in 
the 1930s as the college of hospital administrators but in 1985 changed its name. Their code reported in Darr (1991) and Griffith (1993) was enacted in 1988. In 1990 this college had over 23,000 affiliates throughout the United States.

The code outlines four broad areas of ethical responsibility (and outlines considerable detail for each area): 1. the healthcare executive's responsibilities to the profession of healthcare management; 2. the healthcare executive's obligations to the organisation and to patients, clients or others served; 3. the healthcare executive's responsibilities to community and society [in particular are noted actions such as c) participate in public dialogue on healthcare policy issues and advocate solutions that will improve the health status and promote quality health care; and d) consider the short term and long term impact of management decisions on both the community and on society]; 4. the healthcare executive's duty to report violations of the code.

It is of interest that this code focuses on the profession, the health organisation, the patient and on society, obviously advocating that the health manager has duties towards all these groups. Similarly to the NZIM code, duties to the organisation receive a high priority.

\section{Complaints against doctors and managers for breaches of ethics}

In the past complaints about the ethical conduct of medical practitioners were dealt with by the NZMA and ultimately the Medical Council of New Zealand for disciplinary purposes. The Medical Council, and some of the Colleges of particular medical specialties, also issue ethical guidelines on specific issues from time to time. As referred to in Chapter Two complaints are now (i.e., as from mid-1996) investigated by the Health \& Disability Commissioner's Office, prior to referral to appropriate committees for action.

In recent years the Medical Council has received approximately 100 complaints per year against doctors. The majority of complaints are lodged by patients but a small number are received from members of the patient's family, other doctors, practice nurses, healthcare managers, lawyers on behalf of patients, or other agents. Charges have involved bad prescribing, deaths of patients, doctor competence, or breaches of the trust relationship between doctors and patients particularly in relation to sexual misconduct. Fraud and medical manslaughter are also referred to the Council from time 
to time by the courts system. Some complaints "reflect the puzzlement of patients or their relatives over a sequence of medical events. Either the facts are not fully provided or explained by the doctors concerned, or the physiological or pathological connection linking them has not seemed to them sensible.”(Medical Council of NZ, Annual Report 1993, p.12). Disciplinary sanctions range from a warning or fine through to being taken off the medical register and/or criminal prosecution. The Council's "limited powers to prescribe appropriate re-education or training rather than imposing disciplinary sanctions” (Medical Council of NZ, Annual Report 1995, p.35) underpin changes brought about by the Medical Practitioners Act 1995 which outline new competence, recertification and Annual Practising Certificate provisions.

It has been much harder, if not impossible, to trace complaints against health managers as there has been no central body to deal with such issues. Hence complaints would tend to have been lodged with each health organisation, and possibly dealt with in individual performance reviews or ultimately through the termination of an employment contract, but would seldom be a matter of public record. Of course this situation is changing with the advent of the Health \& Disability Commissioner's Office where health consumers may lodge complaints against managers, doctors and any agent of a health provider.

\section{Summary}

In summary, when one reviews these codes of ethics applying to doctors and managers several features of contrast are apparent:

- The code of ethics for doctors has a much longer history, is further reaching, more specific, and more directly enforceable than that for managers.

- It is only with the advent of the Health \& Disability Services Consumers' Code of Rights that managers are publicly held to account. The Code of Rights, however, is not a statement of management ethics (although it could contribute to one), it is an attempt to shape and create certain behaviours and procedures in health provider organisations.

- The codes of ethics emphasise the doctor's focus on the patient and profession, and the manager's focus on the organisation.

- All the codes recognise the importance of their particular profession, the consumers'/patients' and societal interest. 
Whether these codes truly represent behavioural norms (as suggested by Veatch, 1981) is a matter for debate and investigation.

\section{Method in Applied Ethics}

Several research methods have found particular popularity in applied ethics. Empirical research on medical ethics has relied very heavily on case studies, and questionnaires including vignettes of ethical dilemmas to which participants give responses. However, within these methods there has been a strong bias towards focusing on the sensational cases and dilemmas at the expense of any detailed examination of what is, and what influences, ethical behaviour on a day to day basis in medical practice.

Similarly, in business and managerial ethics research the case study and the questionnaire including scenarios of ethical dilemmas tend to be the predominant methods employed by researchers. They too are drawn by the headline scandals and dilemmas, although there has been more surveying of managerial attitudes to ethics in general than there has in the medical profession or in the health sector. Additionally there has been more research on the moral reasoning of managers. Most of this, however, has relied on questionnaires based on Kohlberg's theory of moral development or linking to personal values via the Rokeach value instrument. At base, questionnaires of these sorts, while adding to our knowledge of moral development or personal values, do not add much to our understanding of what is an ethical manager, or the types of issues which are ethical dilemmas for managers.

Randall and Gibson (1990) in a critical review of the methodology employed in the study of ethical beliefs and behaviour of organisation members highlighted a number of flaws in the existing empirical research methods. In particular they noted that "business ethics researchers need to develop reliable and valid instruments, (and) to conduct pretests of those instruments...in the target population” (p.462). They observed that the majority of business ethics studies they reviewed were conducted through mail surveys (81\%) and relied heavily on samples of marketing managers. Other methods included laboratory experiments (6\%), in-person interviews (4\%), and combination of interviews and surveys (3\%). The surveys used either a direct question format or scenarios/vignettes, both of which were seen as problematic due to their vagueness and 
generality. Randall and Gibson recommended overcoming this by conducting structured interviews within the target industry, and developing scenarios and questions using industry-specific terminology which are relevant and realistic. They considered inperson interviews valuable in exploratory research on ethical beliefs and conduct if the findings are sufficiently detailed. However they were concerned that a social desirability bias may cause individuals in all self-report type research to over-report ethical conduct, that is, the major differences that can occur between what people say they would do and what they actually do.

Broadening the field of enquiry to administrative ethics, Frederickson (1994) notes eight different research methods of varying popularity: surveys, experiments (i.e., presentation of hypothetical ethical dilemma vignettes), interviews, data (i.e., codes of ethics/reported incidence of whistleblowing or ethics violation etc), case studies, history, naturalistic enquiry or ethnography, and stories. All these methods have certain advantages and disadvantages in the exploration of ethics in practice. The advantages for most methods involve either:

i) precision in data gathering and statistical analysis through the ability to control for a range of variables; the ability to replicate the research, to cover a broad geographical area, and quickly access a very large sample - these are all advantages of survey, hypothetical ethical dilemma vignette techniques, and review of existing data; or

ii) being able to determine the reasons for certain opinions or actions, thus to explore issues further; generating a richer set of data - these are advantages of case study and interview research, ethnography and story techniques;

The disadvantages associated with many of these methods include:

i) the tendency to impose a pre determined analysis framework and thus risk becoming a self fulfilling prophecy;

ii) the tendency to only get at the "top of the head" responses (i.e., the politically correct answer, or how one would like to be perceived) rather than disclosing the actual influences on behaviour;

iii) the risks of being morally right but at the expense of one's job or career future are not present in most methods (i.e., the practicality of the various nuances which influence judgement and behaviour in the work environment);

iv) the possibility of researcher bias in posing questions and interpreting answers;

v) questions of dubious generalisability of results; 
vi) the huge time investment required from the researcher in naturalistic enquiry as they become a trusted member of the "community" which they are investigating;

vii) the time investment required of the busy managers and professionals by some of these methods of investigation.

In any research method there is a trade off between advantages and disadvantages to arrive at a way of exploring the research question. In an attempt to bring ethical theory and practice closer together controlling these trade offs in choice of method is a critical issue. Many researchers attempt to overcome this by employing a combination of methods - most commonly interviews and surveys, or vignettes and surveys. This

process of triangulation in research is one of establishing data trustworthiness through multiple data sources, methods and theoretical schemes.

\section{The Contribution of Psychology to Method in Applied Ethics}

Most of the methods employed in applied ethics empirical research thus far are those common to many of the social sciences including psychology. Psychology has also offered some variations of technique within those common methods which have proved fruitful. For instance, Rokeach’s (1973) human values survey has been widely used in values research, as its predetermined framework makes it easy to administer and analyse. However, its focus is on personal life values rather than occupation or role related ethics, thus the framework can be restrictive for researchers wishing to explore questions other than personal values.

Kohlberg (1984) asserts that moral development occurs in a specific series of stages across cultures. These stages of moral growth range from concern about self to the application of universal moral principles for example, of justice and equality.

Kohlberg's Moral Judgement Interview (MJI) and its many derivatives - the Defining Issues Test (DIT) developed by James Rest (1986), the Stewart and Sprinthall Management Survey (SSMS) for the public sector (1993), and the Nursing Dilemma Test (NDT) cited in Ketefian (1988) - are all aimed at assessing moral reasoning in a context sensitive way for different occupational groups.

Other scales also appear in the research literature, for instance, Forsyth (1980) developed the Ethics Position Questionnaire (EPQ) to measure the extent to which 
individuals adopt one of four ethical ideologies based on a matrix of idealism and relativism. The questionnaire was further tested by Giacalone, Fricker and Beard (1995) in combination with the Ethical Decision Modifiers Questionnaire (EDMQ) and the Punishment for Ethical Infraction Questionnaire (PEIQ). In a similar vein Hogan's (1973) Survey of Ethical Attitudes (SEA) contrasts individuals who follow an "ethics of responsibility" with those who endorse an "ethics of personal conscience". Another multidimensional ethics scale designed by Reidenbach and Robin (1988) is based on five major dimensions they identified in the moral philosophy literature - justice, relativism, egoism, utilitarian and deontological - which they reduce in their 1990 research to three constructs of moral equity, relativist, and social contract.

All these questionnaires focus on assessing and classifying an individual's moral judgements. In addition the majority of research to date has supplied statements or vignettes and asked respondents to respond to them as ethical or unethical. Very little research has approached from the other side and asked respondents themselves what it is to be ethical and what it is to be unethical in particular contexts.

However in a move away from the predetermined analysis framework of questionnaires Gilligan (1982) reports on her use of interviews in the style of Piaget's "methode clinique" in which she used five basic questions to explore moral judgement and self definition. This research broke from tradition by actually asking people how they defined moral problems and what experiences they construed as moral conflicts in their lives and judgements of hypothetical moral dilemmas.

In a similar method Dana and Rand Jack (1988) conducted in-depth interviews with thirty-six lawyers on moral choice and conflict. Each interview explored their decision to practise law, experience of law school, how legal practice affected their relationships, experience of self, understanding of morality and justice, plus they were asked to describe moral dilemmas they encountered in the practice of law, and to respond to two hypothetical moral dilemmas designed to measure care and rights reasoning. This method of in-depth interview has become very popular in recent years as it has all the attractions of ethnography and stories mentioned earlier, such as, the richness of information that is obtained, the feeling for the researcher of being in touch with reality, and the ability to have interviewees explain comments or opinions. The drawback of this method is its time consuming nature and hence for most researchers consequent 
limitations on sample size. Also the possibility for over-interpretation by the researcher either within the interview itself or after the event remains a danger of methods which create the image of 'knowing' the interviewee having discussed so much with them! Additionally a number of researchers have also been criticised for confusing descriptive and normative ethics in their research.

Argyris and Schon (1974, 1978), and Argyris (1982, 1990) attempted in their research to overcome the problem of the 'politically correct' answer or as they put it:

when someone is asked how he would behave under certain circumstances, the answer he usually gives is his espoused theory of action for that situation. This is the theory of action to which he gives allegiance, and which, upon request, he communicates to others. However, the theory that actually governs his actions is his theory-in-use, which may or may not be compatible with his espoused theory; furthermore, the individual may or may not be aware of the incompatibility of the two theories. (1974, p.7)

They uncovered this phenomenon in the course of their research on organisations in which they adopted the approach of action research popularised by themselves and Kurt Lewin and his colleagues. In this approach the core relationship is not experimenter and subject, or psychologist and interviewee, rather it is consultant and client achieving agreed change for the organisation and empowering the clients to continue with such change processes. The particular method employed by Argyris and Schon was that of direct observation and tape recording of situations in the organisation. The consultant then infers the culturally accepted meanings of the data, reconstructing the reasoning that must have been used to produce what was observed. This is then fedback to those observed (the clients) for validation/agreement/consensus. Similar to the use of ethnography and naturalistic enquiry in applied ethics research, this has the advantage of not being confined by an already established questioning or interpretive framework. On the other hand it requires the establishment of a relationship of total trust between consultant and client, and it can be a very expensive and time consuming process. Argyris and Schon admit that they never transcribed and analysed all the material they generated in the organisation as there was just so much of it!

\section{Criteria for Choice of Research Method and Repertory Grid Technique}


In order to compare medical ethics and health management ethics the present researcher wished to: understand what is an ethical doctor and an ethical health manager, examine certain influences on their decisions in ethically challenging situations, and identify ethical issues for doctors and health managers. A certain amount can be revealed through the exploration of existing data and research as has been summarised in previous chapters. However to add further empirical knowledge, the researcher required a method or combination of methods that met several criteria - the method needed to:

- Be grounded in actual practice/day to day reality

- Overcome the opinions, espoused values or politically correct viewpoints

- Avoid over-interpretation by the researcher

- Answer the research questions

- Be attractive and informative for busy participants (i.e,. they gain from the process)

The various techniques already offered by psychology to applied ethics research meet some of these criteria but not all. However another approach founded in clinical psychology and now widely used in organisational psychology does provide a base to meet all the researcher's criteria - Kelly’s Personal Construct Theory and repertory grid interview technique.

Kelly (1955) in his theory of personal constructs maintained that people make sense of their world through patterns or templates which they create and then attempt to fit over reality (i.e. they are ways of construing the world). By using such personal constructs we are able to make our world more predictable and manageable. In Kelly's words "they are what enables man, and lower animals too, to chart a course of behaviour" (p.9). Hence:

the personal construct system which each person develops is the set of representations or models of the world they have developed, a set which is acquired through social experience, some of it preverbal, some of it verbally transmitted and not all of it accessible to the individual in terms of self consciously held concepts. In all cases, this system is to some degree unique to the individual. This personal construct system is not immutably fixed - as with scientists' hypotheses, further experience may modify it. (Ryle, 1975, p.7) 
Kelly developed the repertory grid interview technique as an instrument for eliciting personal constructs. The technique is now used widely in a variety of settings. For example Stewart, Stewart and Fonda (1981) report on its applications in business for market research, career counselling, training evaluation, questionnaire design, investigating organisational climate and managerial effectiveness. It has also been widely used by management consultants and researchers to identify management competencies (Boam \& Sparrow, 1992; Rippin, 1995), to access the structure of manager's thoughts (Smith \& Stewart in Margerison \& Kakabadse, 1979), and to identify the components of organisational fit (Marshall, 1992).

\section{The repertory grid interview}

Repertory grid is a structured interview technique which elicits constructs by requiring subjects to draw comparisons between a set of environmental elements or events (i.e., people or things, usually anything from 4 to 9 elements in total) that represent the area of research interest. In most cases the researcher provides a list of roles or categories to elicit the appropriate elements. For example to investigate friendship one might use these element categories: best friend, spouse, former friend, acquaintance, colleague. These elements are each written on a separate small card by the participant so that they are able to easily bring the appropriate person to mind when required. This first step is referred to as ‘element selection’ (Dunn \& Ginsberg, 1986; Stewart et al., 1981).

The second step is 'element comparison' (or construct elicitation) in which the researcher randomly divides the elements into groups of three (referred to as triads) and asks the subject to describe ways in which two of the elements are similar but different from the third. This elicits a construct and its evaluative bipolar dimensions - the description of the two similar elements is the emergent pole and the description of the third element is the implicit pole. These poles are not necessarily the opposite of each other, but often that is the case. For instance in comparing elements in an investigation of friendship, one bipolar construct might be, "talks about absolutely everything” versus “talks on specific matters only”.

The third step is 'element evaluation' in which subjects are asked to rate each element in turn against each construct. Generally rating takes the form of a scale from one to seven, or one to five, where "one" indicates the element is most like the emergent pole of the construct and "five" ("seven”) indicates least like the emergent pole/most like the 
implicit pole. The number of constructs generated varies across subjects but it would be unusual to exceed 13 constructs (Marshall 1992).

The fourth and final step is 'grid analysis'. The repertory grid interview yields a ratings matrix of elements by constructs - these are analysed to give insight to the structure and content of people's cognitive constructs. A variety of analysis methods are popular depending on the purpose for collecting the data (e.g., questionnaire design, individual counselling, understanding cognitive structuring etc.). Analysis ranges from frequency counts and content analysis of constructs to factor analysis and cluster analysis looking for correlations among constructs.

The technique was seen as having a number of advantages over more conventional indepth interview methods for this research. Firstly, it enables one to discover the constructs that doctors and managers use in categorising ethical/unethical colleagues. This is in no small part due to the fact that repertory grid is a far less self conscious way of eliciting the ethical constructs of the individual. To enquire directly "what is ethical” is more likely to draw a politically correct response or espoused theory, whereas with repertory grid one obtains the answer to that question by having the person draw comparisons between a selection of ethical and unethical doctors and managers they have known. Thus the responses are grounded in reality and are automatically displaying the criteria being used to judge people ethical and unethical.

Secondly it does not allow over-interpretation or undue influence by the researcher as the structured nature of the process ensures the subject defines their constructs and rates them (Stewart et al., 1981). It does not impose a predetermined framework on subjects or on the constructs they generate.

Thirdly, although the grid technique focuses very much on the individual it has proved a useful tool for generating construct information to be explored at group level. Bannister and Fransella (1986) note that "methodologically, the grid can be used either to investigate the individual or particular aspects common to many subjects without violating the theoretical assumption that we are all unique in certain other respects" (p.54) 
However, although the technique has so many advantages over other methods and is appealing to participants due to its novel triadic element approach, it is time consuming - usually an hour and a half per interview - which can be restrictive when dealing with busy managers and professionals.

The present researcher decided to employ a combination of methods, including repertory grid, to investigate managerial ethics and medical ethics in the health sector.

\section{Selection of Combination of Methods for the Research}

The researcher decided on a combination of repertory grid interviews and survey questionnaire, supplemented by a review of available data (i.e., codes of ethics). The grid interviews with a small sample of doctors and health managers would provide information on which to base the design of a survey questionnaire for distribution to a much larger sample. This minimised the time commitment for participants in the research, and enhanced the range of information that could be collected.

Essentially with the results of the grid interviews the researcher is able to design a questionnaire that asks questions that come from the perceptions of doctors and health managers themselves, instead of something obviously derived from moral philosophy, moral psychology, theology and the other common sources of theoretical ethical discourse.

\section{Summary}

In this chapter I have briefly traversed the empirical literature of medical ethics, business/management ethics and health management ethics. A number of gaps are evident in the empirical base of medical and managerial ethics - gaps in knowledge and gaps in research practice. A consideration of method in applied ethics highlights the opportunities that exist to more effectively blend the disciplines of psychology and philosophy. Hence the next task of this thesis is the design and conduct of empirical research to probe the ethics of health managers and doctors, the issues they face and the influences on them in ethically challenging situations. 


\section{SECTION THREE: EMPIRICAL RESEARCH}

This section reports the conduct and results of the pilot study, the interview study, and the main survey study. The purpose of this empirical research was to identify what managers and doctors regard as ethical, what influences their decision-making in ethically challenging situations, and what types of ethical issues they face now and in the future. The research was carried out in three phases.

In the first phase a pilot study was completed in which six doctors and managers from a Crown Health Enterprise (CHE) were interviewed using the repertory grid interview approach. The aim of the pilot study was to see whether the interview procedure was acceptable to participants and able to elicit useful information. The study confirmed the approach as useful, and pointed to ways in which the interview could be improved for the second phase.

In the second phase, a series of repertory grid interviews were conducted with 19 doctors and managers from seven CHEs throughout New Zealand. This yielded a good range of information for inclusion in the design of a survey questionnaire, and highlighted areas that warranted further investigation through the survey.

In the third phase, the ethical constructs and role perceptions identified in the first and second phases were incorporated into a questionnaire which was distributed to 799 doctors and managers in three CHEs. The questionnaire posed a range of questions on role perceptions, dilemmas faced, influences on ethically challenging decisions, ethical issues, and required respondents to rate an ethical manager, ethical doctor, unethical manager and unethical doctor on a range of constructs and rate which constructs contributed most to being an ethical manager and to being an ethical doctor. The main aim was to identify similarities and differences between doctors and managers. It also provided the opportunity to compare New Zealand responses on influences with overseas responses and to compare ethical issues identified with those receiving most attention in the applied ethics literature.

Chapter 6 reports on the first two phases of the research and Chapter 7 on the third phase. 


\section{The Pilot Study}

\section{Empirical Research Questions}

The empirical research questions for the pilot study were: i) do doctors and managers regard the same factors as underpinning the ethics of doctors and managers? ii) how do doctors and managers perceive the ethical frame of their activity? iii) are there any common features in ethical dilemmas per se for doctors and managers in terms of what informs their decision-making?

\section{Research Participants}

The research participants were a convenience sample of three managers and three doctors from a Crown Health Enterprise to which the researcher gained access through personal acquaintance with the Chief Executive (who was not in the sample). The three doctors were male, hospital specialists (from different specialties), with an average of 18 years experience in the medical profession. Two of the managers were male, one female; all were in second tier management positions (i.e., reporting direct to the Chief Executive), with an average of seven years management experience of which, on average, one year had been in management in the health sector. It is pertinent to note at this point that the pilot study was conducted within the first year of the 1993 reform of the health sector and establishment of Crown Health Enterprises. These reforms saw an unprecedented number of management positions in CHEs filled by managers from outside the health sector. For more detail refer to Chapter 2.

\section{Interview Procedure}

Prior to the interview all participants had received a two-page letter which outlined the research in brief, the aim of the pilot study, the credentials of the researcher and supervisors, the content of the interview, and the standard provisions of the research ethics applying to their participation (refer to Appendix C for a copy of the letter). 


\section{$\underline{\text { Introduction to interview }}$}

At the beginning of the interview participants were thanked for their assistance and talked through the letter which outlined the aim of the research (to study and compare medical ethics and managerial ethics in the health sector) and the aim of the pilot study (to test the interview method for its acceptability to participants and ability to elicit information). The repertory grid interview process was explained and it was emphasised that the researcher would take notes but that there was no taping and no possibility of identifying the participant or any manager or doctor to whom they referred. Participants were informed that they would be asked to comment on the process at its conclusion.

Firstly some general questions were asked: name, position, age, length of time in current occupation/profession and position, training/education for the role. Then some contextual questions: what do you regard as the purpose of Crown Health organisations? What do you regard as the role of a doctor in Crown Health organisations? What do you regard as the role of a manager in Crown Health organisations? The researcher then proceeded with the first repertory grid as outlined below.

\section{First repertory grid}

Element selection. Participants were shown four cards labelled 1 to 4: on card 1 they were asked to write the initials, nickname or any symbol that would easily bring to mind "an anonymous current or former colleague or acquaintance you regard as a highly ethical doctor”, on card 2 the same instructions applied to an unethical doctor, on card 3 a highly ethical health sector manager, and on card 4 an unethical health sector manager. They were told that the researcher did not want to know who these people were, and that they could keep or destroy the cards at the conclusion of the interview.

Element comparison and construct elicitation. The participant was presented with successive triad combinations of the cards and asked: 
"Can you tell me something that two of these have got in common that makes them different from the third in terms of their 'ethicalness'- that is, their behaviour or decisions at work and what appears to guide it ?”

When a range of combinations, or the participant's capacity for fresh ideas, had been exhausted the researcher and participant confirmed the constructs that had emerged.

Element evaluation. The participant then rated the four people (elements) against each of the bipolar constructs that had been elicited from them in the previous step, using a 1 to 5 scale. The participant was also asked to rank order the importance of their constructs for guiding ethical behaviour generally.

\section{$\underline{\text { Second repertory grid }}$}

The researcher then repeated the procedure for the second repertory grid, but in this case the element selection involved six cards and participants were asked to note a word or symbol on three of the cards to represent three "situations you have been personally involved in (in your work role) which you considered to contain a serious ethical dilemma"; and then three "everyday decision making situations in which you have been personally involved (in your work role) that you consider did not involve any serious ethical dilemma”.

In the element comparison and construct elicitation each participant was presented with a number of successive triad combinations and asked:

“Thinking about these three situations in an ethical sense what is the same about two of them that is different from the third that informed your judgement/decision making?” The researcher presented the same triadic combinations to each participant, continuing until no new constructs emerged.

The constructs were confirmed with the participant who then rated each of the situations (elements) against each bipolar construct using a 1 to 5 scale.

The participant was asked what they considered to be the 5 most important constructs that contribute to a situation being a serious ethical dilemma. 


\section{Evaluation questions}

Participants were asked a range of evaluation questions about the interview process such as, were the instructions adequate? How could they be improved? How were the repertory grid interviews? Was there anything you wanted to say that you did not get the chance to? Was the length of time a problem? Did you feel the interview elicited your views accurately? Any comments on the researcher? Other comments?

\section{Results}

The focus of interest for the pilot study simply required content analysis of constructs, that is, counting the number of times similar or identical constructs had occurred and identifying which constructs appeared to be the most important to the interviewees. This type of analysis is the most appropriate to point to ways of improving the interview process for the next study and to identify trends that could be found in a larger study.

On average the interviews were two to two and a half hours in duration. Only four of the six people interviewed were able to complete the repertory grids. The two (one doctor and one manager) who could not complete the grids were unable to identify in their mind the elements that were required in each grid (i.e., ethical and unethical people, and ethical dilemma situations). It was clear with one of these people and in part true of the other participants (particularly the managers new to the health sector) that thinking about their activities in an ethical frame was not a usual frame of reference for them.

\section{$\underline{\text { Responses to introductory questions }}$}

The researcher asked a number of questions at the beginning of the interview which were aimed at grounding the participant in their work context, and obtaining background information. The first question asked "what do you regard as the purpose of Crown Health organisations ?” In answer there was general agreement from both managers and doctors indicating "best quality care for best use of scarce resources". The only difference of perception was that the doctors seemed to be thinking of hospital 
based services whereas the managers were thinking more broadly of health services (not necessarily hospital based), for example, primary health services.

The second question asked "what do you regard as the purpose of the role of the doctor in Crown Health organisations?” The doctors regarded themselves as “providing that component of health care that medical people are trained to deliver in the health care team”. Some mentioned responsibilities in training junior doctors and some an additional administrative role. The managers regarded doctors as "technicians" who “deliver clinical service” which "enables the organisation to meet its strategic direction and goals". They also thought that senior doctors had a responsibility "to set and deliver clinical policies”, and all had "responsibility for quality and practising expertise”.

Thus it appears that there may be a slight difference in orientation to the understanding of the role of the doctor in the organisation depending on where the respondent sits in the organisational structure. Not surprisingly the managers' view of the role is couched in organisational terms and sees the doctors' role as purely instrumental in achieving organisational purpose. To a certain extent the doctors also described themselves instrumentally, but in relation to the health care team and delivery of health care rather than the broader, less defined, notion of organisational/strategic purpose. Of course this may just be highlighting semantic differences in the way doctors and managers express constructs.

The third question asked "what do you regard as the purpose of the role of a manager in Crown Health organisations ?” Doctors' responses to this were generally “a facilitatory role"; "to get contracts so we have work to do"; and "a monitoring role over the organisation”. Some differentiated the role according to the tier of management referred to. For example, second tier ensure resources are available for work to be done, third tier has a hands-on operational role concerned with people management in their department, managing the budget, dealing with public, and so on. The managers themselves in response to this question all differentiated between the tiers of management. Similar to some of the doctors, the managers saw third tier as "day to day operational management", second tier as "setting strategy and policy, and securing resources”; and the Chief Executive as the "flagwaver/seller of the organisation”. 
This first grid explored perceptions of ethical and unethical doctors and managers. Initially the researcher manually reviewed the constructs to discover which constructs appeared to account for the greatest discernment between ethical and unethical doctors and managers. The findings were as follows:

Doctors' perceptions. The doctors perceived ethical doctors in terms of constructs which formed a list of ten positively stated attributes. They perceived ethical managers in terms of eight positively stated attributes - many the same attributes as those they listed for ethical doctors. All the constructs are listed in Table 6.1. It is interesting to note that these constructs all seem to relate to a sense of openness and transparency of reason and action.

Doctors perceived unethical doctors with mainly the negation or absence of the positive attributes listed above, although interestingly they may be perceived as technically competent (i.e., “understand clinical matters”), and they were perceived as possessing one critical "vice" - self-interest. They also perceived unethical managers with mainly the negation or lack of positive constructs and possession of two vices - self interest and financial concern for the organisation (which was also viewed as a virtue in some instances). The four constructs in common between unethical managers and unethical doctors were: no global financial concern, not self-critical, no perceptible ethical framework, self-interested.

Managers' perceptions. Managers perceived ethical managers as possessing a number of positive constructs and of not possessing certain vices (i.e., not self-interested, not dishonest, not unreasoned decisions). They perceived ethical doctors and ethical managers similarly, as is illustrated in Table 6.2.

Managers perceived unethical managers as not possessing a range of positive constructs and of possessing some vice (e.g., money and status too important). However they perceived unethical doctors and unethical managers in slightly different ways listing the lack of certain different positive constructs and possession of different vices, however there are four common constructs : money and status too important, not always honest, not aware/understanding of others, not consistent in saying and doing. 
Table 6.1: Constructs elicited from doctors to describe ethical doctors and ethical managers

Ethical doctors:

Approachability

Not always self-interested

Non corruptibility

Adherence to truth

Perceptible ethical framework

Acts in the best interests of the patient

Absence of self-interest

Logical problem solving

Self-critical

Global financial concern (i.e., beyond individual

patient)

\section{Ethical managers:}

Approachability

Not always self-interested

Non corruptibility

Adherence to truth

Perceptible ethical framework

Financial concern for organisation

Concern for others' welfare

Personal loyalty

Table 6.2: Constructs elicited from managers to describe ethical doctors and ethical managers

\begin{tabular}{ll}
\hline Ethical doctors: & Ethical managers: \\
\hline Not always self-interested & Not always self-interested \\
Awareness/understanding of others & Awareness/understanding of others \\
Not dishonest & Not dishonest \\
Honest & Honest \\
Commitment to public health system & Commitment to public health system \\
Not unreasoned decisions & Not unreasoned decisions \\
Realism/breadth of outlook & Realism/breadth of outlook \\
Consistency in saying and doing & Consistency in saying and doing \\
\hline
\end{tabular}


Common and most discerning constructs. The manual review of the data highlighted a number of common constructs that emerged across individuals and six that were far more keenly discerning between ethical and unethical people (i.e., scores were polarised on these constructs). These six constructs were: less reasoned/black and white decisions/ need to be right, commitment to public health system, concern for/understanding of others, approachability, self-interest and lack of it, global financial concern.

For the purposes of the pilot study it was not appropriate to attempt to aggregate the individual data in any meaningful way. However, for the sake of speculative interest the researcher calculated mean scores of the construct ratings on each of the four participants' grids. These showed a clear differentiation between ethical and unethical people. Table 6.3 shows clearly lower mean scores for ethical people than for unethical. In many ways such results are not surprising as the research is directly asking individuals for constructs that measure on an ethical/unethical dimension.

Table 6.3: Overall mean ratings of elements against each participant's constructs (Pilot Study)

\begin{tabular}{l|llll}
\hline & \multicolumn{4}{|c}{ Mean ratings of } \\
\hline Participants & ethical & unethical & ethical \\
doctor & doctor & 3.6 & 1.8 & unethical \\
manager & 3.8 \\
\hline doctor 1 & 1.6 & 3.4 & 1.6 & 4.4 \\
doctor 2 & 1.4 & 3.4 & 2.1 & 2.7 \\
manager 1 & 1.7 & 4.0 & 1.2 & 3.5 \\
manager 2 & 1.3 & & & \\
\hline
\end{tabular}

Note: Ratings were on a 1 to 5 scale, 1 representing the ethical pole of the construct, 5 representing the unethical pole of the construct.

\section{$\underline{\text { Responses to the second repertory grid }}$}

The second grid explored perceptions of work situations in which participants had been personally involved. The constructs elicited relate to what participants believed informed their judgement in those situations. These constructs have been manually reviewed by the researcher. 
Doctors' perceptions. The doctors described a total of 13 constructs which inform judgement in serious ethical dilemmas. Compared with the managers the doctors identified a very long list of factors influencing their decision making, however on the basis of manual review a number of these failed to discern consistently between serious ethical dilemmas and everyday decision situations. This may be because the constructs were not probed enough in the interview, or it could be because all decisions doctors face have an ethical component. The information from the doctors also highlighted the potentially wide variation of influencing factors depending on the nature of the particular situation.

Not unexpectedly some of the constructs identified by doctors relate very much to the nature of the doctor-patient relationship, (e.g., patient very ill, patient competent/can consent, doctor knows the patient's beliefs, patient wants to take inadvisable risk). Some constructs related to things lacking in the situation, (e.g., lack of truth, aberrant colleagues, divided loyalty). Also a more personal set of constructs emerged, (e.g., personal ethical standards in conflict, necessity for personal intervention, personal danger). And finally a few constructs that relate to features of the situation, (e.g., clinical standards issue, no single correct course of action, research issues). The researcher believes that with more probing it may have been possible to further refine some of these constructs. If that had been done it might have had the effect of reducing the number of constructs slightly as some of them may relate to a single deeper core construct.

Managers' perceptions. Managers described nine constructs in total that inform judgement in serious ethical dilemmas. Interestingly, similar to the doctors' perceptions six of the constructs relate to the lack of certain conditions in the serious ethical dilemma situation. These were lack of transparency; lack of honesty; lack of thinking through; lack of clear guidelines; selective use of information; not loyal to company. The other three constructs relate to what is present in the situation. These were high risk; involves doctors; more complex/mentally taxing.

No descriptive statistics have been calculated for this data as the range of constructs was so broad. It is in the conduct of this second repertory grid that the researcher wished to make some changes on the basis of the pilot study experience. These changes are described in more detail in the following discussion. 


\section{Participants' evaluation of the pilot study}

At the conclusion of the interview the researcher asked each participant a set of evaluation questions about the pilot study. All participants considered that the interview had elicited their views accurately, and some discovered things they had not articulated before. Some said they had difficulty thinking of ethical and unethical people. The managers had difficulty because they were relatively new to the health sector. The doctors had some difficulty because they considered everybody tries for a certain level of ethicalness, hence they reported thinking about people they don't like whose opinions they do not respect.

All participants thought that the second repertory grid would have felt more complete if the researcher had invited them to describe in overview each of the situations they were thinking of - thus placing their constructs in some clearer context.

\section{Discussion}

The questions on role perception drew a subtle, but interesting difference in doctors' and managers' responses which warranted further study. Managers appeared to perceive the doctors' role as purely instrumental to achieving organisational goals, while doctors perceived their role as instrumental to health care/patient care. These may be the same thing expressed in different ways, maybe not, and further investigation was carried out in the larger interview study to shed more light on role perceptions.

The first repertory grid worked well with clear agreement in the division between ethical and unethical people. Managers and doctors appeared to perceive and be perceived as ethical for broadly similar reasons, but as unethical for some quite different reasons. An explanation for this could be that the classification of people as ethical is based more on whether we "like them" rather than on clearly demonstrated ethical behaviour. However, this issue was explored and eliminated in the larger interview study.

The constructs which typify a serious ethical dilemma are not dissimilar to those attributed to ethical and unethical colleagues in the first repertory grid. Not surprisingly 
the managers seemed to highlight situations which cause them to focus on the organisation and people in relation to the organisation. Doctors highlighted situations which caused them to focus on individual patients and/or their medical research. In the larger study it was vital, as identified in participant feedback, to obtain a more complete description of the dilemma situations from participants so that the researcher had more contextual information (e.g., do doctors face dilemmas that are solely focused on the individual, do managers face dilemmas that are solely related to the overall good of the organisation?). The researcher considered it important to know the type of situations doctors and managers faced (and whether these were similar or different), as well as knowing the factors that influenced decision making in these situations. These are areas that impacted on the design of the next phase.

\section{The Interview Study}

\section{Empirical Research Questions}

The empirical research questions for the interview study were: a) what do doctors and managers perceive as their role? b) do doctors and managers regard the same things as underpinning the ethics of doctors and managers? c) how do doctors and managers perceive the ethical frame of their activity? d) are there any common features in ethical dilemmas per se for doctors and managers in terms of what informs their decision making?

\section{Participants}

The participants were a sample of eleven managers and eight doctors from seven Crown Health Enterprises throughout New Zealand.

Three of the managers were female, and eight were male. Two of the doctors were female and six were male. Six of the managers (two female and four male) had previously been health professionals (two were nurses, four were doctors).

The managers reported an average age of 44.8 years (range: 35 to 53 years), the doctors reported an average age of 45.6 years (range: 27 to 66 years). The average length of 
management experience for the managers was 9.8 years (range: 2 to 25 years), the average length of working experience in the health sector for the managers (i.e., in management and non-management roles) was 14 years (range: 1.5 to 22 years), and for the doctors was 20.4 years (range: 3 to 42 years).

\section{$\underline{\text { Selection of participants }}$}

The researcher hoped to obtain a richness of interview data to feed into the design of the survey questionnaire. Thus the key criteria used to select doctors and managers to participate in the interviews were: the geographical and population base spread of the CHEs in which they worked; ease of access via contacts; and participants who were good informants (i.e., a mix of the professionally politically active, those interested in ethics, and those suggested by others as good informants). For the purpose of the study managers were defined as those who were Chief Executives, and second tier or third tier managers in CHEs. Doctors were defined as those practitioners working at Registrar level or above in a CHE.

In most cases initial contact was established with prospective participants because the researcher knew them or had a referral from a third party. All participants received a two page letter similar to that used in the pilot study, which gave a brief overview of the research, credentials of the researcher and supervisors, purpose of the interview and its content, and the standard provisions of the research ethics applying to their participation (refer to Appendix D for a copy of the letter). The letter was followed by a telephone call from the researcher to respond to any questions, to seek agreement to participate in the research and to set a time for the interview to take place. 


\section{Interview Procedure}

\section{$\underline{\text { Variations from pilot study procedure }}$}

As a result of the pilot study experience there were a small number of key improvements made to the interview process which are noted in the following description of the interviews. In brief these changes were aimed at; a) improving procedure by making it clearer for participants, b) building on the information already obtained in the pilot study (e.g., having participants rate the constructs generated in the pilot study as well as their own constructs), and c) obtaining a broader range of information (e.g., having participants describe the ethical situations they were thinking of, and having them rank influences on their decision making).

\section{$\underline{\text { Introduction to interview }}$}

Exactly the same procedure and question format as that used in the pilot study was used in order to ground participants in the context of the manager and doctor work role in CHEs.

\section{First repertory grid}

The researcher proceeded with the first repertory grid in exactly the same manner as outlined in the pilot study: element selection, element comparison and construct elicitation, and finally element evaluation. The same elements (highly ethical doctor, unethical doctor, highly ethical health sector manager and unethical health sector manager) were used as well as the same question in order to generate element comparison:

"Can you tell me something that two of these have got in common that makes them different from the third in terms of their 'ethicalness'- i.e., their behaviour or decisions at work and what appears to guide it ?”

The only variation from the procedure followed in the pilot study was in the final stage of element evaluation explained below. 
Element evaluation. Similar to the pilot study the participant then rated the 4 people (elements) against each bipolar construct they had generated using a 1 to 5 scale. The participant also rated the elements against 11 constructs supplied by the researcher which had been generated by the pilot study. These are listed in Table 6.4.

\section{Table 6.4: Bipolar constructs supplied for rating in first repertory grid}

\begin{tabular}{ll}
\hline Emergent pole of construct: & Implicit pole of construct: \\
\hline Self-interested & Not self-interested \\
Altruistic & Not altruistic \\
Self-aware & Not self-aware \\
Honest & Dishonest \\
Perceptible ethical framework & No ethical framework \\
Concern for others & Lacking concern for others \\
Global financial concern & Lacks global financial concern \\
Consistency in say \& do & Not consistent in say \& do \\
Approachable & Not approachable \\
Reasoned decisions & Lacking reasoned decisions \\
Focuses on best interests of patient & Lacks focus on best interests of patient \\
\hline
\end{tabular}

The participant was also asked to rank order what they considered to be the five most important constructs for guiding ethical behaviour. They were instructed that the five could be chosen from any of the rated constructs, that is, their own or the supplied constructs.

\section{$\underline{\text { Second repertory grid }}$}

The researcher then repeated the procedure for the second repertory grid focusing the element selection on ethical dilemmas and everyday decisions similarly to the pilot study. In a variation from the pilot study the participant was asked to briefly describe the detail of each element, (i.e., the three ethical dilemmas and three everyday decisions).

In the element comparison and construct elicitation each participant was presented with a number of successive triad combinations and asked: 
"Thinking about these three situations in an ethical sense what is the same about two of them that is different from the third that informed your judgement/decision making?”

Another variation from the procedure followed in the pilot study was in the final stage of element evaluation explained below.

Element evaluation. Similar to the pilot study the participant then rated the 6 situations (elements) against each bipolar construct they had generated using a 1 to 5 scale.

The participant also rated the elements against 7 constructs supplied by the researcher which had been generated in the pilot study. These are listed below in Table 6.5.

\section{Table 6.5: Bipolar constructs supplied for rating in the second repertory grid}

\begin{tabular}{ll}
\hline Emergent pole of construct: & Implicit pole of construct: \\
\hline Lack of clear guidelines & Clear guidelines \\
Mentally taxing & Not mentally taxing \\
Contains level of risk & Lacking level of risk \\
In conflict with personal ethical standards & No conflict with personal ethical standards \\
Long term impact thought through & Lack of thinking through to long term \\
Honest & Dishonest \\
Transparent decision process & Lack of transparency in decision process \\
\hline
\end{tabular}

The participant was then asked what they considered to be the 5 most important constructs that contribute to a situation being a serious ethical dilemma. The participant was free to choose these 5 from their own constructs and the supplied constructs.

\section{Influences on decision making}

In the final part of the interview another variation on the pilot study was introduced in order to discover more about the influences on decision making. Hence the participants were asked to: "rank order the importance of the influence on your decision of the following in each of the six decision making situations we have just explored”. The influences to be ranked included - self (own values, beliefs, motivations); your profession; your role in the organisation; your organisation/employer; management team; health team; patient/individual/staff member; any other major influence.

\section{Results}


The purpose of the interview study was to further explore the ethics of doctors and managers, and ultimately to assist in the design of a questionnaire to be distributed to a broader sample of doctors and managers. Hence the data analysis needed to summarise the results and point to specific items to be included in the questionnaire and/or trends for confirmation through the larger sample of the survey. Marshall (1992) used repertory grid to identify broad dimensions of organisational fit - 9 interviews yielded 64 bipolar constructs which she grouped into 6 categories on the basis of content analysis, and thus generated a scale based on these for use with another sample. Although factor analysis and discriminant analysis are popular for analysis of repertory grid, they are not as reliable on small samples with less than 20 subjects (Bell, 1994., Stewart, 1981).

Thus for this research a mix of basic analysis techniques were employed to draw useful information from the interviews. These were content analysis of constructs and basic descriptive statistics, that is, frequency counts of occurrence of similar or the same constructs, identifying which constructs are rated as the most important by the interviewees, and using participants' own words to provide more precise definition of constructs.

\section{$\underline{\text { Responses to introductory questions }}$}

At the beginning of the interview participants were asked about their perception of the current role of a doctor in a CHE, and the current role of a manager in a CHE. A brief content analysis of their responses identified the most common themes in their perceptions. These themes are summarised below:

Managers most commonly saw the doctor's role as "medical expert to ensure best patient outcome within available resources”.

Doctors, however, saw their role as - "takes responsibility for patient care", and "member of health team".

Managers most commonly saw their role as "facilitator to help the organisation to work", and "guardian of public money, ensuring ongoing viability of the organisation”. 
Doctors saw the manager's role as "facilitator to allow doctors to work and the organisation to function”.

\section{Constructs from the first repertory grid interview: ethical and unethical colleagues}

The ranking of the 5 most important constructs for guiding ethical behaviour served as a useful mechanism to have participants prioritise their constructs, and those supplied by the researcher, into a list which could be used in further research. There were a total of 27 constructs mentioned by doctors and managers in the ranking procedure. Fourteen of these constructs were cited by two or more people as represented in Table 6.6.

Not surprisingly, given the nature of their work, doctors most often chose: focus on patients' best interests, and managers most often chose honesty, in the top 5 contributors to ethical behaviour. Also popular with doctors were: honesty, reasoned decisions, and openness/willingness to listen and consult. The constructs: focused on patients' best interests, not totally self-interested, and consistency in words and actions were popular with managers.

The thirteen other constructs which emerged in the top five but were each only cited by one subject were: ability to admit when wrong, flexibility of approach, motivated by greed for money, principled, facing up to situations, considers public good of decisions, approachable, consideration of colleagues, accountability for treatment of individuals, accountability for management of the system, accountability under medical discipline, personal integrity, active to try to change things for the better, meaningful decisions, practicality, and takes hard decisions. These results were considered in the design of the subsequent phase of research.

It was also possible to calculate the overall mean scores of the elements (i.e., ethical and unethical doctors and managers) rated against the 11 constructs supplied by the researcher (Table 6.7). This enabled a scan for non discerning constructs which should be eliminated from further study, and for any other trends in the constructs which may warrant further investigation. It is interesting to note that 9 of these constructs feature in the list of 5 most important guides of ethical behaviour in Table 6.6. 
Table 6.6: Frequency with which constructs are cited amongst the 5 most important guides of ethical behaviour

\begin{tabular}{|c|c|c|c|}
\hline Construct title & $\begin{array}{l}\text { Frequency cited } \\
\text { overall (percentage) } \\
n=19\end{array}$ & $\begin{array}{l}\text { Frequency cited by } \\
\text { doctors (percentage) } \\
n=8\end{array}$ & $\begin{array}{l}\text { Frequency cited by } \\
\text { managers } \\
\text { (percentage) } n=11\end{array}$ \\
\hline $\begin{array}{c}\text { Focused on patients' best } \\
\text { interests }\end{array}$ & $13(68.4 \%)$ & $7(87.5 \%)$ & $6(54.5 \%)$ \\
\hline Honesty & $13(68.4 \%)$ & $5(62.5 \%)$ & $8(72.7 \%)$ \\
\hline Not totally self-interested & $8(42.1 \%)$ & 3 (37.5\%) & $5(45.4 \%)$ \\
\hline Reasoned decisions & 7 (36.8\%) & $4(50.0 \%)$ & $3(27.2 \%)$ \\
\hline $\begin{array}{l}\text { Consistency in words and } \\
\text { actions }\end{array}$ & $6(31.5 \%)$ & $2(25.0 \%)$ & $4(36.3 \%)$ \\
\hline $\begin{array}{l}\text { Focus on others/concern for } \\
\text { others }\end{array}$ & $5(26.3 \%)$ & $2(25.0 \%)$ & $3(27.2 \%)$ \\
\hline $\begin{array}{l}\text { Perceptible ethical } \\
\text { framework }\end{array}$ & $5(26.3 \%)$ & $2(25.0 \%)$ & $3(27.2 \%)$ \\
\hline Global financial concern & $4(21.0 \%)$ & $1(12.5 \%)$ & $3(27.2 \%)$ \\
\hline $\begin{array}{l}\text { Openness/willingness to } \\
\text { listen and consult }\end{array}$ & $4(21.0 \%)$ & $4(50.0 \%)$ & $0(0.0 \%)$ \\
\hline $\begin{array}{l}\text { Long term focus in decision } \\
\text { making }\end{array}$ & $3(15.7 \%)$ & $2(25.0 \%)$ & $1(9.0 \%)$ \\
\hline $\begin{array}{l}\text { Self-awareness in decision } \\
\text { making }\end{array}$ & $3(15.7 \%)$ & $1(12.5 \%)$ & $2(18.1 \%)$ \\
\hline $\begin{array}{l}\text { Hardworking/contributes to } \\
\text { service }\end{array}$ & $2(10.5 \%)$ & $1(12.5 \%)$ & $1(9.0 \%)$ \\
\hline $\begin{array}{l}\text { Committed to public health } \\
\text { system }\end{array}$ & $2(10.5 \%)$ & $0(0.0 \%)$ & $2(18.1 \%)$ \\
\hline $\begin{array}{l}\text { Committed to social equity } \\
\text { and justice }\end{array}$ & $2(10.5 \%)$ & $2(25 \%)$ & $0(0.0 \%)$ \\
\hline
\end{tabular}


Table 6.7: Overall mean scores of elements (ethical and unethical doctors and managers) rated against supplied constructs

\begin{tabular}{lllll}
\hline $\begin{array}{l}\text { Suggested Ethical } \\
\text { Pole of Constructs: }\end{array}$ & $\begin{array}{l}\text { ethical } \\
\text { doctors }\end{array}$ & $\begin{array}{l}\text { unethical } \\
\text { doctors }\end{array}$ & $\begin{array}{l}\text { ethical } \\
\text { managers }\end{array}$ & $\begin{array}{l}\text { unethical } \\
\text { managers }\end{array}$ \\
\hline Not self-interested & 1.61 & 4.15 & 1.92 & 4.23 \\
Altruistic & 1.84 & 4.23 & 2.38 & 4.46 \\
Self-aware & 1.38 & 2.61 & 1.38 & 2.76 \\
Honest & 1.15 & 3.69 & 1.15 & 3.92 \\
Perceptible ethical & 1.23 & 4.00 & 1.23 & 4.15 \\
$\quad$ framework & & & & \\
Concern for others & 1.23 & 3.15 & 1.31 & 3.92 \\
Global financial & 2.31 & 4.00 & 1.15 & 2.31 \\
$\quad$ concern & & & & 3.53 \\
Consistent in word and & 1.31 & 3.53 & 1.31 & 3.31 \\
$\quad$ action & & 3.07 & 1.46 & 3.15 \\
Approachable & 1.15 & 3.00 & 1.23 & 3.46 \\
Reasoned decisions & 1.23 & 3.31 & 1.38 & \\
Focus on patients' best & 1.00 & & & \\
$\quad$ interests & & & &
\end{tabular}

Note: 1 = strongly agree the suggested ethical pole of the construct describes this person, 2 = agree, $3=$ neutral, $4=$ agree and $5=$ strongly agree the suggested unethical pole of the construct describes this person.

It is clear from these mean scores that most of the constructs differentiate between ethical and unethical people with the exception of self aware. Additionally the construct of global financial concern yields an unusual set of mean scores which may point to a difference in managers and doctors.

When participants compared ethical and unethical colleagues in the repertory grid triad combinations, similar to the trend of the pilot study, the unethical were commonly characterised as lacking the positive attributes of the ethical. However, there were also 11 new constructs of unethicalness which emerged from individual participants (i.e., each was mentioned by one person only) and these are listed in Table 6.8. 
Table 6.8: Bipolar constructs where the emergent pole represents unethical elements

\begin{tabular}{ll}
\hline Emergent pole of construct: & Implicit pole of construct: \\
\hline Manipulative, uses others for own ends & Not manipulative, recognises others skills \\
Status driven & Not status driven \\
Power hungry & Not power hungry \\
Aggressive & Not aggressive \\
Poor interpersonal skills & Good interpersonal skills \\
Overtly disrespectful to others & Respects others \\
Flippant & Not flippant \\
Hidden agendas & Know where you stand \\
Distorts information to own ends & Makes decisions logically \\
Opportunistic/short term & Long term focus in decision making \\
Ethics as expedient prop & Does not use ethics expediently \\
\hline
\end{tabular}

\section{$\underline{\text { Constructs for consideration in next phase of research }}$}

The researcher reviewed all the constructs, both supplied and generated in the interviews, using interview notes of construct descriptions and broadly categorised the constructs into four categories: character, motivation, behavioural style and approach to decisions. This provided a manageable framework in which to place the constructs, eliminating those that were non discerning according to element ratings, and merging those which were very similar or the same in meaning. As the exercise required classification of constructs on the basis of criteria that have been developed for the first time, it was necessary to check its reliability hence an independent rater was asked to review the list of constructs placing them into the four categories and highlighting those with similar meaning or ambiguous meaning. As a result 26 constructs (refer Appendix E) were arrived at to aid the design of the survey questionnaire in the next phase of research.

$\underline{\text { Second repertory grid constructs: ethical dilemmas }}$

The second repertory grid focused on identifying what informs the judgement of managers and doctors in serious ethical dilemmas and everyday decision making. There were a total of 23 constructs mentioned by doctors and managers in the ranking of the 5 
most important constructs that contribute to a situation being a serious ethical dilemma. Seventeen of these constructs were cited by two or more people as represented in Table 6.9 .

Table 6.9: Frequency with which constructs are cited amongst the 5 most important constructs that contribute to a situation being a serious ethical dilemma

\begin{tabular}{|c|c|c|c|}
\hline Construct title & $\begin{array}{l}\text { Frequency cited } \\
\text { overall (percentage) } \\
\mathrm{N}=19\end{array}$ & $\begin{array}{l}\text { Frequency cited by } \\
\text { doctors } \\
\text { (percentage) } N=8\end{array}$ & $\begin{array}{l}\text { Frequency cited by } \\
\text { managers } \\
\text { (percentage) } \mathrm{N}=11\end{array}$ \\
\hline Contains level of risk & $12(63 \%)$ & $3(37.5 \%)$ & $9(81.8 \%)$ \\
\hline $\begin{array}{l}\text { Conflicts with personal } \\
\text { ethical standards }\end{array}$ & $8(42 \%)$ & $3(37.5 \%)$ & $5(45.4 \%)$ \\
\hline Conflicting rights & $8(42 \%)$ & $4(50 \%)$ & $4(36.3 \%)$ \\
\hline Uncertainty of outcome & $6(31.5 \%)$ & $4(50 \%)$ & $2(18.1 \%)$ \\
\hline $\begin{array}{l}\text { Lack of clarity of process or } \\
\text { guidelines for } \\
\text { decision }\end{array}$ & $6(31.5 \%)$ & $1(12.5 \%)$ & $5(45.4 \%)$ \\
\hline $\begin{array}{l}\text { Not thought through to long } \\
\text { term }\end{array}$ & $6(31.5 \%)$ & $3(37.5 \%)$ & $3(27.2 \%)$ \\
\hline $\begin{array}{l}\text { Lack of transparency of } \\
\text { decision }\end{array}$ & $4(21 \%)$ & $1(12.5 \%)$ & $3(27.2 \%)$ \\
\hline Protection from harm & $3(15.7 \%)$ & 3 (37.5\%) & $0(0 \%)$ \\
\hline $\begin{array}{l}\text { Difficult to involve individual } \\
\text { in decision making }\end{array}$ & $3(15.7 \%)$ & $2(25 \%)$ & $1(9 \%)$ \\
\hline $\begin{array}{l}\text { Maximum benefit to the } \\
\text { service/community }\end{array}$ & $3(15.7 \%)$ & $1(12.5 \%)$ & $2(18.1 \%)$ \\
\hline Effect on others & $3(15.7 \%)$ & $2(25 \%)$ & $1(9 \%)$ \\
\hline Safety vs affordability & $3(15.7 \%)$ & $1(12.5 \%)$ & $2(18.1 \%)$ \\
\hline $\begin{array}{l}\text { External pressures on } \\
\text { decision making }\end{array}$ & $2(10.5 \%)$ & $1(12.5 \%)$ & $1(9 \%)$ \\
\hline Lack of honesty & $2(10.5 \%)$ & $1(12.5 \%)$ & $1(9 \%)$ \\
\hline Lack of information & $2(10.5 \%)$ & $1(12.5 \%)$ & $1(9 \%)$ \\
\hline Complexity & $2(10.5 \%)$ & $1(12.5 \%)$ & $1(9 \%)$ \\
\hline Confidentiality & 2 (10.5\%) & $0(0.0 \%)$ & 2 (18.1\%) \\
\hline
\end{tabular}

As can be seen from the seventeen constructs listed there was a wide spread of those considered important, which probably reflects the varying nature of the ethical dilemmas which participants were thinking about in the interview. Thus the researcher decided to distil more information from the interview material focusing on the broader 
types of dilemmas faced by doctors and managers. In order to do this two independent raters were given a list of 12 labels (refer Table 6.10), and verbatim descriptions of the 57 ethical dilemmas from the interviews. They were asked to "use the labels to classify each of the dilemmas outlined...you may consider that the dilemmas can be classified under more than one of these categories in which case could you please list all the categories you consider most pertinent to the dilemma, and if possible indicate by underlining which you consider to be the most salient category in the dilemma”. The labels were generated by the researcher on the basis of the actual dilemma situations participants had discussed in the interview, and the types of dilemma classification commonly used in the applied ethics literature. The constructs that had been generated (refer Table 6.9) were also checked against the labels to ensure they were captured by these broader labels of types of ethical dilemma.

\section{Table 6.10: Ethical dilemma classification labels}

\begin{tabular}{ll}
\hline Label: & Definition: \\
\hline COMP & issues to do with competence of staff or colleagues \\
RES & issues to do with resource allocation (ie. financial resources or staffing resources) \\
CONF & issues to do with confidentiality \\
PUBINT & issues to do with public interest \\
INDFAIR & issues to do with individual fairness ( generally related to employees) \\
ORGINT & issues to do with the organisation's interests \\
PATINT & issues to do with patient interests \\
RIGHTS & issues to do with rights \\
SELF & issues to do with self-interest \\
FAMILY & issues to do with the rights of the family of a patient \\
AUT & issues to do with the autonomy of the patient \\
PROFNL & issues to do with being a member of a profession and the profession’s interests \\
\hline
\end{tabular}

The independent raters assigned two to four labels to each dilemma. They were in broad agreement on the classification of 52 of the dilemmas (91.2\%). The five cases on which vastly different or no classifications were given by the raters were all dilemmas which were rather vague in their description.

On the basis of these classifications the researcher calculated the frequency of the various types of dilemmas cited by managers and doctors, these are listed in Table 6.11 
Table 6.11: Frequency of types of ethical dilemma cited by doctors and managers in the interview

\begin{tabular}{llrcr}
\hline & $\begin{array}{l}\text { Frequency in } \\
\text { doctors' dilemmas }\end{array}$ & \multicolumn{3}{c}{$\begin{array}{l}\text { Frequency in } \\
\text { managers' dilemmas }\end{array}$} \\
Label: & $(\underline{\mathbf{n}}=\mathbf{2 4 )}$ & $\mathbf{\%}$ & $\underline{\mathbf{n}=33)}$ & $\mathbf{\%}$ \\
\hline COMP & 2 & $8.3 \%$ & 7 & $21.2 \%$ \\
RES & 4 & $16.6 \%$ & 14 & $42.4 \%$ \\
CONF & 1 & $4.1 \%$ & 2 & $6.0 \%$ \\
PUBINT & 4 & $16.6 \%$ & 17 & $51.5 \%$ \\
INDFAIR & 0 & $0.0 \%$ & 5 & $15.1 \%$ \\
ORGINT & 0 & $0.0 \%$ & 7 & $21.2 \%$ \\
PATINT & 20 & $83.3 \%$ & 10 & $30.3 \%$ \\
RIGHTS & 0 & $0.0 \%$ & 1 & $3.0 \%$ \\
SELF & 0 & $0.0 \%$ & 0 & $0.0 \%$ \\
FAMILY & 7 & $29.1 \%$ & 0 & $0.0 \%$ \\
AUT & 8 & $33.3 \%$ & 0 & $0.0 \%$ \\
PROFNL & 5 & $20.8 \%$ & 5 & $15.1 \%$ \\
\hline
\end{tabular}

It is obvious from these frequencies that the dilemmas discussed by doctors predominantly centred around issues to do with the patient's interests and allied to this autonomy issues and rights of the patient's family. For managers the predominant issues were those of public interest and resource allocation. Patient and organisation interest also featured as did issues to do with competence of staff or colleagues.

\section{Influences on decision making}

At the conclusion of the interview participants were asked to rank the influence on their decision making (in the 3 dilemmas and 3 everyday situations they had just discussed) of 7 factors plus any others they wished to add. The rankings were averaged across managers and doctors to give a guide to which influences appeared to have the greatest impact. Tables 6.12 and 6.13 summarise the rankings. 
Table 6.12: Averaged rankings of influences on ethical dilemma decisions

\begin{tabular}{lll}
\hline Source of influence: & Doctors' average ranking & Managers' average ranking \\
\hline Affected patient or staff member & 1.6 & 2.8 \\
Health team & 3.2 & 4.5 \\
Self (own values, beliefs) & 3.3 & 3.5 \\
My profession & 3.4 & 5.1 \\
My role in the organisation & 5.3 & 3.2 \\
My organisation/employer & 6.3 & 4.9 \\
Management team & 6.9 & 5.8 \\
\hline
\end{tabular}

Note: 1 = most influence, 7 = least influence

Table 6.13: Averaged rankings of influences on everyday decisions

\begin{tabular}{lll}
\hline Source of influence: & Doctors' average ranking & Managers’ average ranking \\
\hline Affected patient or staff member & 2.6 & 3.0 \\
My profession & 2.8 & 5.5 \\
Health team & 3.5 & 3.9 \\
Self (own values, beliefs) & 3.4 & 4.2 \\
My role in the organisation & 4.5 & 3.1 \\
My organisation/employer & 5.9 & 4.4 \\
Management team & 6.7 & 4.1 \\
\hline
\end{tabular}

Note: 1 = most influence, 7 = least influence

Not surprisingly in these rankings the doctors are influenced by their profession, and the managers are influenced by their role in the organisation. Other influences which were cited by managers included: legal implications, media and political pressure, CHE rules and procedures, own experience and knowledge of issues. Those cited by doctors included: resource utilisation, legal climate, family of patient, and public values. Hence this question was developed further in the main study to assess a broader range of influences.

Other comments on, and observations of, the repertory grid interviews

It is worth noting that all participants enjoyed the novelty of the repertory grid interview process, and many commented afterwards that they had verbalised things they had not consciously thought about before. The doctors were, on the whole, familiar and comfortable with thinking about ethics and ethical issues, similarly the managers with 
health professional backgrounds or over 4 years service in the health sector. However, the managers with limited health sector experience grappled with the unfamiliarity of ethics as a frame of reference.

One manager who had been a doctor commented that there was very little support within the management structure to assist making decisions on ethical issues, whereas within the medical structure there was considerable support if one wished to draw from it. Several managers said that management ethics tends to be more individually derived than medical ethics which has external codes, formulations, tradition and teaching. They went on to comment that because of this doctors tend to view themselves as ethical and managers as unethical.

Both groups noted the gulf that can exist between doctors and managers, with the former focusing on the patient at any cost and the latter taking a purely financial perspective on matters. Several lamented what they perceived as the loss of common purpose for managers and doctors. They felt that managerial and medical work had changed significantly in the past decade, and that there was more pressure from the media, public and government than previously.

\section{Discussion}

Several key trends emerge from this exploratory research in the areas of role perception, constructs underpinning ethicalness, ethical dilemmas and the influences on decision making. These are briefly discussed in terms of how they impacted on the next phase of the research.

\section{$\underline{\text { Role perception }}$}

Similar to the pilot study there were subtle but potentially important differences in the role perception by doctors and managers which may lead to a mismatch of their mutual expectations. In particular the doctors viewed their own role and that of managers as essentially to contribute to the patient's care, and the managers viewed the roles to essentially be cost effective/sparing of resources. This difference may explain some of the reported feeling of loss of common purpose, at least at a superficial level - as doctors consider managers focused on financial priorities, and managers consider 
doctors focused on patients without heed to resource implications. It was also clear from the interviews that a number of participants saw a difference between the roles as they are, and the roles as they thought they should be. This distinction proved to be a useful one to carry into the survey questionnaire to ensure clarity of response.

\section{$\underline{\text { Constructs underpinning ethicalness }}$}

The interviews confirmed that there are a number of constructs which managers and doctors use to judge ethicalness. These constructs range across matters of personal character, motivation, behavioural style and approach to decisions. This is not surprising given the stimulus question which asked participants about the ethicalness of others "that is, their behaviour or decisions at work and what appears to guide it".

The interviews showed that doctors and managers agree on the constructs that contribute to being ethical, but they prioritise them differently as shown in Table 6.6. It is possible that this prioritisation is a reflection of the nature of their perceived role and what is important to it: for doctors the role focus is the patient and the immediate delivery of health care; for the manager the focus is the organisation and its ability to deliver health care. Thus, for example, although global financial concern is considered a feature of ethical doctors it is considered to be a more striking feature of managers, likewise ethical managers have a focus on the patient's best interests but it is considered of even greater salience to ethical doctors (refer Table 6.7). The interview study confirmed most of the constructs from the pilot study and yielded additional constructs in relation to ethicalness. The next phase of the research clarified further how managers and doctors used these constructs - some proving more important/salient than others.

Similar to the pilot study the unethical were characterised by the possession of overriding self-interest and thus the absence/lack of ethical attributes, (e.g., not focused on patients best interests, not principled, not honest, etc). But more importantly in these interviews further constructs underpinning unethicalness emerged such as greed for money or status or power, opportunistic, manipulative (refer Table 6.8). This means that unethicalness is not simply a lack of ethical attributes but also the possession of certain unethical attributes. The next phase of the research may be able to confirm and further explore how these unethical attributes feature in respondents' views of ethical and unethical colleagues. 
In the pilot study the researcher speculated on the possibility that like and dislike of colleagues may underly one's classification of them as ethical or unethical. The interview study did not reveal any constructs that related to liking/disliking and the researcher concluded that this area is not one of immediate concern.

\section{Ethical dilemmas and influences on decision making}

The second repertory grid interview yielded numerous constructs which inform judgement in serious ethical dilemmas. However, although there were some common themes amongst the constructs, there was also much that varied from dilemma to dilemma which made the interview a difficult one for participants. Where common themes were evident they did reveal a subtle difference in the orientations of doctor and manager. This is apparent in Table 6.9 listing the most important contributing constructs to a serious ethical dilemma. In this example doctors most popularly chose: uncertainty of outcome and conflicting rights, whereas managers chose: level of risk, lack of clarity of process or guidelines for discussion. Both also noted conflicts with personal ethical standards. The slightly different responses may be due to semantic/jargon differences between doctors and managers, i.e., doctors frequently describe health issues in terms of expected outcome or prognosis, and managers frequently characterise management decisions in terms of risk and management of risk. They may in fact be describing similar phenomena which are considered in different contexts. The next phase of the research used standard language, when possible, to try to explore how doctors and managers classified the same dilemmas.

The results of the interview study showed that doctors and managers face different types of ethical dilemmas (refer Table 6.9). Once again this is possibly a reflection of their different roles and of different training and ethical codes. Doctors are more often concerned with the individual patient and managers with the interests of the organisation and the public as a whole. Thus one could argue that their level of focus is different - doctors focusing one to one (doctor-to-patient), and managers focusing one to many (manager-to-organisation/public). The frequency of the different types of dilemma fit this characterisation and they were consistent with the findings of McNeill et al. (1994) in Australian hospitals, although that research did not differentiate the concerns of doctors from those of managers/administrators. 
This difference in orientation is also reflected in the reported main influences on decision making (both looking to the affected patient or staff member but then the manager looking to his/her role in the organisation, and the doctor looking to the health team or their own values). Hence both occupations appear to focus on what they believe they are there to do. It is interesting to compare this with the findings of Canadian researchers Lemieux-Charles et al. (1993), who asked clinician managers (i.e., doctors and nurses with management responsibilities) to rate the importance of 18 different influences on ethical issues associated with resource allocation. They found own beliefs/values, clinical experience and law/legal standards as the most important influences. These latter two influences were not offered as options in the interview study, however they were both volunteered as influences by some of the participants. Thus in the next phase of the research a revised and expanded list of influences was used to ascertain whether doctors and managers were influenced by similar or different factors.

In summary then, the interviews yielded for further testing a range of constructs, classifications of ethical dilemmas, and sources of influence, and some questions for exploration. What is an ethical doctor or manager? What factors influence ethical decisions? Do doctors and managers similarly prioritise considerations in ethical dilemmas? What are the most common ethical dilemmas doctors and managers face? These are the questions for which the interviews have provided a base of information which was used in the design of the main study. 


\section{Questionnaire Design}

Variables for inclusion in the survey questionnaire were selected on the basis of the results of the interview study, a review of the applied ethics literature, and feedback from a pre-test and academic research colleagues.

Five empirical research questions underpin the questionnaire design:

(i) What is the role of doctor and manager in a CHE, and what do they think it should be?

(ii) What do doctors and managers think makes an ethical doctor and an ethical manager - are they different or similar?

(iii) Do doctors and managers see an ethical problem in the same way or differently ?

(iv) What do doctors and managers see as the ethical frame of their activity ?

(v) What are the common influences on ethical issue decisions - are they the same or different for doctors and managers?

To address these questions the questionnaire was divided into four sections:

Section A - the role of doctors and managers in Crown Health Enterprises (research question i);

Section B - ethical and unethical doctors and managers (research question ii);

Section C - ethical dilemmas (research questions iii, iv and v); and

Section D - background (demographic) information.

\section{Pre-testing of Questionnaire}

The questionnaire was pre-tested on a convenience sample of two managers and two doctors. They were sent the questionnaire in the mail and asked to complete it; the researcher then met with each respondent to discuss what they thought of the questionnaire, (i.e., length, clarity, relevance, etc). Some minor alterations were made as a result of the pre-test. A copy of the final questionnaire is contained in Appendix F. 


\section{Selection of Survey Participants}

The key criteria used to select CHEs to participate in the survey was the geographical and population base spread of each CHE. The researcher wanted to ensure a good blend of metropolitan, provincial centres, and rural services in the survey; together with coverage of the range of medical specialties associated with different population bases, (e.g., large metropolitan areas tend to have hospitals that deal with 'high tech' tertiary level medical interventions and care).

For the purpose of the survey managers were defined as those who were Chief Executives, second tier or third tier managers in CHEs - hence in hospitals this equated to the General Manager (second tier) and their direct reports (third tier). Doctors were defined as those who were working at Registrar level or above in a CHE. The researcher approached six CHE Chief Executives, and five General Managers of large hospitals within a particular CHE, for agreement to distribute the survey to all their managers and doctors. Three CHE Chief Executives and four General Managers accepted. The final sample covered all managers and doctors (as defined above) in all the hospitals and allied services of two CHEs, and all the hospitals and allied services (except for one hospital) of a third large CHE. The researcher also obtained the approval of six ethics committees in order for the survey to proceed.

\section{Questionnaire Administration}

The researcher had specified contact people within each CHE who were to assist in the distribution of the questionnaire. The questionnaires were in envelopes addressed by name to the doctors and managers - some were name labelled by the CHE, or with labels provided by the CHE (practice varied from hospital to hospital, CHE to CHE). The survey questionnaires were couriered to the contact people who then distributed them via the internal mail system of the CHE. The survey questionnaire was sent with a requested return date of six weeks hence. Reminder copies of the questionnaire were sent to all doctors and managers three weeks later. For the purposes of anonymity, specified by the ethics committees, the questionnaires were not coded or identified in any way thus reminders had to be sent to all. A summary of the results of the survey was offered and 151 (53\%) of the respondents requested the summary and supplied address details for its receipt. 


\section{Participants}

The questionnaires were sent to 799 managers and doctors employed in the three Crown Health Enterprises participating in the research. Of these 126 were managers (of third tier management level and above), and 673 were doctors (of Registrar level or above).

In total 284 people responded giving a response rate of $35.5 \%$ (32.5\% of the doctors and $50 \%$ of the managers). There were 260 useable responses of which 197 were from doctors and 63 from managers. The 24 responses that were not useable were all from doctors, and all said that they were too busy to fill in a questionnaire. Appendix G contains a full breakdown of the profile of respondents, their gender, role, education and training and future employment.

A breakdown of the managerial respondents shows that $57 \%$ of them were ex-health professionals (i.e., ex-nurses, physiotherapists, doctors, etc), and the other $43 \%$ had non-health professional backgrounds. Most of the ex-health professionals worked in direct health service delivery areas like medical/surgical or clinical support services, mental health/disability services. A number of the non-health professional background managers worked in those areas too, and $18 \%$ of them worked in finance/human resources or communication roles (compared with $1.5 \%$ of the ex-health professionals in those roles). Seventy-two percent of the ex-health professionals were female, while $37 \%$ of the non-health professionals were female, hence in the overall manager group 57\% were female. Preliminary testing of differences between the two groups of managers (ex-health professional, and non-health professional) was completed to determine whether they should be analysed as separate groups or as a single manager group. The differences were relatively few therefore the researcher decided to pool managers as a single category.

In terms of general representativeness of the two sample groups the survey covers approximately $20 \%$ of the total doctor (i.e., hospital doctors not general practitioners) and manager population (based on 1994 figures obtained from the Ministry of Health and the Medical Council of New Zealand). The doctors who responded are representative of the overall doctor population in terms of area of specialty as illustrated by Table G5 in Appendix G which compares percentage of respondents in each 
specialty with percentage of doctors in New Zealand of that specialty (as recorded in the 1995 New Zealand Register of Specialists). It is much harder to assess the representativeness of the manager sample as there is very little information available which profiles the total manager population. However, those managers who responded came from the full range of management work areas (as illustrated in Table G6 of Appendix G) and thus there is some ground for assuming that the sample is representative.

\section{Results}

The purpose of the survey questionnaire was to address the five research questions in order to shed light on our understanding of medical ethics and managerial ethics in health organisations. Hence the data analysis needed to draw comparisons between the manager responses and the doctor responses with sufficient confidence for the results to be used for possible future research by others. Thus comparisons of means and a range of tests of significance were performed for several of the questions, while others were analysed via analysis of variance techniques.

\section{$\underline{\text { Section A: The role of managers and doctors in Crown Health Enterprises }}$}

What is the role of doctor and manager in a CHE, and what do they think it should be?

Survey participants were provided with a list of statements descriptive of possible perceptions of the role of a manager and the role of a doctor in a CHE. These were generated by the interview study, as was the differentiation between 'the role is' and 'the role should be', in order to avoid conflation of the two by respondents.

Participants were asked to choose the "three statements you believe best describe what the role is, and which three statements best describe what the role should be”.

The null hypothesis, that there would be no difference in role perceptions between doctors and managers, was evaluated using the chi square test statistic.

Question 1 focused respondents on the manager's role. This revealed that managers and doctors have significantly different perceptions of what the manager's role is - Table 7.1 shows that this applied to 7 of the 11 role statements. The only statement on which 
there was substantive agreement was 'facilitator to allow organisation to function'. The managers believed the manager's role is also - 'responsible for ensuring ongoing viability of the service/organisation', 'management expert to ensure best patient outcome within available resources', and 'facilitator to allow health professionals to work'. Doctors did not concur with this view of the role. Although 50\% of them saw it as 'responsible for ensuring ongoing viability of the service/organisation', this was still significantly less than the $73 \%$ of managers with this view; in addition the doctors saw the role as 'allocator of resources/gatekeeper', 'member of management team', 'employee of the CHE' and 'guardian of public money'.

Interestingly when we look at what respondents believe the role should be there are no significant differences in managers' and doctors' views. The consensus of opinion features most prominently a management role which is: 'facilitator to allow health professionals to work', 'management expert to ensure best patient outcome within available resources', 'facilitator to allow organisation to function' and 'responsible for ensuring ongoing viability of the service/organisation'.

The McNemar change test was used to evaluate the significance of changes in doctors' and managers' views between 'what the role is' and 'what the role should be'. Siegel and Castellan (1988) note that it is an appropriate test for data such as these, where each subject is used as its own control and measurements are on a nominal scale. The McNemar test uses a chi square statistic, however, where the sample size is small $(<35)$ a binomial test is invoked.

Table 7.2 reports the change in managers' and doctors' views. The doctors' views changed significantly on 8 out of the 11 role statements indicating that their perception of what the manager's role should be is significantly different to what they believe the manager's role is. On the other hand, the managers' views changed significantly on 5 out of the 11 statements.

Table 7.1: Doctors' and managers' views of what the role of a manager in a CHE is, and what it should be

\begin{tabular}{l|l}
\hline & $\%$ \\
\hline
\end{tabular}




\begin{tabular}{|c|c|c|c|c|c|c|}
\hline The manager's role: & $\begin{array}{l}\% \\
\text { doctors } \\
\text { think the } \\
\text { role is: }\end{array}$ & $\begin{array}{l}\% \\
\text { managers } \\
\text { think the } \\
\text { role is: }\end{array}$ & $\chi^{2}$ & $\begin{array}{l}\text { doctors } \\
\text { think the } \\
\text { role } \\
\text { should } \\
\text { be: }\end{array}$ & $\begin{array}{l}\text { managers } \\
\text { think the } \\
\text { role } \\
\text { should } \\
\text { be: }\end{array}$ & $\chi^{2}$ \\
\hline $\begin{array}{l}\text { a) facilitator to allow health } \\
\text { professionals to work }\end{array}$ & $12 \%$ & $48 \%$ & $35.6^{* * *}$ & $76 \%$ & $76 \%$ & ns \\
\hline $\begin{array}{l}\text { b) facilitator to allow } \\
\text { organisation to function }\end{array}$ & $44 \%$ & $56 \%$ & ns & $64 \%$ & $52 \%$ & ns \\
\hline $\begin{array}{l}\text { c) guardian of public } \\
\text { money }\end{array}$ & $25 \%$ & $13 \%$ & $4.0^{*}$ & $4 \%$ & $3 \%$ & ns \\
\hline $\begin{array}{l}\text { d) responsible for ensuring } \\
\text { ongoing viability of the } \\
\text { service/organisation }\end{array}$ & $50 \%$ & $73 \%$ & $10.2^{* *}$ & $59 \%$ & $58 \%$ & ns \\
\hline $\begin{array}{l}\text { e) management expert to } \\
\text { ensure best patient } \\
\text { outcome within available } \\
\text { resources }\end{array}$ & $18 \%$ & $53 \%$ & $27.6^{* * *}$ & $63 \%$ & $74 \%$ & ns \\
\hline f) independent professional & $4 \%$ & $2 \%$ & ns & $1 \%$ & $3 \%$ & ns \\
\hline $\begin{array}{l}\text { g) member of management } \\
\text { team }\end{array}$ & $48 \%$ & $18 \%$ & $18.9 * * *$ & $19 \%$ & $19 \%$ & ns \\
\hline $\begin{array}{l}\text { h) responsible for patient } \\
\text { care }\end{array}$ & $0 \%$ & $2 \%$ & ns & $4 \%$ & $6 \%$ & ns \\
\hline i) employee of the CHE & $45 \%$ & $11 \%$ & $24.6^{* * *}$ & $3 \%$ & $2 \%$ & ns \\
\hline $\begin{array}{l}\text { j) allocator of resources/ } \\
\text { gatekeeper }\end{array}$ & $48 \%$ & $21 \%$ & $15.1 * * *$ & $6 \%$ & $2 \%$ & ns \\
\hline k) other & $4 \%$ & $3 \%$ & ns & $0 \%$ & $3 \%$ & $6.2 *$ \\
\hline
\end{tabular}

Note: All chi-square tests were based on actual frequencies with $\mathrm{df}=1$. Each research participant could choose up to three roles.

${ }^{*} \mathrm{p}<.05, * * \mathrm{p}<.01, * * * \mathrm{p}<.001, \mathrm{~ns}=$ not significant. 
Table 7.2: Difference (\% should be - \% is) in doctors' and managers' views of the role of the manager in the $\mathrm{CHE}$

\begin{tabular}{|c|c|c|c|c|}
\hline The manager's role: & $\begin{array}{l}\text { Difference in } \\
\text { doctors' } \\
\text { views }\end{array}$ & $\begin{array}{l}\chi^{2} \\
\text { or binomial } \\
\text { test (a) }\end{array}$ & $\begin{array}{l}\text { Difference in } \\
\text { managers' } \\
\text { views }\end{array}$ & $\begin{array}{l}\chi^{2} \\
\text { or binomial } \\
\text { test (a) }\end{array}$ \\
\hline $\begin{array}{l}\text { a) facilitator to allow health } \\
\text { professionals to work }\end{array}$ & $+64 \%$ & $119.1^{* * *}$ & $+26 \%$ & $\mathrm{p}=.000 * * *$ \\
\hline $\begin{array}{l}\text { b) facilitator to allow } \\
\text { organisation to function }\end{array}$ & $+20 \%$ & $11.7 * * *$ & $-4 \%$ & ns \\
\hline c) guardian of public money & $-21 \%$ & $28.3^{* * *}$ & $-10 \%$ & ns \\
\hline $\begin{array}{l}\text { d) responsible for ensuring } \\
\text { ongoing viability of the } \\
\text { service/organisation }\end{array}$ & $+9 \%$ & ns & $-15 \%$ & $\mathrm{p}=.041 *$ \\
\hline $\begin{array}{l}\text { e) management expert to } \\
\text { ensure best patient outcome } \\
\text { within available resources }\end{array}$ & $+45 \%$ & $74.2^{* * *}$ & $+21 \%$ & $\mathrm{p}=.006^{* *}$ \\
\hline f) independent professional & $-4 \%$ & ns & $-1 \%$ & ns \\
\hline $\begin{array}{l}\text { g) member of management } \\
\text { team }\end{array}$ & $-29 \%$ & $29.3 * * *$ & $+1 \%$ & ns \\
\hline h) responsible for patient care & $+4 \%$ & $\mathrm{p}=.015^{*}$ & $+4 \%$ & ns \\
\hline i) employee of the CHE & $-42 \%$ & $73.9 * * *$ & $-9 \%$ & $\mathrm{p}=.031 *$ \\
\hline $\begin{array}{l}\text { j) allocator of resources/ } \\
\text { gatekeeper }\end{array}$ & $-42 \%$ & $70.3^{* * *}$ & $-19 \%$ & $\mathrm{p}=.001^{* *}$ \\
\hline k) other & $-4 \%$ & ns & $0 \%$ & ns \\
\hline
\end{tabular}

(a) All chi-square tests were based on actual frequencies with $\mathrm{df}=1$, using the McNemar change test. Where an exact p value is given this is because the binomial test has been invoked due to small cell size. ${ }^{*} \mathrm{p}<.05,{ }^{* *} \mathrm{p}<.01,{ }^{* * *} \mathrm{p}<.001, \mathrm{n} . \mathrm{s}=$ not significant

In summary then, it is clear that doctors view the manager's current role as a gatekeeping, CHE/organisation oriented role and would prefer to have it as a facilitatory, patient focused, helping others to work, type of role. Managers view their current role as having all those responsibilities, that is, both gatekeeping and facilitating, patient focused and organisation oriented, and similar to doctors' responses they would prefer to have it as the facilitatory, patient focused, helping others to work, type of role. 
Question 2 focused on the doctor's role. In this case the views of managers and doctors only differed significantly on 4 out of 12 statements (refer Table 7.3). Two main differences are of particular interest. These are that significantly more managers believed the doctor's role is currently one of 'independent professional', whereas significantly more doctors believed that the doctor's role is one of 'employee of the CHE'. So the managers see doctors currently acting as independent professionals whereas the doctors do not perceive their role in this way and in fact currently see it as an employee of the CHE (i.e., without the duties and self regulated freedom of the professional role, but rather with the responsibilities and constraints of the organisational employee). There was general agreement on two statements 'responsible for patient care', and 'medical expert to ensure best patient outcome within available resources'. Both agreed on 'member of health team' although significantly more doctors (71\%) than managers (50\%) believed this statement.

When we look at what the doctor's role should be responses differ significantly on only 2 out of the 12 statements; 'responsible for patient care' which is more strongly believed by doctors than managers, and 'responsible for ensuring ongoing viability of the service/organisation' where (although the percentages are not large) significantly more managers subscribe to this view of what the doctor's role should be.

Overall the main features of the consensus on the doctor's role as it should be include 'member of health team', 'responsible for patient care', and 'medical expert to ensure best patient outcome within available resources'.

Once again the McNemar change test, and the binomial test, were performed to assess the change in views on the doctor's role as it is and as it should be (refer Table 7.4). The doctors changed their views significantly on 5 out of the 12 statements, most notably the belief that the role is 'employee of the CHE', 'highly skilled technician', 'allocator of resources/gatekeeper' and 'responsible for ensuring ongoing viability of the services/organisation' dropped off significantly for what the role should be. On the other hand support for 'medical expert to ensure best patient outcome within available resources' increased significantly for what the role should be. 
The managers changed their views significantly on 6 out of the 12 statements. The belief that the doctor's role is 'independent professional' and 'responsible for patient care' dropped off significantly for what the role should be. On the other hand 'member of health team', 'medical expert to ensure best patient outcome within available resources', 'facilitator to allow other health professionals to work' and 'responsible for ensuring ongoing viability of the service/organisation' all had significantly more support from managers for what the doctor's role should be.

In summary, doctors and managers have significantly different views of the current roles of managers and doctors, but similar views of what the manager's and doctor's role should be. This is illustrated by the fact that doctors differed significantly from managers on 7 statements with regard to the manager's present role, and on 4 statements with regard to the doctor's present role. Doctors differed significantly from managers on only one statement with regard to what the manager's role should be, and on only 2 statements with regard to what the doctor's role should be. In addition, the manager's and doctor's role as it should be is different from perceptions of what the manager's and doctor's role is currently. This is illustrated by the fact that doctors' views of what the manager's role is compared to what it should be differed significantly on 8 out of 11 statements, and managers' views differed significantly on 5 out of 11 statements. Also doctors' views of what the doctor's role is versus what it should be differed significantly on 5 out of 12 statements, and managers' views on 6 out of 12 statements. 
Table 7.3: Doctors' and managers' views of what the role of a doctor in a CHE is, and what the role should be

\begin{tabular}{|c|c|c|c|c|c|c|}
\hline The doctor's role: & $\begin{array}{l}\% \\
\text { doctors } \\
\text { think the } \\
\text { role is: }\end{array}$ & $\begin{array}{l}\% \\
\text { managers } \\
\text { think the } \\
\text { role is: }\end{array}$ & $\chi^{2}$ & $\begin{array}{l}\text { \% } \\
\text { doctors } \\
\text { think the } \\
\text { role } \\
\text { should } \\
\text { be: }\end{array}$ & $\begin{array}{l}\text { \% } \\
\text { managers } \\
\text { think the } \\
\text { role } \\
\text { should } \\
\text { be: }\end{array}$ & $\chi^{2}$ \\
\hline a) independent professional & $13 \%$ & $52 \%$ & $38.9^{* * *}$ & $15 \%$ & $8 \%$ & ns \\
\hline b) member of health team & $71 \%$ & $50 \%$ & $9.1 * *$ & $79 \%$ & $87 \%$ & ns \\
\hline $\begin{array}{l}\text { c) responsible for patient } \\
\text { care }\end{array}$ & $82 \%$ & $84 \%$ & ns & $86 \%$ & $63 \%$ & $19.0 * * *$ \\
\hline d) employee of the CHE & $30 \%$ & $16 \%$ & $5.4 *$ & $4 \%$ & $10 \%$ & ns \\
\hline $\begin{array}{l}\text { e) medical expert to ensure } \\
\text { best patient outcome } \\
\text { within available } \\
\text { resources }\end{array}$ & $52 \%$ & $63 \%$ & ns & $82 \%$ & $87 \%$ & ns \\
\hline f) highly skilled technician & $16 \%$ & $24 \%$ & ns & $9 \%$ & $11 \%$ & ns \\
\hline $\begin{array}{l}\text { g) allocator of } \\
\text { resources/gatekeeper }\end{array}$ & $8 \%$ & $3 \%$ & ns & $3 \%$ & $2 \%$ & ns \\
\hline $\begin{array}{l}\text { h) facilitator to allow other } \\
\text { health professionals to } \\
\text { work }\end{array}$ & $5 \%$ & $0 \%$ & ns & $7 \%$ & $11 \%$ & ns \\
\hline $\begin{array}{l}\text { i) facilitator to allow } \\
\text { organisation to function }\end{array}$ & $5 \%$ & $0 \%$ & ns & $4 \%$ & $3 \%$ & ns \\
\hline $\begin{array}{l}\text { j) guardian of public } \\
\text { money }\end{array}$ & $0 \%$ & $0 \%$ & ns & $1 \%$ & $0 \%$ & ns \\
\hline $\begin{array}{l}\text { k) responsible for ensuring } \\
\text { ongoing viability of the } \\
\text { service/organisation }\end{array}$ & $12 \%$ & $3 \%$ & $4.2 *$ & $5 \%$ & $18 \%$ & $8.2^{* *}$ \\
\hline l) other & $3 \%$ & $3 \%$ & ns & $2 \%$ & $0 \%$ & ns \\
\hline
\end{tabular}

Note: All chi-square tests were based on actual frequencies with $\mathrm{df}=1$. Each research participant could choose up to three roles.

${ }^{*} \mathrm{p}<.05,{ }^{* *} \mathrm{p}<.01,{ }^{* * *} \mathrm{p}<.001$, ns=not significant. 
Table 7.4: Difference (\% should be - \% is) in doctors' and managers' views of the role of the doctor in the $\mathrm{CHE}$

\begin{tabular}{|c|c|c|c|c|}
\hline The doctor's role: & $\begin{array}{l}\text { Difference in } \\
\text { doctors' } \\
\text { views }\end{array}$ & $\begin{array}{l}\chi^{2} \\
\text { or binomial } \\
\text { test (a) }\end{array}$ & $\begin{array}{l}\text { Difference in } \\
\text { managers' } \\
\text { views }\end{array}$ & $\begin{array}{l}\chi^{2} \\
\text { or binomial } \\
\text { test (a) }\end{array}$ \\
\hline a) independent professional & $+2 \%$ & ns & $-44 \%$ & $21.8^{* * *}$ \\
\hline b) member of health team & $+8 \%$ & ns & $+37 \%$ & $16.7 * * *$ \\
\hline c) responsible for patient care & $+4 \%$ & ns & $-21 \%$ & $\mathrm{p}=.007 * *$ \\
\hline d) employee of the CHE & $-26 \%$ & $47.4 * * *$ & $-6 \%$ & ns \\
\hline $\begin{array}{l}\text { e) medical expert to ensure best } \\
\text { patient outcome within available } \\
\text { resources }\end{array}$ & $+30 \%$ & $42.6^{* * *}$ & $+24 \%$ & $\mathrm{p}=.004 * *$ \\
\hline f) highly skilled technician & $-7 \%$ & $4.9 *$ & $-13 \%$ & ns \\
\hline $\begin{array}{l}\text { g) allocator of } \\
\text { resources/gatekeeper }\end{array}$ & $-5 \%$ & $\mathrm{p}=.041 *$ & $-1 \%$ & ns \\
\hline $\begin{array}{l}\text { h) facilitator to allow other } \\
\text { health professionals to work }\end{array}$ & $+2 \%$ & ns & $+11 \%$ & $\mathrm{p}=.015^{*}$ \\
\hline $\begin{array}{l}\text { i) facilitator to allow } \\
\text { organisation to function }\end{array}$ & $-1 \%$ & ns & $+3 \%$ & ns \\
\hline j) guardian of public money & $+1 \%$ & ns & $0 \%$ & ns \\
\hline $\begin{array}{l}\text { k) responsible for ensuring } \\
\text { ongoing viability of the } \\
\text { service/organisation }\end{array}$ & $-7 \%$ & $\mathrm{p}=.034 *$ & $+15 \%$ & $\mathrm{p}=.022 *$ \\
\hline l) other & $-1 \%$ & ns & $-3 \%$ & ns \\
\hline
\end{tabular}

(a) All chi-square tests were based on actual frequencies with $\mathrm{df}=1$, using the McNemar change test. Where an exact p value is given this is because the binomial test has been invoked due to small cell size. ${ }^{*} \mathrm{p}<.05,{ }^{* *} \mathrm{p}<.01,{ }^{* * *} \mathrm{p}<.001, \mathrm{~ns}=$ not significant. 


\section{Section B: Ethical and Unethical Doctors and Managers}

What do doctors and managers think makes an ethical doctor and an ethical manager are they different or similar?

Questions 3, 4, 5 and 6 were drawn directly from the results of the repertory grid interview process. Respondents were asked to think of "four people you know, have known or have known of, as follows:

- a doctor who acts in a highly ethical manner some or all of the time

- a doctor who acts in an unethical manner some or all of the time

- a CHE manager who acts in a highly ethical manner some or all of the time

- a CHE manager who acts in an unethical manner some or all of the time.”

They were asked to "think of what characterises each of these people when they are acting ethically or unethically” and then rate each of them on a 5 point scale against 21 bipolar constructs. The ethical pole anchored the 1 of the scale, and the unethical pole anchored the 5 of the scale.

It should be noted that there were a number of missing cases in questions 3, 4, 5 and 6 . An initial total of 58 missing cases was reduced to 47 by replacing single missing values with the subject's mean rating on that question. Unfortunately there were over 30 cases where an entire question (either 3, 4, 5, or 6) had been left out. Some respondents provided comment to explain the omission - 20 doctors noted that they did not know any managers well enough to comment, or that they did not know any unethical doctors or unethical managers. One manager noted not knowing any unethical doctors and managers. Other missing cases carried no explanatory comment.

A three-way mixed multivariate analysis of variance (MANOVA) was used to analyse the results. In this design, doctor/manager raters were a between-subjects variable, whereas ethical/unethical and doctors/managers were treated as two within-subject variables. The 21 constructs were considered jointly as the multivariate dependent variable. MANOVA has the advantage over separate univariate analyses in that it examines the dependent variables jointly in one single analysis. 
The analysis showed that the three main effects were significant, as were the 3 two-way interaction effects, but these were complicated by a significant three-way interaction effect $(\underline{F}(21,191)=2.15, \underline{p}<.01)$ as illustrated in Figure 7.1.

\section{Figure 7.1: Mean ratings of ethical doctor, unethical doctor, ethical manager,}

\section{unethical manager by doctor and manager raters}

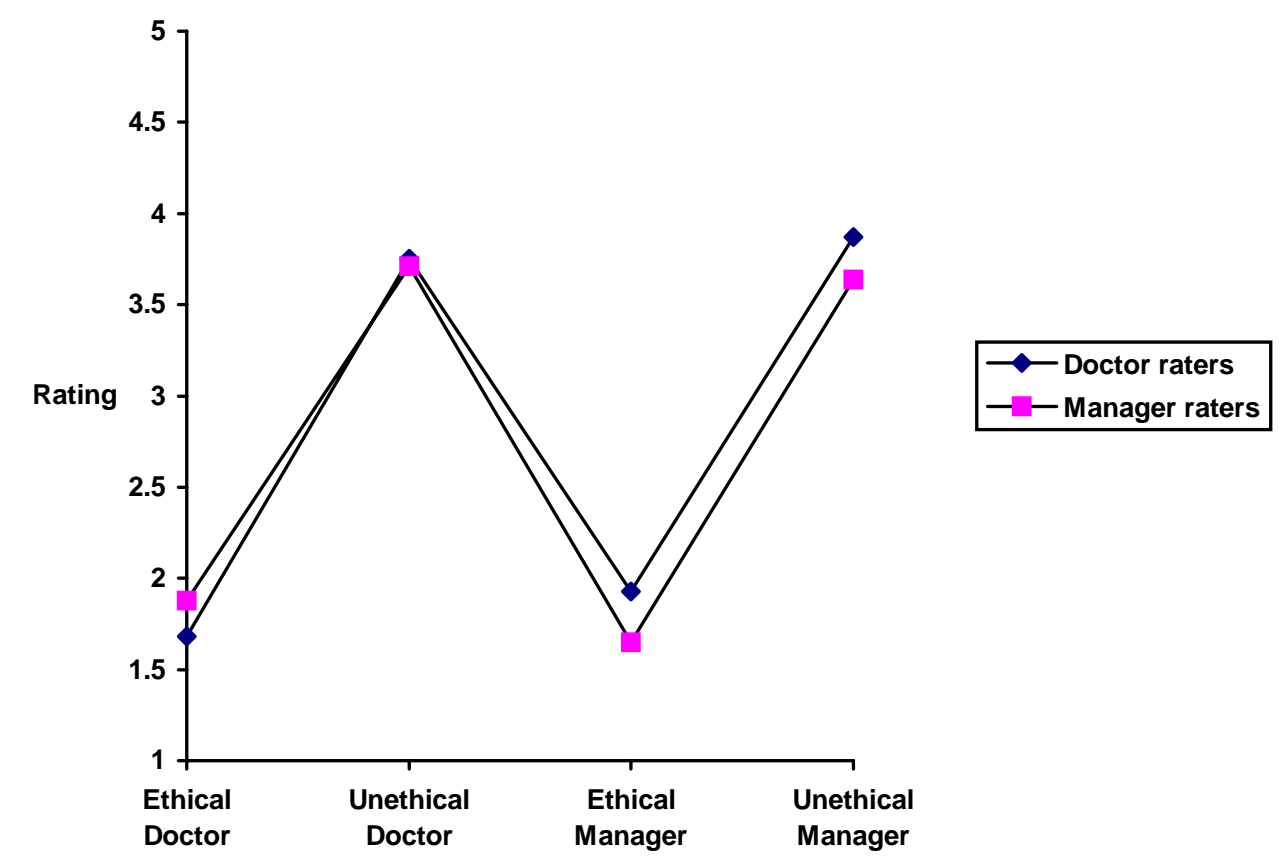

Note: 1 = ethical end of pole, 5 = unethical end of pole

The three-way interaction illustrated in Figure 7.1 shows that doctors rate ethical doctors as more strongly typified by ethical constructs than ethical managers, and managers rate ethical managers as more strongly typified by ethical constructs than ethical doctors. Additionally it shows that doctors rate unethical managers as more strongly typified by unethical constructs than unethical doctors, and managers rate unethical doctors as more strongly typified by unethical constructs than unethical managers. Thus in effect there appears to be in-group evaluative bias occurring where one rates one's own role group more positively and less negatively than the other role group.

Further examination of variables was conducted by separate univariate analyses of variance (ANOVA) treating the constructs individually with doctor/manager raters as the between-subjects variable, and ethical/unethical and doctors/managers treated as within-subject variables. Through this analysis it was hoped to discover which 
constructs contributed the most to the overall three-way interaction. The analysis revealed that the main sources contributing to the three-way interaction effect were constructs a, d, f, i, j, k and l, as reported below in Table 7.5.

\section{Table 7.5: Three-way interaction effect reported from a three-way mixed univariate ANOVA}

\begin{tabular}{ll}
\hline Constructs: & Overall three-way interaction effect \\
\hline $\begin{array}{l}\text { a) committed to, and works hard for, the public health } \\
\text { service }\end{array}$ & $\underline{\mathrm{F}}(1,222)=5.53, \underline{\mathrm{p}}<.05$ \\
d) not motivated by need for power and control & $\underline{\mathrm{F}}(1,224)=5.77, \underline{\mathrm{p}}<.05$ \\
f) focus on and concern for others & $\underline{\mathrm{F}}(1,223)=5.80, \underline{\mathrm{p}}<.05$ \\
i) not self-interested at the expense of others & $\underline{\mathrm{F}}(1,223)=14.84, \underline{\mathrm{p}}<.001$ \\
j) recognises and uses skills of others for their good and & $\underline{\mathrm{F}}(1,223)=4.84, \underline{\mathrm{p}}<.05$ \\
$\quad$ the good of the service & $\underline{\mathrm{F}}(1,221)=11.89, \underline{\mathrm{p}}<.01$ \\
k) principled, has standards which are lived up to & \\
privately and publicly & $\underline{\mathrm{F}}(1,223)=9.16, \underline{\mathrm{p}}<.01$ \\
\hline
\end{tabular}

A perusal of the cell means of the seven significant constructs shows a similar pattern of interaction as that reported in the MANOVA. Thus the complex three-way interaction was best represented by those seven bipolar constructs. This means that doctors believe ethical doctors (followed by ethical managers), and managers believe ethical managers (followed by ethical doctors), are more strongly 'committed to and work hard for the public health service', 'not motivated by need for power and control', 'focused on and concerned for others', 'not self-interested at the expense of others', 'recognise and use the skills of others for their good and the good of the service', 'principled, have standards which are lived up to privately and publicly', 'focused on patients' best interests'. Whereas doctors believe that unethical managers (followed by unethical doctors), and managers believe that unethical doctors (followed by unethical managers), are more strongly 'not committed to and do not work hard for the public health service', 'motivated by need for power and control', 'lack concern for others', 'self-interested at the expense of others', 'manipulative, use people for their own ends', 'not principled', and 'not focused on patients' best interests'. Hence this conjures up quite a clear picture particularly in the ethical/unethical dimension of the highly ethical person being principled, concerned about others and committed to the public health service; while the unethical person does not care about others or the public health service except to use 
them for personal gain, and is motivated by power and control. As has already been observed, the highly ethical description applies more strongly to one's own role group, and the unethical description more strongly to the other role group.

Question 7 asks respondents to indicate which three of the 21 constructs they have been rating would contribute the most to a person being a highly ethical doctor and to a person being a highly ethical health manager. The results (refer to Tables 7.6 and 7.7) show that responses cover the range of all 21 constructs. However chi square tests reveal some significant differences in the constructs chosen by managers and doctors, and there is a higher percentage of endorsement for certain constructs by both doctors and managers in those cases where $20 \%$ or more of both doctors and managers have chosen a construct.

Table 7.6 shows that significantly more doctors than managers consider 'honest, tells the truth' as important for the highly ethical doctor, while significantly more managers than doctors consider 'takes a long term/strategic view of issues and able to see wider implications of decisions', 'recognises and uses skills of others for their good and the good of the service', and 'complies with all rules and ethical codes "to the letter"' (although this variable only had 5\% support from managers). In addition, the most often endorsed constructs for the highly ethical doctor as chosen by both managers and doctors are: 'focused on the patients best interests' (44\% and 57\% respectively) and 'has clear set of ethical principles or reasons underpinning decisions' (41\% and 32\%). 
Table 7.6: Percentage of doctors and managers who chose each construct for defining a highly ethical doctor

\begin{tabular}{|c|c|c|c|}
\hline Construct: & $\begin{array}{l}\text { Doctors } \\
\underline{\mathbf{n}}=190\end{array}$ & $\begin{array}{l}\text { Managers } \\
\underline{\mathbf{n}}=59\end{array}$ & $\chi^{2}$ \\
\hline $\begin{array}{l}\text { a) committed to, and works hard for, the public health } \\
\text { service }\end{array}$ & $15 \%$ & $22 \%$ & ns \\
\hline b) honest, tells the truth & $38 \%$ & $15 \%$ & $10.1 * *$ \\
\hline c) not motivated by greed for more money & $7 \%$ & $7 \%$ & ns \\
\hline d) not motivated by need for power and control & $5 \%$ & $8 \%$ & ns \\
\hline e) flexible, open to others' ideas, consultative & $13 \%$ & $7 \%$ & ns \\
\hline f) focus on and concern for others & $14 \%$ & $5 \%$ & ns \\
\hline $\begin{array}{l}\text { g) takes a long term/strategic view of issues and able to see } \\
\text { wider implications of decisions }\end{array}$ & $6 \%$ & $27 \%$ & $17.9^{* * *}$ \\
\hline h) focuses on best interests of the organisation & $1 \%$ & $3 \%$ & ns \\
\hline i) not self-interested at the expense of others & $6 \%$ & $3 \%$ & ns \\
\hline $\begin{array}{l}\text { j) recognises and uses skills of others for their good and } \\
\text { the good of the service }\end{array}$ & $3 \%$ & $14 \%$ & $9.2^{* *}$ \\
\hline $\begin{array}{l}\text { k) principled, has standards which are lived up to privately } \\
\text { and publicly }\end{array}$ & $23 \%$ & $15 \%$ & ns \\
\hline l) focused on patients' best interests & $57 \%$ & $44 \%$ & ns \\
\hline $\begin{array}{l}\text { m) has clear set of ethical principles or reasons } \\
\text { underpinning decisions }\end{array}$ & $32 \%$ & $41 \%$ & ns \\
\hline n) ability to admit when wrong and manage consequences & $16 \%$ & $12 \%$ & ns \\
\hline o) makes decisions logically using all available information & $16 \%$ & $15 \%$ & ns \\
\hline p) considers "public good” of their decisions/actions & $3 \%$ & $7 \%$ & ns \\
\hline $\begin{array}{l}\text { q) displays global financial concern, ie. thinking beyond an } \\
\text { individual patient }\end{array}$ & $2 \%$ & $5 \%$ & ns \\
\hline r) consistent in what is said and done & $5 \%$ & $5 \%$ & ns \\
\hline s) complies with all rules and ethical codes "to the letter" & $0 \%$ & $5 \%$ & $5.9 *$ \\
\hline t) complies with the "spirit" of relevant ethical codes & $19 \%$ & $19 \%$ & ns \\
\hline u) technically competent in their role & $16 \%$ & $19 \%$ & ns \\
\hline
\end{tabular}

Note: All chi-square tests were based on actual frequencies (and not percentages) with $\mathrm{df}=1$. Research participants could choose up to three constructs.

${ }^{*} \mathrm{p}<.05,{ }^{* *} \mathrm{p}<.01,{ }^{* * *} \mathrm{p}<.001$, ns $=$ not significant 
Table 7.7 shows that significantly more managers than doctors consider 'takes a long term/strategic view of issues and able to see wider implications of decisions' and 'recognises and uses skills of others for their good and the good of the service' as important for highly ethical managers. The most highly endorsed constructs for highly ethical managers as chosen by both managers and doctors are: 'takes a long term/strategic view of issues and able to see wider implications of decisions' (this is supported $60 \%$ of managers and $38 \%$ of doctors - as already mentioned this is significantly more support from managers), 'committed to, and works hard for, the public health system' (33\% and 38\% respectively), 'honest, tells the truth' (20\% and $32 \%)$, 'recognises and uses skills of others for their good and the good of the service' (33\% and 20\%), and 'flexible, open to others' ideas, consultative' (26\% and 24\%).

Once again the McNemar change test was employed to ascertain any significant differences in the constructs chosen for defining the highly ethical doctor as compared to those chosen for defining the highly ethical manager. This was carried out for doctor respondents first. The results showed that the doctors' choices differed significantly on 15 out of the 21 variables. By contrast, in the second analysis for manager respondents, the managers' choices differed on only 6 out of the 21 variables (refer to Table 7.8). Thus the doctors differentiated a highly ethical manager from a highly ethical doctor on more constructs than managers did.

In summary, a highly ethical doctor and a highly ethical manager are not similar in all respects. They differ primarily in the ethical doctor being 'focused on the patients' best interests' and making decisions in a 'principled' way, while the ethical manager is 'taking a long term/strategic view of issues and is able to see the wider implications of decisions'.

Doctors and managers themselves are different in what they regard as most important for highly ethical doctors and managers. Doctors place significantly greater emphasis on 'honesty' and truth-telling. Managers place significantly greater emphasis on 'taking a long term/strategic view of issues', and the 'recognition and use of others' skills'. In addition, more than twenty percent of doctors endorse 'focus on patients' best interests', 'honesty', 'principled decisions', and ‘principled living' for highly ethical doctors; but 
for highly ethical managers they endorse 'commitment to the public health service', 'a long term/strategic view', 'honesty', and 'openness to others' ideas'. On the other hand, managers endorse, for highly ethical doctors, 'focus on patients' best interests', 'principled decisions', 'a long term/strategic view', and 'commitment to the public health service'; but for highly ethical managers they endorse 'a long term strategic view', 'commitment to the public health service', 'recognition and use of others' skills', and 'openness to others' ideas'. 
Table 7.7: Percentage of doctors and managers who chose each construct for defining a highly ethical manager

\begin{tabular}{|c|c|c|c|}
\hline & Doctors & Managers & \\
\hline Construct: & $\underline{\mathbf{n}}=185$ & $\underline{n}=60$ & $\chi^{2}$ \\
\hline $\begin{array}{l}\text { a) committed to, and works hard for, the public health } \\
\text { service }\end{array}$ & $38 \%$ & $33 \%$ & ns \\
\hline b) honest, tells the truth & $32 \%$ & $20 \%$ & ns \\
\hline c) not motivated by greed for more money & $2 \%$ & $0 \%$ & ns \\
\hline d) not motivated by need for power and control & $11 \%$ & $8 \%$ & ns \\
\hline e) flexible, open to others' ideas, consultative & $24 \%$ & $26 \%$ & ns \\
\hline f) focus on and concern for others & $3 \%$ & $3 \%$ & ns \\
\hline $\begin{array}{l}\text { g) takes a long term/strategic view of issues and able to see } \\
\text { wider implications of decisions }\end{array}$ & $38 \%$ & $60 \%$ & $5.6^{*}$ \\
\hline h) focuses on best interests of the organisation & $10 \%$ & $8 \%$ & ns \\
\hline i) not self-interested at the expense of others & $2 \%$ & $0 \%$ & ns \\
\hline $\begin{array}{l}\text { j) recognises and uses skills of others for their good and } \\
\text { the good of the service }\end{array}$ & $20 \%$ & $33 \%$ & $5.3^{*}$ \\
\hline $\begin{array}{l}\text { k) principled, has standards which are lived up to privately } \\
\text { and publicly }\end{array}$ & $15 \%$ & $7 \%$ & ns \\
\hline l) focused on patients' best interests & $20 \%$ & $12 \%$ & ns \\
\hline $\begin{array}{l}\text { m) has clear set of ethical principles or reasons } \\
\text { underpinning decisions }\end{array}$ & $18 \%$ & $27 \%$ & ns \\
\hline n) ability to admit when wrong and manage consequences & $6 \%$ & $7 \%$ & ns \\
\hline o) makes decisions logically using all available information & $16 \%$ & $13 \%$ & ns \\
\hline p) considers “public good” of their decisions/actions & $10 \%$ & $5 \%$ & ns \\
\hline $\begin{array}{l}\text { q) displays global financial concern, ie. thinking beyond an } \\
\text { individual patient }\end{array}$ & $9 \%$ & $8 \%$ & ns \\
\hline r) consistent in what is said and done & $9 \%$ & $10 \%$ & ns \\
\hline s) complies with all rules and ethical codes "to the letter" & $1 \%$ & $2 \%$ & ns \\
\hline t) complies with the "spirit" of relevant ethical codes & $6 \%$ & $7 \%$ & ns \\
\hline u) technically competent in their role & $8 \%$ & $7 \%$ & ns \\
\hline
\end{tabular}

Note: All chi-square tests were based on actual frequencies (and not percentages) with $\mathrm{df}=1$. Research participants could choose up to three constructs.

${ }^{*} \mathrm{p}<.05, * * \mathrm{p}<.01,{ }^{* * *} \mathrm{p}<.001$, ns=not significant. 
Table 7.8: Test of significance of difference in choice of constructs for highly ethical doctor and highly ethical manager, by doctors and managers

\begin{tabular}{|c|c|c|}
\hline Construct: & $\begin{array}{l}\text { Doctors' } \\
\text { choices: } \\
\chi^{2} \text { or binomial (a) }\end{array}$ & $\begin{array}{l}\text { Managers' } \\
\text { choices: } \\
\chi^{2} \text { or binomial (a) }\end{array}$ \\
\hline $\begin{array}{l}\text { a) committed to, and works hard for, the public health } \\
\text { service }\end{array}$ & $27.1^{* * *}$ & ns \\
\hline b) honest, tells the truth & ns & ns \\
\hline c) not motivated by greed for more money & $\mathrm{p}=.03^{*}$ & ns \\
\hline d) not motivated by need for power and control & ns & ns \\
\hline e) flexible, open to others' ideas, consultative & $8.2^{* *}$ & $\mathrm{p}=.001^{* * *}$ \\
\hline f) focus on and concern for others & $\mathrm{p}=.0000^{* * *}$ & ns \\
\hline $\begin{array}{l}\text { g) takes a long term/strategic view of issues and able to see } \\
\text { wider implications of decisions }\end{array}$ & $55.1^{* * *}$ & $\mathrm{p}=.0003^{* * *}$ \\
\hline h) focuses on best interests of the organisation & $\mathrm{p}=.003^{* *}$ & ns \\
\hline i) not self-interested at the expense of others & ns & ns \\
\hline $\begin{array}{l}\text { j) recognises and uses skills of others for their good and } \\
\text { the good of the service }\end{array}$ & $21.0^{* * *}$ & $\mathrm{p}=.001^{* * *}$ \\
\hline $\begin{array}{l}\text { k) principled, has standards which are lived up to privately } \\
\text { and publicly }\end{array}$ & $4.9 *$ & ns \\
\hline l) focused on patients' best interests & $61.0^{* * *}$ & $\mathrm{p}=.0001^{* * *}$ \\
\hline $\begin{array}{l}\text { m) has clear set of ethical principles or reasons } \\
\text { underpinning decisions }\end{array}$ & $13.8^{* * *}$ & ns \\
\hline n) ability to admit when wrong and manage consequences & $8.6^{* *}$ & ns \\
\hline o) makes decisions logically using all available information & ns & ns \\
\hline p) considers "public good" of their decisions/actions & $\mathrm{p}=.002 * *$ & ns \\
\hline $\begin{array}{l}\text { q) displays global financial concern, ie. thinking beyond an } \\
\text { individual patient }\end{array}$ & $\mathrm{p}=.002 * *$ & ns \\
\hline r) consistent in what is said and done & ns & ns \\
\hline s) complies with all rules and ethical codes "to the letter" & ns & ns \\
\hline t) complies with the "spirit" of relevant ethical codes & $\mathrm{p}=.000 * * *$ & $\mathrm{p}=.04 *$ \\
\hline u) technically competent in their role & $6.9 * *$ & $\mathrm{p}=.008^{* *}$ \\
\hline
\end{tabular}

(a) All chi square tests were based on actual frequencies (and not percentages) with $\mathrm{df}=1$, using the McNemar change test, and the binomial test. Where exact $\mathrm{p}$ values are given this because the binomial test has been invoked due to small cell size.

${ }^{*} \mathrm{p}<.05,{ }^{* *} \mathrm{p}<.01,{ }^{* * *} \mathrm{p}<.001, \mathrm{~ns}=$ not significant. 


\section{$\underline{\text { Section C: Ethical Dilemmas }}$}

Do doctors and managers see an ethical problem in the same way or differently?

In this section Question 8 poses two ethical dilemmas drawn from examples given by interview subjects. The first is a managerially oriented dilemma, the second a medically oriented dilemma, but both dilemmas are sufficiently broad to ensure that manager and doctor role groups would have an opinion on them. Respondents were asked from the perspective of their role, as a manager or doctor, to rank the top three of five possible considerations they believe apply in each dilemma. Once again the consideration options were drawn directly from the interview data. In coding the responses for analysis the top ranked consideration was scored 3, the second ranked 2, the bottom ranked 1 , and the two considerations which did not receive a rank were coded with 0 .

A two-way mixed analysis of variance was performed on the responses to each dilemma. In this design, doctor/manager raters were a between-subjects variable, whereas the five considerations were treated as the within-subject variable. The results are graphed in Figure 7.2. In Dilemma One (a managerially oriented dilemma on capital priorities), one of the two main effects was significant - the considerations main effect, $\underline{F}(4,1012)=260.41, \underline{\underline{p}}<.001$. The doctor/manager raters main effect was not significant. There was also a significant interaction effect of considerations and doctor/manager raters, $\underline{F}(4,1012)=17.95, \underline{p}<.001$. As shown in Figure 7.2, doctor and manager raters differ mainly on 'interests of the organisation', 'autonomy of the patient', and 'patient interests'. Post hoc tests examining the means show that managers ranked interests of the organisation significantly more highly than doctors did $(\underline{\mathrm{t}}=-6.61, \mathrm{df}=87.43, \mathrm{p}<.001$, two-tailed), and doctors ranked autonomy of the patient significantly more highly than managers did ( $\underline{\mathrm{t}}=4.69, \mathrm{df}=152.27, \mathrm{p}^{<.001}$, two-tailed). However doctors and managers agree that the two most important considerations are patient interests, and public interest. Both ranked patient interests highly but doctors ranked it more highly than managers ( $\mathrm{t}=2.16, \mathrm{df}=254, \underline{\mathrm{p}}<.05$, two-tailed). It should be noted that in the post hoc tests, when Levene's Test for Equality of Variances is found to be significant, a corrected t test has been applied and reported. As a result the corrected t tests have varying degrees of freedom. 
Figure 7.2: Mean rankings of considerations important to resolving ethical dilemmas by doctors and managers

\section{Dilemma One: Choosing Capital Priorities}

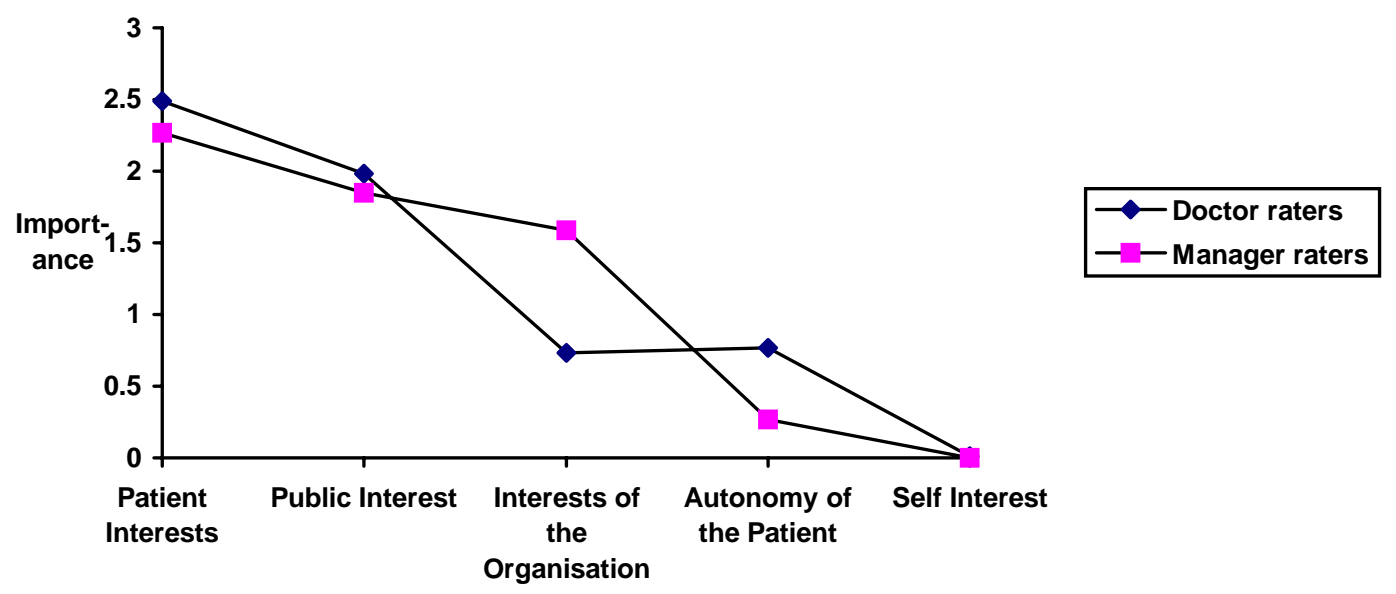

Note: 3 = most important, 2 = second most important, 1 = third most important,

$0=$ no ranking

\section{Dilemma Two: End of Life Decision}

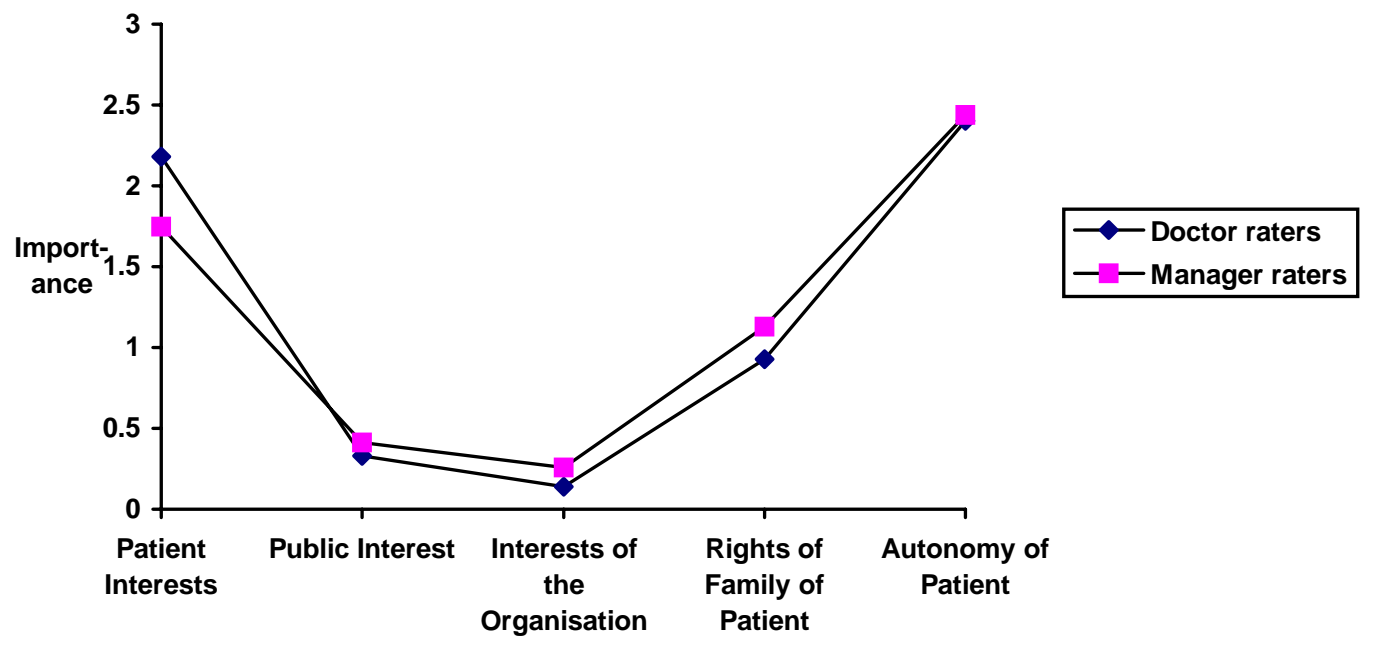

Note: 3 = most important, 2 = second most important, $1=$ third most important

$0=$ no ranking.

In Dilemma Two (a medically oriented dilemma about an end of life decision), similar to the first dilemma, one of the two main effects one was significant - the considerations main effect, $\underline{F}(4,1008)=260.51, \underline{p}<.001$. The doctor/manager rater main effect was not significant. There was also a significant interaction effect, $\underline{F}(4,1008)=4.25, \underline{p}<.01$. In the 
second dilemma it is clear that the main difference lies between some considerations not between the raters. Post hoc testing of means confirms that the doctors and managers ranked similarly, with only one significant difference which was on patient interests. As in dilemma one both doctors and managers ranked patient interests highly but doctors ranked it significantly higher than did managers ( $\underline{\mathrm{t}}=3.00, \mathrm{df}=88.13, \underline{\mathrm{p}}<.01$, two-tailed). Manager and doctor raters are in agreement that the most important considerations in this dilemma are autonomy of the patient, patient interests, with rights of the family of the patient a much lower third priority; and that the least important are public interest and interests of the organisation. This is consistent with the medical focus of the dilemma and shows that managers were using similar criteria to doctors.

Thus one can observe that on each dilemma the doctors and managers ranked the considerations not too dissimilarly, with patient interests ranked highly in both situations. In the managerially oriented dilemma (dilemma one) the public interest and interests of the organisation received more prominence alongside patient interests; in contrast on the medically oriented dilemma (dilemma two) autonomy of the patient and patient interests were more prominent.

Question 9 asked respondents “approximately how often do you encounter ethical dilemmas in your work?”. Respondents could give one of nine responses (from hourly, which was coded as 9 , through to never, which was coded as 1 ). $\mathrm{T}$ tests were performed to discern any significant differences in the frequency reported by doctors compared with that reported by managers. There was no significant difference in the frequency with which doctors and managers encountered ethical dilemmas in their work (doctors mean=7.08, standard deviation=1.38; managers mean=6.67, standard deviation=1.64). Hence we conclude that doctors and managers report a similar frequency of ethical dilemmas in their work. However, this does not tell us anything about the nature of those ethical dilemmas and that is the focus of the next question.

What do doctors and managers see as the ethical frame of their activity?

Question 10 asked respondents to nominate from a list of 11 phrases describing typical considerations in ethical dilemmas the four which most often applied to the ethical dilemmas they faced in their work. The 11 typical consideration phrases were drawn from the interview study as classified by the 2 independent raters (refer to Chapter 6). 
Table 7.9 shows which considerations were cited by doctors and managers. Chi-square tests of significance illuminate the considerations cited significantly differently by the two groups. Doctors, not surprisingly, cite patient interests, the rights of the family of a patient, and the autonomy of the patient significantly more often than managers. Whereas managers cite competence of staff and colleagues, individual fairness (generally related to treatment of employees), and the interests of the organisation/institution significantly more often than doctors. Equally frequently cited by managers and doctors are considerations of resource allocation.

Table 7.9: The considerations which most often apply to the ethical dilemmas faced by doctors and managers

\begin{tabular}{|c|c|c|c|}
\hline Consideration & Doctors & Managers & $\chi^{2}$ \\
\hline a) competence of staff or colleagues & $26 \%$ & $65 \%$ & $29.1^{* * *}$ \\
\hline $\begin{array}{l}\text { b) resource allocation (ie. financial resources } \\
\text { or staffing resources) }\end{array}$ & $68 \%$ & $72 \%$ & ns \\
\hline c) the public interest & $26 \%$ & $28 \%$ & ns \\
\hline d) patient interests & $84 \%$ & $42 \%$ & $43.2 * * *$ \\
\hline e) the interests of the organisation/institution & $17 \%$ & $45 \%$ & $19.3^{* * *}$ \\
\hline $\begin{array}{l}\text { f) individual fairness (generally related to } \\
\text { treatment of employees) }\end{array}$ & $13 \%$ & $45 \%$ & $27.1 * * *$ \\
\hline g) the rights of the family of a patient & $40 \%$ & $15 \%$ & $13.2^{* * *}$ \\
\hline h) the autonomy of the patient & $57 \%$ & $25 \%$ & $18.8^{* * *}$ \\
\hline $\begin{array}{l}\text { i) being a member of a profession and the } \\
\text { profession's interests }\end{array}$ & $13 \%$ & $15 \%$ & ns \\
\hline j) confidentiality of information & $36 \%$ & $37 \%$ & ns \\
\hline k) self-interest/your own interests & $6 \%$ & $3 \%$ & ns \\
\hline
\end{tabular}

What are the common influences on ethical issue decisions - are they the same or different for doctors and managers?

In question 11 respondents were asked about the level of support they received within the CHE for reflecting on the ethics of particularly difficult decisions. They were asked to rate the support they received from three sources: colleagues, manager, and the CHE overall. A two-way mixed analysis of variance was performed on doctors' and managers' responses. In this design doctor and manager raters were the between- 
subjects variable, and the source of support (colleague, manager, CHE) was the withinsubject variable. The two main effects were significant, i.e., doctor/manager raters effect $(\underline{F}(1,244)=64.24, \underline{p}<.001)$ and source of support $(\underline{F}(2,243)=51.20, \underline{p}<.001)$. The two-way interaction was also significant, $\underline{\mathrm{F}}(2,488)=37.95, \underline{\mathrm{p}}<.001$. As shown in Figure 7.3 both doctors and managers considered they received good collegial support, but then doctors reported increasingly low support from their manager and the CHE overall. Managers however rated the support of their manager better than that of colleagues, and they regarded the CHE support as satisfactory.

Figure 7.3: Level of support from colleagues, manager and CHE overall, for reflection on the ethics of difficult decisions

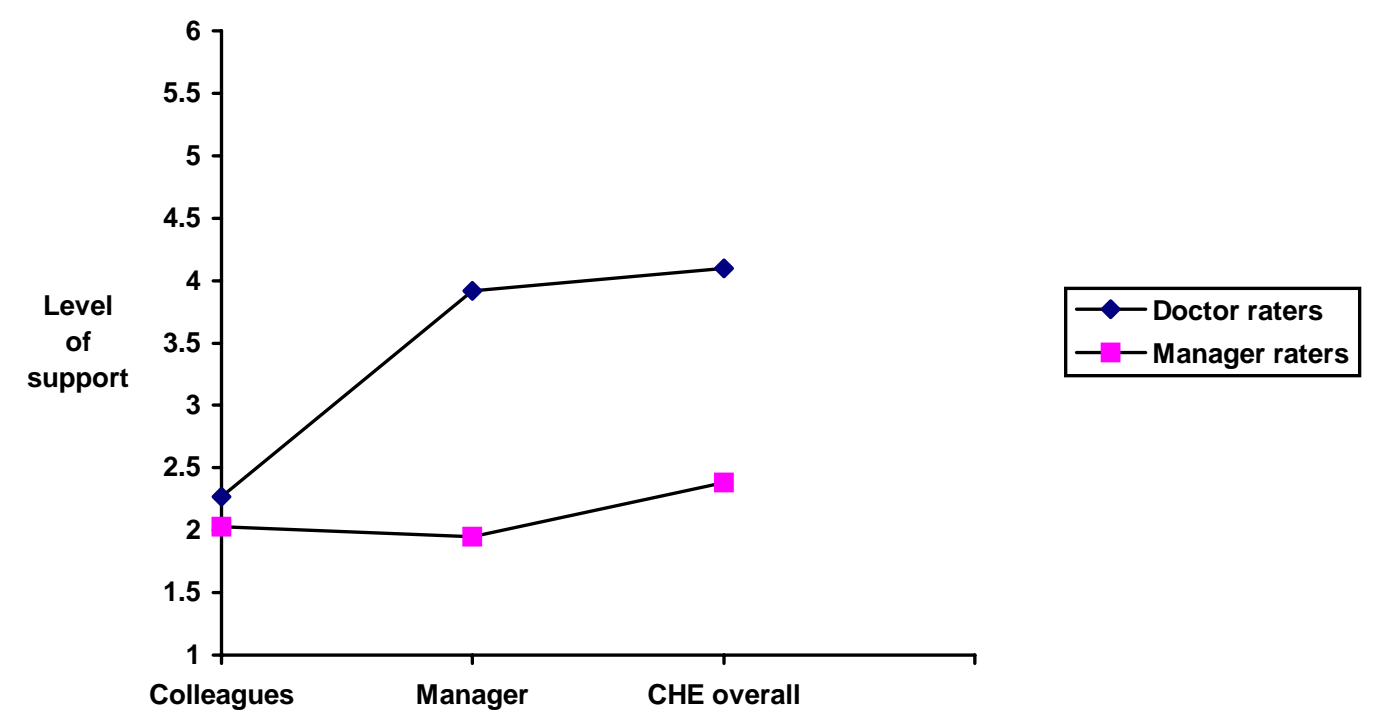

Note. Level of support: $1=$ excellent, $2=$ good, $3=$ satisfactory, $4=$ variable, $5=$ =not satisfactory, $6=$ =none

In question 12 respondents were asked to indicate how often they would explicitly take account of each of a list of 26 factors in their decision making over ethically challenging situations. The 26 factors were a combination of 11 items used in a Canadian study with clinician and nurse managers (Lemieux-Charles et al., 1993), plus additional items from the interview study.

Tables 7.10 and 7.11 show the 26 factors in descending order of frequency with which they were reported as taken into account by doctors and managers, respectively. The 
factors most often cited and most frequently taken into account by doctors were: my clinical experience, the affected patient, my own beliefs/values, and medical colleagues. For managers they were: legal standards or legislation, the affected staff member, CHE procedure/guidelines, my own beliefs/values, and my managerial experience.

Thus, the doctors and managers have in common, their frequent reliance on own beliefs/values, their clinical or managerial experience respectively, and the affected patient or staff member respectively. The difference in these most frequently cited and used factors lies in the doctors' reliance on medical colleagues while in contrast the managers rely on legal standards and CHE guidelines. Although doctors do cite referring to legal standards relatively frequently, on the whole their reliance on forms of guideline, policy, or ethical code falls more into the "sometimes" category. Thus it would appear that doctors rely more on a mixture of experience, beliefs/values and intra professional support focused on the affected patient and their clinical status when faced with ethically challenging situations. Managers, however, rely on a mixture of standards and guidelines, experience and beliefs focused on the affected staff member and the organisational problem. In a similar type of question Lemieux-Charles et al. (1993) also found doctors were more likely to be influenced by their personal beliefs/values and general clinical experience. They also found that other managers were more likely to be influenced by legal standards. 
Table 7.10: Frequency with which doctors take into account certain factors when faced with ethically challenging situations

\begin{tabular}{|c|c|c|c|}
\hline Factor & Mean (a) & S.D & $\%$ (b) \\
\hline x) my clinical experience & 4.61 & 0.61 & $98 \%$ \\
\hline t) the affected patient & 4.44 & 0.77 & $90 \%$ \\
\hline h) my own beliefs/values & 4.33 & 0.94 & $83 \%$ \\
\hline k) medical colleagues & 4.28 & 0.66 & $91 \%$ \\
\hline g) legal standards or legislation & 3.91 & 1.02 & $69 \%$ \\
\hline o) clinical literature & 3.73 & 0.84 & $66 \%$ \\
\hline i) the interdisciplinary health team & 3.59 & 1.22 & $68 \%$ \\
\hline u) the affected staff member & 3.56 & 1.57 & $65 \%$ \\
\hline r) mentor or confidante & 3.09 & 1.30 & $47 \%$ \\
\hline q) my role in the organisation & 3.07 & 1.35 & $41 \%$ \\
\hline b) Medical Council policy & 2.83 & 1.23 & $31 \%$ \\
\hline e) CHE procedure/guidelines & 2.69 & 1.22 & $27 \%$ \\
\hline y) financial resources & 2.61 & 1.12 & $20 \%$ \\
\hline a) NZMA code of ethics & 2.59 & 1.32 & $29 \%$ \\
\hline m) ethics committees & 2.53 & 1.31 & $25 \%$ \\
\hline d) CHE ethical statements/mission/policy & 2.36 & 1.16 & $15 \%$ \\
\hline z) my religious/spiritual beliefs & 2.33 & 1.53 & $25 \%$ \\
\hline j) the management team & 2.27 & 1.15 & $14 \%$ \\
\hline p) ethical case study literature & 2.21 & 1.10 & $13 \%$ \\
\hline f) RHA or Core Services guidelines & 2.02 & 1.16 & $11 \%$ \\
\hline l) managerial colleagues & 1.94 & 1.15 & $9 \%$ \\
\hline n) clergy/hospital chaplain & 1.72 & 1.01 & $5 \%$ \\
\hline w) my managerial experience & 1.49 & 1.49 & $14 \%$ \\
\hline s) ethicist & 1.46 & 0.91 & $3 \%$ \\
\hline c) NZIM or other code of ethics & 1.15 & 1.25 & $6 \%$ \\
\hline v) management journals & 0.96 & 0.80 & $2 \%$ \\
\hline
\end{tabular}

(a) Range 5 (all the time), 4 (often), 3 (sometimes), 2 (hardly ever), 1 (never) and 0 (not applicable)

(b) Based on percentage of 5's and 4's 
Table 7.11: Frequency with which managers take into account certain factors when faced with ethically challenging situations

\begin{tabular}{|c|c|c|c|}
\hline Factor & Mean (a) & S.D & $\%$ (b) \\
\hline g) legal standards or legislation & 4.29 & 0.86 & $90 \%$ \\
\hline u) the affected staff member & 4.19 & 1.06 & $83 \%$ \\
\hline e) CHE procedure/guidelines & 4.18 & 0.95 & $85 \%$ \\
\hline h) my own beliefs/values & 4.17 & 1.12 & $80 \%$ \\
\hline w) my managerial experience & 4.10 & 1.13 & $82 \%$ \\
\hline j) the management team & 3.85 & 0.92 & $72 \%$ \\
\hline d) CHE ethical statements/mission/policy & 3.83 & 1.05 & $78 \%$ \\
\hline l) managerial colleagues & 3.73 & 0.72 & $61 \%$ \\
\hline q) my role in the organisation & 3.65 & 1.30 & $62 \%$ \\
\hline y) financial resources & 3.38 & 1.17 & $52 \%$ \\
\hline i) the interdisciplinary health team & 3.29 & 1.62 & $65 \%$ \\
\hline r) mentor or confidante & 3.24 & 1.39 & $54 \%$ \\
\hline f) RHA or Core Services guidelines & 3.18 & 1.24 & $46 \%$ \\
\hline t) the affected patient & 2.81 & 2.03 & $50 \%$ \\
\hline v) management journals & 2.54 & 1.26 & $24 \%$ \\
\hline x) my clinical experience & 2.36 & 2.09 & $47 \%$ \\
\hline k) medical colleagues & 2.36 & 1.91 & $41 \%$ \\
\hline m) ethics committee & 2.17 & 1.44 & $20 \%$ \\
\hline o) clinical literature & 2.07 & 1.50 & $17 \%$ \\
\hline p) ethical case study literature & 1.98 & 1.27 & $7 \%$ \\
\hline c) NZIM or other code of ethics & 1.84 & 1.61 & $14 \%$ \\
\hline z) my religious/spiritual beliefs & 1.69 & 1.37 & $10 \%$ \\
\hline s) ethicist & 1.34 & 1.24 & $7 \%$ \\
\hline n) clergy/hospital chaplain & 1.31 & 0.93 & $0 \%$ \\
\hline b) Medical Council policy & 1.26 & 1.38 & $3 \%$ \\
\hline a) NZMA code of ethics & 1.04 & 1.35 & $4 \%$ \\
\hline
\end{tabular}

(a) Range 5 (all the time), 4 (often), 3 (sometimes), 2 (hardly ever), 1 (never) and 0 (not applicable)

(b) Based on percentage of 5's and 4's

Independent samples t tests were performed on each of the factors to ascertain whether there were any significant differences in doctor and manager responses - these are reported in Table 7.12. Twenty of the factors revealed significantly different responses by doctors and managers. These differences were expected in at least 9 instances, where the factors could be interpreted as generally specific to one role group. For example the NZMA code of ethics, Medical Council policy, clinical literature, medical colleagues, the affected patient and clinical experience could be seen as specific to doctors, whereas 
the New Zealand Institute of Management (NZIM) or other code of ethics, management journals, managerial colleagues, the affected staff member and managerial experience could be seen as specific to managers. However on the other factors it revealed that managers take account of CHE ethical statements/mission/policy, CHE procedure/guidelines, RHA or Core Services guidelines, and legal standards or legislation, significantly more frequently than doctors. This reinforces the impression that on the whole managers are far more guideline and procedure oriented in ethically challenging situations. Possibly managers are looking for the answer, or a neutral basis for decision, in guidelines. Doctors are seemingly more comfortable dealing with colleagues and patient and the clinical situation to arrive at a course of action or in fact deciding themselves on the basis of these factors and their experience. Interestingly managers "hardly ever" (mean response $=1.85$, refer Table 7.11 or 7.12) take account of the NZIM or other code of ethics. Thus it is the relevant organisational or health sector guidelines they appeal to rather than any global ethical codes. Doctors “sometimes" (mean response $=2.59$, refer Table 7.10 or 7.12 ) take account of the NZMA code of ethics; and the CHE procedure/guidelines and Medical Council policy are referred to more frequently. Once again this may be due to the greater relevance of specific guidelines rather than global ethical statements/principles. However, it also means that doctors have for reference two or three sets of codes/guidelines which may or may not be compatible across CHEs. Other significant differences show that managers take account of financial resources more frequently than doctors (refer to Table 7.13), and that doctors take account of their religious/spiritual beliefs more often than managers.

The factors in which there was no significant difference in response also provide some interesting insights to managers and doctors. As already discussed both role groups frequently cite taking into account their own beliefs/values. However both also "often" take account of the interdisciplinary health team, and often or "sometimes" take account of a mentor or confidante. Both "sometimes" to "hardly ever" take account of the ethics committee, the ethical case study literature, and an ethicist, in ethically challenging situations. 
153

Table 7.12: $T$ tests showing differences in the frequency with which doctors and managers take into account certain factors when faced with ethically challenging situations

\begin{tabular}{|c|c|c|c|}
\hline \multirow[t]{2}{*}{ Factor } & \multirow{2}{*}{$\begin{array}{l}\text { Doctors } \\
\text { Mean (a) }\end{array}$} & \multirow{2}{*}{$\begin{array}{l}\text { Managers } \\
\text { Mean (a) }\end{array}$} & \multirow[t]{2}{*}{ t value(b) } \\
\hline & & & \\
\hline a) NZMA code of ethics & 2.59 & 1.04 & $7.65^{* * *}$ \\
\hline b) Medical Council policy & 2.84 & 1.26 & $7.79^{* * *}$ \\
\hline c) NZIM or other code of ethics & 1.15 & 1.85 & $-3.03 * *$ \\
\hline d) CHE ethical statements/mission/policy & 2.37 & 3.83 & $-9.15^{* * *}$ \\
\hline e) CHE procedure/guidelines & 2.69 & 4.19 & $-9.91 * * *$ \\
\hline f) RHA or Core Services guidelines & 2.02 & 3.18 & $-6.29 * * *$ \\
\hline g) legal standards or legislation & 3.91 & 4.29 & $-2.83 * *$ \\
\hline h) my own beliefs/values & 4.33 & 4.17 & 0.98 \\
\hline i) the interdisciplinary health team & 3.59 & 3.29 & 1.28 \\
\hline j) the management team & 2.27 & 3.85 & $-10.91 * * *$ \\
\hline k) medical colleagues & 4.28 & 2.36 & $7.62^{* * *}$ \\
\hline l) managerial colleagues & 1.94 & 3.73 & $-14.31 * * *$ \\
\hline m) ethics committee & 2.53 & 2.17 & 1.72 \\
\hline n) clergy/hospital chaplain & 1.72 & 1.31 & $2.92^{* *}$ \\
\hline o) clinical literature & 3.73 & 2.07 & $8.15^{* * *}$ \\
\hline p) ethical case study literature & 2.21 & 1.98 & 1.21 \\
\hline q) my role in the organisation & 3.07 & 3.65 & $-3.00 * *$ \\
\hline r) mentor or confidante & 3.09 & 3.24 & -0.72 \\
\hline s) ethicist & 1.46 & 1.35 & 0.68 \\
\hline t) the affected patient & 4.44 & 2.81 & $5.98^{* * *}$ \\
\hline u) the affected staff member & 3.56 & 4.19 & $-3.49 * * *$ \\
\hline v) management journals & 0.96 & 2.54 & $-9.09 * * *$ \\
\hline w) my managerial experience & 1.49 & 4.10 & $-14.40 * * *$ \\
\hline x) my clinical experience & 4.61 & 2.36 & $8.18^{* * *}$ \\
\hline y) financial resources & 2.61 & 3.38 & $-4.44 * * *$ \\
\hline z) my religious/spiritual beliefs & 2.33 & 1.69 & $3.02 * *$ \\
\hline
\end{tabular}

(a) Range 5 (all the time), 4 (often), 3 (sometimes), 2 (hardly ever), 1 (never) and 0 (not applicable)

(b) Independent Samples t test, ${ }^{*} \mathrm{p}<.05,{ }^{* *} \mathrm{p}<.01,{ }^{* * *} \mathrm{p}<.001$.

In a similar design to the Canadian study of clinician and nurse managers (LemieuxCharles et al., 1993), question 13 asks respondents to select and rank the 3 items from the 26 in question 12 which are most helpful when addressing ethical issues. A univariate analysis of variance was employed examining the responses according to whether raters were managers or doctors. This yielded significant differences in 13 out 
of 25 influences, and one influence which was not nominated as helpful by any subject (ie. clergy/hospital chaplain). The significant results, which are documented in Table 7.13, show not surprisingly that doctors find the NZMA code, their medical colleagues, the affected patient, and their clinical experience more helpful than managers do; while the managers find CHE ethical statements/mission/policy, CHE procedure/guidelines, RHA or Core Services guidelines, legal standards or legislation, the management team, their managerial colleagues, the affected staff member, their managerial experience and financial resources more helpful than doctors do.

Table 7.13: Analysis of variance of three most helpful factors when addressing ethical issues

\begin{tabular}{lllc}
\hline & Doctors & Managers' & \\
Factor & $\begin{array}{l}\text { mean rating of } \\
\text { helpfulness }\end{array}$ & $\begin{array}{l}\text { mean rating of } \\
\text { helpfulness }\end{array}$ & $\underline{\mathbf{F}} \mathbf{( 1 , 2 4 6 )}$ \\
\hline a) NZMA code of ethics & 0.21 & 0.00 & $6.28^{*}$ \\
d) CHE ethical statements/mission/policy & 0.04 & 0.47 & $28.82^{* * *}$ \\
e) CHE procedure/guidelines & 0.03 & 0.61 & $52.98^{* * *}$ \\
f) RHA or Core Services guidelines & 0.00 & 0.08 & $12.07^{* *}$ \\
g) legal standards or legislation & 0.35 & 0.93 & $18.92^{* * *}$ \\
j) the management team & 0.02 & 0.29 & $18.76^{* * *}$ \\
k) medical colleagues & 1.31 & 0.20 & $46.80^{* * *}$ \\
l) managerial colleagues & 0.02 & 0.13 & $5.83^{*}$ \\
t) the affected patient & 1.10 & 0.32 & $20.19^{* * *}$ \\
u) the affected staff member & 0.02 & 0.15 & $8.86^{* *}$ \\
w) my managerial experience & 0.01 & 0.55 & $51.44^{* * *}$ \\
x) my clinical experience & 0.83 & 0.22 & $15.56^{* * *}$ \\
y) financial resources & 0.01 & 0.07 & $4.02^{*}$ \\
\hline
\end{tabular}

Note. $3=$ most helpful, $2=$ second most helpful, $1=$ third most helpful, $0=$ not chosen ${ }^{*} \mathrm{p}<.05,{ }^{* *} \mathrm{p}<.01,{ }^{* * *} \mathrm{p}<.001$.

It is also informative to examine the factors to which doctors and managers responded similarly. For instance in Table 7.14 it is evident that 'my own beliefs/values' was found helpful by over $40 \%$ of both doctors and managers, similarly 'the interdisciplinary health team' was found helpful by over $20 \%$ of both groups. From this table we can also conclude that the most often cited helpful factors for doctors are: 'medical colleagues', 'the affected patient', 'my own beliefs/values' and 'my clinical 
experience'; and for managers they are: 'my own beliefs/values', 'legal standards or legislation', 'CHE procedure/guidelines’ and 'my managerial experience'.

Table 7.14: Percentage of times each factor was chosen by doctors and managers in the "top three" most helpful when addressing ethical issues

\begin{tabular}{|c|c|c|}
\hline Factor & $\begin{array}{l}\text { Doctors } \\
\underline{\mathbf{n}}=191\end{array}$ & $\begin{array}{l}\text { Managers } \\
\underline{\mathbf{n}}=59\end{array}$ \\
\hline a) NZMA code of ethics & $13 \%$ & $0 \%$ \\
\hline b) Medical Council policy & $5 \%$ & $0 \%$ \\
\hline c) NZIM or other code of ethics & $0 \%$ & $5 \%$ \\
\hline d) CHE ethical statements/mission/policy & $2 \%$ & $20 \%$ \\
\hline e) CHE procedure/guidelines & $2 \%$ & $34 \%$ \\
\hline f) RHA or Core Services guidelines & $0 \%$ & $7 \%$ \\
\hline g) legal standards or legislation & $21 \%$ & $41 \%$ \\
\hline h) my own beliefs/values & $45 \%$ & $41 \%$ \\
\hline i) the interdisciplinary health team & $21 \%$ & $22 \%$ \\
\hline j) the management team & $1 \%$ & $15 \%$ \\
\hline k) medical colleagues & $62 \%$ & $12 \%$ \\
\hline l) managerial colleagues & $1 \%$ & $8 \%$ \\
\hline m) ethics committee & $3 \%$ & $5 \%$ \\
\hline n) clergy/hospital chaplain & $0 \%$ & $0 \%$ \\
\hline o) clinical literature & $13 \%$ & $3 \%$ \\
\hline p) ethical case study literature & $2 \%$ & $2 \%$ \\
\hline q) my role in the organisation & $2 \%$ & $5 \%$ \\
\hline r) mentor or confidante & $7 \%$ & $7 \%$ \\
\hline s) ethicist & $0 \%$ & $0 \%$ \\
\hline t) the affected patient & $49 \%$ & $14 \%$ \\
\hline u) the affected staff member & $1 \%$ & $12 \%$ \\
\hline v) management journals & $0 \%$ & $2 \%$ \\
\hline w) my managerial experience & $0 \%$ & $29 \%$ \\
\hline x) my clinical experience & $41 \%$ & $10 \%$ \\
\hline y) financial resources & $0 \%$ & $3 \%$ \\
\hline z) my religious/spiritual beliefs & $4 \%$ & $0 \%$ \\
\hline
\end{tabular}

Questions 14 and 15 were open ended, providing opportunity for extended comment by respondents. These responses were summarised by the researcher and by an independent person, to arrive at the following summary of results.

Question 14 asked respondents "what further support, if any, would you like for reflection on the ethics of particularly difficult decisions?” 
Forty-five percent of doctor respondents gave comments in response to this question. The main themes in their responses were:

- Access to more open discussion between professionals, more case studies, more debriefing, by regular forum or email

- Access to more information - legislative, policy and guidelines, better guidelines where there is a restriction of resources and thus less medical futility, better education of everyone on current CHE policies

- Need for increased public awareness of limitations of health service and medical practice - modify expectations or put pressure on government to increase funding

- Need meaningful dialogue with management

- Access to a medical specialist trained in ethics or a respected ethicist; or a medical superintendent type role - a wise, experienced clinician to provide clinical leadership, and objective advice on ethical and medicolegal issues

- Need a multidisciplinary clinical ethics committee

Some respondents talked of the fact that the "big" decisions are increasingly beyond the province of doctors as resource allocation is in the hands of managers and politicians.

Others mentioned professional disagreement over treatment protocols as another factor which adds to the difficulty and confusion of ethically challenging situations. This taken in conjunction with the responses to question 12 may explain, in part, why doctors are far less reliant on guidelines than managers, and far more likely to take account of patient focused issues. Additionally it may contribute to explaining why managers perceive doctors' current role as operating as independent professionals - this could be a particularly likely impression if there is not even intra professional agreement on issues.

The 35\% of managers who responded to question 14 expressed similar themes to the doctors:

- More published information re ethics and legality, case studies for managers and guidelines

- Education for all staff on ethics

- Expert assistance 
Some managers expressed the view that health managers have been placed in an impossible situation to manage governmental outcomes, clinicians' needs, public expectation and individual patient wants and desires - thus becoming the "fall guys" for everyone.

Question 15 asked respondents "what future ethical issues do you believe will be confronted in the health sector by doctors and by managers?”

Sixty-seven percent of managers and $77 \%$ of doctors responded to this question. The overwhelming theme in both doctors' and managers' responses to this question is that of lack of resources and decisions relating to allocation of resources. Underpinning this is widespread concern about prioritisation - who will do it, how it will be done and by whom. Throughout there appears to be an acknowledgment that neither doctors nor managers are trained, or necessarily appropriate, to make some of the increasingly hard ethical decisions.

Doctors and managers identified the following ethical issues to be faced by doctors in the future:

- Rationing, financial constraints in the public health system: how to ensure quality of care does not suffer, who is liable when treatment is unsatisfactory due to lack of resources, who should make rationing decisions - doctors, managers, patients, RHA, society, government?, age as a constraint for resourcing, perverse incentives in short term contracting for services

- Unrealistic expectations of patients, families and the media; increasingly hostile environment for doctors, increased litigation and fear of it leading to defensive medicine

- Increasing conflict for doctors as health changes lead to more opportunities in private practice

- Abortion, euthanasia, management of diseases of the elderly, transplantation of animal organs, foetal medicine, gene therapy

- Ability to withhold treatment

- Expensive drugs, and the fact that medical science is way ahead of ethical guidelines

- Informed consent

- Limitation of research by Privacy Act or ethical concerns 
Doctors and managers identified the following ethical issues to be faced by managers in the future:

- Financial restraint - increase in number of patients not funded for in health, desire of system driven by three yearly political cycle to action short term efficiency gains, conflict of managers receiving financial rewards for keeping costs down, progressive disempowerment of managers by purchasers exerting funding pressures

- To whom do managers owe their allegiance? the hierarchy, or their department/staff and patients?

- Private practice in public hospitals or privatisation

- More legal accountability of managers

- Comprehending the complexity of health services

- Keeping and motivating good health professionals in the public health system

In summary, these comments from doctors and managers highlight various areas of dissonance between different stakeholders/participants in the public health sector. For instance between public expectation and the health system's resources/ability to deliver, between medical technology/capability and the government's ability to fund it, between manager representing the organisation's interest and doctor representing the patients' interests. It is not surprising then that both managers and doctors want the greater access to sources of wisdom (be they guidelines or people or training) expressed in question 14.

These issues amplify the tensions that have potentially existed throughout the history of medicine and management in health and will be explored further in the following chapter.

\section{Section D: Background Information}

Much of Section D contains demographic information which is reported in table form in Appendix G. However there were a few questions in this section which probed areas of more general interest, similar to those explored by the Canadian study of LemieuxCharles et al. (1993). These areas enquired whether respondents had received any formal ethics training, what it was, and how useful it had been. A surprisingly similar 
percentage of doctors (31\%) and managers (30\%) reported they had received some formal ethics training. The vast majority of doctors who had ethics training received this as part of their medical training, amongst the managers the training had been received in business and health management courses at a University, or in professional training (as accountant, social worker, nurse, therapist, etc.). Sixty-three percent of managers found their ethics training very or extremely helpful, whereas only $27 \%$ of doctors responded in these categories. Sixty-five percent of doctors who received ethics training found it somewhat or a little helpful, 31\% of managers who received ethics training responded in this category. Eight percent of doctors and five percent of managers found the ethics training not at all helpful. Thus it seems that on the whole ethics training is helpful to the managers and doctors who receive it.

Respondents were also asked how long they had worked in the health sector, and whether they would continue to work in the health sector for the majority of the rest of their working life. Doctors and managers had a similar profile in terms of years of service in the health sector, for instance $67 \%$ of the doctors and $69 \%$ of the managers had worked in the health sector for over 10 years. A full breakdown is contained in Appendix G, Table G8. When asked if they would remain working in the health sector $94 \%$ of the doctors said yes, and $64 \%$ of the managers said yes. This could be due to managerial skills being more generic across different organisations and industries, and there being an expectation of job mobility and career movement of managers. However this may have some implications both positive and negative in terms of continuity, long term commitment, fresh ideas, etc.

\section{Summary}

The survey questionnaire set out to explore five empirical research questions which focused on roles, ethical doctors and ethical managers, doctors' and managers' perception of ethical dilemmas, the ethical frame of their activities, and the common influences on their ethical decisions. The questions have been broadly traversed and consistent patterns have emerged, in summary:

\section{Roles}

Doctors and managers had significantly different views of the current roles of managers and doctors, but similar views of what the managers' and doctors' role should be. They 
agreed that the manager's role should be a facilitatory type of role which helps others to work and is patient focused. Doctors believed that the current function of the manager's role was gatekeeping and organisation focused, whereas managers believed their current role was already similar to visions of how the role should be. They both agreed that the doctor's role should be as a member of a health team, responsible for patient care and medical expert to ensure best patient outcome within available resources. The picture of the doctors' current role was more mixed with a main point of difference being that managers saw doctors currently as independent professionals, while doctors saw their role currently as CHE employees. This could lead one to speculate about how willing doctors are to be managed by managers.

\section{Ethical doctor and ethical manager}

An ethical doctor and an ethical manager are not similar in all respects. An ethical doctor is focused on patients' best interests and making decisions in a principled way, whereas an ethical manager takes a long-term view of issues and the wider implications of decisions. Doctors placed a greater emphasis on honesty and truth-telling as an ethical characteristic, whereas managers placed more emphasis on taking a long term view of issues, and on recognising and using others' skills.

The complex interaction of doctor/manager rater with ethical/unethical doctor/manager was best discerned by seven bipolar constructs. These constructs formed a clear picture in the ethical/unethical dimension of the ethical person being principled, concerned about others and committed to the public health service; while the unethical person does not care about others or the public health service except to use them for personal gain, and is motivated by power and control. The interaction also revealed clear in-group evaluative bias where doctors rated ethical doctors as more strongly typified than ethical managers by ethical constructs, while managers rated ethical managers as more strongly typified than ethical doctors by ethical constructs. The bias extends to the finding that doctors rated unethical managers as more strongly typified by unethical constructs, and managers rated unethical doctors as more strongly typified by unethical constructs.

\section{Perception of ethical dilemmas}

Doctors and managers gave broadly similar responses to each other to a managerially oriented dilemma, and also to a medically oriented dilemma. In the managerial dilemma 
the managers ranked interests of the organisation more highly than the doctors did, and both ranked patient interest and public interest most highly. In the medical dilemma the doctors ranked patient interests more highly than the managers did; but overall their patterns of response were very similar.

\section{Ethical frame of activities}

Both doctors and managers reported encountering ethical dilemmas in their work on a frequent basis, but the considerations which applied in the dilemmas were not always the same. In common was the frequent consideration of resource allocation, but otherwise doctors cited patient interests, autonomy of the patient, and rights of the patients' family; and managers cited competence of staff/colleagues, individual fairness and interests of the organisation/institution. Managers felt supported by colleagues, managers and the organisation as a whole in ethical dilemmas, but doctors did not - they only felt supported by their colleagues.

\section{Influences on decision making}

Doctors relied on a mixture of experience, beliefs and intra-professional support in ethically challenging situations - which tended to be focused on the clinical status of the affected patient. Managers relied on a mixture of standards, guidelines, experience and beliefs - which tended to be focused on organisational problems and affected staff members. Thus not surprisingly doctors reported finding clinical and professional resources most helpful, while managers found organisational and managerial resources most helpful in ethically challenging situations.

A clear picture emerges from the outset in the responses to questions about role which identifies doctors as patient oriented and managers as organisation oriented, and this is reinforced by subsequent responses. Thus we can summarise that both doctors and managers encounter ethical dilemmas in their work; both have distinct roles which appear to influence the types of ethical dilemmas they face, and both are surrounded by particular support systems which influence their decisions in ethically challenging situations. Both see future dilemmas centreing on the problems of prioritisation for resource allocation, neither feeling particularly competent in that role. In the next section we will explore this picture of managers and doctors and the search for ethical common ground. 


\section{SECTION FOUR: CRITICAL ASSESSMENT \& CONCLUSIONS}

This fourth and final section assesses the findings of the empirical research against the backdrop of the socio-cultural and ethical environments which have been explored in previous sections. Chapter 8 reviews the findings of the main study comparing these with the applied ethics literature. Chapter 9 highlights the major conclusions that can be drawn from the research and future directions for research. 


\section{CHAPTER 8}

\section{MEDICAL ETHICS AND MANAGERIAL ETHICS: IS THERE COMMON GROUND?}

This chapter provides further discussion of the results of the main study. It looks first at insights the results give into the role of managers and doctors, then at similarities and differences highlighted in ethical managers and ethical doctors, the ethical dilemmas they face, and the influences on their decision making. A discussion of future ethical issues leads into an exploration of the separatist thesis.

\section{The Role of Managers and Doctors in CHEs}

It has been observed earlier in this thesis that both managers and doctors are employees caught in the tension between a humanitarian organisation and a resource constrained enterprise. The common belief is that doctors are the upholders of the humanitarian organisation and managers deal with the resource constrained enterprise. Their respective role perceptions are in line with these observations. The main study revealed that doctors view the manager's current role as a gatekeeping, CHE/organisation oriented role and would prefer to have it as a facilitatory, patient focused, helping others to work, type of role. On the other hand managers view their current role as already having those responsibilities (i.e., both gatekeeping and facilitating, patient focused and organisation oriented). However, similarly to doctors' responses, they would prefer to have it as the facilitatory, patient focused, helping others to work, type of role. It is clear from these responses that currently managers may feel a tension between being resource gatekeeper and humanitarian facilitator, hence their preference (and that of doctors) for managers to be focused on patients and facilitating work in the hospital. This role preference accommodates managers' duties as agents of an organisation which is focused on the delivery of health services within available resources, rather than the profit making focus of most commercial managers.

There was disagreement between doctors and managers over the makeup of the current role of the doctor, primarily because managers saw doctors currently as independent professionals, while doctors saw themselves as CHE employees. This is an interesting 
point of difference. Doctors who are used to being independent obviously feel that their independence has been diminished as they take on the role and duties of an employee. The managers who are used to dealing with people of employee status obviously consider that doctors are still too independent and have not taken on all the duties of an employee. Maybe the reality lies somewhere in between these two perceptions. The professional/technical employee will always retain a certain amount of independence through their superior technical knowledge, and the manager needs to find ways of managing that. Raelin (1991), in his book on managers managing professionals, observes that "although management needs to integrate the services of the professional with the other activities of the organisation, management also depends on the professional for those services and recognises its limited control over the regulation of technical performance" and hence that there is a "potential conflict between the need for control by management and the need for autonomy by the professional” (p.15). Additionally, as Raelin observes later, "the salaried professional typically shares his or her loyalty to the company with loyalty to society and to the profession” (p.248). This view of multiple loyalties was foreshadowed in the chapter 3 discussion of accountability in which Stacey (1992) commented on the variety of ways in which doctors may be held accountable for their actions by patients, colleagues, employer, profession and the state.

Looking at the doctor's role as it should be, both doctors and managers agreed that it should be as a member of a health team, responsible for patient care and as medical expert to ensure best patient outcome within available resources. This role perception seems to accommodate the doctor's duty of care to the patient, whilst also acknowledging the organisational and resource context in which that care occurs.

Thus it appears that there is a preference for more of a shared responsibility by managers and doctors for the humanitarian organisation and resource constrained enterprise, focused on health service delivery. 


\section{Ethical Doctors and Ethical Managers - Similarities and Differences}

It is interesting to compare what we know from the literature with results from the main study. The normative literature of moral philosophy consistently maintains that there are a number of key principles underpinning medical and managerial practice. These are principles like beneficence, non maleficence, respect for autonomy, and justice. They are applied to both medicine and management but with different goals in mind, as expounded by Glaser (1994) and Bryson (1994). Both Glaser and Bryson suggest that the concept of beneficence can be applied at the levels of the individual, organisation and society. By this formulation the doctor is primarily concerned, although not exclusively, about individual beneficence (i.e., focused on the patient's best interests), the manager is focused on organisational beneficence (i.e., focused on the best interests of the organisation as a whole), and government policy makers are focused on societal beneficence. Hence, in discussion of beneficence, care is needed to avoid inappropriate conflation of the concerns of the principle at one level to another level, and consequent talking past each other. Additionally Bryson highlighted that different roles may accord different priority to the varying principles. For example, a patient may emphasise respect for autonomy, a doctor may emphasise individual beneficence, a manager may emphasise organisational beneficence, and a policy maker may emphasise distributive justice. The survey responses confirm this difference in emphasis and orientation of the principles between doctor and manager. The survey results showed that seven constructs accounted for most of the multivariate three-way interaction between ethical/unethical doctors/managers and doctor/manager raters. These constructs confirm a number of themes present in the applied ethics literature:

- A common theme in the business ethics literature is that self-interest or an overriding focus on economic goals leads to unethical behaviour. One of the constructs was 'not self-interested at the expense of others vs self-interested at the expense of others'.

- Another theme in the business ethics literature is the need for managers to lead by example/to model ethical behaviour, this too is an ideal attributed to professional groups like doctors. One of the constructs was 'principled, has standards which are lived up to privately and publicly vs not principled'.

- A further trend in the literature is to see health management as different from management generally. Health management includes leadership on ethical issues which are complex clinically and administratively, as well as consideration of patient 
and others well-being (e.g., Darr, 1991; Griffith, 1993; Maxwell, 1994; McNerney, 1985). Similarly the medical ethics literature emphasises patient well-being as the doctor's prime focus. Two of the constructs were 'focus on and concern for others vs lack of concern for others', and 'focused on patients' best interests vs not focused on patients' best interests'.

- Both the medical and the health management literature discuss respect for persons as an important principle and it is arguable that this is reinforced by the construct 'recognises and uses skills of others for their good and the good of the service'.

- The other two constructs emerging from the research were 'committed to, and works hard for, the public health service vs not committed to, and does not work hard for the public health service', and 'not motivated by need for power and control vs motivated by need for power and control'. These two could almost be seen as an extrapolation of the self-interest construct.

Chapters 4 and 5 have also highlighted the accepted belief that business acts out of selfinterest, but that professionals limit their self-interest. Bayles (1989) characterised the professional's fiduciary relationship of trust with the client as requiring the professional to possess seven key virtues which were identified as honesty, candour, competence, diligence, loyalty, fairness and discretion. The responses to question 7 in the survey (defining a highly ethical manager and a highly ethical doctor) confirm a number of the virtues which Bayles theorised. For instance the most important constructs contributing to a highly ethical doctor were seen as honesty (compare with Bayles’ honesty); acting in the patients best interests, and ethical principles underpinning decisions (compare these two with diligence, competence and fairness); and for a highly ethical manager, taking a long term/strategic view of issues (compare with Bayles’ fairness); recognising and using others' skills for the good (compare with Bayles' fairness); commitment to/works hard for the public health service (compare with Bayles' loyalty and diligence); honesty (compare with Bayles’ honesty), and flexible open to others' ideas (compare with Bayles' candour). The interesting point from this comparison is that although Bayles outlined these virtues for the virtuous/ethical professional (i.e., doctor), the responses to the survey show that they apply equally well, if not better, to the ethical health manager. 
These results also highlight the different focus of the medical and managerial roles (patient versus organisational issues). The doctor's heavy emphasis on honesty and truth-telling as ethical behaviour, is similar to findings of other research discussed in Chapter 5 (e.g., Miyaji 1993; Rawwas et al., 1994). The manager's emphasis on long term/strategic view of issues is similar to findings of other research into management ethics ( e.g., Soutar et al. 1996).

This research has captured doctors' views of themselves and of the health manager, and health managers' views of themselves and of the doctor. What is new, although not entirely unexpected, is that those views of each role are so different, but that they are also so consistently held by both groups.

\section{Ethical Dilemmas}

Beauchamp (1994), as discussed in Chapter 4, noted that although principles are starting points for discussion in health care ethics, they are not solutions or answers in themselves. But do doctors and managers start from a similar point? There is very little consideration in the literature of how doctors and managers respond to similar dilemmas even though they are both involved in health care dilemmas. In this research both responded to a managerial and a medical dilemma, and they responded surprisingly similarly, although in the managerial dilemma doctors did place significantly more emphasis on patient interests and managers on organisation interests. The results showed, even though this was just one example, that different priorities apply depending on the type of dilemma (i.e., medical or managerial) and that the interests of the organisation did not rate highly with doctors at all in either dilemma.

These results are illuminated further when we look at the results of doctors' and managers' choices of the considerations which most often applied to the ethical dilemmas they faced in their work. Both frequently considered resource allocation in their ethical dilemmas. Managers also frequently considered competency of staff and colleagues, individual fairness (generally relating to treatment of employees) and the interests of the organisation significantly more often than doctors. Doctors considered patient interests, rights of the family of a patient, and autonomy of the patient significantly more often than managers. Thus, given that they applied broadly similar principles in the two ethical dilemmas, these results show that they tend to be exposed 
to different types of ethical dilemmas in their work. When we relate this to their role perceptions discussed earlier, and the nature of medical and managerial work outlined in Chapter 3, the results are not surprising. The doctor's role is one of medical expert responsible for patient care, hence the considerations in dilemmas focus around the patient. The manager's role is one of responsibility for the organisation and facilitating work within the organisation, hence the considerations in dilemmas focus around the organisation and the people within it.

Interestingly, doctors and managers reported a similar frequency of ethical dilemmas in their work. The frequency was much higher than that found by Derry reported in Frederick (1987), or by Soutar et al. (1996) in their survey of managers of publicly listed companies. Thus one could conclude that health management has more ethical issues inherent in the role than managerial roles in other industries. This adds weight to the suggestion in some of the ethics of health management literature that the role is different to that of the commercial manager thus requiring incorporation of additional ethical principles, such as respect for persons, in decision making.

Both doctors and managers considered they received good collegial support for reflection on the ethics of difficult decisions. However, doctors reported increasingly low support from their manager and the CHE overall. Managers, on the other hand, rated the support of their managers higher than that of their colleagues and regarded the CHE support as satisfactory. These are interesting results as they seem to point once again to the difference in role and background. Doctors are from a profession in which much weight is placed on collegiality, and on professional autonomy. On the whole they are judged by their peers not by their managers. For many doctors their immediate realm of contact is with colleagues, a number commenting in the survey that they did not know any managers. Managers most often receive their guidance and performance feedback from their own manager, not from their colleagues with whom they may only have sporadic contact or with whom they may compete for future promotions. Hence both doctors and managers are unlikely to receive support for ethical reflection from those areas in which there is no formal or informal mechanism to ensure it happens. Later in the survey doctors and managers made a range of suggestions on further support mechanisms and these will be discussed shortly.

\section{Influences on Decision Making}


The reflection of the role and nature of work in the work behaviours and preferences of doctors and managers is also apparent in how they rated influences on their decision making in ethically challenging situations. On the whole managers reported relying more often on legal standards, guidelines and procedures, plus their own beliefs/values and managerial experience. Doctors relied more often on medical colleagues, their own clinical experience, and their own beliefs/values. These results are similar to those found by Lemieux-Charles et al. (1993), who also reported personal beliefs/values, the law, and general clinical experience as the main influencing factors on the resource allocation decision making of managers (including doctors who were managers). Again they reflect the phenomena of the professional grouping and training of doctors as against the manager as agent of the organisation and its procedures.

In common with this 1993 study, the present research found only limited reported use of ethics committees and ethicists in ethically challenging decisions. Similarly codes of ethics did not feature as a major influence either, although of course one could argue that rather than being overtly referred to these may have become assimilated into the behavioural repertoire of a professional. This is a reasonable argument given the findings in the literature which confirm no relation between ethical behaviour and ethical codes, but find that experience/familiarity with the content of an ethical problem and open discussion of issues were shown to lead to deeper moral reasoning (Mathews, 1988; Stewart \& Sprinthall, 1993).

For managers that are recruited from other industries to health, the managerial issues look the same as those they have encountered elsewhere. However the ethical issues that attach to many health management issues are unique and require ethical resourcefulness to resolve adequately. Equally for managers who are ex-health professionals these are not clinical issues but managerial issues that must be worked through appropriately. The fact that so much seems to rely on one's own beliefs/values, and on one's clinical or managerial experience, underscores the importance of providing opportunity for people to broaden their experience, to promote and model an ethical work environment to allow staff to develop ethical work habits/processes. 


\section{Support Required for Ethical Reflection and Future Ethical Issues for Doctors and} Managers

We noted earlier that managers reported that they received satisfactory support from the CHE for reflection on the ethics of difficult decisions, but that doctors reported receiving better support from their colleagues than from the CHE. When asked what further support they required the doctors and managers supplied a range of requests, as discussed in Chapter 7, which focused around the need for more information, more discussion between doctors and management and within their own groups, access to a wise expert (to provide ethical leadership), and the need to modify public expectations of the health service. The perennial problem in providing more information and more discussion is the protest that time is in very short supply for both doctors and managers. One way to overcome this is to schedule regular de-brief and information sharing sessions so that they become incorporated as part of routine rather than additional extras. Access to a wise expert for the doctors meant someone with medical training and experience, and ethical wisdom. In the past this role had been filled by good medical superintendents who were part of the triumvirate management of Hospital Boards, providing professional leadership and administration. The breakdown of the triumvirate structure and the introduction of general management, whilst on the whole bringing about many positive changes in health management, also sacrificed some unrecognised roles - in particular that of professional mentor and ethical confidante. Our modern clinical directors fill some of the professional leadership role in many CHEs, however there may still be room for a more neutral role (i.e., one not connected into career structures and futures) advising both doctors and managers.

The need to modify the public expectations of the health service is a common theme and could ultimately lead to the breakdown of western public health systems as we know them. The public, often through the media, or through pressure applied to local politicians, are more militant in demanding their individual rights to health care. These rights are often demanded with complete disregard of wider community needs, and accepted guidelines or criteria to qualify for care. In effect the state and the medical profession have brought this situation upon themselves through a recent history of offering universal care by an all powerful profession and an egalitarian state. But the state's money will not stretch far enough and the doctors are reluctant to deny treatment to any patient. Hence the resultant tension between individual, state and doctor. 
These responses are not dissimilar to the findings of Lemieux-Charles et al. (1993), who reported that opportunities to consult with colleagues and superiors were helpful, but that one third of their respondents stated their organisation often or always ignored issues and one quarter perceived their organisation as smoothing over issues. They went on to speculate that ignoring or smoothing over issues avoids conflict which might arise as a result of discussions and thus that an ability to resolve conflict would be useful. Hence in both pieces of research managers and doctors were shown to feel the tension of maintaining a humanitarian organisation in a resource constrained environment for a public with high expectations. This is further reinforced in the current research by responses identifying future ethical issues for doctors and managers, many of which focus on the lack of resources and decisions relating to the allocation of resources.

Maxwell (1994) cited four main areas of health management activity which he claimed all involved a variety of ethical challenges. The future ethical issues identified in the main study confirm the truth of his claim.

\section{i) Managing clinical activity}

For managers the dilemmas in managing clinical activity concern how to retain good staff in the public health system, and how to maintain standards of care in an environment of scarce resources. For doctors the dilemmas focus on the boggling array of advancing medical technology, each with its own set of ethical problems (e.g., euthanasia, gene therapy, foetal medicine, transplantation of animal organs, expensive drug therapies, management of diseases of the elderly).

\section{ii) Allocating resources}

There is concern expressed by both doctors and managers over who is appropriate to make resource prioritisation decisions. Neither group feels suitably trained or mandated to make increasingly hard and far reaching ethical decisions, and one could argue that it is not appropriate for them to do so. But one could argue that neither is it appropriate for doctors and managers on the ground to claim the decisions are too hard and should be made by government. There is a responsibility to contribute to that decision process for the good of the individual patient and for the good of the organisation and the community it serves. On a day to day basis resources need to be allocated and health 
work goes on, but when it comes to long term planning the environment is less certain, as is responsibility for decision making.

iii) Managing the politics of health

Currently, New Zealand and other western democracies have health systems which are driven by three or four yearly political cycles and thus short term gains. Health managers must also contend with the unrealistic expectations of patients, families, the media and the policymakers to deliver more with less.

iv) Rendering public account

Positive changes have resulted from rendering public account (e.g., informed consent). On the other hand doctors and managers consider that they work in an increasingly hostile environment. The price of individual rights without balance is increased litigation against both role groups leading ultimately to defensive and futile medical and managerial practices.

The sheer volume and scope of ethical issues, to which there is seldom a simple answer, highlights the importance of a number of points already alluded to in the research. For instance, the importance of ethical leadership both professionally and administratively and the need for well developed formal and informal support mechanisms for reflecting on the ethics of particularly difficult questions. In addition, by exposing managers and doctors to a range of experience, it may be possible to encourage deeper moral reasoning and greater comfort with open discussion. At a broader level, national guidelines on particular ethical issues may also be useful. However, above all there needs to be clarity over the decision making role of the government, the health manager and the doctor. Achieving such clarity will require an acknowledgment that no-one wants to make the hard decisions but that they should be made by the appropriate person/s and following an appropriate process.

British politician and doctor, Lord Owen (1976), noted in his book on the politics of medicine that "society senses the impotence of medicine and yet wishes to believe in its strength. This ambivalence towards medicine is reflected in society's attitude to doctors, and the ambivalence is returned by doctors towards society.” (p.89) This comment could equally well be applied to doctors and managers. Doctors sense the impotence of management and yet wish to believe in its strength, and this ambivalence towards 
management is reflected in doctors' attitude to managers. The ambivalence is returned by managers towards doctors. Managers and doctors have in common the fact that the nature of their work (refer Chapter 3) involves making judgements in the midst of uncertainty, and sometimes they get it wrong - they are fallible. It is this shared history of status and yet fallibility which brings us to consider whether doctors and managers have similar ethical duties or whether a separatist argument of uniqueness for the medical professional is valid.

\section{Doctors, Managers and the Separatist Thesis}

As discussed in Chapters 4 and 5 the separatist thesis maintains that professionals, by virtue of their expertise and their consequent roles, have rights and duties that are unique and that may be different or even contrary to the rights and duties found in other areas of morality. Gewirth (1986) and Goldman (1980) have provided convincing arguments to deny the validity of this claim. However, Overman and Foss (1993) assert that empirically they can prove the validity of the separatist thesis as applied to physicians compared to ordinary citizens. A body of the medical ethics literature covertly reinforces the idea that the ethical duties applying to doctors are somehow different to those applying to other people. One could suggest however, that as MacIntyre (1984) warned, the very nature of applied ethics draws attention to the application of particular principles as if they were unique to the situation being discussed. Indeed, as we have seen in previous chapters, there is no uniqueness in the principles that range across the collective literature of professional, medical, business, public sector and management ethics. For instance, business and professional relationships, while having many different features within each relationship, share a common core of trust between two or more parties.

The business ethics literature tells us that trust is reliant on honesty, truth-telling, confidentiality and responsible behaviour (Solomon 1996; Sternberg, 1995; Vallance, 1994). The health management literature adds respect for persons (Darr, 1991; Griffith, 1993; Mariner 1995). The medical and professional ethics literature tells us that trustbased relationships are reliant on virtues such as honesty, candour, competence, diligence, loyalty, fairness and discretion (Bayles, 1989). Both sets of literature refer, in varying degrees of seriousness, to duties of non-maleficence, beneficence and justice. The language of business ethics and professional ethics may be different but the 
meanings are surprisingly similar. The main study of this research has shown that the ethical doctor and the ethical manager can be considered and explained within a general moral framework which allows for the different focus of their roles. This was illustrated by the seven bipolar constructs which explained the complex three-way interaction of doctors and managers rating ethical/unethical manager/doctor, and the responses to the medical and managerial dilemmas within a single general framework.

Managers have the power of hierarchically conferred status, and control over an organisation, or part of an organisation, which we expect to be exercised responsibly, ethically. Similarly doctors have the power of expert knowledge over a patient, or group of patients, which we also expect to be exercised responsibly, ethically. The widespread popularity of performance management systems are testament to the strong desire of the modern organisation to maintain and enhance the expertise/competence and responsible performance of all employees; managers, professional employees, and other staff. The only difference for professional employees, like doctors, is that their own professional grouping often accepts responsibility for monitoring ongoing education and competence requirements. This research has shown competence of staff and colleagues as one of the major considerations reported in the ethical dilemmas of health managers.

Goldman (1980) differentiated between the moral authority to act and the moral content of the act. This differentiation allows for the fact that we are fallible, hence sometimes the moral content of the act is misjudged, but the moral authority (and obligation) to act remains. He believes that doctors, although important, do not encompass our most fundamental moral values and must learn to act within the same moral framework as the rest of us; thereby relinquishing a degree of moral authority they have assumed for making decisions for others. In the decades since 1980, when this argument was made, the pressure for greater patient autonomy has been realised in legislation and the procedures of health organisations/professionals. This research shows patient interests and patient autonomy as high priority issues for doctors. The high degree of concern displayed in this research by doctors and managers over increasingly challenging resource allocation decisions is also testament to difficult moral decisions, and a feeling of lack of moral authority to make such decisions. Indeed in the New Zealand health setting the Code of Health \& Disability Services Consumers Rights, 1996, (refer to Chapter 5), accords duties to all health providers whether doctors, managers, other health professionals, general staff, or any agent of a health provider. These ethical 
duties, imposed by law, do not acknowledge any right or duty as unique to professionals or to managers.

The author suggests that there is nothing in the language of the separatist thesis that one cannot say within a general moral framework after allowing different emphases or priorities as demanded by each role. The normative commitments are no different. However this is not to say that medical ethics and health management ethics are the same, rather that discussion of them can be accommodated in a general moral framework. Thus we can conclude that health management ethics has priorities related to the manager:organisation relationship, and that medical ethics has priorities related to the doctor:patient relationship.

\section{Summary}

Doctors and health managers work in common moral ground, with different ethical imperatives according to their respective roles. Both doctors and managers can recognise an ethical and an unethical colleague in either role, and both define the characteristics of those colleagues consistently. The ethical doctor is honest, focused on patients' best interests, and has ethical principles underpinning his/her decisions. The ethical manager is honest, committed to and works hard for the public health system, is flexible and open to others' ideas, recognises and uses others' skills for their own good and that of the service, and above all takes a long term/strategic view of issues and the wider implications of decisions.

Both doctors and managers are aware of the considerations in managerial and medical dilemmas, prioritise them broadly similarly with greater emphasis on patient interest by doctors and on organisational interest by the managers. In the context of their own roles the nature of the dilemmas they face is different and thus different considerations apply. Doctors' dilemmas more often feature patient interests, family of patient interests, and patient autonomy issues; whereas managers' dilemmas more often feature staff competence, and individual fairness to staff issues. Both of them most regularly face issues of resource allocation. 
They are roles with different support networks, doctors' primarily collegial, while managers' are primarily hierarchical. This underscores the essential difference in the cast of their roles. The doctor gives expert care to patients in order to increase their well-being or at least reduce discomfort. The manager facilitates the functioning of the organisation and those that contribute to it, or at least does not hinder the viability of the organisation. Ironically their points of greatest commonality, the patient and organisational resource allocation, are also their areas of greatest division. 


\section{CHAPTER 9}

\section{CONCLUSION}

This thesis has reviewed several bodies of literature in an attempt to shed new light on the area of applied ethics. It has also tried to fill several gaps in that literature as it pertains to ethics in health organisations. In particular it has drawn a comparison between medical ethics and managerial ethics in health organisations; and looked at those sets of ethics in their organisational and role context, not as some isolated case study. As a result we can draw a number of conclusions about: medicine and management in health organisations; doctors, managers and ethics; the contribution of the research to applied ethics and to psychology; and future directions for research.

\section{Medicine and Management in Health Organisations}

History has lead medicine and management to this point. A number of key themes of connection and contrast have punctuated the relationship of medicine and management in health organisations over time, and the ethical imperatives that accompany the role of doctor and of manager. It was observed in Chapter 2 that, rather than discussing organisational structure in health organisations, it is in fact more salient to discuss the negotiation and renegotiation of order among participants over time. Indeed, doctor, manager, board/trustees, state and patient have enjoyed fluctuating fortunes in the public health system. Health organisations have metamorphosed from the cottage hospitals offering rest to the indigent and dying. Now they are complex organisations supporting a range of health professionals focused on the ongoing health of the public, including hospitals which treat the sick and house an ever expanding world of medical possibility. The placid caretaker has transformed to the powerful general manager with a team of other managers. The independent medical professional has in the public system become the technically skilled employee (and in the private system has remained the independent professional/entrepreneur). The submissive and grateful patient has become the informed and expectant, empowered yet vulnerable, health consumer. The state has changed from benefactor and protector of citizens to high level arbitrator deciding which citizens deserve health care. Boards have moved from financial guardians, to the community voice, and back to being financial guardians. 
The growing tension underpinning this renegotiation of order has been the result of the competing demands of capitalism and democracy, individual rights vs equal rights, and insufficient resources to meet the needs of every individual. Health organisations try to balance these tensions every single day. They represent in microcosm the larger challenge that faces all western post industrial societies trying to fund health, education and welfare systems.

The health sector in New Zealand has been restructured in the 1990s on the grounds of economic efficiency and control and in line with broader public sector reform. Many commentators agree there was some need for it. One wonders, however, whether the health sector has yet fully developed the infrastructure to cope with a vastly different world of medical possibility and financial constraint. The new health structures are about efficiency and transparency, and recently individual rights. They are not about enhancing or supporting difficult and ethically challenging decisions. If we look at recent structural developments in New Zealand, the National Health Committee is the only attempt to support difficult decision making through the central development of treatment guidelines and cut-off points. But even their guidelines risk being undermined when media pressure is applied. Several celebrated cases in the media resulted in the then Minister of Health reversing the denial of treatment decisions made by CHEs. Ethics Committees lend some support to decision making but their mandate is potentially so broad that they are fully occupied with research approvals. Additionally it is variable how much credibility they have with doctors and managers. Certainly in this research they were reported as having little to no influence on decision making in ethically challenging situations. Hence doctors and managers are left to establish their own common ground and mechanisms for dealing with difficult decisions.

As has been revealed in this research, for doctors support tends to be found collegially and from one's own clinical experience. For managers it is hierarchically in the organisation, from standards and the law, and from personal experience. However there is a desire expressed by research participants for other forms of support - for more information, for debriefing of difficult situations, for access to an ethically wise medically trained expert, for more communication between doctors and managers.

There is no doubt that more challenging decisions lie ahead in health. The research identified many such challenges associated with medical technologies, the most 
pressing those associated with resource allocation. Much of the pressure of resource allocation decisions draws not only from the weighty moral content of the decisions, but also from doubt on the part of the decision maker as to their moral authority (or even any general mandate) to decide. If, as has been argued earlier, doctors and managers sit within a general moral framework which allows different priorities according to their roles, it is no wonder resource allocation decisions become a frustrating battle of conflicting priorities. Clear responsibility for decision making and decision processes needs to be articulated as a matter of urgency, to determine which decisions appropriately belong with doctors, which with managers, which with the government, which with the community, which with the patient/consumer, which with a combined group of these parties? and how should they be made?

\section{Doctors, Managers and Ethics}

The literature of applied ethics gave us a number of principles and virtues in medical and managerial ethics. For doctors, we were told, various permutations of autonomy, beneficence, non maleficence and justice are the key ethical principles to be balanced in any situation. History showed us that these principles have been with us, in some form, since earliest recorded time. The kingdom which King Hammurabi ruled in 1750BC gave weight to non-maleficence and justice, the Hippocratic tradition added beneficence, and the 20th century has added autonomy. It could also be argued that the 19th and 20th centuries, through democratic governments and the advent of modern organisations, have expanded the levels at which these principles are applied, that is, at the level of the individual, the organisation or society.

For managers, we were told that justice, honesty, trustworthiness and non-injury should underpin practice. Additionally in health management respect for persons and beneficence should enter one's considerations. Certainly this research has shown that doctors and managers are clear in what they consider are the important factors contributing to an ethical doctor and an ethical manager. The ethical doctor is honest, principled and beneficent. As one of the departing CHE Chief Executives (formerly from a commercial sector background) commented on public radio "doctors focus on the patient....and thank God". The ethical manager is also honest, hard working, flexible and open, recognises and utilises others' skills, and, above all, takes a long term/strategic view of issues and the wider implications of decisions. This was 
reinforced by the doctors' and managers' mutual role perceptions and expectations. Doctors as medical experts and managers as organisational facilitators, both focused on the patient's well-being. This was their vision of how the roles should be. Further, by the common considerations they face in ethical dilemmas, for doctors these are issues of patient autonomy, rights of the patient's family, the best interests of the patient, and resource allocation. For managers these are issues of staff competence, fairness to staff, and resource allocation.

Hence codes of medical ethics, the medical ethics literature, and this research, confirm that the prime focus of medical ethics is the patient (their clinical status and best interests, their autonomy). It showed that the medical profession through its education processes and enculturation in the hospital setting, draws its main support from medical colleagues and not from the organisation. For most doctors the profession is the constant factor in their working lives. Hospitals and organisations may change but doctors continue in the medical profession attending to the needs of patients.

Codes of management ethics (such that they are), the limited literature on managerial ethics, and this research, confirm that the focus of managerial ethics is the organisation (its viability, the services it delivers, the performance of those within it, and its consumers). Managers, not having the benefit of homogeneous group education processes and enculturation, draw their main support from the hierarchy which has recruited them. For most managers their position in an organisational hierarchy is the common theme of their working lives. They may move to different organisations (even industry sectors) but they continue in the management hierarchy attending to the needs of the organisation.

These views emphasise the fundamental difference that this research confirms between the roles of doctors and managers, and hence their ethics:

- For doctors the hospital organisation is merely the venue where medical work occurs, but the patient is their work and the focus of their energies.

- For managers the organisation is the focus of their being, the organisation is their work.

All manner of differences in perspective and priorities derive from this core difference in orientation. 


\section{Contribution of the Research to Applied Ethics and to Psychology}

A number of flaws and gaps in the existing applied ethics literature have been identified in this thesis. These have been apparent in a covert confusion of terms at a meta-ethical level, narrowness of research and discussion, and inadequacies of method.

As discussed in Chapter 4, of particular note has been the lack of common definition of ethical principles, and in some instances the resulting conflation of principles. Conflation was shown at its worst in the overlapping areas of bioethics, medical ethics and health care ethics. There is clearly a need for all applied ethicists, from whatever discipline, to be consistent in their definitions of the ground which they propose to address. This research has also highlighted the importance in applied ethics of awareness of the level at which discussion is occurring; individual, organisational or societal. Again this requires vigilance to avoid confusion.

The largest gap of all, however, is the fertile yet untended ground in which this thesis falls - the comparison of medical ethics and managerial ethics in health organisations. This research has shown that medical ethics and managerial ethics are not the same, but they can be discussed within a general moral framework. It has shown that the two roles have in common some of the character virtues required to be an ethical person, (e.g., honesty, diligence, fairness, discretion). It has also shown that the focus of the role of manager and the role of doctor are quite different, and that the ethical dilemmas they face call upon quite different types of considerations. However, faced with the same dilemmas, doctors and managers made similar choices, albeit that managers show concern for the organisation's interests where doctors show very little and place all emphasis on the patient's interests.

Additionally, it seems clear that the applied ethics literature benefits from the contribution of active empirical research. Such research lifts thinking from the individualistic case study and "what if" situations, to the recognition of roles, groups and organisations and the influences they have on how we lead our lives. The literature is remarkable for the paucity of research and discussion on anything other than individuals in the health setting. This research has been able to contribute insights to 
roles and groups in health organisations, and the day to day dynamics that influence them, without becoming seduced by the heart rending detail of the sensational ethical dilemmas which fill the literature. The joy of the sensational is that there is no doubt that one is facing an ethical dilemma of huge proportion. The challenge of the day to day, the humdrum, is the handling of ethical issues as a matter of course. The contribution of this research is an understanding of medical ethics and managerial ethics on a day to day basis.

In Chapter 5 we addressed the methods commonly used in applied ethics research and chose a combination of methods from which we hoped to overcome some of the problems which have plagued research in this area. The repertory grid interview technique proved a useful data collection tool and yielded a rich set of construct information to form the basis of the survey questionnaire. However, the perennial problem of voluntary survey research is the self-selecting nature of the sample. Only people at least moderately interested in ethics will bother to take the time to complete the questionnaire or take part in the interview. It is the nature of modern organisations that managers and professionals are increasingly busy and inundated with requests for information. As a result survey questionnaires need to be brief, clearly worded and attractively laid out. However, brevity, while possibly increasing responses, restricts the scope of the research. This research opted for scope and possibly sacrificed a few responses. Sensitivity over privacy issues made it impossible for the researcher to contact the survey sample directly (e.g., by telephone), although postal reminders did increase the response rate. The level of non-response (67\% for doctors, $50 \%$ for managers) was not unusual for surveys of these groups. While it may be argued that such non-response limits one's ability to generalise the results to the total doctor and manager population, the clear themes and preferences identified in these results provide a confident basis for speculation and theorising. Response levels will continue to be a challenge to researchers, particularly in the health sector, and requires careful deliberation over choice of research methods. However it is clear that method in applied ethics research has much to gain from psychology and the social sciences.

This research also contributes to the knowledge base of psychology. In Chapter 5 we discovered that industrial/organisational psychology has not paid much attention to ethics in organisations. However, this research shows that ethical belief can be an important influence on organisational behaviour. In addition we discussed a body of 
psychological research on individual ethics and values, but role-specific ethics (such as those attaching to the management role, and the professional role) have not been explored. Given that there is a large literature on role conflict and role ambiguity the gap in regard to role-related ethics seems surprising. However, this research provides organisational psychology with insights to role-related ethics and the difference in perspective of managers and doctors which impacts on organisational behaviour.

\section{Future Directions for Research}

No research is complete without thoughts of improvements or areas for further discovery. A number of new directions for research are apparent, some in medical and/or managerial ethics, and some in applied ethics generally. For instance:

1. This research has suggested that health management ethics are, in several important ways, different from business management ethics. However, it was never the intention of the research to investigate these two branches of management ethics, hence the differences are nothing more than strong suggestions at this stage. It would be interesting in future research to actively compare health managers and commercial business managers - their roles, the ethical challenges they face, and what they regard as an ethical manager.

2. This research focused on those managers and doctors working in the public health system. It would be informative to conduct similar research in the private health sector.

3. Above all, this research has illustrated the power of role perceptions and role expectations to shape what is seen as ethical or unethical. It would be interesting to further test the linkage between these factors, both for its contribution to theory formulation in applied ethics, and for its potential contribution to deeper understanding of organisational behaviour. 


\section{Postscript}

At the completion of this thesis there has been a change of government in New Zealand. The new coalition government has announced that there are to be further changes to the health system. The most prominent of these changes is that Crown Health Enterprises are no longer required to make a profit, but they are to operate in a 'businesslike' manner. All the managers and doctors who gave up their time to take part in this research may now feel somewhat vindicated, as the government appears to have realised that health management in a public health system is indeed a special sort of management, and not one that fits directly into the commercial/business mould. 


\section{REFERENCES}

Alam, K. (1991). Business ethics in short supply in New Zealand. Massey Focus, (Spring), 6-7.

Almond, B. (Ed.). (1995). Introducing applied ethics. Oxford, U.K.:Blackwell.

Argyris, C. (1982). Reasoning, learning and action: Individual and organisational. San Francisco: Jossey-Bass.

Argyris, C. (1990). Overcoming organisational defenses - Facilitating organisational learning. Boston: Allyn and Bacon.

Argyris, C., \& Schon, D.A. (1974). Theory in practice: Increasing professional effectiveness. San Francisco: Jossey-Bass.

Argyris, C., \& Schon, D.A. (1978). Organizational learning: A theory of action perspective. Reading, Mass.: Addison-Wesley.

Auckland Healthcare: Annual Report 1994/95.

Baker, R., Porter, D., \& Porter, R. (Eds.). (1993). The codification of medical morality, volume 1: Medical ethics and etiquette in the eighteenth century. (Philosophy \& Medicine Series no. 45). Dordrecht: Kluwer Academic.

Bannister, D., \& Fransella, F. (1986). Inquiring man: The psychology of personal Constructs. (3rd ed.). London: Croom Helm.

Bayles, M.D. (1989). Professional ethics. (2nd ed.). Belmont, Calif.: Wadsworth.

Beauchamp, T.L. (1994). The ‘Four Principles’ Approach. In R. Gillon (Ed.). Principles of health care ethics. (pp.3-12). Chichester, U.K.: John Wiley \& Sons. 
Beauchamp, T.L., \& Childress, J.F. (1979). Principles of biomedical ethics. New York: Oxford University Press.

Beauchamp, T.L., \& Childress, J.F. (1989). Principles of biomedical ethics. (3rd ed.). New York: Oxford University Press.

Belgrave, M.P. (1985). Medical men and lady doctors : The making of a New Zealand profession 1867 - 1941. Unpublished Doctoral Thesis, Victoria University of Wellington.

Bell, R. (1994). Using SPSS to analyse repertory grid data. Unpublished manual, Department of Psychology, University of Melbourne.

Bendix, R. (1956). Work and authority in industry: Ideologies of management in the course of industrialisation. New York: Wiley.

Beresford, E.B. (1991). Uncertainty and the shaping of medical decisions. Hastings Center Report, July-August, 6-11.

Blanchard, K., \& Peale, N.V. (1988). The power of ethical management. London: Heinemann Kingswood.

Boam, R., \& Sparrow, P. (1992). Designing and achieving competency: A competencybased approach to developing people and organisations. London: McGraw-Hill.

Boyatzis, R. (1982). The competent manager: a model for effective performance. New York: Wiley.

Brennan, M., Ennis, M., \& Esslemont, D. (1992). The ethical standards of New Zealand business managers. New Zealand Journal of Business, 14, 100-124. 
Bryson, J.E. (1993, August). Applied ethics re-examined: Contributions from organisational psychology. Paper presented at AAPAE Conference: Philosophy and applied ethics re-examined, University of Newcastle, Australia.

Bryson, J.E. (1994). Global health ethics ?: Pluralism rules OK. New Zealand Medical Journal, 107, 271-273.

Buchanan, A.E., \& Brock, D.W. (1989). Deciding for others: The ethics of surrogate decisionmaking. Cambridge: Cambridge University Press.

Callahan, J.C. (Ed.).(1988). Ethical issues in professional life. New York: Oxford University Press.

Campbell, A.V. (1984). Moral dilemmas in medicine. (3rd ed.). Edinburgh: Churchill Livingstone.

Chapman, C.B. (1984). Physicians, law and ethics. New York: New York University Press.

Chown, E. (1990). Ethical dimensions of health administration. (Monograph Series). Ottawa: Canadian College of Health Service Executives.

Clouser, K.D., \& Gert, B. (1994). Morality vs principlism. In R. Gillon (Ed.), Principles of health care ethics, (pp.251-266). Chichester, U.K.: John Wiley \& Sons.

Cole, D. (1995). Medical practice in New Zealand: A guide to doctors entering practice. (August 1995). Wellington: Medical Council of New Zealand.

Cooper, C.L. (Ed.).(1991). Industrial \& organisational psychology. (Volume 1). Aldershot: Edward Elgar Publishing.

Cooper, T.L. (Ed.). (1994). Handbook of administrative ethics. New York: Marcel Dekker. 
Corfield, P.J. (1995). Power and the professions in Britain 1700 -1850. London: Routledge.

Cousins, M., \& Hussain, A. (1984). Michel Foucault. London: MacMillan.

Coverdale, J., Thomson, A.N., \& White, G.E. (1995). Sexual contact between general practitioners and patients: attitudes and prevalence. British Journal of General Practice; 45, 245-247.

Cox, C.J., \& Cooper, C.L. (1988). High flyers: An anatomy of managerial success. Oxford, U.K.: Blackwell.

Darr, K. (1991). Ethics in health services management. (2nd ed.). Ann Arbor, Mich.: Health Professions Press.

DeGeorge, R.T. (1982). Business ethics. NewYork: Macmillan.

DeMarco, J.P., \& Fox R.M. (Eds.). (1986). New directions in ethics: The challenge of applied ethics. New York: Routledge \& Kegan Paul.

Duncan, W.J. (1989). Great ideas in management. San Francisco: Jossey-Bass.

Dunham, R.B., \& Pierce J.L. (1989). Management. Glenview, Ill.: Scott Foresman.

Dunn, W.N., \& Ginsberg, A. (1986). A sociocognitive network approach to organizational analysis. Human Relations, 40, 955-976.

Dunnette, M.D., \& Hough, L.M. (Eds.).(1990). Handbook of industrial and organisational psychology. (2nd ed.).(Vol. 1). Palo Alto, Calif.: Consulting Psychologists Press. 
Dunnette, M.D., \& Hough, L.M. (Eds.).(1991). Handbook of industrial and organisational psychology. (2nd ed.).(Vol. 2). Palo Alto, Calif.: Consulting Psychologists Press.

Dunnette, M.D. (1991). Blending the science and practice of industrial and organisational psychology: where are we and where are we going?. In M.D.Dunnette \& L.M.Hough (Eds.), Handbook of industrial and organisational psychology, (2nd ed.,Vol.2, pp.1-27). Palo Alto, Calif.: Consulting Psychologists Press.

Dunsire, A. (1994). Ethics in governance: the United Kingdom 1979-1990. In R.M.Thomas (Ed.), Teaching ethics: Government ethics, (Vol.1, pp.315-334). Cambridge, U.K.: Centre for Business and Public Sector Ethics.

Feldman, S.P. (1996). The ethics of shifting ties: Management and the breakdown of culture in modernity. Journal of Management Studies 33(3), 283-299.

Fondas, N., \& Stewart, R. (1994). Enactment in managerial jobs: A role analysis. Journal of Management Studies 31(1), 83-103.

Forsyth D.R. (1980). A taxonomy of ethical ideologies. Journal of Personality and Social Psychology, 39, 175-184.

Foucault, M. (1973). The birth of the clinic: An archaeology of medical perception. New York: Pantheon Books.

Frederick, W.C. (Ed.).(1987). Research in corporate social performance and policy: Empirical studies of business ethics and values. (Vol.9). Greenwich, Conn.: JAI Press.

Frederickson, H.G. (Ed.).(1993). Ethics and public administration. Armonk, N.Y.: M E Sharpe. 
Frederickson, H.G. (1994). Research and knowledge in administrative ethics. In Cooper, T. (Ed.), Handbook of administrative ethics, (pp.31-48). New York: Marcel Dekker.

Freeman, R.E. (1990). Ethics in the workplace: recent scholarship. In C.L.Cooper \& I.T.Robertson (Eds.), International review of industrial \& organisational psychology, (Vol. 5, pp.149-167). Chichester, U.K.: John Wiley \& Sons.

Freidson, E. (Ed.). (1963). The hospital in modern society. New York: Free Press of Glencoe.

Fritzsche, D.J., \& Becker, H. (1984). Linking management behaviour to ethical philosophy - An empirical investigation. Academy of Management Journal, 27(1), 166-175.

Fritzsche, D.J. (1995). Personal values: Potential keys to ethical decision making. Journal of Business Ethics 14, 909-922.

Fulford, K.W.M., Gillett, G., \& Soskice, J.M. (1994). Medicine and moral reasoning. Cambridge, U.K.:Cambridge University Press.

Gewirth, A. (1986). Professional ethics: The separatist thesis. Ethics, 96 (January), 282300.

Giacalone, R.A., Fricker, S., \& Beard, J.W.(1995). The impact of ethical ideology on modifiers of ethical decisions and suggested punishment for ethical infractions. Journal of Business Ethics, 14, 497-510.

Gibbs, A. (Chairman).(1988). Unshackling the hospitals: Report of the hospital and related services taskforce. Wellington, N.Z.: New Zealand Government.

Gilligan, C. (1982). In a different voice: Psychological theory and women's development. Cambridge, Mass.: Harvard University Press. 
Gilligan, C. (1987). Moral orientation and moral development. In E.F.Kittay \& D.T.Meyers (Eds.), Women and moral theory, (pp.19-33). Totowa, N.J.: Rowman \& Littlefield.

Gilligan, C., Ward, J.V., Taylor, J.M., \& Bardige, B. (Eds.).(1988). Mapping the moral domain. Cambridge, Mass.: Harvard University Press.

Gillon, R. (Ed.)., \& Lloyd, A. (Assitant Ed.).(1994). Principles of health care ethics. Chichester, U.K.: John Wiley \& Sons.

Glaser, J.W. (1994). Three realms of ethics. Kansas City, MO.: Sheed \& Ward.

Goldman, A.H. (1980). The moral foundations of professional ethics. Totowa, N.J.: Rowman and Littlefield.

Goss, M.E.W. (1963). Patterns of bureaucracy among hospital staff physicians. In E.Freidson (Ed.), The hospital in modern society, (pp.170-194). New York: Free Press of Glencoe.

Granshaw, L., \& Porter, R. (Eds.).(1989). The hospital in history. London: Routledge.

Griffith, J.R. (1993). The moral challenges of health care management. Ann Arbor, Mich.: Health Administration Press.

Grodin, M.A. (Ed.).(1995). Meta medical ethics: The philosophical foundations of bioethics. Boston: Kluwer Academic.

Hales, C.P. (1986). What do managers do? A critical review of the evidence. Journal of Management Studies 23(1), 88-115.

Haralambos, M., van Krieken, R., Smith, P., \& Holborn, M. (1996). Sociology: Themes and perspectives. Melbourne: Addison Wesley Longman. 
Hegarty, W.H., \& Sims, H.P.Jr. (1978). Some determinants of unethical decision behaviour: An experiment. Journal of Applied Psychology, 63(4), 451-457.

Hogan, R. (1973). Moral conduct and moral character. Psychological Bulletin, 79, 217232.

Hurley, G. (1988). The decay of business ethics. Management, November:27-34.

Jack, D., \& Jack, R. (1988). Women lawyers: Archetype and alternatives. In C.Gilligan, J.V.Ward, J.M.Taylor, \& B.Bardige (Eds.), Mapping the moral domain, (pp.263288). Cambridge, Mass.: Harvard University Press.

Jackall, R. (1988). Moral mazes. New York: Oxford University Press.

Jamieson, D. (1988). In D.M.Rosenthal \& F.Shehadi (Eds.), Applied ethics and ethical theory, (pp.116-138). Salt Lake City: University of Utah Press.

Jensen, U.J., \& Mooney, G. (Eds.).(1990). Changing values in medical and health care decision making. Chichester, U.K.: John Wiley \& Sons.

Johnson, E.A., \& Johnson, R.L. (1982). Hospitals in transition. Rockville, Md.: Aspen Systems Corporation.

Jonsen, A.R. (1990). The new medicine \& the old ethics. Cambridge, Mass.: Harvard University Press.

Jonsen, A.R. (1991). Of balloons and bicycles or the relationship between ethical theory and practical judgement. Hastings Center Report, (September-October),14-16.

Kelly, G.A. (1955). The psychology of personal constructs, vol 1: A theory of personality, vol 2: Clinical diagnosis and psychotherapy. New York: W.W. Norton. 
Ketefian, S., with Ormond, I. (1988). Moral reasoning and ethical practice in nursing: an integrative review. New York: National League for Nursing.

Kohlberg, L. (1984). Essays on moral development. San Francisco: Harper \& Row.

Kolb, D.A., Rubin, I.M., \& McIntyre, J.M. (Eds.).(1984). Organisational psychology: readings on human behaviour in organisations. Englewood Cliffs, N.J.: PrenticeHall.

Koontz, H. (1961). The management theory jungle. Journal of the Academy of Management, 4(3), 182-186.

Koontz, H. (1980). The management theory jungle revisited. Academy of Management Review, 5(2), 175-187.

Laugesen, M., \& Salmond, G. (1994). New Zealand health care: A background. Health Policy, 29(1,2), 11-25.

Leavitt, H.J., \& Pondy, L.R. (Eds.).(1964). Readings in managerial psychology. Chicago: University of Chicago Press.

Lemieux-Charles, L., Meslin, E.M., Aird, C., Baker, R., \& Leatt, P. (1993). Ethical issues faced by clinician/managers in resource-allocation decisions. Hospital \& Health Services Administration, 38(2), 267-285.

Lemieux-Charles, L., Meslin, E., \& Wortley, J.T. (1993). Ethical issues faced by clinician-managers in resource allocation: results of a provincial survey. (Technical Report No. 13). Hospital Management Research Unit, University of Toronto.

Levey, S. (Ed.).(1992). Hospital leadership and accountability. Ann Arbor, Mich.: Health Administration Press. 
Lippke, R.L. (1995). Radical business ethics. Lanham, Md.: Rowman \& Littlefield.

Longstaff, S. (1993). In respect of fairness. Unpublished report for New Zealand Department of Health.

Mant, A. (1977). The rise and fall of the British manager. Basingstoke: Macmillan Press.

Margerison, C., \& Kakabadse, A. (Eds.).(1979). European insights - Leadership and organisation development. Bradford, West Yorkshire: MCB Human Resources.

Mariner, W.K. (1995). Business vs medical ethics: Conflicting standards for managed care. Journal of Law, Medicine \& Ethics, 23, 236-246.

Marshall, B. (1992). Identifying the components of organisational fit. Department of Human Resource Management Working Paper Series 92/6, Faculty of Business Studies, Massey University, New Zealand.

Mathews, M.C. (1988). Strategic intervention in organisations - Resolving ethical dilemmas. Newbury Park, Calif.: Sage Publications.

Maxwell, R.J. (1994). Health care management: Are ethics relevant?. In R.Gillon (Ed.), Principles of health care ethics, (pp.819-828). Chichester, U.K.: John Wiley \& Sons.

May, W.F. (1994). The virtues in a professional setting. In K.W.M.Fulford, G.Gillett, \& J.M.Soskice, Medicine and moral reasoning, (pp.75-90). Cambridge, U.K.: Cambridge University Press.

Medical Council of New Zealand. (1993). Annual Report for year ended 30 June 1993.

Medical Council of New Zealand. (1994). Annual Report for year ended 30 June 1994. 
Medical Council of New Zealand. (1995). Annual Report for year ended 30 June 1995.

MidCentral Health Ltd: Annual Report 1994/95.

Ministry of Health and Crown Health Enterprise Establishment Unit. (1993). Ethical standards for Crown Health Enterprises: Guidelines. (September). Wellington: New Zealand Government.

Mintzberg, H. (1980). The nature of managerial work. Englewood Cliffs, N.J.: PrenticeHall.

Miyaji, N.T. (1993). The power of compassion: Truth telling among American doctors in the care of dying patients. Social Science and Medicine, 36(3), 249-264.

McDonald, G.M. (1992). Business ethics in Hong Kong. Business Ethics: A European Review, 1(1), 59-61.

McDowell, B. (1991). Ethical conduct and the professional's dilemma: choosing between service and success. New York: Quorum Books.

MacIntyre, A. (1981). After virtue: A study in moral theory. London: Duckworth.

MacIntyre, A. (1984). Does applied ethics rest on a misnomer ?. The Monist, 67(4), 498-513.

McNeill, P.M., Walters, J.D., \& Webster, I.W. (1994). Ethical issues in Australian hospitals. The Medical Journal of Australia, 160(17 January), 63-65.

McNerney, W.J. (1985). Managing ethical dilemmas. Journal of Health Administration Education(Summer), 331-340.

Nelson Marlborough Health Services Ltd: Annual Report 1994/95. 
Neutze, J. (1993). Health reforms and the public hospitals. New Zealand Medical Journal, (2 January), 17-18.

Ng, S.H.(1980). The social psychology of power. London: Academic Press.

Ng, S.H., Jenkins, L., Dixon, A., \& Cram, F. (1992). Nurses and their work: Te mahi naahi. Wellington: Department of Health, Health Research Services.

Overman, E.S., \& Foss, L. (1993). The ethics of physicians and citizens: an empirical test of the "separatist thesis". In Frederickson, H.G. (Ed.), Ethics and public administration, (pp.121-135). Armonk, N.Y.: M.E.Sharpe.

Owen, D. (1976). In sickness and in health: The politics of medicine. London: Quartet Books.

Paul, K. (Ed.).(1987). Business environment and business ethics: The social, moral and political dimensions of management. Cambridge, Mass.: Ballinger.

Peach, J. (1994). An approach to the development of management skills: A retrospective evaluation of the national health services management development programmes 1988 to 1992. Unpublished Masters Dissertation, Massey University, Palmerston North.

Pellegrino, E.D., \& Thomasma, D.C. (1988). For the patient's good: The restoration of beneficence in health care. New York: Oxford University Press.

Perrow, C. (1963). Goals and power structures: a historical case study. In Freidson, E. (Ed.), The hospital in modern society,(pp.112-146). New York: Free Press of Glencoe.

Peters, T.J., \& Waterman, R.H. (1984). In search of excellence: Lessons from america's best-run companies. New York: Warner Books. 
Prokopenko, J. (1989). Management implications of structural adjustment. (Man Dev/54). Geneva: International Labour Office.

Raelin, J.A. (1991). The clash of cultures: Managers managing professionals. Boston, Mass.: Harvard Business School Press.

Randall, D.M., \& Gibson, A.M. (1990). Methodology in business ethics research: A review and critical assessment. Journal of Business Ethics, 9, 457-471.

Rawls, J. (1971). A theory of justice. Oxford: Clarendon Press.

Rawwas, M.Y.A., Strutton, D., \& Pelton, L. (1994). Ethical attitudes of mental health practitioners: Balancing therapeutic practices and treatments. Journal of Business Ethics, 13, 597-608.

Reidenbach, R.E., \& Robin, D.P. (1988). Some initial steps toward improving the measurement of ethical evaluations of marketing activities. Journal of Business Ethics, 7, 871-879.

Reidenbach, R.E., \& Robin, D.P. (1990). Towards the development of a multidimensional scale for improving evaluations of business ethics. Journal of Business Ethics, 9, 639-653.

Reiser, S.J. (1994). The ethical life of health care organizations. Hastings Center Report, 24(6), 28-35.

Rest, J. (1986). Moral development: Advances in research and theory. New York: Praeger.

Rippin, S.M. (1995). Competencies used to assess the effectiveness of New Zealand managers. Unpublished Doctoral Dissertation, Victoria University of Wellington.

Rokeach, M. (1973). The nature of human values. New York: Free Press. 
Rosen, G. (1963). The hospital: historical sociology of a community institution. In E.Freidson (Ed.), The hospital in modern society, (pp.1-36). New York: Free Press of Glencoe.

Roth, J.K. (Ed.).(1995). International encyclopedia of ethics. London: Fitzroy Dearborn.

Ryle, A. (1975). Frames and cages: The repertory grid approach to human understanding. London: Published for Sussex University by Chatto and Windus.

Salmond, G., Mooney, G., \& Laugesen, M. (1994). Introduction to health care reform in New Zealand. Health Policy, 29(1,2), 1-5.

Schein, E. (1980). Organisational psychology. (3rd ed.). Englewood Cliffs, N.J.: Prentice-Hall.

Schon, D.A. (1983). The reflective practitioner: How professionals think in action. New York: Basic Books.

Scott, C. (1993). Viewpoint: Health Issues. Public Sector, 16,4.

Seedhouse, D. (1994, April). Health care values or business values?. Paper presented at AIC Medico Legal Conference, Auckland, New Zealand.

Senge, P.M. (1993). The fifth discipline: The art and practice of the learning organisation. London: Century Business.

Shortell, S.M., \& Kaluzny, A.D. (1988). Health care management: A text in organisation theory and behaviour. (2nd ed.). Albany, N.Y.:Delmar Publishers.

Siegel, S., \& Castellan, N.J. (1988). Nonparametric statistics for the behavioural sciences. (2nd ed.). New York: McGraw-Hill. 
Simon, H. (1960). The new science of management decision. New York: Harper.

Solomon, R. (1996). Virtue ethics and business ethics. In K.Woldring (Ed.), Business ethics in Australia and New Zealand - Essays and cases, (pp.22-41). South Melbourne: Thomas Nelson.

Soutar, G., McNeil, M., \& Molster, C. (1996). Ethical decisions: the impact of the work environment. In K.Woldring (Ed.), Business ethics in Australia and New Zealand Essays and cases, (pp.84-99). South Melbourne: Thomas Nelson.

Stacey, M. (1992). Medical accountability: A background paper. In A.Grubb (Ed.), Challenges in medical care, (pp.109-140). Chichester, U.K.:Wiley.

Starr, P. (1982). The social transformation of American medicine. New York: Basic Books.

Sternberg, E. (1994). Just business: Business ethics in action. London: Warner.

Stewart, D., \& Sprinthall, N. (1993). The impact of demographic, professional, and organizational variables and domain on the moral reasoning of public administrators. In H.G.Frederickson (Ed.), Ethics and public administration, (pp.205-219). Armonk, N.Y.: M.E.Sharpe.

Stewart, V., Stewart, A., \& Fonda, N. (1981). Business applications of repertory grid. London: McGraw Hill.

Stoeckle, J.D. (1988). Reflections on modern doctoring. The Milbank Quarterly, 66, (Supplement 2), 76-91.

Strange, T. (1992). Ethics: Can they be taught?. Management, December: 49-54. 
Sylvan, R. (1993,August). What is wrong with applied ethics. Paper presented at the AAPAE Conference: Philosophy and Applied Ethics Re-examined, University of Newcastle, Australia.

Tannebaum, A.S. (1966). Social psychology of the work organization. Belmont, Calif.: Wadsworth.

ten Have, H., \& Kimsma, G. (1990). Changing conceptions of medical ethics. In U.J.Jensen, \& G.Mooney (Eds.), Changing values in medical and health care decision making, (pp.33-52). Chichester, U.K.: John Wiley \& Sons.

Thomson, A.N., \& White, G.E. (1995). Attitudes toward sexual contact between general practitioners and their patients. New Zealand Medical Journal, 108, 247-249.

Toulmin, S. (1973). How medicine saved the life of ethics. Perspectives in Biology and Medicine 25(4), 736-750.

Trice, H.M. (1993). Occupational subcultures in the workplace. Ithaca, N.Y.: ILR Press.

Tuleja, T. (1985). Beyond the bottomline: How business leaders are turning principles into profits. New York: Facts on File Publications.

Vallance, E. (1995). Business ethics at work. Cambridge, U.K.: Cambridge University Press.

Veatch, R.M. (1988). Models for ethical medicine in a revolutionary age. In J.C.Callahan (Ed.), Ethical issues in professional life, (pp.89-92). New York: Oxford University Press.

Veatch, R.M. (1981). A theory of medical ethics. New York: Basic Books. 
Vogel, M.J. (1989). Managing medicine: creating a profession of hospital administration in the United States, 1895-1915. In L.Granshaw and R.Porter (Eds.), The hospital in history, (pp.243-260). London: Routledge.

Wake Carroll, B. (1993). The biases of management. London: Routledge.

Wall, A. (1989). Ethics and the health services manager. London: King's Fund.

Wall, A. (1993) Values and managers. Bulletin of Medical Ethics, (August), 3-4.

Weber, J. (1993). Exploring the relationship between personal values and moral reasoning. Human Relations, 46(4), 435-463.

Woldring, K. (Ed.).(1996). Business ethics in Australia and New Zealand - Essays and cases. South Melbourne: Thomas Nelson.

Wolf, S.R. (Ed.).(1996). Feminism and bioethics: Beyond reproduction. New York: Oxford University Press.

Wren, D. (1987). The evolution of management thought. (3rd ed.). New York: John Wiley \& Sons.

Yukl, G.A., \& Van Fleet, D.D. (1992). Theory and research on leadership in organisations. In M.D.Dunnette \& L.M.Hough (Eds.), Handbook of industrial \& organisational psychology, (2nd ed.)(Vol. 3, pp.147-197). Palo Alto, Calif.: Consulting Psychologists Press.

Zaner, R.M. (1988). Ethics and the clinical encounter. Englewood Cliffs, N.J.: PrenticeHall. 


\section{APPENDICES}

Appendix A: New Zealand Medical Association Code Of Ethics

Appendix B: New Zealand Institute of Management Code of Ethics

Appendix C: Letter to pilot study participants

Appendix D: Letter to interview study participants

Appendix E: Ethical/unethical bipolar constructs from interviews

\section{Appendix F: Survey Questionnaire}

\section{Appendix G}

Table G1: Survey sample representativeness by group

Table G2: Survey sample response rate by group

Table G3: Survey sample by gender and age group

Table G4 : Manager sample - health professional and non health professional backgrounds by gender and age group

Table G5: Doctor sample by area of work/specialty

Table G6: Manager sample by area of work

Table G7: CHE budget responsibility

Table G8: Survey sample by health sector work experience and education and training

Table G9: Survey sample by helpfulness of education and training

Table G10: Survey sample by hospital size

Table G11: Sample by future employment in health sector 


\section{Appendix A: New Zealand Medical Association Code Of Ethics}

\section{CODE OF ETHICS}

Principles of Ethical Behaviour applicable to all physicians including those who may not be engaged directly in clinical practice.

1. Consider the health and well-being of your patient to be your first priority.

2. Strive to improve your knowledge and skill so that the best possible advice and treatment can be afforded to your patient.

3. Honour your profession and its traditions.

4. Recognise both your own limitations and the special skills of others in the prevention and treatment of disease.

5. Protect the patient's secrets even after his or her death.

6. Let integrity and professional ability be your chief advertisement.

GUIDE TO THE ETHICAL BEHAVIOUR OF PHYSICIANS

The Profession of Medicine has a duty to safeguard the health of the people and minimise the ravages of disease. Its knowledge and conscience must be directed to these ends. Ethical codes have developed to guide the members of the profession in achieving them. The Hippocratic Oath was an initial expression of such a code. More recent codes have developed from this and from a consideration of modern ethical dilemmas and these are embodied in the Declaration of Geneva (1948) and the World Medical Association International Code of Medical Ethics (1949, 1968 and 1983), and in the following statements by the World Medical Association which deal with particular issues: The Declaration of Helsinki dealing with biomedical research (1964, 1975 and 1983); the Declaration of Oslo dealing with therapeutic abortion (1970 and 1983); the declaration of Tokyo dealing with a doctor's responsibility towards prisoners (1975); the Declaration of Lisbon dealing with patient's rights (1981); and the Declaration of Venice which deals with terminal illness (1983). These have been endorsed by each member organisation, including the New Zealand Medical Association, as general guides having worldwide application.

The New Zealand Medical Association accepts the responsibility of delineating the standard of ethical behaviour expected of New Zealand Medical Practitioners.

An interpretation of these principles is developed in the following pages, as a guide for individual doctors.

\section{RESPONSIBILITIES TO THE PATIENT}

\section{Standard of Care}

1. Practise the science and art of medicine to the best of one's ability in full technical and moral independence and with compassion and respect for human dignity.

2. Continue self education to improve one's personal standards of medical care.

3. Ensure that every patient receives a complete and thorough examination into their complaint or condition. 
4. Ensure that accurate records of fact are kept.

\section{Respect For Patient}

5. Ensure that all conduct in the practise of the profession is above reproach, and that neither physical, emotional nor financial advantage is taken of any patient.

\section{Patient's Right}

6. Recognise a responsibility to render medical service to any person regardless of colour, religion, political belief, and regardless of the nature of the illness so long as it lies within the limits of expertise as a practitioner.

7. Accept the right of all patients to know the nature of any illness from which they are known to suffer, its probable cause, and the available treatments together with their likely benefits and risks.

8. Allow all patients the right to choose their doctors freely.

9. Recognise one's professional limitations and, when indicated, recommend to the patient that additional opinions and services be obtained.

10. Keep in confidence information derived from a patient, or from a colleague regarding a patient, and divulge it only with the permission of the patient except when the law requires otherwise.

11. Recommend only those diagnostic procedures which seem necessary to assist in the care of the patient and only that therapy which seems necessary for the well-being of the patient. Exchange such information with patients as is necessary for them to make informed choices where alternatives exist.

12. When requested, assist any patient by supplying the information required to enable the patient to receive any benefits to which he or she may be entitled.

13. Render all assistance possible to any patient where an urgent need for medical care exists.

\section{Continuity of Care}

14. Ensure that medical care is available to one's patients when one is personally absent, when professional responsibility for an acutely ill patient has been accepted, continue to provide services until they are no longer required, or until the services of another suitable physician have been obtained.

\section{Personal Morality}

15. When a personal moral judgement or religious conscience alone prevents the recommendation of some form of therapy, the patient must be so acquainted and an opportunity afforded the patient to seek alternative care.

Clinical Research (This section summarises the principles outlined in the Declaration of Helsinki)

16. Recognise that medical progress is based on research which ultimately must rest on experimentation and systematic observations involving human subjects. Accept a responsibility to medicine to participate in such studies where possible.

17. Before initiating any clinical research involving human beings ascertain that previous research and the purpose of the experiment justify this additional investigation. Determine that the studies proposed may reasonably be expected to provide the answer to questions raised. Ensure that a responsible committee that is independent of the investigators appraises any such clinical research both 
scientifically and ethically. Ascertain that the study is sufficiently planned and supervised so that the subjects are unlikely to suffer any harm. Before proceeding obtain the consent of all subjects or their agents, but only after explaining the purpose of the clinical research and any possible health hazard which can be reasonably foreseen.

Do not allow a refusal to participate in a study to interfere with the doctor-patient relationship.

18. Never allow the interests of science or society to take precedence over considerations related to the well-being of the subject. In any medical study ensure that every patient is assured of the best proven diagnostic and therapeutic methods. 19. Protect the right of any doctor to prescribe and any patient to receive any new drug or treatment which in the doctor's mature and considered judgement offers hope of saving life, re-establishing health or alleviating suffering. In all such cases the doctor must fully inform the patient about the drug or treatment including the fact that the treatment is new or unorthodox where such is the case.

\section{Reporting Medical Research}

20. Ensure that the first communication of the results of research is through recognised scientific channels in order that the results may be open to scrutiny from an informed group within the profession who can establish an opinion of its merits to help its balanced presentation to the public.

\section{Clinical Teaching}

21. Recognise that clinical teaching is the basis on which sound clinical practice in the future is based. Before embarking on any clinical teaching involving patients ensure that they fully understand what is involved and have freely consented to what is proposed. Do not allow a refusal to participate in a study or in teaching to interfere with the doctor-patient relationship. In any teaching exercise ensure that every patient is assured of the best proven diagnostic and therapeutic methods.

\section{The Dying Patient}

22. Always bear in mind the obligation of preserving life, but allow death to occur with dignity and comfort when the death of the body appears to be inevitable.

\section{Transplantation}

23. Accept that when the death of the brain has occurred cellular life in the body may be supported if some parts of the body might be used to prolong or improve the health of others.

24. Recognise full responsibility to the donor of organs that are to be transplanted to give to the donor or his or her relatives full disclosure of such an intent and the purpose of the procedure; in the case of a living donor also explain the risks of the procedure.

25. Ensure that the determination of the time of death of any donor patient is made by doctors who are in no way concerned with the transplant procedure or associated with any proposed recipient in a way that might exert any influence upon any decisions made.

\section{Fees to Patients}


26. Be responsible in setting a value on your services and consider the personal service rendered when determining any fee. Be prepared to discuss any fee with the patient.

RESPONSIBILITIES TO THE PROFESSION

\section{Personal Conduct}

27. Recognise that the profession demands integrity in and dedication to its search for truth and its service to mankind.

28. Ensure that one's professional conduct is beyond reproach and report to the appropriate body of peers any conduct by a colleague which may be considered unethical or unbecoming to the profession. In other circumstances avoid impugning the reputations of other doctors.

29. Accept a responsibility for one's personal health both mental and physical. To this end have the right, except in an emergency, to refuse to accept a patient, or, in any other situation i.e. not an emergency, to withdraw from the responsibility for the care of any patient provided that the patient is given adequate notice of this intention and alternative care is reasonably available. (This rule must, however, not be allowed to over-ride rule 6.)

\section{Contracts}

30. Only enter into a contract with an organisation if it will allow the maintenance of professional integrity.

31. Only offer to a colleague a contract which has terms and conditions equitable to both parties.

\section{Addressing the Public}

32. Recognise a responsibility to give the generally-held opinions of the profession when interpreting scientific knowledge to the public. In presenting any personal opinion which is contrary to the generally-held opinion of the profession, indicate that this is the case.

\section{Advertising}

33. Build a professional reputation based upon ability and integrity. Only advertise professional services or make professional announcements where the chief purpose of the notice is the factual presentation of information reasonably needed by any person to make an informed decision about the appropriateness and the availability of services that may meet his or her medical needs. Any advertisement must be demonstrably true in all respects, may not contain any testimonial or endorsement of clinical skills, and shall not be likely to bring the profession into disrepute.

34. Avoid advocacy of any particular non-medical commercial product if one is identified as a member of the medical profession.

35. Totally avoid the use of secret remedies. Ensure that any new therapeutic or diagnostic method is described through professional channels and the benefits, if proved made available to the profession at large.

\section{Consultation}

36. Request the opinion of an appropriate colleague acceptable to the patient if diagnosis or treatment is difficult or obscure, or if the patient requests it. Having 
requested the opinion of a colleague, make available all relevant information and indicate clearly whether he or she is to assume the continuing care of the patient during this illness.

37. When an opinion has been requested by a colleague, report in detail the findings and recommendations to the referring doctor and provide the patient with an appropriate report. Continue with the care of the patient only at the specific request of the attending physician and with the consent of the patient.

\section{Patient Care}

38. Ensure that those persons assisting in the care of the patient are properly qualified to do so. Ensure that any doctor to whom the care of the patient is delegated is fully competent to carry out that care.

39. Make available to a colleague, on the request of the patient, a report of the findings and treatment of that patient.

40. Recognise that an established relationship between a doctor and patient has a value such as to dictate that it should not be disturbed unless there are compelling reasons to do so.

\section{Financial Arrangements}

41. Motives of profit shall never be permitted to influence the free and independent exercise of professional judgement on behalf of a patient.

\section{RESPONSIBILITIES TO SOCIETY}

\section{Personal Conduct}

42. Strive to improve the standards and quality of medical services in the community. 43. Accept a share of the profession's responsibility to society in matters relating to the health and safety of the public, health education, and legislation affecting the health or well-being of the community.

44. When a witness, recognise a responsibility to assist a court in arriving at a just decision. In all circumstances certify only that which has been personally verified. 45. Accept that it is not an individual doctor's role to determine society's attitudes in matters such as abortion or in vitro fertilisation but attempt always both to protect any patient and safeguard the rights of the doctor within society.

46. Regardless of society's attitude, no doctor shall countenance, condone or participate in the practice of torture or other forms of cruel, inhuman, or degrading procedure whatever the offence of which the victim of such procedures is suspected, accused, or guilty.

\section{Provision of Service in a Competitive Environment}

47. Doctors must at all times regard their duty to a patient, or to patients collectively, as overriding any loyalty to an employer or other health provider entity. In particular, doctors must not allow the commercial interests of an employer or health provider to interfere with;

a. the free exercise of clinical judgement in determining the best ways of meeting the needs of individual patients or the community, or

b. cooperation with such other health providers as may be in the patient's interest, or 
c. the completion of any treatment or package of care, or

d. the publication of regular and honest reports of their service provision, aims and achievements.

48. Doctors must not act, or allow the units that employ them to act, against the public interest.

49. Standards of care should not be compromised in order to meet financial or commercial targets whether these are set by a doctor personally or by an organisation. 


\section{Appendix B: New Zealand Institute of Management Code of Ethics}

Draft Code, NZIM News, Management magazine, December 1994

The management profession is an integral part of the successful operation of modern public and private organisations and the ability of those organisations to contribute to societal well-being. The New Zealand Institute of Management recognises this. It is committed to the pursuit of excellence for all organisations which utilise the skills of its members, so as to promote ultimately the well-being of New Zealand.

Such a goal can be attained only through the commitment of its members to the highest standards of managerial integrity and the realisation of this ideal through ethical action. The essential element of such ideals is the recognition by each member of his or her individual responsibilities as a manager to the stakeholder groups in the organisation that uses his or her skills as a manager.

This code of ethics embodies the ideals of the New Zealand Institute of Management. it sets out the responsibilities that each member has to his or her stakeholder groups. It should bind all members. The overarching responsibility upon all members is, when using one's management skills, to act at all times so as to discharge the responsibilities as manager with integrity. No code can cover all possible eventualities. Wise judgement and counsel are often required. nevertheless, this code provides the starting point.

As a member of the New Zealand Institute of Management I shall:

RESPONSIBILITIES TO THOSE WHO USE OUR MANAGERIAL SKILLS (EMPLOYERS)

1. At all times discharge my responsibilities as a manager with integrity, not misuse authority or office and ensure proper disclosure of any financial interest which conflicts with the financial interests of the organisation.

RESPONSIBILITIES TO THE COMMUNITY

2. Have regard for the interests of society in acting loyally and honestly in carrying out the policies of the organisation.

3. Demonstrate humanity and avoid all discriminatory practices including those relating to race, sex, religion and politics.

RESPONSIBILITIES TO THOSE WHO ARE THE OBJECT OF OUR MANAGERIAL SKILLS (PUBLIC, CUSTOMERS, FELLOW EMPLOYEES)

4. Not injure or attempt to injure, maliciously or recklessly, directly or indirectly, the professional reputation of others.

5. Respect the confidentiality of information which comes to me in the course of my duties.

6. Ensure the fair and equitable treatment of employees and respect cultural and moral values and the dignity of the individual.

7. Comply with the laws of New Zealand and operate within the spirit of those laws.

8. Make every endeavour to conserve the environment, balancing the rights of future generations with current economic needs. 
RESPONSIBILITIES TO THE PROFESSION

9. To behave in such a manner as to uphold the standing and reputation of the New Zealand Institute of Management. 


\section{Appendix C: Letter to pilot study participants}

Date

Name

Job Title

CHE name

Address

Town

Dear Name

\section{DOCTORAL RESEARCH: A COMPARISON OF MANAGERIAL ETHICS AND MEDICAL PROFESSIONAL ETHICS IN THE HEALTH SECTOR}

I am conducting a pilot study for my $\mathrm{PhD}$ research to look at ethics in the health sector, in particular the similarities and differences between the ethics of medical professionals and managers. Although there is a large body of ethics-related literature in health there has been very little actual empirical research in this particular area.

I would really appreciate it if you would be willing to take part in my pilot study. The aim of the pilot is to see whether the interview procedure is acceptable to participants and is able to elicit useful information.

By way of background, I have a Master of Science in Industrial and Organisational Psychology from the University of Canterbury and am a New Zealand registered psychologist. I am from a medical family and have worked as a manager and consultant in both the public and private sectors. I am being supervised in my doctoral research by Professor Sik Hung Ng (Psychology Department, Victoria University of Wellington) and Chris Parkin (Philosophy Department, Victoria University and Wellington School of Medicine).

Your participation in the pilot study would involve an interview with me in which I would firstly ask some general questions including age, length of time in current position, length of experience as medical professional and/or manager, your perception of the manager role and the medical professional role. I would then use a semi structured interview format in which I ask you to think of four people as follows:

1) An anonymous current or former colleague or acquaintance you regard as a highly ethical doctor

2) An anonymous current or former colleague or acquaintance you regard as an unethical doctor

3) An anonymous current or former colleague or acquaintance you regard as a highly ethical health sector manager

4) An anonymous current or former colleague or acquaintance you regard as an unethical health sector manager 
You will not be asked to reveal the identity of the people you have in mind, but you will be led through a process of drawing some comparisons between them.

Finally I will ask you to think of six occupation related situations you have been in three which have been situations of serious ethical dilemma, and three everyday situations. In these cases also I will lead you through a process of drawing some comparisons. You will not be asked to disclose any confidential information however a general description of the cases/situations you have in mind will be necessary.

On completion of the interview I will seek your comments on the process, so that it can be refined prior to the final study. You will receive a feedback report on the findings of the pilot study.

This pilot study has been approved by the Human Ethics Committee at Victoria University with the following standard provisions:

Your participation is entirely voluntary

Confidentiality is guaranteed, your individual anonymity will be preserved, and that of any individuals to whom you may refer in the course of the interview

You may withdraw from the pilot study at any point prior to the completion of data collection

You will be asked to evaluate the process and will receive feedback on the results of the research

At the beginning of the interview you will be asked to sign an informed consent form agreeing to take part in the research

I would be most grateful if you would be willing to take part in this research, and I am happy to answer any questions you may have in regard to the research, the area it relates to, or my background. I realise that your time is precious and I will schedule the interview to suit you. We will need to allow and uninterrupted (if possible) twohour time slot for the interview process.

I will contact you in the next day or so, or feel free to contact me on phone: $x x x x$.

I look forward to meeting with you.

Yours sincerely

Jane Bryson 


\section{Appendix D: Letter to interview study participants}

Date

Name

Job Title

CHE name

Address

Town

Dear Name

\section{DOCTORAL RESEARCH: A COMPARISON OF MANAGERIAL ETHICS AND MEDICAL PROFESSIONAL ETHICS IN THE HEALTH SECTOR}

Thank you for agreeing to be interviewed for my $\mathrm{PhD}$ research on "Day Date (timing)". I am looking forward to meeting with you and thought it useful to briefly outline my research and the interview format.

My research is looking at ethics in the health sector, in particular the similarities and differences between the ethics of medical professionals and managers. Although there is a large body of ethics related literature in health there has been very little empirical research in this particular area.

The aim of the interviews is to gather views from a range of doctors and managers on which to draw some conclusions and to develop a survey questionnaire to be distributed to a wider sample.

By way of background, I have a Master of Science in Industrial and Organisational Psychology from the University of Canterbury and am a New Zealand registered psychologist. I am from a medical family and have worked as a manager and consultant in both the public and private sectors. I am being supervised in my doctoral research by Professor Sik Hung Ng (Psychology Department, Victoria University of Wellington) and Chris Parkin (Philosophy Department, Victoria University and Wellington School of Medicine).

In your interview with me I will ask firstly, some general questions including age, length of time in current position, length of experience as medical professional and /or manager; and your perception of the manager role and the medical professional role. I will then use a semi structured interview format in which I ask you to think of four people as follows:

1) An anonymous current or former colleague or acquaintance you regard as a highly ethical doctor

2) An anonymous current or former colleague or acquaintance you regard as an unethical doctor

3) An anonymous current or former colleague or acquaintance you regard as a highly ethical health sector manager 
4) An anonymous current or former colleague or acquaintance you regard as an unethical health sector manager

You will not be asked to reveal the identity of the people you have in mind, but you will be led through a process of drawing some comparisons between them.

Finally I will ask you to think of six occupation related situations in which you have been personally involved (in your professional or managerial role) three which have been situations of serious ethical dilemma (i.e. where there have been competing choices and/or no clear course of action), and three everyday/run of the mill decision situations. In these cases also I will lead you through a process of drawing some comparisons. You will be asked, in confidence, to give a general description of the cases/situations you have in mind.

This research has been approved by the Human Ethics Committee at Victoria University with the following standard provisions:

* Your participation is entirely voluntary

* Confidentiality is guaranteed, your anonymity will be preserved, and that of any individual to whom you may refer in the course of the interview. Grouped data only will be reported in the research, and data will be secured and destroyed once the research is complete

* You may withdraw from the research at any point prior to the completion of data collection

* You will receive feedback on the results of the research

Thank you for agreeing to take part in my research, I'll be happy to answer any questions when we meet in your office on "Day Date", or you can contact me beforehand on $\mathrm{ph} / \mathrm{fax}: \mathrm{xxxxxxx}$.

Yours sincerely,

Jane Bryson 


\section{Appendix E: Ethical/unethical bipolar constructs from interviews}

ethical pole:

\section{Character:}

honest, tells the truth

principled, has standards which are lived up to

privately and publicly

\section{Motivation:}

committed to public health system

committed to social equity and justice

hardworking for the public health service

focus on and concern for others

not self-interested at the expense of others

focused on patients' best interests

recognises and uses skills of others for their good

and that of the service

considers public good of decisions/actions

displays global financial concern

not motivated by greed for more money

not motivated by need for power and control

not status driven

does not use ethics expediently

\section{Behavioural style:}

ability to admit when wrong and manage result no hidden agendas/know where you stand consistent in what is said and what is done flexible, open to others ideas, consultative

not aggressive

respects others

good interpersonal skills

not flippant

\section{Approach to decisions:}

takes long term/strategic view of issues and able to see wider implications of decisions

perceptible ethical framework, has clear set of ethical principles underpinning decisions

reasoned decisions, makes decisions logically

using all available information dishonest, deceitful

not principled

not committed to public health system

not committed to social equity and justice

lack of contribution to the public health service

lack of concern for others

self-interested at the expense of others

not focused on patients' best interests

manipulative, uses others for own ends

disregards public good

lacking in global financial concern

motivated by greed for more money

motivated by need for power and control

status driven

ethics as expedient prop

denial of mistakes/errors

hidden agendas/don't know where you stand

not consistent in what is said and what is done

rigid, closed to others views, their way is the only

right way

aggressive

overtly disrespectful to others

poor interpersonal skills

flippant

short term, opportunistic at expense of longer

term

not clear how decisions or conclusions arrived at

makes decisions using information selectively to support own views 
Appendix F: Survey Questionnaire 


\section{Appendix G}

Table G1: Survey sample representativeness by group

\begin{tabular}{lllll} 
& Sample: & & Returned: & \\
& $\underline{\mathbf{n}}$ & $\mathbf{\%}$ & $\underline{\mathbf{n}}$ & $\mathbf{\%}$ \\
\hline Overall Sample & 799 & $100 \%$ & 284 & $36 \%$ \\
Doctors & 673 & $84 \%$ & 221 & $78 \%$ \\
Managers & 126 & $16 \%$ & 63 & $22 \%$ \\
\hline
\end{tabular}

Table G2: Survey sample response rate by group

\begin{tabular}{lllll}
\hline & Sample: & & \multicolumn{2}{l}{ Returned: } \\
& $\underline{\mathbf{n}}$ & $\mathbf{\%}$ & $\underline{\mathbf{n}}$ & $\mathbf{\%}$ \\
\hline Overall Sample & 799 & $100 \%$ & 284 & $36 \%$ \\
Doctors & 673 & $84 \%$ & 221 & $33 \%$ \\
Managers & 126 & $16 \%$ & 63 & $50 \%$ \\
\hline
\end{tabular}

Table G3: Survey sample by gender and age group

\begin{tabular}{|c|c|c|c|c|c|c|}
\hline & \multicolumn{2}{|c|}{ Overall } & \multicolumn{2}{|c|}{ Doctors } & \multicolumn{2}{|c|}{ Managers } \\
\hline & $\underline{\mathbf{n}}$ & $\%$ & $\underline{\mathbf{n}}$ & $\%$ & $\underline{\mathbf{n}}$ & $\%$ \\
\hline \multicolumn{7}{|l|}{ Gender } \\
\hline Male & 167 & $65 \%$ & 140 & $72 \%$ & 27 & $43 \%$ \\
\hline Female & 91 & $35 \%$ & 55 & $28 \%$ & 36 & $57 \%$ \\
\hline \multicolumn{7}{|l|}{ Age Group } \\
\hline under 25 years & - & - & - & - & - & - \\
\hline 25 to 34 years & 72 & $28 \%$ & 60 & $31 \%$ & 12 & $19 \%$ \\
\hline 35 to 44 years & 91 & $35 \%$ & 63 & $32 \%$ & 28 & $44 \%$ \\
\hline 45 to 54 years & 59 & $23 \%$ & 42 & $21 \%$ & 17 & $27 \%$ \\
\hline 55 to 65 years & 33 & $13 \%$ & 27 & $14 \%$ & 6 & $10 \%$ \\
\hline over 65 years & 4 & $1 \%$ & 4 & $2 \%$ & - & - \\
\hline
\end{tabular}

1. Counts and percentages do not include missing data 
Table G4 : Manager sample - health professional and non health professional backgrounds by gender and age group

\begin{tabular}{|c|c|c|c|c|}
\hline & \multicolumn{2}{|c|}{$\begin{array}{l}\text { Managers (ex health } \\
\text { professionals) }\end{array}$} & \multicolumn{2}{|c|}{$\begin{array}{l}\text { Managers (non health profnl } \\
\text { background) }\end{array}$} \\
\hline & $\underline{\mathbf{n}}$ & $\%$ & $\underline{\mathbf{n}}$ & $\%$ \\
\hline \multicolumn{5}{|l|}{ Gender } \\
\hline Male & 10 & $28 \%$ & 17 & $63 \%$ \\
\hline Female & 26 & $72 \%$ & 10 & $37 \%$ \\
\hline \multicolumn{5}{|l|}{ Age group } \\
\hline 25 to 34 years & 5 & $42 \%$ & 7 & $58 \%$ \\
\hline 35 to 44 years & 17 & $61 \%$ & 11 & $39 \%$ \\
\hline 45 to 54 years & 11 & $65 \%$ & 6 & $35 \%$ \\
\hline 55 to 65 years & 3 & $50 \%$ & 3 & $50 \%$ \\
\hline over 65 years & - & & - & \\
\hline
\end{tabular}

Table G5: Doctor sample by area of work/specialty

\begin{tabular}{lrrl}
\hline Area & Doctors & \multicolumn{2}{c}{ New Zealand Register of specialists } \\
& \multicolumn{1}{c}{$\mathbf{n}$} & $\mathbf{\%}$ & $\mathbf{( 1 9 9 5 )}-\mathbf{\%}$ \\
\hline Anaesthetics & 33 & $17 \%$ & $12 \%$ \\
Obstetrics \& Gynaecology & 4 & $2 \%$ & $7 \%$ \\
Pathology & 9 & $5 \%$ & $6 \%$ \\
Intensive Care & 4 & $2 \%$ & - \\
Ophthalmology & 5 & $3 \%$ & $3 \%$ \\
Psychiatry & 13 & $7 \%$ & $10 \%$ \\
Community Medicine & 2 & $1 \%$ & $6 \%$ \\
Orthopaedics & 11 & $6 \%$ & $5 \%$ \\
General Surgery & 9 & $5 \%$ & $8 \%$ \\
Medicine or medical specialty & 56 & $28 \%$ & $19 \%$ \\
Paediatrics & 17 & $9 \%$ & $6 \%$ \\
Other surgical specialty & 9 & $5 \%$ & $3 \%$ \\
other & 24 & $12 \%$ & - \\
\hline
\end{tabular}


Table G6: Manager sample by area of work

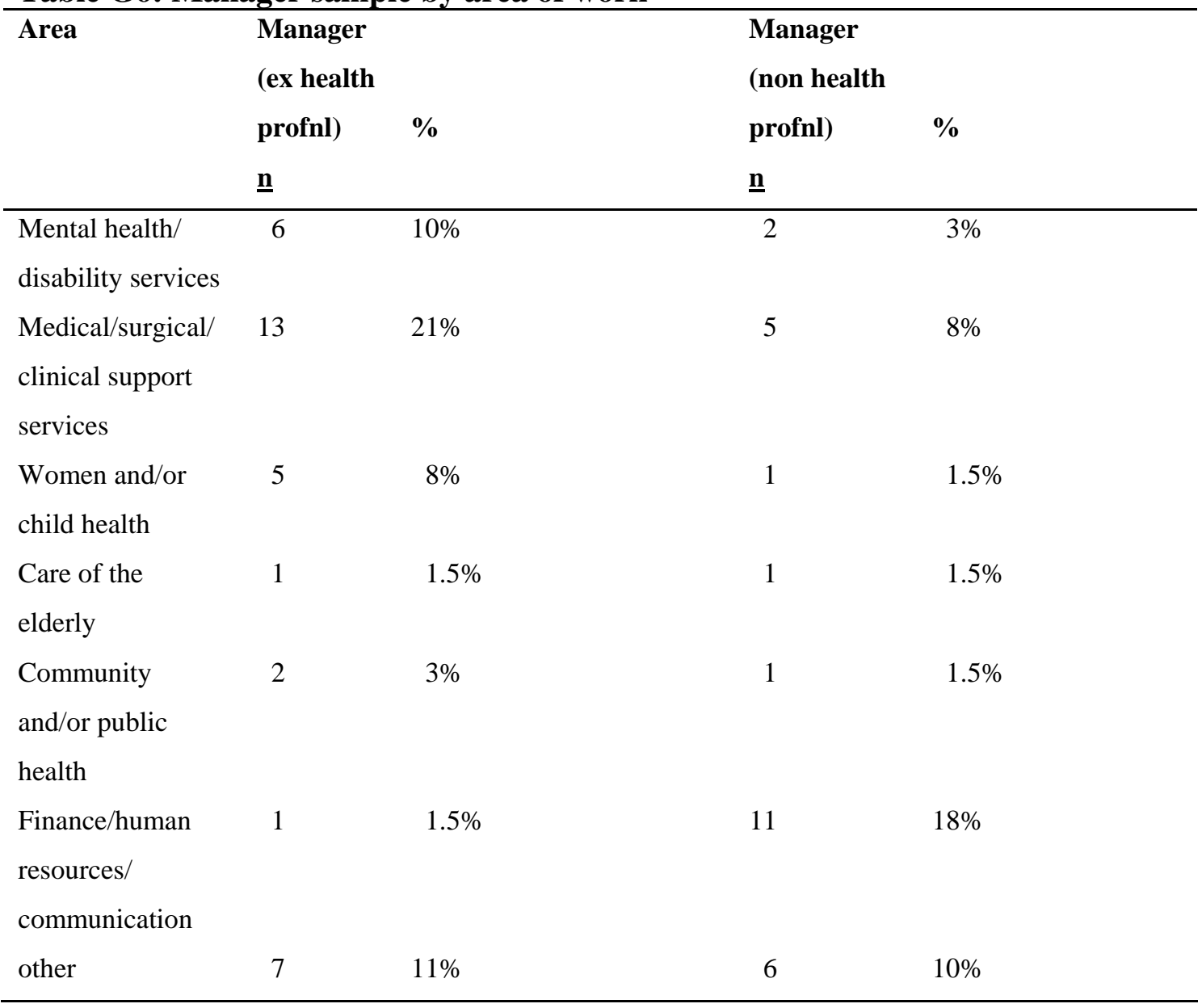

Table G7: CHE budget responsibility

\begin{tabular}{lcclc}
\hline & Doctors & \multicolumn{2}{l}{ Managers } \\
& $\underline{\mathbf{n}}$ & $\mathbf{\%}$ & $\underline{\mathbf{n}}$ & $\mathbf{\%}$ \\
\hline Budget responsibility & 29 & $15 \%$ & 54 & $86 \%$ \\
No budget responsibility & 167 & $85 \%$ & 9 & $14 \%$ \\
\hline
\end{tabular}


Table G8: Survey sample by health sector work experience and education and training

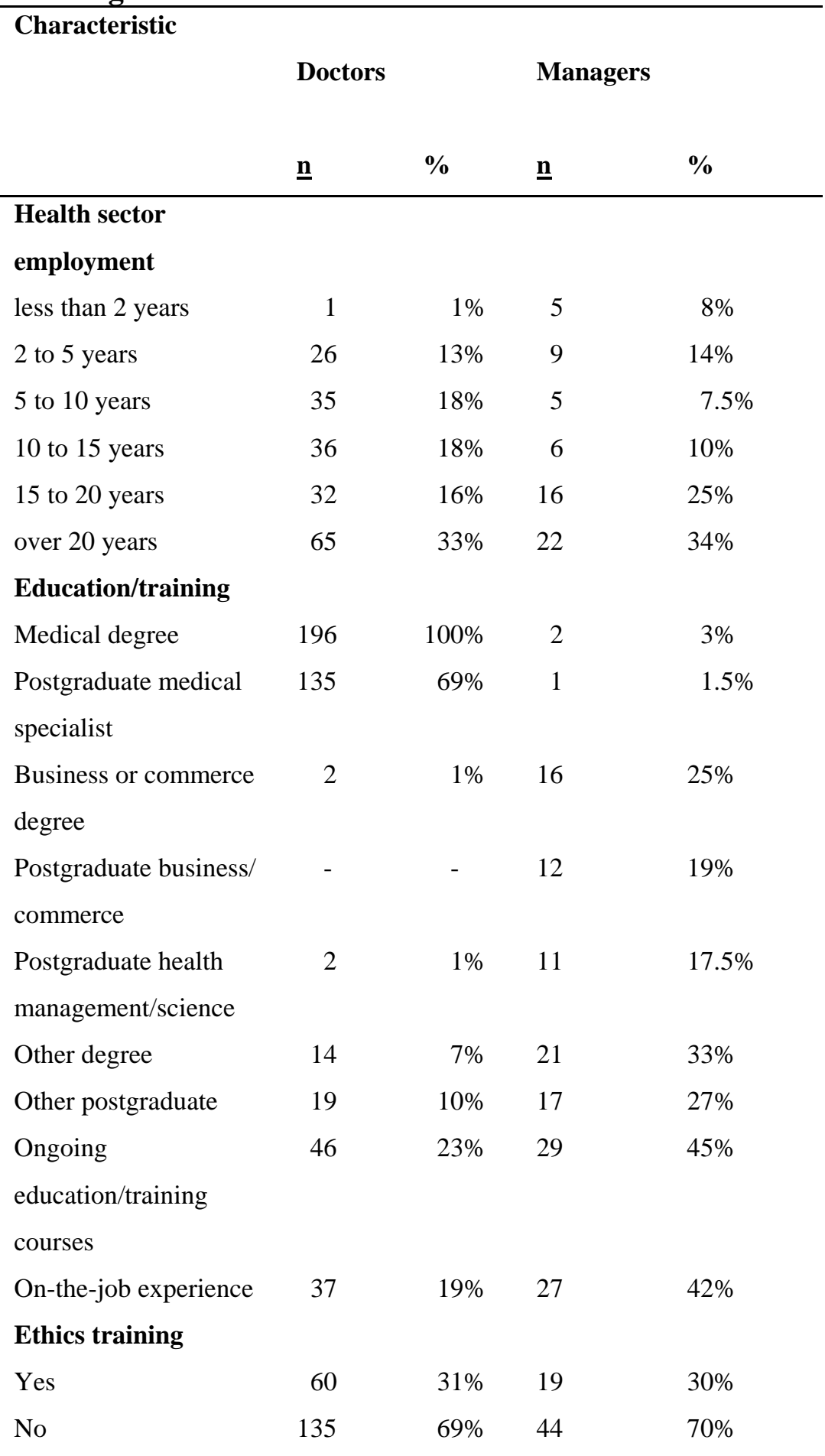


Table G9: Survey sample by helpfulness of education and training

Doctors Managers

\begin{tabular}{lrrrr} 
& $\underline{\mathbf{n}}$ & $\mathbf{\%}$ & $\underline{\mathbf{n}}$ & $\mathbf{\%}$ \\
\hline Education usefulness & & & & \\
extremely helpful & 12 & $6 \%$ & 5 & $8 \%$ \\
very helpful & 47 & $24 \%$ & 28 & $46 \%$ \\
somewhat helpful & 73 & $38 \%$ & 20 & $33 \%$ \\
a little helpful & 54 & $28 \%$ & 7 & $12 \%$ \\
not at all helpful & 8 & $4 \%$ & 1 & $1.5 \%$ \\
Ethics training & & & & \\
usefulness & & $3 \%$ & 1 & $5 \%$ \\
extremely helpful & 2 & $24 \%$ & 11 & $58 \%$ \\
very helpful & 15 & $35 \%$ & 2 & $10 \%$ \\
somewhat helpful & 22 & $30 \%$ & 4 & $21 \%$ \\
a little helpful & 19 & $8 \%$ & 1 & $5 \%$ \\
not at all helpful & 5 & & & \\
\hline
\end{tabular}

Table G10: Survey sample by hospital size

\begin{tabular}{lcccc}
\hline & Doctors & & \multicolumn{2}{l}{ Managers } \\
& \multicolumn{1}{c}{$\mathbf{n}$} & \% & $\underline{\mathbf{n}}$ & \% \\
\hline 100 or more beds & 177 & $91 \%$ & 53 & $87 \%$ \\
less than 100 beds & 13 & $7 \%$ & 2 & $3 \%$ \\
not applicable & 4 & $2 \%$ & 6 & $10 \%$ \\
\hline
\end{tabular}

Table G11: Sample by future employment in health sector

\begin{tabular}{lllll} 
& Doctors & \multicolumn{3}{c}{ Managers } \\
& $\underline{\mathbf{n}}$ & $\mathbf{\%}$ & $\underline{\mathbf{n}}$ & $\mathbf{\%}$ \\
\hline $\begin{array}{l}\text { Yes - remain in health } \\
\text { sector }\end{array}$ & 184 & $94 \%$ & 38 & $64 \%$ \\
$\begin{array}{l}\text { No - will not remain in } \\
\text { health sector }\end{array}$ & 11 & $6 \%$ & 21 & $36 \%$ \\
\hline
\end{tabular}

